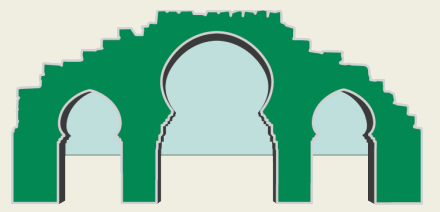

argelina.org
Revista Argelina

Revista semestral de Estudios Argelinos
Primavera 2018

Número 6

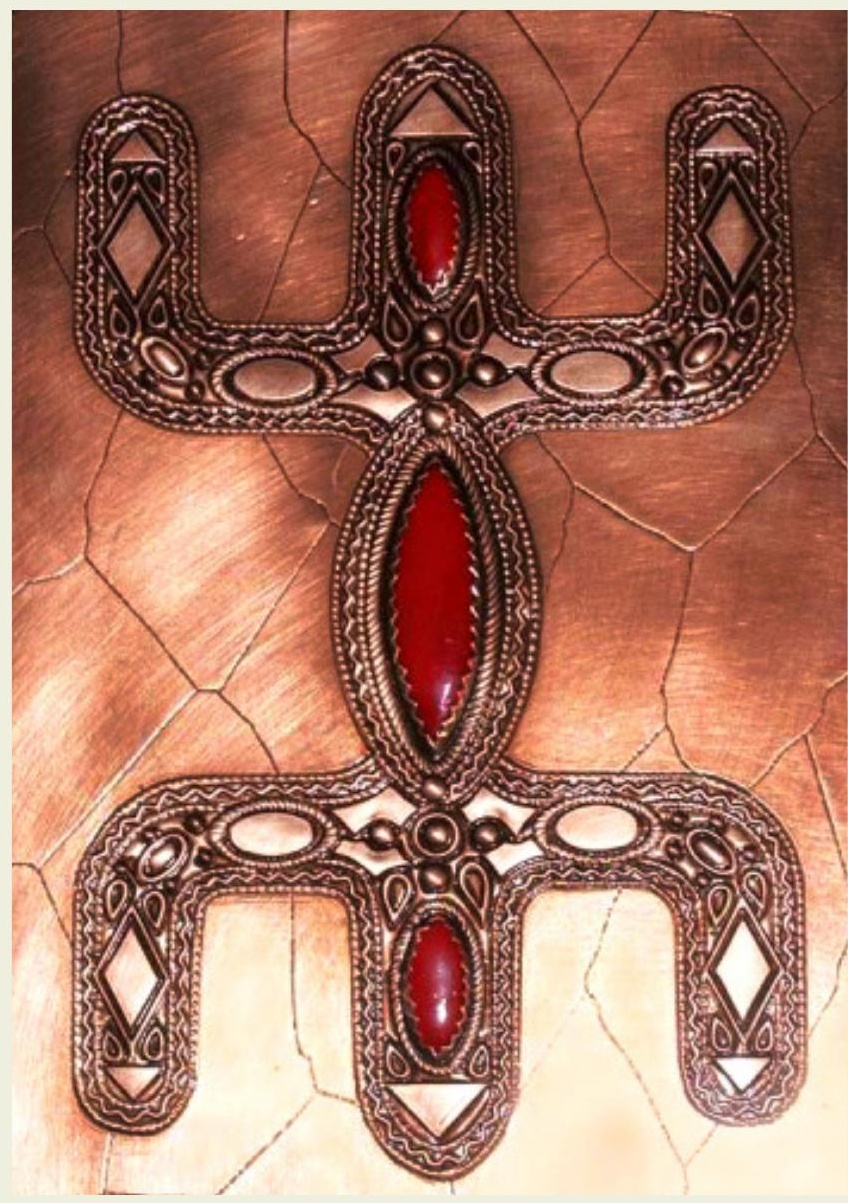


Número 6 · Primavera 2018

\section{Revista Argelina}

Revista semestral de Estudios Argelinos 



\section{Revista Argelina}

Revista semestral de Estudios Argelinos

Número 6

Comité editorial:

Directora: Naima Benaicha Ziani

Subdirector: Isaac Donoso

Editora: Oum Hani Rahmani

Secretario técnico: Didac Conesa

\section{Comité científico:}

Emilio Sola

Universidad de Alcalá de Henares

Abdallah Hammadi

Universidad de Constantina

Juan Martos Quesada

Universidad Complutense de Madrid

Carmen Barceló

Universidad de Valencia

Miguel Ángel Manzano

Universidad de Salamanca 


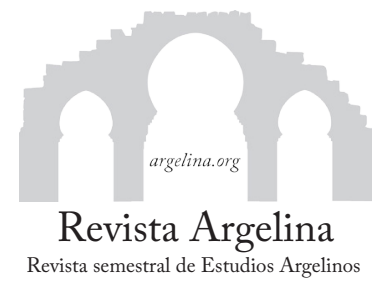

Revista Argelina. Revista semestral de Estudios Argelinos es una publicación electrónica semestral editada por el Área de Estudios Árabes e Islámicos de la Universidad de Alicante que edita dos números anuales de investigación y reflexión en torno a las letras, cultura, historia y actualidad de Argelia. Una versión extendida de la revista se publica en papel por la Editorial Hispano-Árabe.

\section{Exención de responsabilidad:}

Las opiniones y datos contenidos en cada texto son de exclusiva responsabilidad de sus autores. Revista Argelina no comparte necesariamente las opiniones vertidas por los autores ni se hace responsable de los trabajos.

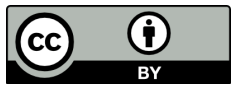

licencia de Creative Commons Reconocimiento 4.0 Internacional.

(C) De los autores de los artículos originales.

(C) Revista Argelina, 2018

ISSN: $2444-4413$

La revista esta disponible a texto completo en internet en:

https://argelina.ua.es

http://argelina.org

\section{Portada:}

Representación del símbolo amazigh "Aza" correspondiente a la letra $Z$ del alfabeto tifinagh. Pieza de arte realizada en cobre puro grabado sobre tabla de madera, $300 \times 230 \mathrm{~mm}$.

Fuente: http://berberosaharan.com

Imprime:

Editorial Hispano-Árabe

http://www.editorial-hispanoarabe.com

Calle de los Jazmines No 17

Talamanca de Jarama

28160 Madrid

Tel. 639707720 


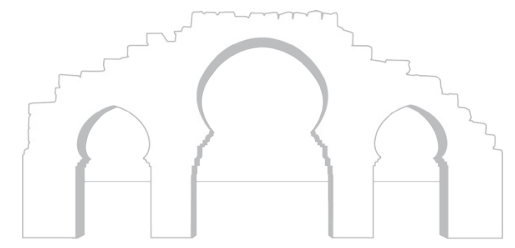

\section{Revista Argelina $\cdot$ Número $6 \cdot$ Primavera 2018}

\section{Índice}

Editorial

Ensayo

Karim Akouche

Le paradoxe de la liberté

\section{Artículos y notas}

Meriem Skander

Les «Métamorphoses » d'Apulée

Danielle Pister

La Kahina, la reine palimpseste

Mohand Ibrahim

Introduction à l'œuvre de Bélaìd Aït Ali, comme première initiative d'écriture de Tamazight en caractère latin

Ahfir Abdellah

The historical roots of Amazigh and its Arabization factors in Algeria

Azeddine Terbeche

Las festividades de los amazigh en Argelia

Naima Rahmani y Necera Bekкouche

Las manifestaciones de la celebración de la fiesta de enero de los amazigh. Un estudio interpretativo de creencias, rituales y leyendas en la zona de Beni Snous (Tremecén) como modelo

\section{Reseñas y comentarios bibliográficos}

Mohand Akli Haddadou, Introduction à la littérature berbère suivi d'une Introduction à la littérature kabyle (I. Donoso) 101

\section{Biblioteca}

A. MacCallum Scott, "Algeria. I. The Dwellers in the Garden of Allah", y Rachel Humphreys, "Algeria. II. The Story of Old Barbary and New France", en J.A. Hammerton (ed.), Peoples of All Nations: Their Life Today and Story of Their Past, by Our Foremost Writers of Travel Anthropology \& History, Londres, The Amalgamated Press Limited, 1920, vol. 1, pp. $65-111$. 



\section{EDITORIAL}

«J'ai l'espoir de préparer le lit à des desseins plus radicaux et qu'un jour la culture de mes pères vole d'elle-même. »

«La culture n'est pas seulement un héritage reçu, c'est aussi un projet assumé ».

Mouloud Mammeri

El fenómeno amazigh representa en la Argelia actual mucho más que un instrumento de comunicación entre los miembros de esta comunidad; es también un símbolo de identidad al que se aferran más allá del idioma y de su cultura. Este fenómeno proviene de un proceso evolutivo milenario que ha marcado tanto el comportamiento lingüístico amazigh como el comportamiento sociocultural de Argelia.

El tamazight o amazigh permanece desde tiempos prehistóricos hasta nuestros días como una única lengua. Sin embargo, este idioma, indudablemente, ha tomado préstamos de otras lenguas y ha entrado en interacción con otras culturas durante su larga existencia. La amazighidad está lejos de ser un caso escolástico aislado, un descubrimiento exótico o inusual. Es un caso entre muchos otros en el mundo que refleja hoy la imagen del reclamo de identidad tanto autóctona como auténtica. A diferencia de otros idiomas, el amazigh, la lengua materna del norte de África, ha sido capaz de mantener viva una gran parte de esta nación durante los últimos dos milenios, y esto a pesar de una sucesión de invasiones, servidumbres y colonizaciones.

También es un grito contra la opresión, la hegemonía y la represión. También es para el pueblo amazigh una determinación de reclamar esta naturaleza nacional inalienable tan profunda como su cultura y sus raíces. Es necesario señalar que para los especialistas más advertidos, la lengua 
se considera como una institución social que existe solo en virtud de una convención establecida entre los miembros de la comunidad lingüística en cuestión.

El pueblo argelino cuenta con el honor de ser poseedor de una historia milenaria que ha participado en el enriquecimiento de la cultura mediterránea, y de ser el receptor de la herencia de una lengua como el amazigh, rica por su patrimonio lingüístico y cultural. Por todo ello bien merece el reconocimiento oficial recientemente otorgado con el deseo de desarrollarla adecuadamente con vistas a impulsar al país hacia mejores horizontes.

Sirva este número como impulso al desarrollo y reconocimiento de esta cultura tan argelina como milenaria. 


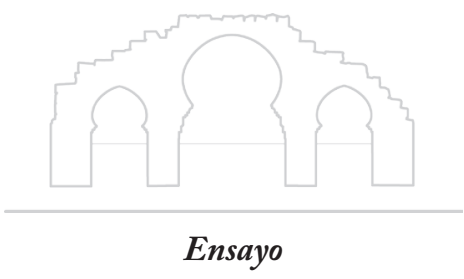





\title{
LE PARADOXE DE LA LIBERTÉ
}

\author{
Karim Akouche \\ Escritor
}

\section{LE SYNDROME DU NOMADE}

Les peuples lyriques sont fragiles. Irresponsables, exagérant tout le temps, ils sont dans la démesure, l'approximatif et le conjoncturel. Ils pratiquent deux arts dangereux : l'autoflagellation et l'autoglorification. Ils sont les meilleurs du monde ou les derniers. La lie de l'humanité ou son miel. Toujours dans l'excès, jamais dans l'équilibre.

Ils affectionnent aussi, sans le savoir, ce mot : le libertisme, ou l'excès de liberté, ce qui travestit l'esprit de liberté. Ils se qualifient d'insoumis, mais ils sont en réalité, d'une manière ou d'une autre, gouvernés, administrés. Ils ont des maîtres : leur langue est rabaissée, leur art folklorisé, leur mémoire minorisée.

J'appelle cela « le syndrome du nomade ». Le gitan, un nomade, peut avoir une maison, mais il préfère vivre dans sa roulotte, dans un campement, à la belle étoile. Il a un robinet chez lui, une salle de bains, mais il choisit les cours d'eau et les sources naturelles. « Pourquoi enfermer l'eau dans des tuyaux? Elle est faite pour couler dans les rivières! » s'écrie en substance un héros gitan dans un film. Ce qui importe, pour lui, ce n'est pas la destination, mais le chemin. Les États, les frontières, les papiers et les lois, il n'en a rien à cirer. Mais la réalité est tout autre : en Europe, les manouches et les tziganes sont pourchassés, dénoncés, haïs. On les appelle « les gens du voyage ». Ils habitent les routes. Ils aiment les défis : ils font face à la police, aux orages, au froid et à la canicule. Ils aiment aussi la danse et la musique. Forgés par la nature et ses caprices, ils font pleurer la guitare et le violon. Django Reinhardt et Paco de Lucía sont des génies, ils ont révolutionné respectivement le jazz et le flamenco...

Parmi les peuples qui sont atteints de manière aiguë par le syndrome du nomade, il y a le mien, les Berbères. Ils se qualifient d'Imaziyen, de femmes et d'hommes libres. Ça sonne bien, c'est poétique, c'est roman- 


\section{Karim Akouche}

tique. Les faits sont, cependant, aux antipodes du fantasme. Les Berbères sont de tout temps colonisés : par les Phéniciens, les Romains, les Byzantins, les Vandales, les Arabes, les Turcs, les Français... Ils résistaient, ils perdaient souvent la guerre, ils gagnaient parfois des batailles. Leurs terres sont une passoire d'où s'écoulent sans cesse les larmes et le sang. Ils ont les pieds dans la boue, mais ils chantent, les poings fermés, ou les doigts en V, «Nekni d Imaziyen! (Nous sommes des hommes libres !) ». Ils ont le don de célébrer la victoire même dans la défaite. Ils honorent les morts plus que les vivants. Ils regardent toujours en arrière, jamais devant. Ils tirent à gauche et à droite, rarement vers le haut. Nostalgiques des époques où régnaient leurs princesses et leurs rois en Afrique du Nord, ils se réfugient dans un passé lointain, un monde enchanté, les légendes, parmi les ogres et les vaches des orphelins, dans les fables et les contes de fées.

L'HISTOIRE DES LIÈVRES DEVENUS LAPINS, OU LA SERVITUDE VOLONTAIRE DES PEUPLES RACONTÉE EN FABLE

Quelque part dans une région montagneuse se trouvait Tizgi, un territoire boisé occupé par un millier de lièvres fiers et heureux. Ils vivaient dans une communauté indépendante et organisée qui dépassait en matière de justice et de démocratie celle des humains. Même s'ils appartiennent avec les lapins et les pikas au même ordre, les lagomorphes, ils avaient une autre conception des lois de l'existence : leur comportement était façonné par des principes de solidarité et de tolérance. Sacralisant la liberté, ils haïssaient la prison et la violence au point de pardonner les coupables et d'excommunier les criminels et les violeurs. Leur système de gouvernance était horizontal : ils n'avaient ni maître, ni esclave, ni chef, ni subalterne. Forgés par les aléas de la forêt, ils développèrent un instinct de défense naturelle : pendant que les uns dormaient, les autres surveillaient; au cas de danger, d'un faucon ou d'un loup rodant aux alentours, ils bondissaient sur leurs longues pattes et prenaient la fuite.

Contrairement à leurs rivaux les lapins, ils ne creusent pas de terriers, ils logent à même le creux des arbres, les branches ou sous les buissons. Ils arrivent au monde presque adultes, poilus et les yeux ouverts. Ils sont tellement sauvages qu'ils se confondent avec la nature : ils changent de 
couleur selon les saisons, leur pelage devient brun l'été et blanc l'hiver. Ils sont plus grands et plus lourds, et ils ont de longues oreilles un peu comme celles des ânons. Ils sont si longilignes et agiles au point que leurs cousins leur inventèrent un sobriquet : «Les petits kangourous sans poche."

Ils avaient tout dans la forêt. L'eau coulait à flot dans les rigoles et diverses plantes poussaient ça et là : entre les trembles, les chênes et les aulnes fleurissaient des trèfles, la vesce et du plantain. Gâtés par la nature, l'hiver ils traversaient les ruisseaux à la nage et l'été ils se livraient à des spectacles de danse sans fin.

À Tizgi régnait la paix jusqu'au jour où un homme monta du village voisin et perturba l'équilibre des choses. Avec des pièges, qu'il camoufla sous la terre et les feuilles, il attrapa plus de cent lièvres.

Le chasseur avait une ferme à l'entrée du village. Il y élevait toutes sortes d'animaux : des poulets, des dindons, des sangliers, des moutons, des vaches, des ânes et des chevaux. Tout seul, il approvisionnait la région en viande, en peau et en lait.

Il construisit des clapiers et y jeta les lièvres. Ces derniers, blessés et humiliés, refusèrent de se nourrir. D'une seule voix, ils boycottèrent les chardons, le chou et la laitue que leur donnait le fermier. Car, pour eux qui vivaient libres dans la forêt, c'était honteux de se retrouver enfermés comme des lapins dans des cages. Lorsqu'ils vivaient en liberté, ils traitaient d'ailleurs ces derniers de « de gros rats soumis ». Le bonheur du lièvre consiste, en effet, à se débrouiller seul, à bâtir un gîte où bon lui semble, à croquer des feuilles, des racines et des fruits qu'il trouve dans la nature.

Les jours passèrent et les lièvres, déterminés, ne mangeaient toujours pas. Ils étaient devenus maigres et pâles. S'ils venaient à mourir, le fermier perdrait des clients à qui il avait promis de la viande biologique. À l'aide d'un tube, attaché à une pompe, il les nourrit de force. Peine perdue : étant violentés et stressés, les lièvres ne grossissaient pas. Conscient de leur côté « sauvage » et récalcitrant, l'éleveur réfléchit à une stratégie de domestication. Il passa plusieurs nuits à observer leur comportement, à lire des manuels et à prendre des notes. 
Il lit dans un livre une phrase qui le secoua : «Ne laissez pas vos serfs s'unir. » Il sépara sur-le-champ les mâles des femelles qu'il plaça dans des clapiers qui se faisaient face. Il battait les premiers tandis qu'il caressait les secondes. Le traitement de faveur dont bénéficiaient les femelles créa la première division dans la communauté. Celles-ci acceptèrent les premières l'eau, les carottes et les céréales de l'éleveur avant que les mâles, à leur tour, fléchissent leur position.

Quelques semaines après, le fermier étiqueta les lièvres, leur mit une chaîne au cou et attribua à chacun un numéro. Certains commencèrent à se comporter comme des lapins et à en tirer une certaine fierté. Leur espace de liberté devint le clapier. Ils n’hésitaient pas à qualifier les lièvres restés encore dans les bois de « sauvages ». Mais quelques-uns restèrent fidèles à leur passé d'animaux libres et indomptables : en signe de protestation, ils déchirèrent leur collier et jetèrent leur numéro.

Le fermier, vexé, prit le plus rebelle d'entre eux et le tua. Il en fit un festin qu'il offrit à ses chiens. Quelques lièvres protestèrent et tentèrent de convaincre les autres d'observer une grève de la faim, mais en vain car l'éleveur affina sa stratégie de domestication et divisa davantage la colonie : il favorisa les beaux, les costauds, les plus clairs au détriment des noirs, les dociles au dépens des trublions.

Lorsqu'il revint pour en prendre un autre, les moins obéissants rechignèrent timidement et les autres, les privilégiés, les découragèrent et leur conseillèrent de se taire. Puis, habitués à voir de temps à autre quelques-uns d'entre eux vendus ou égorgés, ils entrèrent dans les rangs et acceptèrent avec résignation leur nouveau destin.

Un jour, deux lièvres, conscients de leur condition brutale de prisonniers, s'insurgèrent. Ils proposèrent une plateforme de revendications pour rendre à leurs congénères leurs droits bafoués et leur souveraineté confisquée : "Si nous sommes séquestrés dans ces clapiers puants, ce n'est pas à cause du fermier, mais à cause de nous. C'est nous, avec notre consentement, qui avons accepté sa tyrannie. Ce n'est pas lui notre tyran, mais c'est nous qui sommes ses esclaves. »

Une voix, puis deux, puis plusieurs s'élevèrent pour qualifier les rebelles d'agitateurs et de traîtres de la ferme. Découragés, ils terminèrent leur discours avec ces mots : "Nous ne cherchons pas à remplacer le fermier, 
mais nous refusons de lui obéir. Nous ne voulons pas prendre son pouvoir, mais nous désirons nous autogérer. Nous ne vous demandons pas de travailler contre lui, mais pour vous. Nous ne vous invitons pas à le haïr, mais à vous aimer. »

Les deux révoltés frôlèrent le lynchage. Ils furent rapidement dénoncés. L'éleveur les égorgea devant tout le monde. Ce fut la terreur dans la ferme. Plus jamais un lièvre ne se révolta depuis.

Promus, décomplexés, les lièvres serviles, les collaborateurs, les préférés du fermier, les plus lâches, montaient sur leurs frères et leurs sœurs et n'hésitaient pas à les écraser, à les humilier. S'ils supportaient l'injustice de leur maître, c'est parce qu'ils en faisaient subir autant à leurs subordonnés. Ils étaient les complices de l'éleveur, de sa froideur, de sa violence, de sa tyrannie.

Les lièvres, définitivement lapinisés, non seulement cessèrent de se révolter, mais ils se battaient pour être les premiers à être vendus ou sacrifiés. Ils renoncèrent aussi bien à leur liberté qu'à leur dignité.

Les hases et les bouquins s'accouplaient et donnaient naissance à une tribu de levrauts. Ceux-ci, nés et élevés dans des cages, se comportaient exactement comme des lapins : obéissant au fermier et acceptant leur sort sans ronchonner. Chaque fois qu'un lièvre disparaissait de la cage, ceux qui restaient fêtaient l'événement. Se sacrifier pour le fermier était un geste de gratitude, une action noble. Ils étaient fiers de leur peau et de leurs poils qui faisaient le bonheur des fabricants de costumes et de chapeaux, fiers de se donner en cobayes aux laboratoires, fiers de leur viande que s'arrachaient les restaurateurs, fiers aussi d'amuser les enfants dans des foires d'animaux.

Grâce à l'argent gagné de la vente des lièvres, l'éleveur agrandit et modernisa sa ferme. Il cessa de nourrir ses bêtes à l'aide des aliments naturels. Il les gavait aux engrais et aux hormones. Il acheta des baffles qu'il suspendit au-dessus des clapiers. La musique, pensa-t-il, les ferait grossir. Plus ils prendraient du poids, plus ils se vendraient cher.

Quelques années plus tard, le fermier mourut dans un accident de voiture. Les lièvres devenus lapins pleurèrent et le regrettèrent. Sans leur maître, ils furent orphelins. Ils se retrouvèrent dehors, retournèrent 
à Tizgi, dans les bois, loin de la ferme. Ils se sentirent emprisonnés... même à ciel ouvert.

\section{CONCLUSION}

Pour ne pas disparaître, c'est-à-dire exister, participer réellement à l'histoire en marche, les peuples lyriques, à leur tête les Berbères, ont intérêt à sortir du complexe du nomade. Ne doivent-ils pas, pour ce faire, être dans la mesure, jauger à sa juste valeur leur « liberté » ou leur « soumission », penser avec la tête et non avec les émotions, quitter l'âge romantique, l'exaltation de l'adolescence, pour entrer, une fois pour toutes, dans l'âge adulte?

Par Karim Akouche, écrivain et auteur, entre autres, de La Religion de ma mère (roman, 2017), Allah au pays des enfants perdus (roman, 20I2), J'épouserai le Petit Prince (conte, 2014), Toute femme est une étoile qui pleure (poésie-théâtre, 2013) et Lettre à un soldat d'Allah (essai, 20I8).

Por Karim Akouche, escritor y autor, entre otros, de La religión de mi madre (novela, 2017), Alá en el país de los niños perdidos (novela, 20I2), Me casaré con el Principito (cuento, 20I4), Toda mujer es una estrella que llora (poesía-teatro, 2013) y Carta a un soldado de Alá (ensayo, 2018). 


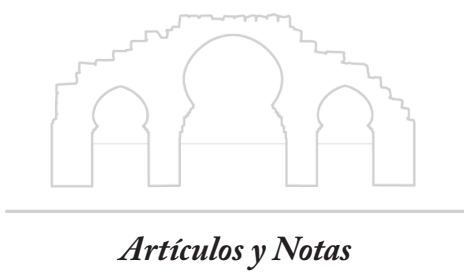





\title{
LES « MÉTAMORPHOSES » D'APULÉE
}

\author{
Meriem Skander
}

\begin{abstract}
Résumé
L'article évoque l'un des premiers écrivains, voire le premier écrivain amazigh à écrire un roman. Exercice littéraire totalement nouveau pour l'époque : Apulée de Madaure, un amazigh qui vécut au deuxième siècle (I25- I80). Riche de ses enseignements, qu'il reçut aussi bien à Carthage qu'à Athènes. Il fut un imminent rhéteur itinérant, un scientifique curieux et un philosophe néo-platonicien reconnu. Il entreprit d'écrire un roman « L'âne d'or » connu également sous le nom des « Métamorphoses », roman qui retrace les mésaventures de Lucien, un Thessalien qui se voit transformé en âne, mais garde toute son âme humaine, il subira cette sentence des années durant, et en tirera une profonde réflexion sur le monde et sur lui-même. L'histoire finit tout de même bien, car Lucien retrouvera sa forme humaine à la fin du récit. Apulée transpose également le récit de « Amour et Psyché » fortement inspiré d'un conte amazigh ancien. Enfin l'on découvre le génie d'Apulée dans son livre, premier roman de l'humanité, au sens philosophique certain.
\end{abstract}

Mots Clés : Apulée, Madaure (M'daourouch), Gétule, Amazigh, Numidie, L'âne d'or, Métamorphoses, Lucien, Photis

\section{Resumen}

El artículo evoca uno de los primeros escritores, por no decir el primer escritor amazigh en escribir una novela. Ejercicio literario completamente novedoso para la época: Apuleyo de Madaura, un amazigh que vivió en el siglo II (I25 - I80). Rico por sus enseñanzas que recibió tanto en Cartago como en Atenas. Era un inminente orador retórico e itinerante, un científico curioso y un filósofo neoplatónico reconocido. Se propuso escribir una novela El asno de oro conocida también bajo el nombre de Las metamorfosis, que persigue trazar las desventuras de Lucio, un Tesaliense que se ve transformado en un asno, pero guarda toda su alma humana, una metamorfosis de la que sacará una profunda reflexión sobre el mundo y sobre sí mismo. La historia acaba bien porque Lucio encontrará su forma humana al final del relato. Apuleyo también transpone la historia de «Eros y Psique» fuertemente inspirada en un viejo cuento amazigh. Finalmente descubrimos el genio de Apuleyo en su libro, la primera novela de la humanidad, en un cierto sentido filosófico.

Palabras clave: Apuleyo, Madaura (M'daourouch), Gétule, Amazigh, Numidia, El asno de oro, Las metamorfosis, Lucien, Photis. 


\section{INTRODUCTION}

Enracinée en Afrique du nord. La culture berbère regorge de savoir-faire matériels et immatériels, témoins de la riche diversité et de la créativité de cette culture séculaire. Outre la langue Amazigh, l'art culinaire, la musique, l'artisanat, etc. La littérature Amazigh, bien que peu connue, n'est pas en reste.

La littérature Amazigh traditionnelle, digne héritière de la grande tradition orale, Amazigh et africaine, fut progressivement transcrite et éditée. Travail ardu des chercheurs pour transcrire cette littérature si riche en images et en enseignements.

De la poésie au conte, de "Mohand U M'hand » à Mouloud Mammeri, en passant par Taous Amrouche ou Mouloud Feraoun, c'est cette littérature qui a fourni à l'humanité son premier roman "Lâne d'or " écrit au deuxième siècle par Apulée de Madaure, un Numide bourgeois qui naquit dans une contrée amazigh à l'est de l'actuelle Algérie. Et qui a toujours revendiqué ses origines amazigh (semi-Numidien - semi-Gétule). Bien que son roman fût écrit en latin, son génie amazigh s'y est superbement épanoui. Les origines berbères d'Apulée constituent la motivation principale de cet intérêt. La littérature Amazigh, qui se développe relativement bien depuis quelques années, est en quête de repères, de mythes et de textes fondateurs ; les origines de l'auteur de «Lâne d'or » représentent une opportunité tentatrice pour la construction, au niveau mythique, d'une identité à la littérature amazigh, notamment dans son expression romanesque.

\section{APULÉE « SAVANT RHÉTEUR »}

Né au deuxième siècle après Jésus-Christ, vers I25, à Madaure. (M'daourouche de nos jours) ville située au nord-est de la Numidie, actuelle Algérie.

Apulée (Lucius Apuleius en latin-Bien que le prénom Lucius n'est prouvé par aucun texte. C'est uniquement d'après le nom de son héros, que dès l'antiquité, on l'appela Lucius Apuleius- et Afulay en tamazight ${ }^{1}$ ) est un écrivain, orateur et philosophe néo-platonicien d'origine Amazigh.

1 Tamazight : langue parlée par les autochtones d'Afrique du nord les Amazigh, ce terme qui 
Issu d'une famille bourgeoise. Son père était «Duumvire » plus haute distinction municipale de l'époque. Apulée endossera ce titre après la mort de son père, qui lui lèguera une fortune de deux millions de sesterces à lui et à son frère, dont il se servira pour voyager, s'instruire et aider ses amis.

Se désignant lui-même comme semi-Numidien - semi-Gétule ${ }^{2}$. Il parla le patois local, d'Afrique du nord, puis le grec et le latin.

Apulée fit ses études primaires à Madaure. Ensuite, du fait de son esprit curieux, partit à Carthage, siège de la province, ou il fit sa formation en rhétorique. Ce qui équivaut au baccalauréat de nos jours. Il se rend après à Athènes, pour recevoir tous les cultes initiatiques en acquérant des connaissances en poésie, en géométrie et en musique. Il suivit les cours de Lukios Kalbenos Tauros, le plus éminent platonicien d'Athènes au milieu du deuxième siècle.

Après sa formation, Apulée entreprit de voyager en Grèce, se rendit entre autres à Samos, et en Phrygie. Il est aussi fort probable qu'il séjourna à Rome, à Ostie, ou il exerçât comme avocat ${ }^{3}$. Apulée revient par la suite à Carthage, à l'époque des incertitudes aussi bien philosophiques que religieuses. Il entendit parler des spéculations philosophiques qui avaient lieu à Alexandrie, du fait qu'un nouveau courant prenait jour : l'Hermétisme. Il voulut en savoir davantage. Il partit donc vers Alexandrie à dos d'âne, parfois en carriole. Mais il tomba malade en cours de route, à Oea (actuelle Tripoli). Il fut hébergé par un ami, et condisciple, Sicinius Pontien, qui a tout fait pour qu'Apulée épouse sa mère. Une riche veuve, très convoitée.

Le mariage fut mal vu par l'entourage de Sicinius Pontien. Qui contestait l'union, en accusant Apulée d'user des sortilèges de la magie sur la veuve, pour quelle accepte de l'épouser. Le procès eut lieu vers I58, Apulée plaida lui-même sa cause $e^{4}$, et fut acquitté. Il consigna sa plaidoirie dans

signifie littéralement « homme libre » désigne également les habitants de Tamazgha (territoire qui s'étend au nord de l'Afrique).

2 Gétule : Hammerstaedt 2002, p. 24 ; Apulée, De magia 24. (en latin : Gaetuli) peuple de l'Afrique du nord dans l'antiquité.

3 Filippo Coarelli, « Apuleio a Ostia? », Dialoghi di archeologia, no 7, 1989, pp. 27-42.

4 Ulrike Riemer, «Apuleius, De magia. Zur Historizität der Rede », Historia, vol. 55, 2006, pp. 178-190, émet cependant des doutes sur l'historicité de ce procès. Peter Schenk fonde l'opinion contraire : Hammerstaedt 2002, Einleitung, p. 42 sq. 
un texte connu sous le nom d'«Apologie » ou « De Magia » (Discours sur la magie)

Apulée resta trois ans à Oéa. Pour se soigner d'abord, aussi parce qu'il était marié. Mais surtout, à l'issue de ses études, il devint rhéteur itinérant, donnant beaucoup de conférences publiques sur tous sujets. Revenu à Carthage. Étant adepte des mystères d'Esculape, il développa son activité scientifique en montant un laboratoire de sciences naturelles pour ses expériences, en disséquant notamment des poissons, ce qui était nouveau. Sa démarche scientifique ainsi que son intérêt pour les secrets de la religion lui valurent plus tard la renommée de magicien.

Apulée écrira deux romans, bien qu'il ne nous en reste qu'un : "L'âne d'or » ou «Les métamorphoses ». Les grammairiens signalent l'existence d'un autre titre : «Hermagorace ». Apulée se vantait d'une activité intellectuelle intense, aussi bien philosophique que scientifique, qui lui valut qu'on lui érige des statues dans sa patrie natale.

Plus tard, il s'établit à Carthage, où il prend une charge de prêtre ; il est probablement devenu sacerdos provinciae (chef des prêtres du culte de l'empereur dans la province d'Afrique proconsulaire ${ }^{5}$. On le mentionne encore dans les années soixante, puis sa trace se perd; on ne connaît ni le lieu ni la date de sa mort, mais celle-ci a sans doute lieu vers i8o.

\section{II. « LES MÉTAMORPHOSES » UN ROMAN FLEUVE}

«Les métamorphoses » dont le titre original est les « onze livres de métamorphoses », en latin « Metamorphoseon libri XI ». Le titre le plus connu est "L'âne d'or » (Asinus aureus). Le livre , considéré comme un chef d'œuvre de l'antiquité, raconte les péripéties de Lucius (comme l'auteur du livre, Lucius Apuleius) un aristocrate qui connaît différentes aventures, après que sa maîtresse, Photis, l'a transformé en âne par accident.

Il apprend que, pour retrouver sa forme humaine, il doit manger des roses. Récit ou se mêlent plusieurs histoires, dont celle d'Amour et Psyché. Le roman est un voyage spirituel de Lucien. Une mise à distance de la sorcellerie par le comique.

5 Mais il peut s'être agi d'une autre fonction sacerdotale : voir Rives 1994, p. 273-290. 
"Je vais, dans cette prose milésienne ${ }^{6}$, te conter toute une série d'histoires variées, et flatter ton oreille bienveillante d'un murmure caressant. Pourvu que tu daignes jeter les yeux sur ce papyrus égyptien, que la pointe d'un roseau du Nil l'a couvert d'écritures. Et, tu t'émerveilleras en voyant des êtres humains changer de nature, et de conditions pour prendre une autre forme. Puis, par un mouvement inverse, se transformer à nouveau en eux-mêmes » ${ }^{7}$.

\section{RÉSUMÉS DES ONZE LIVRES}

Livre I : Le narrateur qui prend le nom de Lucius est le héros du roman ; il rend compte à la première personne de son destin aventureux. Dans le prologue, il s'adresse directement au lecteur et se présente brièvement, la silhouette de l'auteur se mêlant avec celle du héros.

Pendant un voyage d'affaires en Thessalie, connue comme pays de la magie, il rencontre le marchand Aristomène, qui raconte en détail comment son vieil ami Socrate a été assassiné sous ses yeux par la magie de deux sorcières, les deux sœurs Méroé et Panthia. Le compagnon sceptique d'Aristomène ne veut rien savoir de tout cela et tient cette histoire pour une galéjade. Dans la ville d'Ypati Lucius est reçu par son hôte, l'usurier avare Milo.

Livre II : Lucius entend plusieurs fois dans les jours suivants de terribles choses sur le danger de sorcières ; en particulier, il reçoit un avertissement de la femme de Milo, Pamphile, qui fait partie des magiciennes de Thessalie. Ceci ne fait qu'aiguiser sa curiosité. Alors qu'un soir, il rentre ivre de chez des amis, il tombe devant la porte de la maison de Milo sur trois voleurs, qu'il tue avec son glaive.

Livre III : Le lendemain, Lucius est jeté en prison et accusé de meurtre. Il est surpris d'être l'objet de moqueries de tous. La délibération du tribunal a lieu publiquement au théâtre devant une foule immense. Le discours de défense de l'accusé, réussi, n'a pas d'effet. On le force à découvrir les trois cadavres portés sur des civières et recouverts. Il s'avère qu'il s'agit en réalité de trois outres. Le public éclate en rires bruyants et se retire. Finalement, Lucius apprend que l'accusation nétait qu'un mauvais tour. Loccasion en était la « fête du rire ", célébrée ce jour dans la ville.

6 Relative à « Milet », ville grecque ancienne d'Asie mineure.

7 Apulée, L'Âne d'or ou les Métamorphoses, Paris, Gallimard Folio, 1975. 
Dans la maison de Milo, Lucius apprend de la servante Photis, qui partage ses nuits, que Pamphile avait animé les outres par magie, en sorte qu'elles ressemblent à des voleurs. Maintenant, il voudrait être témoin oculaire caché de la magie de Pamphile. Photis hésite à accepter, et laisse Lucius voir comment Pamphile prend la forme d'un grand-duc. Lucius veut maintenant expérimenter par lui-même une telle transformation. Mais comme Photis se trompe d'onguent magique avec lequel on doit s'enduire, Lucius ne se transforme pas en oiseau mais en âne. Sous la forme animale, sa raison humaine lui reste néanmoins sans altération. La servante lui promet de revenir sur cette métamorphose le lendemain matin, mais elle doit acheter les roses qu'il doit manger dans ce but. Jusque-là, il doit rester à l'écurie comme âne. Or la nuit, des voleurs pénètrent dans la maison. Pour transporter leur butin, ils utilisent Lucius comme âne de bât. C'est ainsi que commencent les longues errances de l'âne. Il est lourdement chargé, et méchamment meurtri par les coups, sur des chemins difficiles à travers les montagnes.

Livres IV à vi : Après l'entrée de Lucius dans le monde de la magie, sa curiosité dans ce domaine est satisfaite : maintenant, il est forcé de changer de perspective et considère le monde ordinaire des hommes du dehors. Comme les hommes le tiennent pour un animal normal, ils poursuivent sans scrupule en sa présence leurs occupations et conversations intimes. Lucius observe, écoute et comprend tout ; grâce à ses longues oreilles, il peut percevoir même de très loin. Son rôle lui donne un regard sur les abîmes du monde de tous les jours, qui dans sa perspective paraît au moins aussi affreux que le monde de la magie vu par l'homme ordinaire. Là-dessus, il faut compter que Lucius, qui appartenait parmi les hommes aux couches supérieures, est livré comme animal de charge à des personnes qui se situent bien plus bas par leur niveau social, ou sont même exclues de la société.

Après de grandes fatigues, la troupe de brigands atteint avec Lucius la grotte qui sert de cachette à la bande. Un autre groupe arrive, et on se raconte ses aventures. Il s'avère que les criminels se comportent comme des fous avec le monde environnant, par leurs entreprises et leurs disputes, et en subissent des pertes. 
D'une expédition nocturne, les voleurs ramènent une belle jeune fille nommée Charite, qu'ils ont enlevée pour exiger une rançon. Un essai de fuite de l'âne avec Charite échoue. Les brigands discutent d'une punition cruelle des fugitifs, et l'âne doit mourir.

Livre viI : Un espion des voleurs rapporte que dans l'intervalle, à Ypati, on recherche Lucius que l'on tient pour complice des voleurs; on le recherche aussi pour cela dans la ville où il habite. Peu avant la mise à mort prévue de l'âne, survient le fiancé de Charite, Tleptolème. Il se présente comme un voleur nommé Hémus, et gagne la confiance des brigands. il arrive à duper les voleurs et à libérer Charite, en emmenant l'âne. Dès lors, l'âne appartient au jeune couple et est d'abord bien traité. Puis il tombe dans de grandes difficultés, est utilisé comme animal de transport et doit subir de l'ânier de nombreux mauvais traitements.

Livres viII à $\mathrm{x}$ : Un esclave de Charite survient et rapporte qu'un rival de Tleptolème, repoussé par Charite, a été assassiné. Là-dessus, Charite se suicide, après sêtre vengée de l'assassin. Quand les esclaves des deux apprennent la situation, ils prennent la fuite. L'âne doit les suivre vers un avenir incertain, et subit en chemin à nouveau une aventure dangereuse. Finalement, il est vendu au marché. Son nouveau maitre est un sectateur de la Déesse syrienne, un charlatan qui erre en mendiant avec ses collègues; ils vivent des dons des personnes crédules auxquelles ils annoncent comme voyants le succès à venir. L'âne est à nouveau torturé, et risque sa vie.

Un jour, les menteurs sont arrêtés pour vol, et l'âne est à nouveau vendu au marché. L'acheteur est un meunier, qui l'utilise comme âne de meunier. Au moulin, il est témoin de cruautés à l'égard des esclaves et animaux qui y sont employés, et lui-même est harassé. À côté de cela, il s'aperçoit de l'adultère de la femme du meunier, dont il rend la découverte possible, en forçant l'amant à sortir de sa cachette. Là-dessus, le meunier chasse sa femme. Elle se venge en le faisant mourir par sorcellerie. Ceci signifie pour l'âne un nouveau changement de propriétaire, suivi d'autres. Il souffre de faim et de froid, est témoin de destins terribles, et doit assister à la force brute et à ses suites. Il est aussi mêlé à des perversions sexuelles. Finalement, il réussit à s'enfuir vers Corinthe; il se réfugie dans le port proche de Cenchrées. 
Au début du onzième et dernier livre, arrive le tournant. L'âne se tourne vers la Déesse mère et la prie de l'aider. Révérée par tous les peuples sous divers noms, elle lui apparaît sous la forme d'Isis, et lui annonce son sauvetage pendant sa prochaine fête. Pendant la procession de la fête à Cenchrées, il aura l'occasion de manger les roses salvatrices. En remerciement, il devra après le retour à la forme humaine la servir pour le reste de sa vie. Et en réalité, Lucius se retransforme publiquement devant la foule étonnée. Après quelque temps, Isis le fait initier à ses mystères. Sur ses indications, il déménage pour Rome, où il continue à la servir. Là, il reçoit l'initiation aux mystères d'Isis, et à ceux de son époux Osiris. Il est appelé au collège des prêtres d'Isis et d'Osiris. Le service sacerdotal, qu'il exerce tondu à ras, le remplit de satisfaction. Il gagne sa vie comme avocat. C'est ainsi que ses aventures se terminent heureusement.

\section{IV. « AMOUR ET PSYCHÉ »}

Apulée introduit dans la trame du roman «L'âne d'or » le récit d' "Amour et Psyché » qui remplit deux des onze livres. L'auteur s'est inspiré d'une tradition orale de Numidie, sa région native. Le récit d' "Amour et Psyché » est clairement adapté du conte amazigh "Tinaxda».

Psyché est la plus jeune et la plus belle des trois filles d'un roi. En raison de sa beauté extraordinaire, elle est honorée comme la déesse Vénus, et même considérée comme une incarnation de la déesse, ce qui suscite la jalousie de cette dernière. Vénus charge son fils Amour d'amouracher sa rivale mortelle pour le plus méprisable et le plus malheureux des hommes. En raison de sa beauté extraordinaire, personne n'ose prétendre à sa main ; contrairement à ses sœurs, elle reste seule. Le roi interroge à ce sujet l'oracle du dieu Apollon. Le dieu lui conseille d'orner la jeune fille de vêtements de noces, et de la déposer sur un rocher de la montagne ; un monstre horrible y viendra en volant, et la prendra pour femme. Les parents suivent avec tristesse l'oracle. Mais le monstre n'apparaît pas, et un doux vent emporte Psyché dans la vallée, où elle s'endort.

Quand elle se réveille, elle se retrouve devant un beau palais de structure surnaturelle, et y entre. Une voix sans corps la salue, des servantes invisibles remplissent ses désirs. Toutes les nuits, elle est visitée par un inconnu, qui dort avec elle, sans qu'elle ait le droit de voir son visage. Il 
n'apparaît que dans l'obscurité. Elle passe ainsi un long temps dans le palais. Un jour, elle demande au toujours inconnu, qui est pratiquement son mari, et désigné comme tel, de lui rendre possible de revoir ses sœurs. Il lui accorde avec hésitation, mais l'avertit de n'absolument pas céder à l'envie de ses sœurs de découvrir son identité. Elle lui promet. Les sœurs lui rendent visite et envient son style de vie luxueux. Bien que l'inconnu ait averti Psyché qu'elle le perdrait et ne le reverrait plus jamais si elle ne tenait pas sa promesse et voyait son visage, elle se laisse conduire par ses méchantes sœurs à se méfier de son mari. Elle le soupçonne alors d'être le monstre prophétisé jadis. Sur le conseil de ses sœurs, elle se procure une lampe à huile qu'elle cache, et ressort quand son mari est endormi. Dans la lumière de la lampe, elle voit le dieu Amour. Mais une goutte d'huile tombe de la lampe sur l'épaule d'Amour, sur quoi il se réveille et l'abandonne. Psyché reconnaît qu'elle a été entraînée dans le malheur par ses sœurs, et se venge mortellement sur elles. Quand Vénus apprend que son fils méprise son avis et s'est lié à Psyché, une colère violente contre tous deux la prend. Amour est condamné à la résidence surveillée.

Alors Psyché commence une longue recherche de son Amour perdu. Elle doit se livrer à Vénus, car les autres déesses n'osent pas l'aider. Vénus la fait alors torturer, et, pour la punir et l'humilier, lui donne quatre tâches apparemment infaisables. Psyché réussi trois d'entre elles par le recours à des animaux et plantes prêts à aider : les fourmis, le roseau et l'aigle. La quatrième tâche, la plus difficile, consiste à descendre dans le monde d'en bas, le séjour des morts, pour en rapporter dans un récipient quelque chose de la beauté de Proserpine, l'épouse du dieu y régnant, Pluton. Psyché réussit aussi cette tâche, Proserpine lui confie la boîte fermée. Sur le chemin du retour, Psyché ouvre le couvercle par curiosité. Mais il n'y a rien de visible dans la boîte, aucune beauté, mais un lourd sommeil s'en dégage et entraîne Psyché.

Finalement, Amour peut échapper. Il trouve Psyché et la réveille ; il remet le sommeil dans la boîte. Alors Psyché peut livrer à Vénus le don de Proserpine. Amour se tourne vers Jupiter, en le priant de l'aider. Jupiter prend pitié et trouve la solution : il donne à Psyché une coupe d'ambroisie et lui annonce que par cette nourriture, elle parviendra à l'immortalité. Ainsi promue parmi les immortels, Psyché a acquis un 
statut convenable, même pour Vénus, d'épouse acceptable pour Amour. Les deux fêtent leur mariage parmi les dieux. Le couple a une fille qui est nommée «Volupta » (volupté).

\section{PREMIER ROMAN DE L'HUMANITÉ}

L' «âne d'or » marque une rencontre entre le fictif et le réel. On retrouve l'auteur très présent dans son héros, par sa condition bourgeoise, par sa curiosité des choses de la vie. Le nombre de concordances entre la vie de l'auteur et celle de son personnage, laissent à penser que le roman est autobiographique. Lucius est une partie d'Apulée, son « soi » en gestation. Lucius qui se voit châtié et transformé en âne, subira les douleurs et les affres de sa condition pendant une très longue durée, tout en gardant son âme d'humain, l'esprit lubrique de l'âne. Apulée signe avec son roman, une catharsis, qui marque chez lui un processus d'individuation.

Apulée bâtit son roman sur les ruines de la littérature précédente. Chemin faisant, il critique, voire ridiculise tous les genres littéraires existants. A l'époque, la poésie, ainsi que les autres genres, sont tombés en désuétudes et remplacés par des genres émergents nouveaux, comme le mime, ou le pantomime. Par son concept de roman, que l'on appelait alors «fabula » (fable). Apulée a « déboulonné » la mythologie de son piédestal, étant sujet principal des œuvres littéraires. Pour mystifier le quotidien, qui devient l'objet de la littérature, ce qui était complétement neuf.

\section{Acerca de la autora del artículo}

Meriem Skander, nacida en 1985 en Constantina, Argelia, es fisioterapeuta y escritora, habiendo publicado su primera novela en 2016, bajo el título de «Libertà». 


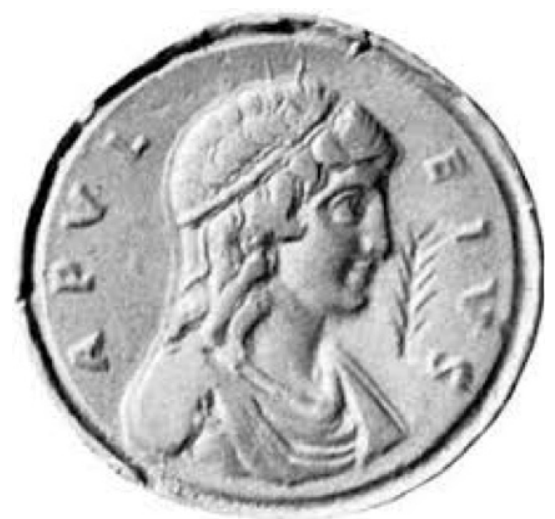

Portrait imaginaire d'Apulée sur un médaillon du IV siècle.

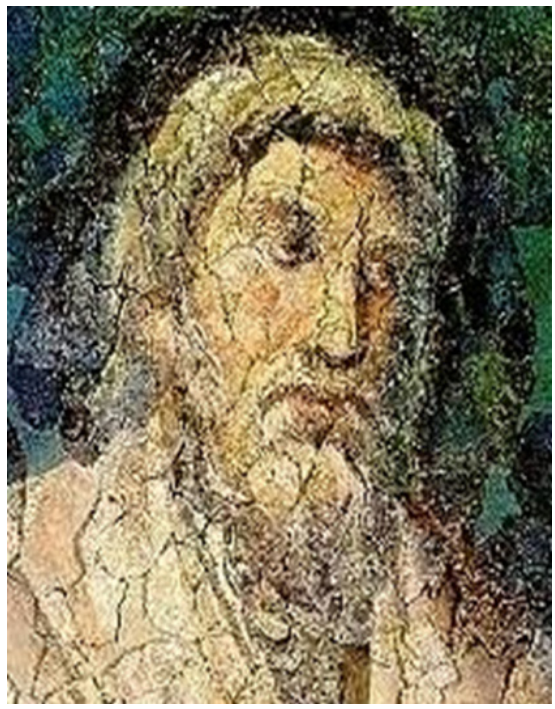

Apulée de Madaure. 
30 Meriem Skander

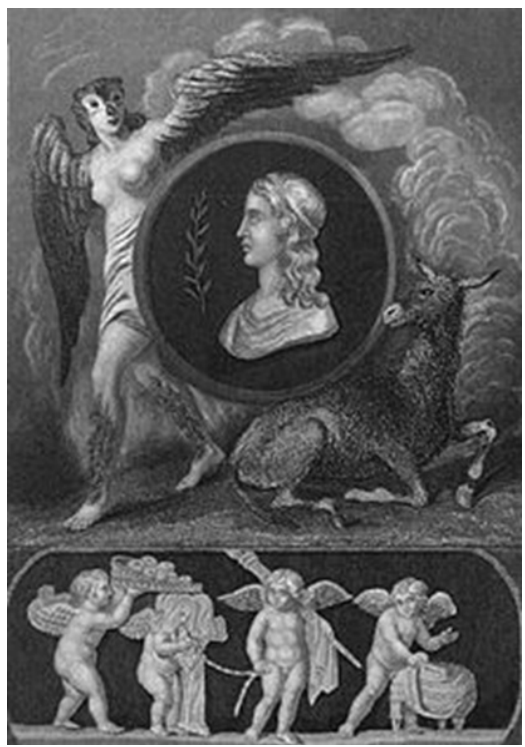

Frontispice des Métamorphoses, Librairies de Bohn, 1902.

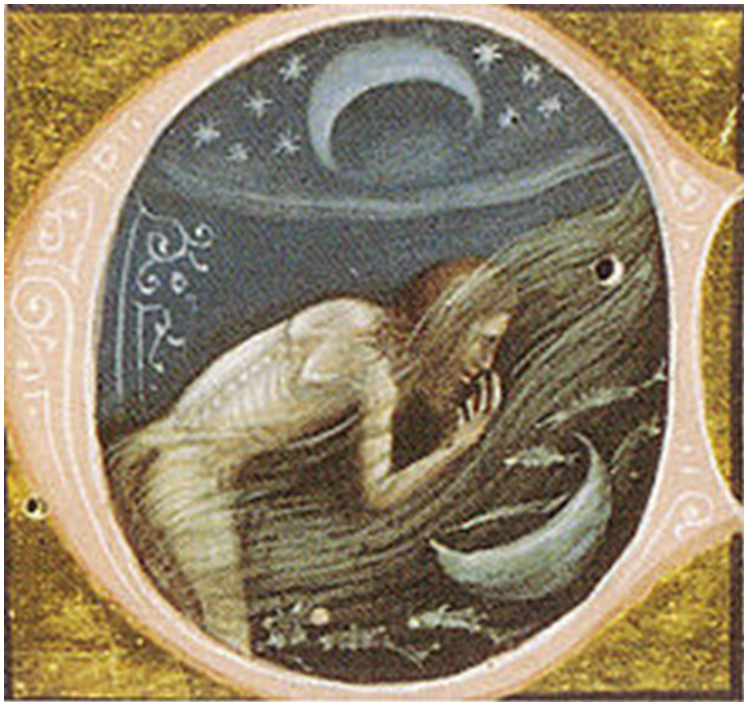

Retour de l'âne vers la forme humaine de Lucius. Miniature d'un manuscrit des Métamorphoses de 1345. 


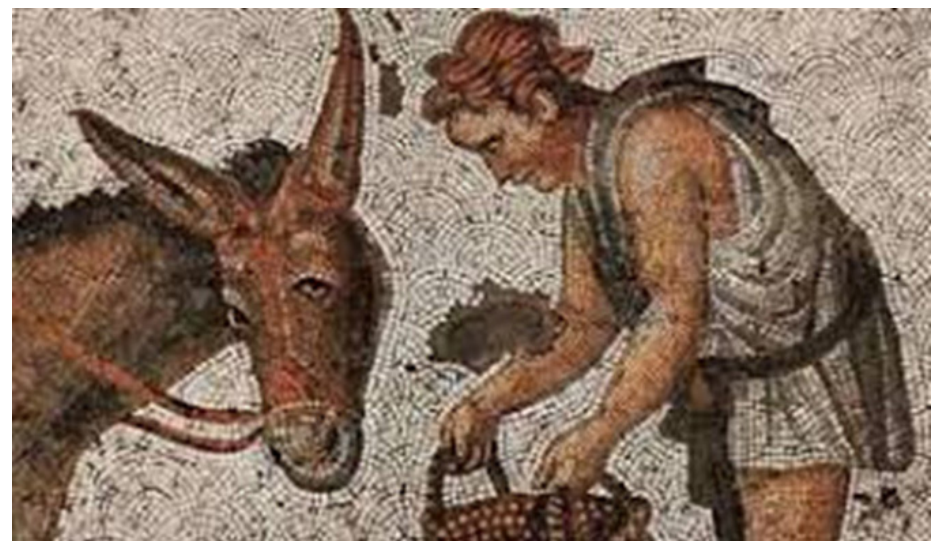

Mosaïque byzantine, $v^{\mathrm{e}}$ siècle, Istanbul.

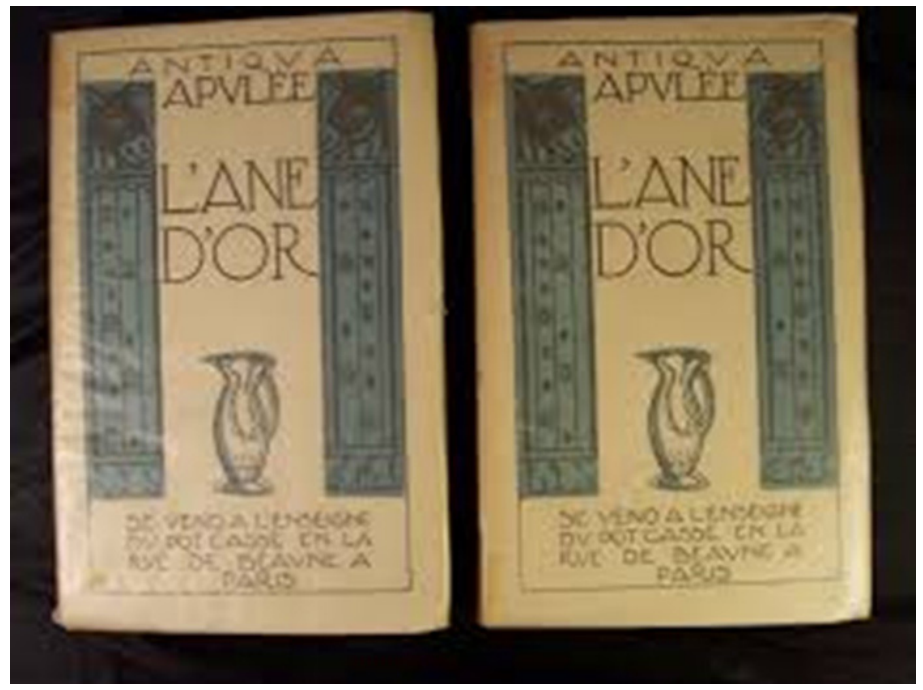

Apulée, L'âne d'or 
32 Meriem Skander

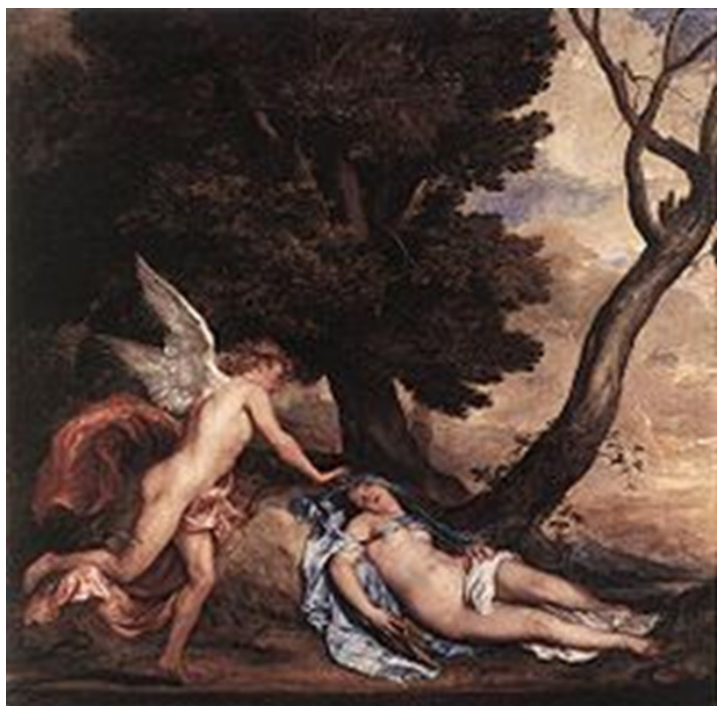

Amour et Psyché, peinture d'Anthonis van Dyck. Royal Collection, Londres.

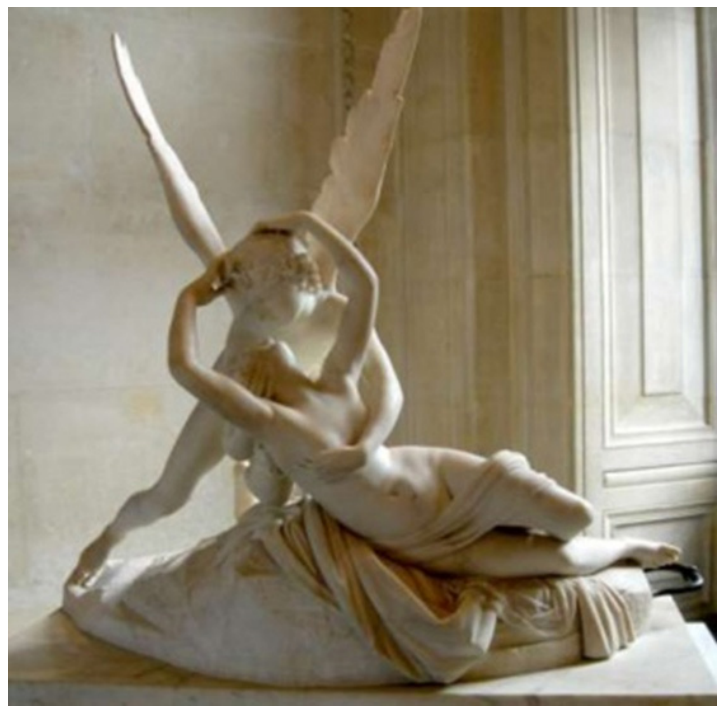

Psyché ranimée par le baiser de l'Amour, sculpture d'Antonio Canova, Louvre, Paris. 


\title{
LA KAHINA, LA REINE PALIMSESTE
}

\author{
Danielle Pister \\ Université de Lorraine (site de Metz)
}

\begin{abstract}
Résumé
La Kahina reste le personnage le plus emblématique de la résistance berbère à la conquête arabe du Maghreb, au viI ${ }^{\mathrm{e}}$ siècle. Paradoxalement, l'ignorance où nous sommes de sa véritable vie, faute de sources fiables, lui a conféré une aura qui lui a permis de continuer à incarner, jusqu'à nos jours, la longue et difficile histoire du Maghreb pour les différentes communautés qui ont vécu sur ce territoire et dont elle reflète la mémoire.
\end{abstract}

Mots clés : Algérie, Arabe, Aurès, Christianisme, Colonisation, Conquête arabe, Femme, Indépendance, Islam, Juif, Mémoire, Maghreb, Mort, Résistance, Tunisie.

\section{Resumen}

La Kahina sigue siendo el personaje más emblemático de la resistencia berberisca a la conquista árabe del Magreb, en el siglo vir. Paradójicamente, la ignorancia en la que nos encontramos de su verdadera vida, por falta de fuentes fiables, le confirió un aura que le permitió seguir encarnado, hasta nuestros días, la larga y difícil historia del Magreb para las distintas comunidades que vivieron en este territorio y cuya memoria refleja.

Palabras claves: Argelia, árabe, Aurès, cristianismo, colonización, conquista árabe, mujer, Independencia, Islam, judío, memoria (informe), el Magreb, muerte, resistencia, Túnez

La fortune éditoriale de la Kahina est inversement proportionnelle à ce que l'on sait de fiable sur le personnage. Quelques lignes suffisent aux historiens contemporains pour en rendre compte. ${ }^{1}$ En revanche, la fascination exercée par son destin reste encore forte aujourd'hui comme en témoignent les nombreux récits générés par une mémoire plurielle.

1 Dans l'Histoire de l'Afrique du Nord de Charles-André Julien, l'équipée de la Kahina occupe deux pages (p. 20-22) du second volume de la réédition parue à Paris, chez Payot en 1975. Bernard Lugan résume son combat en un paragraphe, à la page 70 de son Histoire des Berbères. Un combat identitaire plurimillénaire, Bernard Lugan Éditeur, 2012. Gilbert Meynier lui consacre un paragraphe et demi, p. 196-197, dans L'Algérie des origines. De la prébistoire à l'avènement de l'islam, La Découverte/Poche, 2010. 
Transmis d'abord oralement, avant d'être fixés par écrit, ils ont propagé une légende qui a transformé cette reine berbère en un véritable mythe.

$\mathrm{Au}$ sens étymologique, l'adjectif verbal latin legenda s'applique à un texte hagiographique "devant être lu ». La version écrite d'un récit, concernant des faits présentés comme véridiques, limite les interventions sur le corpus de celui qui en prend connaissance ou de celui qui se charge de le diffuser à un public assemblé à cet effet. La Légende dorée, recueil de vies de saints daté du XIII ${ }^{\mathrm{e}}$ siècle, qu'on lisait lors de la fête de l'un d'entre eux dans les monastères, pendant les repas, ou dans les églises pour édifier les fidèles, en donne un exemple. Au fil du temps, et en l'absence de témoignages irréfutables, auteurs et traducteurs surenchérirent sur les narrations précédentes afin de s'adapter à des publics nouveaux et pour mettre l'accent sur un aspect particulier négligé par les prédécesseurs. La vérité, en admettant qu'on la connût, s'embellit grâce à l'imagination féconde du conteur ou du scripteur. C'est ainsi que l'histoire de la Kahina, reine berbère ayant vécu à la fin du vi ${ }^{\mathrm{e}}$ siècle de notre ère, peut-être jusqu'au tout début du suivant, a gagné en ampleur au fil des siècles, au gré des communautés qui se sont emparées de sa mémoire. En s'éloignant du contexte originel, sa vie devint épopée et le personnage prit la dimension d'un mythe fondateur. Les actes qu'on lui prête furent à ce point magnifiés qu'ils devinrent exemplaires pour son peuple dont ils forgèrent l'âme et le destin. Le passé glorieux éclaira leur présent, voire l'avenir auquel ils aspiraient.

La geste de la Kahina, colportée d'abord oralement, a traversé les siècles grâce aux érudits qui ont transcrit ses exploits, avant que les romanciers ne se laissent séduire par cette reine berbère et ne la transforment en une « reine-palimpseste ». ${ }^{2} \mathrm{Si}$ les chroniques concernant la Kahina se recoupent sur l'essentiel, elles diffèrent sur certains points, parfois importants. Il n'existe pas de témoignages contemporains de son existence, ni de vestiges matériels attestant sa présence à une date et en un lieu précis. ${ }^{3}$ Aucune effigie d'elle ne nous est parvenue, ce qui n'étonne

2 Du grec ancien $\pi \alpha \lambda i \mu \psi \eta \sigma \tau o \varsigma$ / palímpsêstos, « gratté de nouveau »), ce terme désigne un manuscrit constitué d'un parchemin déjà utilisé, dont on a fait disparaitre les inscriptions visibles pour pouvoir y écrire un nouveau texte. Cette pratique fut surtout courante entre les $\mathrm{VII}^{\mathrm{e}}$ et $\mathrm{XII}^{\mathrm{e}}$ siècles, chez les copistes. La cherté des parchemins explique la réutilisation d'anciens manuscrits.

3 Même si la ville de Bir El Atar - à 87 km de Tébessa, dans la région des Aurès en Algérie -, 
pas, s'agissant d'une civilisation nomade qui ne frappe pas de monnaie et communique, pour l'essentiel, oralement.

Les historiens antiques se sont désintéressés de l'Ifriqiya, ${ }^{4}$ après la fin des guerres puniques, en I46 av. J.-C. De la fin du vII ${ }^{\mathrm{e}}$ siècle jusqu'au milieu du $\mathrm{IX}^{\mathrm{e}}$ siècle, aucun texte ne rend compte de la conquête du Maghreb par les Arabes, ni de celle de l'Espagne, de la Sicile ou de l'Égypte. Il faut attendre la fin du XII ${ }^{\mathrm{e}}$ siècle pour que les chroniqueurs espagnols, portugais et arabes, s'intéressent aux dynasties arabes. Le manque de témoignages contemporains sur la Kahina a suscité des doutes sur son historicité, notamment chez l'érudit français Charles Le Beau (I7oII778)..$^{5}$ D'autres historiens virent, au contraire, dans la permanence de sa mémoire la preuve de son existence et du rôle qu'elle a joué dans les dernières années de la conquête arabe de l'Ifriqiya. ${ }^{6}$ Mais comment apprécier la fiabilité des témoignages parus plus d'un siècle et demi après la date présumée de sa mort et, pour la source essentielle, le Kitab al-Ibar (Le livre des exemples) d'Ibn Khaldoun, presque sept siècles plus tard ?7

Les chroniqueurs des conquêtes musulmanes des $\mathrm{VII}^{\mathrm{e}}$ et $\mathrm{VIII}^{\mathrm{e}}$ siècles, qui rapportent la résistance de la Kahina à cette avancée, enrichissent les textes antérieurs en rajoutant des détails non vérifiables. Pour les Berbères d'Afrique du Nord — qui utilisent plus volontiers, pour se désigner, le vocable d'Imazighen, « hommes libres » ou « nobles »-, ce personnage incarne la défense de leur identité, de leur langue, de leur culture. En témoignent encore aujourd'hui les échanges sur les réseaux sociaux qui

affirme abriter le célèbre Bir E1 Kahina (puits de la Kahina) où la reine berbère aurait été jetée par les Arabes après qu'ils l'eurent tuée, bien d'autres lieux portent ce nom. C'est dans la ville antique de Baghaï (wilaya de Kenchela), classée monument du patrimoine national, que se trouverait le château où aurait vécu la Kahina. A ucune fouille archéologique, à ce jour, n’a pu prouver son existence.

4 Province proconsulaire romaine, correspondant à peu près à l'actuelle Tunisie, plus une partie de l'Est de l'Algérie et de la Libye actuelle.

5 Auteur de l'Histoire du Bas-Empire en commençant à Constantin le Grand dont il rédige 21 des 27 volumes, publiés entre $1757-1811$.

6 Déformation de l'appellation latine Africa désignant la partie orientale du Maghreb médiéval, également orthographié Ifriqiyya (en berbère $<\left[\mathrm{HO}<Z S_{0}\right.$, en arabe إفريقية).

7 Auteurs et textes les plus souvent cités : Ibn 'Abd al-Ḥakam (803-871), Conquête de l'Égypte, de l'Afrique du Nord et de l'Espagne (vers 860) ; Al-Mālikī, Abū Bakr 'Abd lāh ibn Muhammad, Riyāạ al-Nufüs (Livre du jardin des âmes) vers 1072 ; Ibn Khaldoun (Tunis, 1332 - Le Caire, 1406), Histoire des Berbères et des dynasties musulmanes de l'Afrique septentrionale, traduite par le baron de Slane, Alger, imprimerie du Gouvernement, 1852. 
confrontent, parfois avec une grande vivacité, les opinions des internautes algériens, tunisiens, marocains ou français sur la Kahina. De nombreux restaurants, et autres boutiques, arborent son nom sur leurs enseignes dans tous les lieux où la diaspora berbère a fait souche. Mais cette ferveur n'est pas moindre dans les communautés juives, ayant vécu en Afrique du Nord jusque dans les années i96o. Ils considèrent également la Kahina comme une ancêtre illustre. Dans les deux cas, son image est marquée par une forte affectivité, liée à une mémoire identitaire et familiale. La référence, quoique plus faible, existe aussi chez les Français, installés en Algérie pendant I32 ans, car elle a servi à justifier, chez certains d'entre eux, leur présence sur cette terre.

C'est cette figure protéiforme, passée de l'histoire à la légende et devenue un mythe, sans jamais perdre totalement sa dimension politique, que nous essaierons d'éclairer. Il ne sera pas question pour autant de faire une enquête historique ${ }^{8}$ ni de nous livrer à une quête des textes aussi poussée que celle menée par Noureddine Sabri. ${ }^{9}$ Plus modestement, nous essaierons de dégager quelques étapes dans l'utilisation littéraire de ce personnage jusqu'à nos jours.

\section{LES DONNÉES HISTORIQUES}

L'histoire étant généralement écrite par les vainqueurs, on peut s'interroger sur les éléments qu'ils retiennent pour peindre leurs adversaires. Le récit est souvent peu informatif et oscille souvent entre apologie et philippique. Ibn-Khaldoun insiste sur les grandes qualités des Berbères qui « ont toujours été un peuple puissant, redoutable, brave et nombreux, comme tant d'autres dans ce monde, tels que les Arabes, les Persans, les Grecs et les Romains. » ${ }^{10} \mathrm{Il}$ ajoute : "On a vu chez les Berbères des choses tellement hors du commun, des faits tellement admirables, qu'il est impossible de méconnaître le grand soin que Dieu a eu de cette nation, l'extrême bonté qu'il lui a toujours témoignée, la combinaison de vertus

8 Nous nous réfèrerons à Gabriel Camps, qui a consacré sa vie à l'étude des Berbères, et à Yves Modéran, spécialiste du haut Moyen Âge en Afrique du Nord.

9 Sabri (Noureddine), La Kahéna. Un mythe à l’image du Maghreb, Paris, L'Harmattan, «Critiques littéraires ", 2011, $271 \mathrm{p}$.

10 Ibn Khaldoun, op. cit., p. 199. 
dont il l'a dotée, les nombreux genres de perfections auxquels il l'a fait atteindre et toutes les diverses qualités propres à l'espèce humaine qu'il lui a permis de réunir et de s'approprier. ${ }^{11}$ La vie de la Kahina illustre de façon exemplaire ces aptitudes hors norme. En fait, l'histoire de cette dernière n'est jamais traitée pour elle-même mais par rapport à la conquête arabe qu'il s'agit de magnifier comme l'« œuvre du Tout-Puissant » : on ne peut mépriser un peuple que Dieu a lui-même élu. D’ailleurs, la victoire des Arabes sera d'autant plus éclatante qu'elle est obtenue sur un adversaire redoutable.

Sans discuter la véracité des faits rapportés par les chroniques, on peut remarquer combien la personnalité et le destin prêtés à la reine berbère se confondent avec la longue histoire des peuples qui ont occupé auparavant l'Afrique du Nord. La mort au combat de ce personnage ne scelle pas seulement le destin d'une femme et de sa tribu, elle symbolise la disparition - même si, en réalité, elle ne fut accomplie que sur le long terme- de ce qui subsistait encore des éléments civilisationnels du pourtour méditerranéen dont ce territoire fut le creuset depuis la plus haute Antiquité. Rappelons que les Berbères sont les descendants des premiers occupants du territoire (vers 8500 av. J.-C.), dont on a retrouvé les traces dans la région de Capsa, la Gabsa de la Tunisie actuelle. Les Phéniciens fondent Carthage en 8I4 av. J.-c. L'activité commerciale de la cité inquiète les Romains qui finiront par la détruire pour s'établir progressivement sur ce territoire, jusqu'à ce les Vandales venus du Nord de l'Europe vers 430, soient à leur tour chassés par les Byzantins (Empire romain d'Orient), en 533. C'est au siècle suivant, peu après la mort du Prophète Mahomet à Médine en 632, que les incursions arabes vont commencer sur un territoire sétendant de la Lybie, à la Tunisie, et à l'Est $\mathrm{du}$ Constantinois actuels.

Cette histoire mouvementée constitue moins une succession de ruptures qu'une accumulation d'apports culturels : les Carthaginois sont largement hellénisés ; la colonisation romaine, très inégale, est menée par des Africains romanisés (certains devinrent des empereurs romains comme Septime Sévère, né à Septis Magna dans l'actuelle Libye); la romanité subsiste à travers les Vandales et les Byzantins se disent romains

11 Ibid., p. 202-203. 
(Roums). Le christianisme, qui s'installe entre la fin du premier et le début du second siècle, va trouver sur cette terre des émules qui joueront un rôle décisif dans l'histoire de l'Église. La personnalité de Saint Augustin d'Hippone, un Numide, donc un Berbère (354-430), résume l'importance de l'Afrique du Nord dans l'histoire des premiers siècles de l'Église à laquelle elle a donné, entre les deuxième et quatrième siècles, trois papes. Les Berbères des cités sont christianisés et romanisés. Les nomades de l'Ouest restent imprégnés par leurs pratiques ancestrales païennes. Ceux de l'Est, adoptent tous les schismes. Mais l'Église africaine, affaiblie par le donatisme qui a suscité une répression des Vandales, adeptes de l'arianisme, contre ce schisme, n'est plus en état d'empêcher l'implantation d'une nouvelle religion. Les Juifs, arrivés à des époques différentes, peut-être avec les Phéniciens, ou plus tard après la destruction du temple de Jérusalem (le premier au VI ${ }^{\mathrm{e}}$ siècle av. J.-C., le second en 70 sous Titus), se sont intégrés à des tribus berbères, à moins que certains de ces derniers ne se soient judaïsés. Enfin, il n'est pas exclu que les troupes des envahisseurs arabes soient accompagnées d'artisans juifs dont ils avaient notamment besoin pour la fabrication de leurs armes.

On peut comprendre que l'on puisse hésiter sur l'appartenance de la Kahina à tel groupe ethnique et à telle religion. L'onomastique offre un premier éclairage. Désignée par tous les chroniqueurs arabes par le surnom d'al-Kāhina, transcrit Kahina ou Kahena, ${ }^{12}$ on a rapproché la racine sémitique KHN de Kahin, le devin. Elle désignerait ici une prophétesse, voire une sorcière. Ce pouvoir, souvent attribué aux femmes dans des cultures païennes, était mis à contribution par les Arabes : ils se faisaient accompagner sur le champ de bataille par des devineresses, chargées de prédire l'issue des combats ou d'influer sur leur issue. Selon En-Noweïri, ${ }^{13}$ la Kahina " prédisait l'avenir et tout ce qu'elle annonça ne manqua pas d'arriver. " ${ }^{14}$ C'est ainsi, qu'avant la dernière bataille où elle sera tuée, et sur les « conseils dictés par les connaissances surnaturelles

12 Sauf s'il s'agit de respecter la graphie d'une citation, on gardera la graphie « Kahina », plus universelle.

13 Ibn 'Abd al-Hakam, dit En-Noweïri, mort vers 1331-33, auteur d'une encyclopédie dont la $5^{\mathrm{e}}$ partie est consacrée à l'histoire. Le baron de Slane en extrait la partie traitant de la guerre contre la Kahina qu'il ajoute, en appendice, à sa traduction de l'Histoire des Berbères d'Ibn Khaldoun.

14 Ibn Khaldoun, op. cit., Appendice, § XI, p. 340 (fragment du chroniqueur En-Noweïri). 
que ses démons familiers lui avaient enseignées ", elle annonce à ses fils sa mort prochaine et leur demande se rendre à l'ennemi avant le combat. ${ }^{15}$

Ibn Khaldoun précise l'identité et la généalogie de celle qu'il distingue parmi les «chefs les plus puissants » des Berbères, «la Kahena, reine du Mont-Auras, et dont le vrai nom était Dihya, fille de Tabeta, fils de Tifan. Sa famille faisait partie des Djeraoua, tribu qui fournissait des rois et des chefs à tous les Berbères descendus d'el-Ater. ${ }^{16}$ Comme il affirme que ces derniers pratiquaient le judaïsme, ${ }^{17}$ on en a déduit que la Kahena était juive. D'où l'identification de son surnom, réduit à ses seules consonnes KHN, à celui de Cohen. De l'hébreu כהן, titre conféré à Aaron, frère de Moïse de la tribu de Lévi, et à sa descendance masculine, signifiant " dévoués » au service du Temple de Jérusalem, notamment pour les sacrifices. Depuis la destruction du Temple, le nom a continué à se transmettre de père en fils. Pour Norbert Slousch, ${ }^{18}$ elle est la dernière représentante des chefs d'origine juive qui descendraient probablement « d'une famille de grands prêtres aaronides de Jérusalem ». Dans ce cas, Kahena désignerait une prêtresse, mais cette fonction est étrangère à toute pratique hébraïque. Dès I963, l'historien israélien H. Z. Hirschberg, en retraduisant le texte d'Ibn Khaldoun et en reprenant de manière rigoureuse l'ensemble du dossier, remit en cause cette interprétation, et de manière plus générale, l'existence même de grandes tribus berbères juives à la fin de l'Antiquité. On a rapproché aussi ce surnom du grec ancien Kópıvva / Kórinna, Corinne en français, « être pur ». En Afrique du Nord, toutes les prêtresses subissaient un rituel de purification, tradition sans doute d'origine animiste. Le Professeur tunisien M'hamed Hassine Fantar avance une autre hypothèse : «elle était kohenet au sens punique du terme... reine-prêtresse... de quelque divinité (païenne et guerrière) dont l'historiographie n'a pas retenu le nom ${ }^{19}$

15 Ibid., p. $214-215$ et p. 341.

16 Ibn Khaldoun, op. cit., p. 213.

17 Ibid., p. 208.

18 Slousch (Norbert), «La race d'El Cahena », in La Revue indigène, n 44, déc. 1909, p. 580-581.

19 On ne peut, pour plus de précisions, que renvoyer à l'étude d'Yves Modéran, « Kahena », in Encyclopédie berbère, 27 | Kairouan - Kifan Bel-Ghomari [En ligne], mis en ligne le 01 juin 2011, consulté le 25 avril 2018. uRL : http://journals.openedition.org/encyclopedieberbere/1306 
Par ailleurs, Dihya ( $\left.₫ \ll \Phi S_{\circ}\right)$, Diya, Dahya, rapproché de l'expression tamazighe (berbère) «Dyhia Tadmut " signifie « belle gazelle », les berbères étant souvent désignés par un sobriquet. On y a vu la déformation de Damiya ou Damya (devineresse) qui, peut-être n'est qu'un diminutif du nom latin Damiana (du grec Damía « Damia », déesse grecque de la fertilité, assimilée à Demeter). Tabeta a été corrigé en Matiya, Tifan en Théophane, ${ }^{20}$ ce qui peut renvoyer aussi bien au judaïsme qu'au christianisme. Or El-Maliki rapporte que lors de sa fuite ultime, « elle avait avec elle une énorme idole de bois qu'elle adorait ; on la portait devant elle sur un chameau ». Certains y ont vu une idole paienne, celle de Gurzil, une divinité amazighe représentée par un taureau. Si le culte du Taureau, symbole de virilité et de puissance, est connu en Afrique du Nord dans l'Antiquité, aucun élément historique ne prouve que Dihya en fut une prêtresse. D'autres parlent d'une statue du Christ, de la Vierge ou du saint patron de la reine. Ce qui amène Mohamed Talbi à y voir la preuve de son appartenance au christianisme. ${ }^{21}$ Déjà, Émile Masqueray (I843-I894), ${ }^{22}$ agrégé d'histoire, anthropologue, ethnologue, linguiste pratiquant l'arabe et plusieurs langues berbères, mettait en doute la judaïté de la Kahina car, pour lui, les Berbères descendraient des colons romains, dégradés et déchus. Pour lui, leur reine ne pouvait quêtre chrétienne.

Gabriel Camps et Yves Modéran s'accordent pour privilégier l'hypothèse d'une Kahina chrétienne, tout en reconnaissant l'absence de preuves irréfutables. ${ }^{23}$ Ils reprennent l'affirmation de Mohamed Talbi, selon laquelle l'Aurès était à cette époque christianisé, comme le prouvent de nombreux vestiges chrétiens. ${ }^{24} \mathrm{Au}$-delà, d'une vérité difficile à démontrer, cette multiplicité d'hypothèse, parfois exclusives les unes des autres, fait du personnage la résultante de toute l'histoire si complexe de l'Ifriqiya

20 Talbi (Mohamed), «Un nouveau fragment de l'histoire de l'Occident musulman l'épopée d'Al-Kahina ", in Les Cabiers de Tunisie, t. xIx, 1er et $2^{\mathrm{e}}$ trim., 1971, p. 19-52.

$21 \mathrm{Ibid}$.

22 Masqueray (Émile), Formation des cités chez les populations sédentaires de l'Algérie (Kabyles du Djurdjura, Chaiuïa de l'Aourâs, Beni Mezâb), Paris, E. Leroux, 1886 ; Éd. Fanny Colonna, Aix-enProvence, Edisud, 1983.

23 Camps (Gabriel), L'Afrique du nord au féminin, Librairie Académique Perrin, 1992, p. 124-139.

24 Modéran (Yves), « Kahena », in Encyclopédie berbère, 27 | Kairouan - Kifan Bel-Ghomari [En ligne], mis en ligne le 01 juin 2011, consulté le 25 avril 2018. URL : http://journals.openedition. org/encyclopedieberbere/1306 
jusqu'à la conquête arabe. Berbère, la Kahina appartient à la population qui la première a occupé le territoire ; l'ascendance chrétienne la relie aux Byzantins qui se voulaient héritiers des Romains, eux-mêmes vainqueurs des Phéniciens. Des trois fils qu'elle aurait eus, Ifran est supposé fils d'un Berbère, Yasdigan celui d'un Romain ("Grec »), et Khaled, le prisonnier arabe qu'elle a adopté. Cette fratrie établit ainsi un lien légitime, autant berbère qu'arabe, entre les trois. Cela explique l'ordre donnée par la Kahina pour qu'ils se rendent à Hassan, le chef Arabe : elle assure ainsi la survie de sa tribu à travers leur descendance, même métissée, et son intégration dans l'identité des nouveaux maîtres. ${ }^{25}$ Son sacrifice légalise, d'une certaine façon, la victoire des nouveaux venus et doit effacer les antagonismes d'hier. ${ }^{26}$ Sont symboliques également les I27 ans de vie que Khaldoun lui prête. ${ }^{27}$ Cela relève avant tout d'une tournure stylistique destinée à souligner l'importance du personnage, à l'exemple des I2O ans prêtés à Moïse dans la Bible. Cela n’empêche pas les romanciers de faire mourir la Kahéna encore dans toute la splendeur de sa beauté !

Les chroniques, avec plus ou moins de détails, présentent cette guerrière comme le dernier rempart contre la conquête de l'Ifriqiya par les Arabes à la fin du viI siècle après la mort, en 688, de Koceïla / Kuseyla, le chef berbère qui avait mis fin à l'avancée triomphale d'Oqba ibn Nafi, en 683, et repris Kairouan, cité où ce dernier avait fondé, sur ce territoire, en 670 , la première mosquée. Pour certains chroniqueurs, la Kahina se serait battue aux côtés de Koceila et ils auraient même été amants. Quand il meurt cinq ans plus tard, elle prend sa relève, après avoir réussi à fédérer des tribus berbères contre les troupes arabes conduites par Hassan. Selon Yves Modéran, l'aventure de la Kahena devrait se placer entre 698 et 702-703. ${ }^{28}$ Après avoir réussi à mettre en échec une première fois l'envahisseur près de l'Oued Nini, elle fait de nombreux prisonniers quelle libère à l'exception d'un seul qu'elle va adopter, Khaled, qui l'aurait trahie en renseignant les Arabes sur ses agissements. À ce sujet, En-Noweiri, parle de la bonté de la Kahina libérant ses prisonniers, avant de dénon-

25 Ibid., p. 139.

26 C'est la thèse défendue par Norman Roth dans "The Kâhina : legendary material in the accounts of the « Jewish berber Queen », The Maghreb Review, Londres, vol. 7, 5-6, 1982, p. 124.

27 Khaldoun, op. cit., tome 3, p. 193.

28 Modéran (Yves), op. cit. 
cer, quelques lignes plus loin, la tyrannie quelle exerce sur les habitants, une fois devenue maîtresse de l'Ifriqiya, notamment lorsqu'elle décide de dévaster le pays pour décourager les envahisseurs. Pour elle, ces derniers ne cherchent qu'à s'emparer des « villes, de l'or et de l'argent ", alors que les Berbères veulent garder les champs pour le pâturage et les cultures. ${ }^{29}$ Finalement vaincue, elle meurt, pour les uns, sur le champ de bataille, glaive à la main ; pour Ibn Khaldoun, décapitée près d'un puits, difficile à situer tant de lieux de l'Aurès portent encore le nom de Bîr-el-Kahina aujourd'hui. ${ }^{30}$ Pour El-Bekri, ${ }^{31}$ c'est à Tabarka, ville côtière du nord-ouest de la Tunisie actuelle, qu'elle est décapitée dans un ravin et que sa tête est ramenée au calife. L'attrait de la légende apportant une plus-value touristique aux lieux supposés historiques, on ne s'étonnera pas qu'un guide de tourisme ${ }^{32}$ rapporte une croyance populaire : blessée, la guerrière se serait fondue dans la nuit et, "parfois le soir, non loin du Marabout de Sidi Amor, une lieue à peine au Sud de Tabarka, près d'un puits où elle se serait donné la mort, l'ombre de la reine erre parmi les bruyères et les typas, sur les rives de l'Oued El Kébir, là tout près de Tabarka. » Mais une telle reine, héritière du long passé de l'Ifriqiya, méritait un lieu grandiose, digne de son destin fabuleux, pour y mourir. L'amphithéâtre romain de Thysdrus (E1 Djem) devient la forteresse où elle s'enferme. Les murs garderaient les traces du dernier combat qu'elle a livré. Ce décor la magnifie et la hisse à la hauteur de la puissance romaine de jadis dont ces pierres furent les témoins.

À ce stade, il n'est plus question de chercher à prouver une quelconque vérité historique. Il suffit de constater que le personnage appartient à un fond culturel que se partagent différentes traditions. Les récits des historiens arabes balancent entre hommages et accusations. La victoire difficile des envahisseurs prouve qu'elle résulte de la volonté d'Allah que rien ne pouvait arrêter. Les qualités de l'adversaire justifient que sa descendance soit intégrée dans les rangs des conquérants. Ses fils iront,

29 En-Noweïri, appendice à l'Histoire des Berbères, traduction de Slane, p. 340-341.

30 Op. cit., tome 1, p. 214.

31 El-Bekri, Description de l'Afrique septentrionale [extrait de Description géographique du monde connu], éd. et trad. en français par le baron de Slane, Alger, 1858-1859 (Journal asiatique, 12-14) ; nouv. éd. Paris, 1913.

32 Guide Hachette Visa, 1994. 
avec les nouveaux maîtres, soumettre l'Espagne. Ainsi se clôt avec cette héroïne un cycle historique.

\section{LA REVIVISCENCE DE LA LÉGENDE}

Si les textes arabes, concernant l'Afrique du Nord étaient connus des érudits européens, l'intérêt porté au passé de celle-ci par les nouveaux maitres de l'Algérie, à partir de I830, puis de la Tunisie à partir de I88I, va générer leur traduction en langue française. Ils permettent à un plus grand nombre de lecteurs de les connaitre et pour certains de les confronter aux traditions orales. William Mac Guckin, baron de Slane (I8oI-1878), Irlandais venu en France pour étudier les langues orientales, réalise la traduction de nombreux textes arabes et s'occupe notamment de l'établissement du catalogue de la bibliothèque d'Alger. Son rôle est important dans la connaissance des textes arabes médiévaux.

Mais les Occidentaux vont élargir les références culturelles pour peindre l'héroïne berbère. Au regard porté par des Musulmans va s'ajouter, parfois pour s'opposer, celui généré par la tradition judéo-chrétienne de la culture européenne. Ainsi, les références bibliques font de la Kahina une " Déborah Berbère ", 33 prophétesse juive qui, selon les chapitres 4 et $5 \mathrm{du}$ Livre des Juges, suscite la résistance de son peuple à l'envahisseur cananéen. Marcelle Magdinier ${ }^{34}$ fait le même rapprochement, doublé de celui avec Judith, qui dans le livre du même nom de l'Ancien Testament, écarte la menace d'une invasion assyrienne en décapitant le général ennemi Holopherne, ce que reprend Jean Hilaire, ${ }^{35}$ assimilant la Kahina au "glaive de Judith ». La reine berbère est ainsi réintégrée dans la tradition judéo-chrétienne à laquelle elle est censée avoir appartenu. Ces références religieuses entrent en résonnance avec les envahisseurs arabes agissant au nom d'Allah.

Parfois l'actualité politique interfère dans les références. Les efforts de l'Église pour se réconcilier avec la République française, avec laquelle elle était en froid à la suite des positions laïques de l'État, aboutissent, en

33 Expression de Georges Marçais (1876-1962), archéologue arabisant, il a consacré plusieurs études importantes à l'art et à l'histoire du Maghreb, notamment à l'Algérie médiévale.

34 Magdinier (Marcelle), 1898-1984, La Kahena, Paris, Calmann-Lévy, 1953.

35 Hilaire (Jean), La Kahena, Rouen, Henri Defontaine Edit. 1918. 
I89o, au « toast d'Alger » ${ }^{36}$ qui, malgré les difficultés persistantes, amorce un rapprochement très relatif, entre Rome et Paris. A terme, on assistera à la canonisation de Jeanne d'Arc (I920). Bientôt, les villes d'Alger, Bône, Philippeville et Oran accueilleront une statue de la nouvelle sainte. C'est dans cette période que paraît un texte anonyme, Une Jeanne d'Arc africaine, épisode de l'invasion des Arabes en Afrique : la Kabina, que Jean Déjeux ${ }^{37}$ date de 1890 , époque où on essaie de donner une assise historique et littéraire aux liens entre la France et l'Algérie. Hélène Stora-Sudaka, en mai I929, dans une conférence sur les " Premières immigrations juives en Berbérie », utilise des références bibliques classiques (rapprochement du don de prophétie de la Kaëna [sic] de celui de Joël dans la Bible, citation empruntée à un poème de Mme Aboulker Benichou qui la qualifie de " Judith ou Débora vivante »). Mais survient une appellation dans l'air du temps, celle de "Jeanne d'Arc berbère ", qui donne une coloration patriotique au propos, confirmée plus loin : «Le croissant s'est levé au lieu du sceptre de la Kaëna superbe. » À son tour, l'étendard de l'islam a pâli « devant une enseigne aux triomphantes couleurs : notre drapeau tricolore », emblème du " génie civilisateur de la France ». Il s'agit bien de célébrer l'œuvre de la colonisation. ${ }^{38}$

La position particulière des écrivains d'Algérie, d'origine juive, s'explique aisément : ils sont passés du statut de dhimmi, avant la conquête, à celui de citoyen français, avec le décret Crémieux de i87o. Ils revendiquent la judaïté de la Kahina et sa latinité, ce qui fait le lien avec la présence française au Maghreb. Ils fixent aussi par l'écrit toute une tradition populaire qui fait de la Kahina une ancêtre glorieuse pour tout un petit peuple marginalisé. C'est sensible dans le recueil La Hara conte, qui rassemble de brefs récits qui circulaient dans ce quartier pauvre où vivaient les Juifs de Tunis. J. Vehel (pour Jacques-Victor Lévy) signe l'un d'eux, « La Belle Kahéna ». Revenant sur la signification de son nom, il prend un plaisir évident à souligner « un point de similitude avec Jeanne d'Arc qui fut, elle aussi, accusée de sorcellerie. » Il renchérit : «Elle était superbe,

36 Mandaté par le Pape Léon Xiır, le cardinal Lavigerie, archevêque d'Alger et de Carthage, participe à l'Amirauté d'Alger à la réception officielle de l'escadre française de la Méditerranée.

37 Déjeux (Jean), Femmes d'Algérie. Légendes, Traditions, Histoire, Littérature, Paris, La Boîte à Documents, 1987, p. 88.

38 Ibid.p. 89-90. 
la Kahéna, dans son armure grise, [...] ayant au côté une petite hache et son épée à garde d'argent ", ajoutant qu'elle " portait à la main une bannière de soie blanche à raies bleues sur laquelle était brodé en lettres d'or le nom de Jéhova ${ }^{39}$. Le récit cumule les superlatifs sur l'héroïne et se conclut sur une phrase enthousiaste : "Quelle légende plus belle que cette incontestable histoire ! $»^{40}$ La proximité presque oxymorique du terme « légende » et de l'adjectif « incontestable » nuance le propos par une note ironique.

L'ascendant du personnage pouvant difficilement se justifier par des pouvoirs magiques à lépoque moderne, les auteurs vont doter l'héroïne d'une beauté extraordinaire. À l'instar de son peuple, elle aura des caractéristiques qui la différencient des Arabes, notamment par sa chevelure " couleur de miel, des yeux couleur de lavande et de métal bleu ${ }^{41}$ Même si Marcelle Magdinier la dote d'une chevelure "d'un noir bleuissant ", " aux grands yeux ténébreux et à la peau bistrée de jolie petite Berbère ». D'une façon générale, elle est éblouissante, comme nimbée de lumière, " telle une vierge de vitrail » écrit Georges Grangean ${ }^{42}$ Les détails s'imposent par leur valeur symbolique, souvent en accord avec la mentalité du moment. Ces détails grâcieux peuvent côtoyer des éléments qui dénotent une forme d'animalité qui se traduit notamment, par une sensualité pour le moins débordante, en particulier chez les auteurs féminins. ${ }^{43}$

Il est un autre moyen de présenter les Berbères, notamment les femmes, comme des êtres irréductibles à la civilisation arabe. Grandjean crée un personnage de femme indomptable, toujours fuyante, et qu'il croie reconnaître sous différentes identités, dont celle de la Kahina. Elle apparât en différents lieux, à des époques éloignées, à la façon d'un mirage. Avec cette personnalité, à la fois pérenne et insaisissable, elle incarne

39 Véhel (J.), « La Belle Kahéna », in La Hara conte... Folklore Judéo-Tunisien, Les Éditions Ivrit, Paris, MCMXXIX, p. 102.

40 Ibid., p. 106.

41 Boisnard (Magali), Le Roman de la Kahéna, Paris, l'Édition de l'art, 1925, p. 42. Gisèle Halimi utilise la même expression pour parler de la couleur des cheveux de la Kahina, mais ses yeux seront verts (La Kabina, Plon, 2006, rééd. 2009, notamment dans la préface du roman).

42 Grandjean (Georges), La Kahena, par l’or, par le fer, par le sang, Aux éditeurs associés, Les éditions du monde modernes, Paris, 1926.

43 Les étreintes sont aussi brûlantes en 1925 (Magali Boisnard) qu’en 2006 (Gisèle Halimi), comme si les auteures s'identifiaient à leur héroïne dont la beauté mature annonce son prochain déclin. 
le combat contre l'envahisseur arabe qui voudrait assigner le féminin à une place obscure dans la société. Façon pour l'auteur de présenter les Français comme des libérateurs. Un certain féminisme, sensible déjà dans les années folles, sous-tend également cette vision qui s'imposera de plus en plus par la suite.

Alors que se déroulent les "événements d'Algérie », qui devaient mener à l'indépendance du pays, La Kahéna, reine des Aurès de Germaine Beauguitte, ${ }^{44}$ défend l'œuvre de la France. Un préfacier reprend l'explication de la conquête arabe au viI ${ }^{\mathrm{e}}$ siècle par l'incapacité des tribus berbères à s'unir politiquement. Un parallèle se fait avec la Régence turque qui n'a pas su assurer la cohésion entre les cités maures et les tribus arabes et berbères, pendant les trois siècles de sa gouvernance. L'absence d'un état-nation aurait conduit la France à intervenir en Afrique du Nord. Implicitement dans ce roman, l'utilisation des villes romaines de Timgad, Djemila, Tipaza, Césarée comme décors de l'action, établit un lien entre l'œuvre romaine et celle entreprise par les Français depuis I830. En I959, quand le roman est publié, les découvertes pétrolières au Sahara font espérer des richesses nouvelles propices au développement du pays. Le souhait est clairement exprimé « que l'œuvre magnifique déjà accomplie, sera poursuivie avec courage et ténacité pour le mieux-être et le bonheur de tous ceux qui peuplent notre belle Algérie française. " Dans le dernier chapitre, "Rencontres dans l'Au-delà », la romancière imagine Saint-Augustin, son « compatriote éminent », accueillant la Khaéna. À son tour, elle recevra Jeanne d'Arc qui annonce : «J'ai bouté l'Anglais hors de France ! », à quoi la Kahéna, répond «Je n'ai pu empêcher l'Arabe de s'implanter dans l'Aurès ». La Pucelle a, en quelque sorte, réparé l'échec de la Berbère, comme la France a mis fin au déclin d'un territoire qui, après la conquête arabe, a été soumis au pouvoir ottoman (I5I2-I830). Une double illustration accompagne le texte : l'une représente "Alger, côte barbaresque qui donnait asile à d'audacieux pirates avant I830 ", l'autre «Le Port d'Alger, un des aspects de la « Nouvelle France », preuve par l'image de l'action civilisatrice de la France.

Dans les mêmes années, la revendication indépendantiste des Algériens s'exprime dans la littérature maghrébine. Le roman de Kateb Yacine,

44 Beauguitte (Germaine), La Kahéna, reine des Aurès, Meaux, Éditions des Auteurs, 1959. 
Nedjma, pose, dès 1956, la question fondamentale de la construction de la nation à travers son histoire, son identité, sa culture. C'est plus tard, en 1974, dans un spectacle intitulé La Guerre de deux mille ans, qu'il utilise le personnage de la Kahina. Le texte sera repris, avec d'autres textes concernant d'autres femmes remarquables par les combats qu'elles ont menés. ${ }^{45}$ Kateb Yacine, étant devenu un opposant au pouvoir tel qu'il s'exerce dans l'Algérie indépendante, prête à la reine berbère les revendications du peuple algérien dont les droits sont bafoués. Pour elle, seule compte «la terre libre d'Amazigh ", les religions ne servant qu'à asservir " aux rois étrangers ». Le seul Dieu est « la terre vivante ». Le pouvoir centralisateur de l'Algérie indépendante, a réveillé les revendications amazighes, notamment sur la reconnaissance du tamazight comme langue officielle, au même titre que l'arabe, revendication qui n'aboutira qu'en 2002. La quatrième de couverture cite l'auteur : « La question des femmes algériennes dans l'histoire [...] m'a toujours parue primordiale », car « c'est la mère qui fait prononcer les premiers mots à l'enfant, c'est elle qui construit son monde ». De ce point de vue, on pourrait affirmer que la Kahina a engendré la nation algérienne, car elle en incarne la combativité inépuisable.

\section{UN MYTHE D'AUJOURD'HUI ?}

Ce lien indéfectible avec la terre, c'est ce que vont découvrir également les Européens installés depuis le XIX ${ }^{\mathrm{e}}$ siècle, dans les pays du Maghreb, comme les populations juives dont la présence était bien antérieure à la colonisation française. À l'indépendance de la Tunisie et de l'Algérie, la douleur de l'exil suscite une littérature qui tente de recréer par les mots l'univers d'autrefois. L'aventure de la Kahina reprend alors sa place dans ce récit mémoriel, car le combat perdu de la reine devient emblématique de leur sort : l'arrachement à la terre natale est vécu comme une défaite.

La singularité de ces œuvres se mesure d'autant mieux si on les compare à La Kabina singulière de Roger Ikor $^{46}$. Cet écrivain n'a jamais

45 Parce que c'est une femme, textes réunis par Zebeïda Chergui, théâtre (entretien de Yacine Kateb avec El Hanar Benali, 1972, La Kabina ou Dibya; Saout Ennissa, La Voix des femmes, Louise Michel et la Nouvelle Calédonie), Paris, Éditions des Femmes - Antoinette Fouque, 2004, 174 p.

46 Ikor (Roger), La Kahina, Paris, Encre, 1979, 212 p. 
vécu au Maghreb et ne découvre l'Algérie qu'en I935, lors d'un voyage et c'est bien plus tard qu'il donne sa version de l'épopée de la reine berbère. Il tourne en dérision tout ce qui a pu être écrit sur elle et népargne ni l'histoire ni les valeurs religieuses, comme s'il voulait tourner une page sur un passé qui n'a plus rien à apporter au présent. Le ton tranche totalement avec d'autres œuvres écrites par ceux qui ont vécu en Algérie ou en Tunisie. Pierre Cardinal, appartenant à une vieille famille pied-noire algéroise, profondément attaché à son pays, même s'il a pris position pour l'indépendance, publie en 1975, un roman intitulé La Kahena ${ }^{47}$. Il n'est nullement question d'une femme mais d'un lieu, une " guelâa ", sorte de grenier fortifié collectif qui, vu de loin, se confond avec la montagne des Aurès. Les rebelles algériens vont en faire un piège pour mettre en déroute les soldats français qui les pourchassent. On serait tenté de voir dans la vieille femme française qui refuse de quitter la terre que ses aïeux ont fait fructifier, comme le lui demande l'armée pour sa sécurité, une réincarnation de la reine berbère. D'autant plus qu'elle est accompagnée de trois enfants qu'elle affirme être les siens, bien qu'ils ne soient apparemment pas européens. Veut-elle croire encore à un monde où la paix ne triompherait pas par les armes mais par l'amour d'une terre commune? La fin tragique reste ambiguë puisque cette femme, comme les Algériens qui ont piégé la grotte et réussi à attirer les soldats français à leur poursuite, meurent dans l'explosion de ce lieu. Seuls survivent les enfants dont on ne sait ce qu'ils deviendront. Une certaine poésie de l'écriture cherche à donner à ce récit une valeur symbolique que le lecteur est libre de choisir : peut-être la nécessaire disparition du passé pour qu'un avenir soit possible?

Une littérature de la diaspora juive tunisienne a trouvé dans la figure de la Kahina une expression forte de l'attachement à ses racines. Georges Memmi dans son roman Qui se souvient du café Rubens? rassemble les souvenirs de son enfance à Tunis, faisant une large place au personnage de sa mère, analphabète mais à la « mémoire infinie. Elle se souvient du roi Salomon [...] elle a bien connu Pharaon d'Égypte, car elle en parle souvent. " «Agée de douze siècles au moins, ma mère se souvient de la 
reine Kahena. ${ }^{48}$ L'amour filial qu'il éprouve maintient le lien avec le pays perdu et avec toute une culture ancestrale dont la reine berbère fait partie au même titre que les références au texte biblique. Les Belles de Tunis de Nine Moati, ${ }^{49}$ raconte la vie de trois générations de femmes en Tunisie, entre 1856 et 1956. Le premier récit concerne le petit peuple de la Hara. Une marieuse vante, au bijoutier des souks qui cherche une épouse, les qualités d'une jeune fille présentée comme une descendante de la Kahe$\mathrm{na}^{50}$ dont la destinée tragique est brièvement rappelée. Lévocation de sa mort s'inscrit clairement dans la filiation du récit de « La Belle Kahena » de J. Vehel qui décrivait la recherche vaine des assaillants de la reine, réfugiée dans la forteresse d'El Djem, jusqu'à ce qu'ils comprennent qu'elle avait dû suivre un souterrain de quelques kilomètres « qui allait jusqu'à la mer, dont les flots berçaient sans doute le corps de la superbes amazone... " ${ }^{51}$ Chez Nine Moati, c'est après un cheminement semblable que les poursuivants découvrent, « un étrange sourire sur les lèvres et ses voiles rouges répandus autour d'elle, la belle Kahena bercée par les flots calmes de la Méditerranée. " ${ }^{52}$ En confrontant ces deux textes, on peut saisir un des mécanismes utilisés dans la transmission orale d'un événement : la reprise d'invariants (le lieu, les circonstances) accompagne des ajouts laissés à la fantaisie du conteur (le corps vu et non pas imaginé, les voiles déployés figurant une sorte de chevelure écarlate qu'on a souvent prêtée au personnage, le sourire perçu comme un défi lancé aux vainqueurs). Autant d'éléments qui relèvent de la mémoire affective : c'est par l'éveil de la sensibilité de l'auditeur, ou du lecteur, qu'un événement, un propos deviennent signifiants et exemplaires. En se répétant, en s'adaptant à différents publics, loin de perdre de leur force, ils gagnent en persuasion et en vérité. Déjà, dans l'exemple précédent, le fils ne peut se détacher des propos de sa mère. La distance tendrement ironique dont il use pour les rapporter souligne combien ils ont bercé son enfance, forgé sa personnalité. Ils continuent à nourrir sa vie.

48 Memmi (Georges), Qui se souvient du café Rubens? Paris, Éditions J.-C. Lattès, 1984, p. 23 et p. 28.

49 Les Belles de Tunis, Éditions du Seuil, 1983.

50 Op. cit., p. 23.

51 J. Véhel, op. cit., p. 106.

52 Les Belles de Tunis, p. 24. 
C'est ce qui manque à La Kabina de Gisèle Halimi. ${ }^{53}$ L'ouvre est hybride, multipliant les références historiques (avérées par huit pages de bibliographie, ce qui est inusité pour un roman), mêlées à une aventure totalement romanesque, au sens d'imaginaire, puisque nous ne perdons aucun élément des pensées intimes de l'héroïne dont pourtant rien n'est attesté. Surtout, on s'aperçoit vite que celle qui s'exprime, c'est l'avocate elle-même. D'ailleurs, elle fait de ce roman le troisième volet d'une trilogie commencée avec La Cause des Femmes (1973), puis Le lait de l'oranger (1988). Autrement dit, ce roman coiffe les récits de ses combats féministes, de sa jeunesse tunisienne, pour les couronner par l'image magnifiée de sa propre personne. Son grand-père ne lui disait-il pas qu'elle avait les mêmes cheveux couleur de miel de la Kahina ? Cela frôle parfois le ridicule quand, usant des dons de prophétesse de l'héroïne, elle lui fait prédire qu'un jour, Arabes et Juifs vivront sur la même terre que l'on devine être celle de la Palestine. Ce n'est pas le contenu du propos qui surprend, mais le procédé littérairement contre-productif, car ce n'est plus la reine qu'on entend, mais la femme engagée dans les combats politiques du $\mathrm{Xx}^{\mathrm{e}}$ siècle réaffirmant ses positions militantes.

\section{UN MYTHE MÉMORIEL}

Pour Norredine Sabri, la Khéna ne peut accéder au statut de mythe, car elle « demeure prisonnière du particulier et du régional, parce que trop ancrée dans l'histoire maghrébine. ${ }^{54}$. Il est vrai que ce contexte est omniprésent, mais nuancé par les circonstances. Cette reine a été " adoptée » par au moins trois communautés différentes. Elle inspire toujours les romanciers, preuve de son éternelle actualité : La Kabéna de la Courtille $e^{55}$ évoque le combat d'une jeune immigrée vivant en France, dont les parents sont assassinés lors d'un voyage en Algérie, pendant la " décennie noire ». Aussitôt, elle décide de les venger en poursuivant tous les adeptes du FIs. La Kahéna désigne aussi le nom d'une maison qui a appartenu à un maire français de Cyrtha, au temps de la colonisation, mais qui renferme des éléments qui permettent au héros (et au lecteur)

53 Halimi (Gisèle), La Kabina, Paris, Plon, 2006 ; rééd. Pocket, 2009.

54 Sabri (Norredine), op. cit., p. 261.

55 Berkani (Berri), La Kahéna de la Courtille, « Ecritures berbères », Paris, L'Harmattan, 2002. 
de reconstituer tout le passé douloureux de l'Algérie : pour l'auteur, seule la mémoire peut construire, par-delà les saccages, un monde durable. ${ }^{56}$ Il y a donc une " plasticité » dans cette référence à l'hérö̈ne berbère qui la dote d'un universalisme indéniable : la perte de l'identité, le combat pour préserver sa liberté, le besoin de préserver ses racines se retrouvent dans l'expérience de toutes les nations.

La Kahina ne serait-elle pas le mythe d'une mémoire blessée?

BIBLIOGRAPHIE SUR LA KAHINA

\section{A / Sources historiques}

El-Bekri, Description de l'Afrique septentrionale [extrait de Description géographique du monde connu], éd. et trad. en français par le baron de Slane, Alger, 1858-1859 (Journal asiatique, 12-14) ; nouv. éd. Paris, 1913.

Iвn Khaldoun, Histoire des Berbères et des dynasties musulmanes de l'Afrique septentrionale, traduite par le baron de Slane, Alger, imprimerie du Gouvernement, 1852.

Julien (Charles-André), Histoire de l'Afrique du Nord. Tunisie - Algérie - Maroc de la conquête arabe à 1830, t. 2, Paris, Payot, rééd. 1975.

Lugan (Bernard), Histoire des Berbères. Un combat identitaire plurimillénaire, Bernard Lugan Éditeur, 2012.

Masqueray (Émile), Formation des cités chez les populations sédentaires de l'Algérie (Kabyles du Djurdjura, Chainïa de l'Aourâs, Beni Mezâb), Paris, E. Leroux, 1886 ; Éd. Fanny Colonna, Aix-en-Provence, Edisud, 1983.

Meynier (Gilbert), L'Algérie des origines. De la prébistoire à l'avènement de l'islam, La Découverte/Poche, 2010.

\section{B / Études sur la Kahina}

Camps (Gabriel), L'Afrique du nord au féminin, Librairie Académique Perrin, 1992. Dejeux (Jean), Femmes d'Algérie. Légendes, Traditions, Histoire, Littérature, Paris, La Boîte à Documents, 1987.

Modéran (Yves), « Kahena ", in Encyclopédie berbère, 27 | Kairouan - Kifan Bel-Ghomari [En ligne], mis en ligne le 01 juin 2011, consulté le 25 avril 2018. URL : http://journals.openedition.org/encyclopedieberbere/1306

56 Bachi, (Salim), La Kahéna, Paris, Gallimard, 2003. 
Slousch (Norbert), «La race d'El Cahena », in La Revue indigène, n 44, déc. 1909 , p. 580-581.

Roth (Norman), "The Kâhina : legendary material in the accounts of the « Jewish berber Queen », The Maghreb Review, Londres, vol. 7, 5-6, 1982.

SABri (Norredine), La Kahéna. Un mythe à l'image du Maghreb, Paris, L'Harmattan, «Critiques littéraires », 2011.

TALBI (Mohamed), «Un nouveau fragment de l'histoire de l'Occident musulman l'épopée d'A1-Kahina », in Les Cabiers de Tunisie, t. xıx, $1^{\text {er }}$ et $2^{\text {e }}$ trim., 1971.

\section{C / Euvres littéraires}

BACHi, (Salim), La Kahéna, Paris, Gallimard, 2003.

Berkani (Berri), La Kahéna de la Courtille, «Écritures berbères », Paris, L'Harmattan, 2002.

Beauguitte (Germaine), La Kahéna, reine des Aurès, Meaux, Éditions des Auteurs, 1959.

Boisnard (Magali), Le Roman de la Kahéna, Paris, l'Édition de l'art, 1925.

Cardinal (Pierre), La Kahena, Paris, Julliard, 1975.

Grandjean (Georges), La Kahena, par l'or, par le fer, par le sang, Aux éditeurs associés, Les éditions du monde modernes, Paris, 1926.

Halimi (Gisèle), La Kabina, Plon, 2006, rééd. 2009.

Hilaire (Jean), La Kabena, Rouen, Henri Defontaine Édit. 1918.

Ikor (Roger), La Kabina, Paris, Encre, 1979.

Magdinier (Marcelle), 1898-1984, La Kahena, Paris, Calmann-Lévy, 1953.

Mеммі (Georges), Qui se souvient du café Rubens ? Paris, Éditions J.-C. Lattès, 1984.

Moati (Nine), Les Belles de Tunis, Éditions du Seuil, 1983.

Parce que c'est une femme, textes réunis par Zebeïda Chergui, théâtre (entretien de Yacine Kateb avec El Hanar Benali, 1972, La Kabina ou Dibya ; Saout Ennissa, La Voix des femmes, Louise Michel et la Nouvelle Calédonie), Paris, Éditions des Femmes - Antoinette Fouque, 2004.

VéHel (Jacques), « La Belle Kahéna », in La Hara conte... Folklore Judéo-Tunisien, Les Éditions Ivrit, Paris, McMxxix. 


\title{
INTRODUCTION À L'CEUVRE DE BÉLAÏD AÏT ALI, comme première initiative d'écriture de tamazight en caractère latin
}

\author{
Mohand Ibrahim
}

\begin{abstract}
Résumé
Bélaïd Aït Ali était un écrivain, un conteur de langue kabyle. Il est célèbre pour avoir publié Les Cabiers en 1964, sous l'impulsion et le soutien des Pères Blancs dont le Père Degezelle. La rencontre ave le Père Degezelle eut lieu en 1945 quand celui-ci partait dispenser des soins aux habitants du village de Bélaid Aït Ali, Azrou. Père Degezelle propose à Bélaiid d'écrire quelques contes en langue kabyle et ce dernier écrit donc celui d'Aubépine.

Bélaïd prend goût à ce nouveau style d'écriture et découvre la profondeur et la délicatesse de la culture berbère. Il donne ainsi une âme à ses contes et transmet un intérêt au lecteur. En s'inspirant et en faisant mieux que ses prédécesseurs, Ben Sedira et Boulifa, il a donné une dimension nouvelle à la littérature kabyle en alphabet latin, notamment en dépassant les contraintes de loral. Il devient donc le pionnier de la littérature kabyle, tamazight, transcrite en alphabet latin.
\end{abstract}

Mots clés : Les Cahiers, Père Blancs, Père Degezelle, contes, kabyle, Aubépine, transcrire, alphabet, latin.

\section{Resumen}

Bélaïd Ait Ali era un escritor, un narrador en lengua cabileña. Es famoso por haber publicado Los Cuadernos en 1964, impulsado por los Padres Blancos, concretamente por el padre Degezelle. El encuentro con el padre Degezelle surgió en I945 cuando éste partió para atender a los habitantes del pueblo de Bélaid Ait Ali, Azrou. El padre Degezelle le propone a Bélaïd escribir algunos cuentos en lengua cabileña y éste escribe "Aubépine".

Bélaïd se enamora de este nuevo estilo de escritura y descubre la profundidad y la delicadeza de la cultura bereber. Sirve para dar un alma a sus historias y transmitir un interés al lector. Inspirándose y haciéndolo mejor que sus predecesores, Ben Sedira y Boulifa, dio una nueva dimensión a la literatura cabileña en alfabeto latino, especialmente sobrepasando las limitaciones de la oralidad. Por lo tanto, se convierte en pionero de la literatura cabileña, tamazight, transcrita en alfabeto latino.

Palabras claves: Los Cuadernos, Padres Blancos, Padre Degezelle, cuentos, cabileño, Aubépine, transcribir, alfabeto, latino. 
Fils d'une institutrice, Bélaïd a connu la langue française dès le berceau ${ }^{1}$. Son instruction s'est faite en français d'abord dans l'école de son village puis en France. Il n'a pas fait d'études universitaire à peine a-t-il fréquenté un collège. A I6 ans il se retrouve marié, avec une femme. Mais Bélaïd est doué d'une intelligence exceptionnelle. Non seulement il maîtrise à merveille la langue de "Molière ", mais il a une connaissance approfondie de son milieu kabyle. Fin observateur, curieux il emmagasinait lait tout ce qui est à sa portée. Grand rat des bibliothèques il assimilait tout ce qu'il lisait. Cette aptitude à comprendre son milieu a fait de lui ce grand écrivain en langue kabyle que nous connaissons. Il nous a laissé de belles pages écrites dans des moments difficiles de sa vie. Il a réussi à nous faire aimer les contes qu'il a rendus de vrais chefs d'œuvre littéraires. Il nous a décrits son village et les personnages qui habitaient avec une précision d'un artiste qu'il était. Car il fut aussi un peintre et un musicien. Il existe encore une aquarelle qu'il a offerte au Père Degezelle, son confident et son ami.

Bélaïd est né le 25 novembre 1909 à Bouira, ville où sa mère exerçait le métier d'institutrice. Bélaïd rentra dans son village d'Azrou Kollal à l'âge de 5 ans (vers I9I4) où il fut scolarisé jusqu'en I920. A cette date son demi frère Mohand Saïd le prit avec lui en France. Il y resta jusqu'en I925, année peut-être où il a perdu son père Ali At Ali. Il avait I6 ans et sa mère s'empressa de le marier à une jeune femme qui, d'après ses confidences était plus âgée que lui. Il la délaissa au bout de quelques mois

1 Mohand Ibrahim est natif du village d'Azrou Kollal, le même village que celui de Bélaïd Aït Ali dans le massif central de la Kabylie. Il fréquanta la même école qu'il quitta avec le certificat d'études primaires et intégra le monde du travail à un âge précoce. Autodidacte, assoiffé de culture, il ne cessa de poursuivre sa formation en suivant des cours du soir après son travail. Dans les années 1980 il retrouve presque par hasard le Père Degezelle qu'il a connu en Kabylie. Depuis cette rencontre, leur principale discussion portait sur Bélaïd. Le Père ne cesse de pousser son interlocuteur à faire quelque chose quand celui-ci lui demandait pourquoi « les cahiers » ne sont pas réédités. Il lui fournit des documents en particulier l'exemplaire du livre édité en 1964 avec les annotations du Père. Il ne reste plus à notre auteur à se mettre au travail. C'est ainsi qu'il s'inscrit à l'inalco pour parfaire ses connaissances sur berbère en général et le kabyle en particulier. C'est ainsi qu'il obtient un diplôme de maîtrise dont le sujet fut une recherche sur la vie et l'œuvre pionnière de Bélaïd Aït Ali dont il tira un ouvrage intitulé : Bélaïd Aït Ali. Errance ou génie littéraire. Mohand Ibrahim s'est attelé aussi à la réécriture moderne de l’œuvre de Bélaïd Ait Ali déjà parue en 1964 sous le titre : Les cahiers de Bélaïd ou la Kabylie d'antan sous le titre (Ițțafțtaren yura Bélcid at Acli af Leqbayel n zzman n zik). 
(certainement par manque de maturité). Le revoilà libre. Il passe son temps entre Azrou, Alger chez ses oncles maternels et en France. A 20 ans, il fut appelé au service militaire. Il gravit les grades jusqu'à sergent chef. Démobilisé, il recommence ses errements en particulier en France où il exerça quelques métiers dans des usines. Vers 1934, il regagne son village pour se remarier avec une fille du village cette fois-ci avec son consentement. Il eut très vite un garçon, Ramdane, mais très vite son bonheur va se briser sur des malentendus survenus entre sa mère et sa femme. Bientôt sa femme quitte le domicile conjugal et rejoint sa mère à Alger emmenant avec elle ce qu'il a de précieux au monde, son fils. A partir de ce jour Bélaïd se trouve désemparé, trahi. Témoin ce poème écrit sur sa femme :

Deg Uzru n at Mangellet

Ayufiy taffat

Yeğょel Rebbi tjerh-iyi.

Faṭima d aclim tečča-t

Hafi ițtetekket

Ttagujilt tyaḍ-iyi.

Ur tnuda d ul-iw tuffa-t

Slascaq $n$ tektabt

Yeččur, yurğa i wimi

Xulfay cwar xtaray-t nețtat

Kra bb ${ }^{w} e h b i b$ neğğa-t

Nniya-s: kem barka-yi!

Annay a Lmalaykkat,

Yak tura yețfat,

Ma skedbay nnayemt-iyi !

Yibb $^{w}$ ass adfel la yekkat

$\mathrm{D}$ aqcic-iw teğğa-t

D idduh yețru : texdec-iyi

Yețyidi win ya yecgen

A kra d-issellen

Ad yeğzel yeshel l'Amour

D lehlek $n$ daymen

Ddwa ulac c'est pour toujours

D ul-im ara kem-ixelșen

A tin ixeddsen

S Rebbi ar d ad d-yas ton tour.
A Azrou des Ait Manguellet

Là où j'ai trouvé la lumière

Dieu a permit qu'elle me blessât

Fatima mangeait du son

Pieds nus elle marchait

J'ai eu pitié de l'orpheline

Sans chercher, elle a trouvé mon coeur

Avec l'amour des livres

Remplit il attendait pour qui

N'écoutant aucun conseil, je l'ai choisie

J'ai abandonné mes amis

Je lui ai dit : toi tu me suffis

Oh! Par tous les Anges

Maintenant que c'est du passé

Si j'ai menti, tuez-moi

Un jour alors qu'il neigeait

Elle a abandonné mon enfant

Dans le berceau il pleurait, elle m'a trahi

De la pitié pour celui qui se trompe

A tous ceux qui écoutent

Qu'ils pensent que l'amour est facile

C'est une maladie de tous les jours

Il n'ya aucun médicament c'est pour toujours

C'est ton cœur qui paiera

A celle qui trahit

Par Dieu, ton tour arrivera un jour 
Bélaïd reprend le chemin de l'exil, il repart en France et sombre dans l'alcool. Bientôt la guerre le rappelle, c'est la mobilisation générale. Il se retrouve envoyé avec son régiment dans le Sud tunisien. La boisson lui fait perdre ses grades et devient simple soldat chargé de l'intendance. En Europe, la guerre fait rage et son régiment est appelé en France occupée. A la veille de son départ, il profite d'une permission pour prendre ses jambes à son cou, il rejoint son village, on ne sait par quel moyen.

C'est à partir de ce moment que sa vie va changer entièrement. Traqué par les gendarmes, il trouve souvent refuge chez ses sœurs mariées dans un village voisin. Il commence aussi à lier connaissance avec un Père Blanc (le Père Degezelle) qui venait lors de ses tournées faire causette avec sa mère. Il faut rappeler que celle-ci était l'une des premières femmes institutrice de la Kabylie. Elle a fréquenté l'école de jeunes filles de Taddart Ufella près de Fort National (Larba at Yiraten). Elle a été élève de cette école dans la même période que Fadma At Mansour Amrouche (la mère de Taos et de Jean Amrouche). D'ailleurs celle-ci l'a citée plusieurs fois dans son livre "L’histoire de ma vie », pages 32 et 37. Elle était son aînée de six ans.

Par la conjonction du besoin des Pères Blancs qui cherchaient à recueillir des textes sur la société kabyle pour alimenter le Fichier de Documentation Berbère (FDB) ${ }^{2}$ et la situation sociale de Bélaïd, déserteur, recherché, abandonné par les siens, débouche à partir de mars I946, en particulier, par l'écriture du premier cahier avec le conte «bu yedmimen » (l'aubépine).

Quand on regarde de plus près ce premier cahier on relève les difficultés de Bélaïd en ce qui concerne la réalisation de cet ouvrage. L'alphabet utilisé est presque similaire à ceux de Boulifa et de Ben Sedira. La semi-consonne «y» est notée « ie ou ia », le «c» est noté en français «ch » le «w » est noté « oua » et beaucoup d'autres phonèmes sont notés en français. Mais dès le deuxième cahier, il introduit d'autres signes pour éclairer le lecteur et lui faciliter la compréhension de ses textes. C'est ainsi qu'il commence à introduire le « $\mathrm{y}$ » et le « w » ainsi qu'à différencier

2 Le FdB est un fichier créé par Les Pères Blancs sous la direction du Père Dallet et dans les fascicules sont édités à Fort National, et recueille des écrits très larges sur la culture et les coutumes sur la Kabylie. 
les phonèmes emphatiques comme le « $\mathrm{z}$ » et le « $\mathrm{z}$ » le « $\mathrm{d}$ » avec son emphatique et sa spirante.

Au fur et à mesure qu'il avance dans l'écriture de ses cahiers il innove et invente un alphabet qui lui est presque propre. Car en 1945 il n'existe aucun alphabet normalisé. Les Pères Blancs eux-mêmes étaient à la recherche de signes pouvant répondre à leur problème. Ce n'est qu'à partir de 1946 que certains signes ont été définitivement adoptés. Comme par exemple le signe « $\varepsilon$ ».

L’ouvre de Bélaïd a donc commencé par un simple conte "Bu yedmimen » (l'aubépine) puis il se laisse coller à la tradition et à sa langue. Contrairement à un Boulifa ${ }^{3}$ qui est soumis à des contraintes professionnelles et scientifiques traduisant des concepts modernes qu'il veut rendre dans sa langue, Bélaïd lui est un conteur, il s'est collé à la tradition et à sa langue. Son expression est tirée du quotidien avec un vocabulaire du peuple sans recherche excessive. Il suffit de lire « Jeddi » (grand père) ${ }^{4}$ pour s'en rendre compte.

D'après une confession de sa femme faite à des membres de sa famille, bien avant sa déchéance, Bélaid consignait déjà ses impressions, en français, sur des bouts de papiers. Car il est curieux de tout ce qu'il voyait et entendait autour de lui. Mais il n'a jamais manifesté une volonté d'écrire en kabyle. Comment peut-il le faire ? Pour lui le kabyle ne s'écrit pas.

Il n'a aucune notion sur l'écriture du kabyle. Mais le Père Degezelle, son seul interlocuteur, ne le lâche pas, il l'encourage et le pousse à écrire un conte. Bélaïd lui répondit :

Il ne m'est doux d'exprimer mes sentiments et j'allais dire, d'une façon sérieuse... que dans cette langue que je vous disais tout à l'heure, encore, avoir parlé dès mes premiers balbutiements du berceau. Je suis kabyle bien sûr... mais mon Père, cela n’empêche que c'est en français que je pense, que mes idées mêmes, se conçoivent, naissent ${ }^{5}$.

3 Si Amar ou Said est né en 1865 à Adeni commune d'irdjen, grande Kabylie. I $\mu$ l est l'auteur de plusieurs ouvrages : Une première année de langue kabyle jourdan 1887, Recueil de poèsies kabyles jourdan 1904 réédité par Yacine Tassadit Editions Awal 1990, Méthode de langue kabyle (cours de 2ème année Jourdan 1913, Le djurdjura à travers l'histoire (deuis l'antiquité jusqu'à 1830). 4 Jeddi voir Les cahiers de Bélaid at Ali, regards sur une oeuvre pionière Tira éditions, 2013, p. 50. 5 Voir Bélaïd Aït Ali. Errance ou génie littéraire, Dar Khattab éditions par Ibrahim M., p. 95. 
En effet jusque dans les années I940, il n'y a pas de production littéraire écrite, juste des collectes de contes, de poésies, de devinettes etc...

Ecoutant ce qu'il écrit encore au Père Degezelle dans une lettre accompagnant le premier cahier :

... Une langue kabyle en « caractères " latins ? Je veux bien, mon Père. Je ne demande pas mieux. Je vous souhaite complète réussite et je vous garantis, enfin, toute le reconnaissance des kabyles, dans les siècles à venir ». Mais dès le deuxième cahier il écrit encore :

Oui mon Père, jamais assez merci, oh ! Pour beaucoup de choses. Et en tout cas - et en premier pour ce que vous voulez mapprendre - et me montrer ... que j'ignorais mon kabyle !

On constate qu'il découvre sa propre langue et il le dit toujours dans une lettre accompagnant le troisième cahier :

Ouf, quel voyage mon Dieu! Quel voyage et cependant quelle douce fatigue ! Il me semble remonter d'un gouffre sans fonds! A tel point qu'à certains moments, j’y ressens ... comme une frayeur. Oui mon Père, je m'effraie - mais quand je vous vois me tenant par la main, je ne moccupe plus que de ... jouir des merveilles qu'on y découvre.

Car - et c'est là l'une des merveilles - je vais de découvertes en découverte, bien que ... en descendant.

Et dire que c'est à vous, mon Père, que je devrais ça. Mais nous parlerons plus tard. Et ... si vous nềtes pas fatigué mon Père. Redescendons.

Son œuvre est composée de plusieurs thèmes :

D'abord quatrecontes : Bu Yedmimen, Awayzniw, Acqa issawalen et Tafunast igujilen : (L'aubépine, l'ogre, le grain magique,la vache des orphelins). Bélaïd ne s'est pas contenté de les écrire tels que nos grands parents nous les racontaient. Il les a transformés en une œuvre littéraire les rendant vivants en s'introduisant parmi les personnages du conte, leur donnant des noms et leur faisant réciter des poèmes de sa composition.

Bélaïd a abordé dans ses cahiers plusieurs thèmes que je classe comme suit :

- Les nouvelles :

Tassa, (le foie) texte sur les rapports enfants parents. 
T,teḍber, (le conseil) une leçon de morale qu'un vieux amusnaw donnait à ses enfants.

At zik (les anciens)

Dayen $d$-hakun (ce qu'ils racontent) où l'on retrouve des petites histoires drôles parfois que l'on raconte sur le comportement des individus (hommes ou femmes) tels que af tazzart, qqaren-as kan leqbayel harcen, ou tamexluqt. (On dit que les kabyles sont rusés ou l'inconnue).

Sya d sya (par-ci par-là)

Lyani d lfaqir (le riche et le pauvre)

Azidan d umerzagu (le sucré et l'amer)

- Il ya aussi des textes que je peux appeler «Tiqșidin ». Ce sont des récits moralisants ayant comme personnages des animaux tels sont les cas de :

Lhăg amcic (le chat pellerin hadj)

Tamacabut inissi d wuccen (le hérisson et le chacal)

Ass mi heddren lehwayec (du temps ou les animaux parlaient)

- D'autres textes peuvent être ethnographiques par exemple :

Jeddi (Grand père)

Af tmusni (Sur l'intelligence)

Lexdubga (les démarches matrimoniales) à lui seul tient un cahier complet Père Degezelle

Mara d-mektiy (quand je me remémore)

$D$ amezwaru unebdu (le premier jour de l'été)

- Par ailleurs il a consacré un cahier complet aussi aux femmes du village :

Dehbiya at Qasi (nom de femme kabyle)

Zayna at Eamruc (nom de femme kabyle)

Tamezwarut ou Amnuy $n$ teqqcicin (la première ou la dispute de fillettes)

Jubra n tbilbuzt (pseudonyme donné à ma grand-mère appelé communément Tillilit étant sa voisine, elle lui procurait de l'eau de source pour la boisson et en échange lui écrivait des lettres destinées à son fils engagé dans la marine). 
Beru (la répudation)

Sbițtar (Scènes d'hôpital où les femmes se rendaient pour des soins prodigués dans le dispensaire)

- Un cahier complet où sont notés une trentaine de poèmes, tous de sa composition.

Mais d'autres poèmes figurent dans d'autres cahiers (pour compléter la fin du cahier ou simplement dans la bouche de ses personnages au milieu d'un conte ou d'un récit).

Enfin il ne faut pas oublier son chef d'œuvre Lwali bb ${ }^{w} e d r a r$ (Le saint de la montagne) qui, à lui tout seul, constitue une œuvre littéraire complète.

Il faut signaler que Bélaïd a utilisé des noms d'emprunt pour décrire des personnages réels tels que sa mère par exemple dans Targit (le rêve) ou Beru (la répudiation) ou encore Afenğal n lqabwa (la tasse de café). Ma grand-mère appelée communément «Tillilit » a pris le sobriquet de «Tabilbuzt »

Ces cahiers, qui sont en réalité des feuilles volantes fournies par le Père Blanc Jules Louis Degezelle sont cousues avec une aiguille et du fil noir, constituent la plus importante production du Fichier de documentation Berbère initié et dirigé par Le Père Dallet. Ils sont édités en I964, c'est-à-dire après l'indépendance de l'Algérie. L'œuvre est passée presque inaperçue à cette époque difficile quand il s'agit de s'intéresser au berbère. Il n'y a que quelques initiés qui ont remarqué cette production. Le premier à en parler fut, nous semble t-il, Vincent Monteil en octobre I967 dans la préface du livre «L'bistoire de ma vie » de Faḍma at Manșour Amrouche. Il disait de lui : «Ziy... comment oublier l'étonnant Bélaïd Ait Ali, mort en I950, dont le fichier berbère des Pères Blancs de Fort-National nous garde précieusement la mémoire ? Sous-officier cassé, ivrogne, clochard, déserteur, de volonté aussi pauvre que son intelligence était belle, il écrivait en français comme en kabyle, et les beaux textes qu'il nous a laissés vont à la rencontre de ceux de Fadhma Amrouche ».

Le deuxième qui a remarqué Bélaïd fut Redjala M'barek éminent intellectuel algérien et qui est le premier kabyle à être sorti diplomé " des Langues $\mathrm{O}$ » ancêtre de l'inalco (Institut National des Langues et Civilisations Orientales) dans un article sur la Kabylie et la culture 
kabyle publié dans l'Encyclopédia Universalis en 1970. Il disait de Bélaïd : «D'ailleurs, le conte, qui a déjà subi des dégradations, semble engagé, bien que timidement, dans une voie qui pourrait déboucher sur la naissance d'une prose consciemment élaborée. Le mérite en revient à Bélaïd Aït Ali dont les Pères Blancs ont publié en 1964, Les Cabiers ou la Kabylie d'antan. Dans une prose empruntée au conte, mais retravaillée et soumise à la contrainte qu'impose la volonté de l'écrit littéraire, ce Kabyle de culture française a raconté des histoires qui tiennent à la fois du conte, du roman et de la confession ».

Puis c'est le silence complet, jusqu'aux événements des années 1980 où les langues commencent à se délier. La première émission radiophonique a été diffusée par radio Beur avec la participation de Ould Braham Idir. Ce dernier récidive en publiant plusieurs articles dans sa revue annuelle «Documents et textes berbères » en I982. Mais la découverte de Bélaïd est sans aucun doute due à sa biographie réalisée dans un mémoire de maitrise qui lui est consacré à l'inalco par Iвrahim Mohand. Ce mémoire légèrement retouché a été édité par les éditions Dar Khettab en 20I5. Auparavant c'est-à-dire dès 2009, il faut noter que le même éditeur Rachid Khettab a numérisé lédition de 1964 pour une diffusion plus large.

Je viens de présenter succinctement la vie et l'œuvre de Bélaïd qui est assez connue maintenant. Mais il reste une autre dimension mal méconnue du public, celle d'artiste peintre. Malheureusement son œuvre pour la plupart est perdue tel un dessin de son village Azrou Kollal réalisé vers les années I940 ou une peinture murale, en couleur, sur la devanture d'un magasin d'un marchand de fruits et légumes, d'un plat rempli de fruits (pastèque, raisin, pomme et poire) effacée par le temps et les hommes inconscients à l'époque de l'importance du sujet.

Il nous reste une aquarelle peinte de sa maison et représentant la montagne du Djurdjura et offerte au Père Degezelle son ami et son confident. Cette peinture est conservée par le Centre de Recherche Berbère de l'Inalco. Elle figure en noir et blanc dans la revue «Textes et Documents Berbères " $\mathrm{n}^{\circ} 2$, année 1982 et en première page de la couverture du livre «Ițtafțțaren yura Bélzid at Asli af Leqbayel n zzman n zik » édition Dar Khettab, en 20I5. Cette nouvelle édition est originale puisque l'auteur (M. IвRAHim) est parti des textes du manuscrit en respectant l'évolution de 


\section{Mohand Ibrahim}

l'écriture des cahiers par Bélaïd et en y insérant les différents échanges qui se sont produits avec le Père Blanc Degezelle, seul interlocuteur de Bélaïd Aït Ali.

\section{ICONOGRAPHIE}

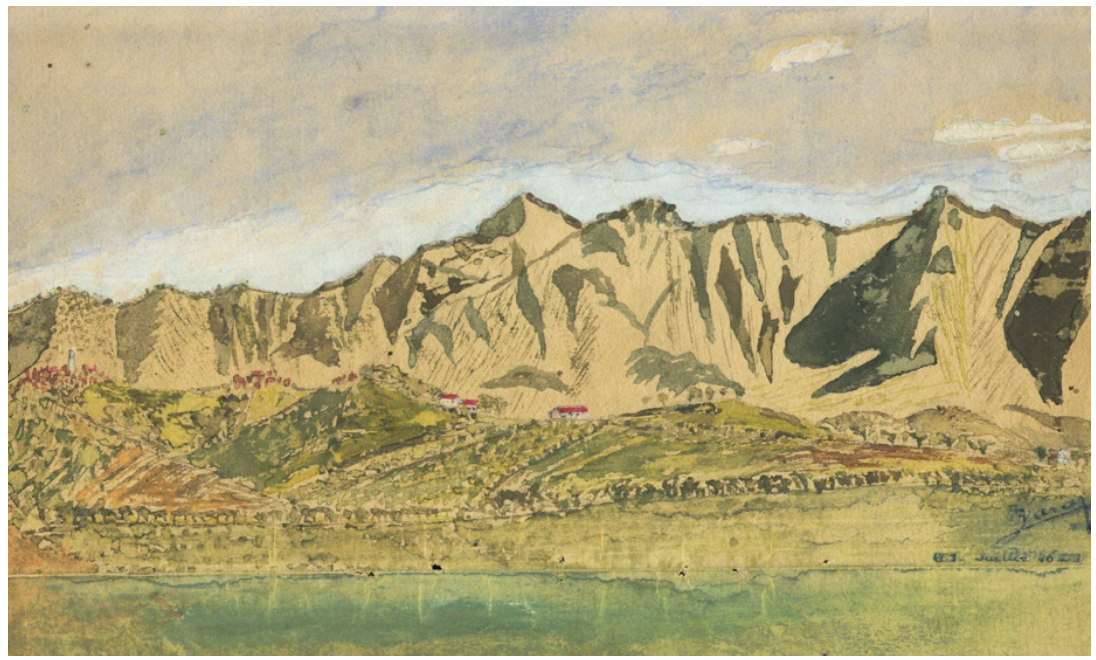

Djurdura, par Belaid

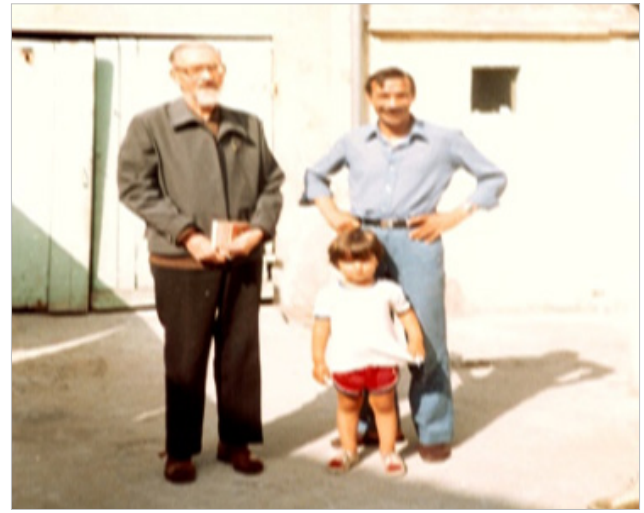

Père Degezelle à gauche dans la cour Acheres avec Mohand Ibrahim, auteur de cet article et un des enfants de celui-ci. 


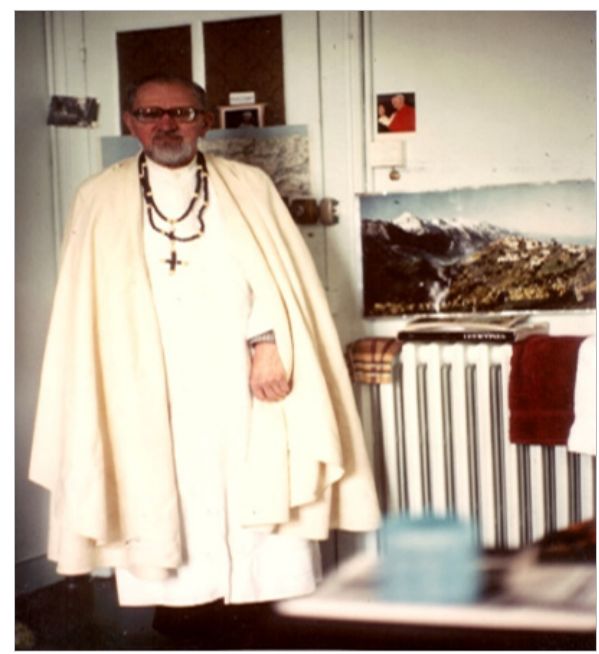

Le Père Degezelle avec l'habit religieux.

Tzem oun ienzzara dachout; istof iefliast iou metoul.

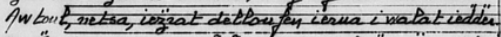

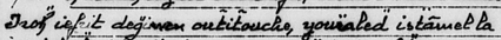
imetchäh ichenfirsio anzoun icietat. Chaçoun

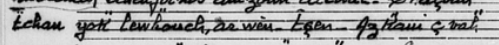

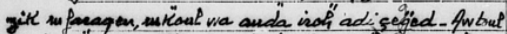

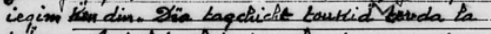
tetsrous. Aolout iwate ts, iscawtes, ienayas:se viga

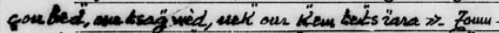

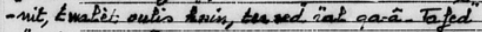

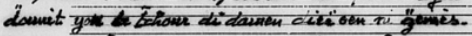

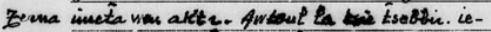

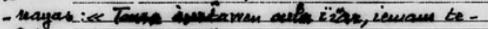

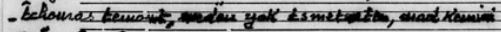

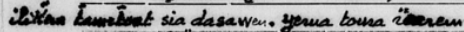

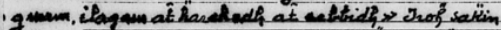

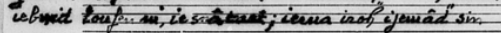

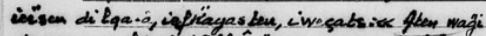

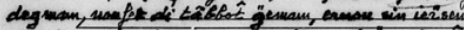

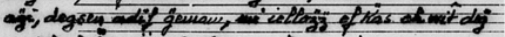

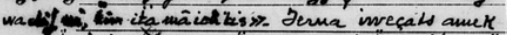

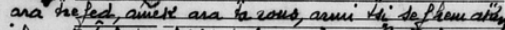

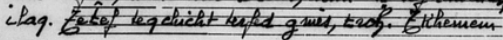

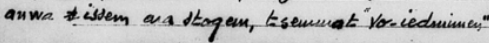

(ahat ini diloul ger isservanen fwedmim of . "Ehol, hat heto, theho... tefai" brimant, bekchem tayedh, elloukn bagi a egicbli - trun dei"k fethis tweit, teçawdhed" än ikwet tad"ent. If wegt ineusi teruter kin rebbi oli teboust ian le- brunt, befwid ain issiektev vol; tEe thaijes.

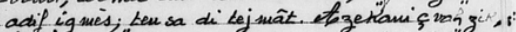
lof jer, nohied iewen mergaz adiezzat, ic fed ra. metorel betes ol Eqaá, iwsenide, Doufeu degchimis. Inah': tametout ticlen.zits, tezien, natehi de iffa "̈nor gavion retbi. Ienchem-Ierva argaz del fahem, iágel sachou ie dh ran iédes- lesteg ïars, is seq seits. Temrayas yor̈ tidets; tehr̈̈anas :

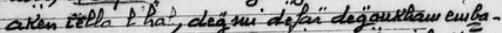

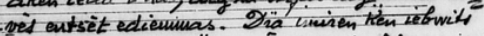

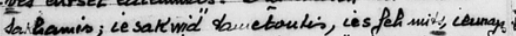

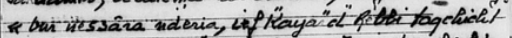

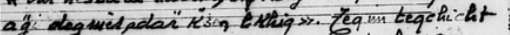

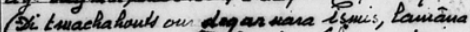

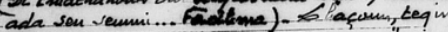

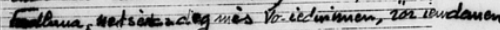

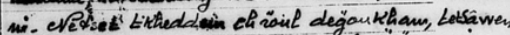

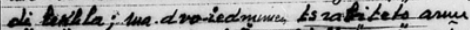

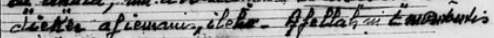
ferhen tèssen diön ken. Oä̈vasmi bekehem

Échantillons de “Les Cahiers” écrits par Belaïd. 
6

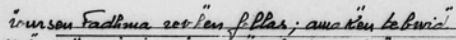

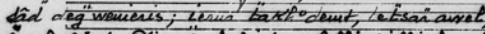

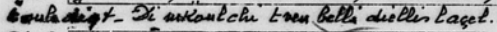

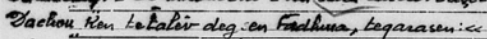

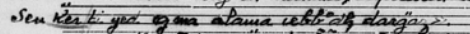

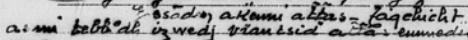

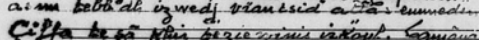

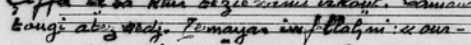

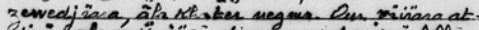

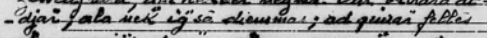

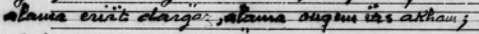

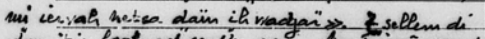

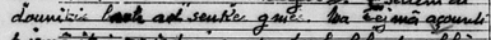

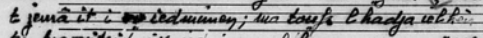

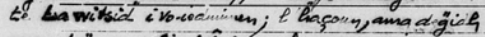

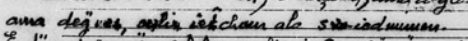

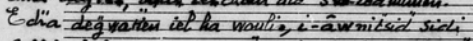

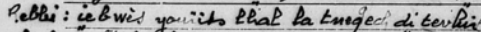

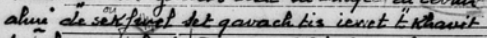

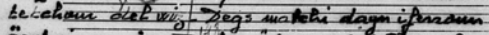

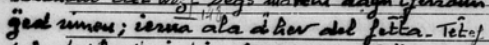

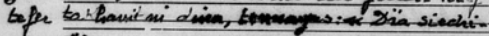

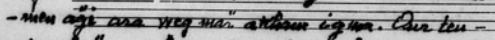

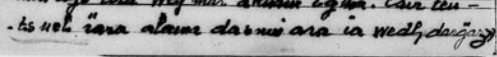

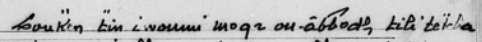
ichinen emi, bla ma ke rethdem, tha dua ta tsev;

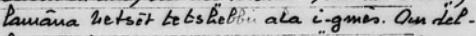

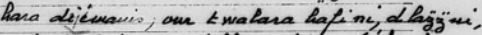

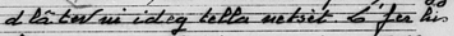

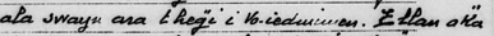

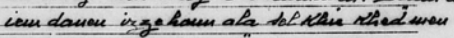

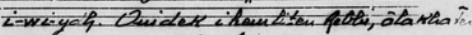
ghen us sere ies hal. Gamana...

"win ithediureus el whin

ie scomialas ols ref mi -

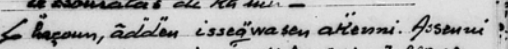

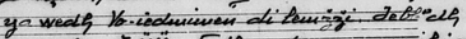

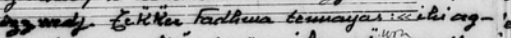

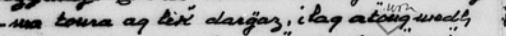

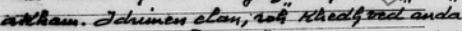

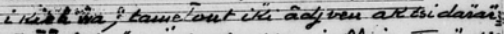

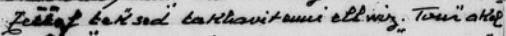

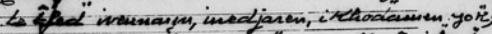

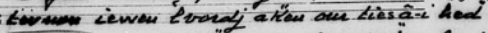

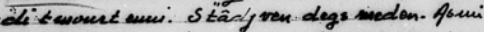

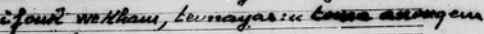
bavier en $\Rightarrow-$

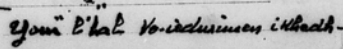

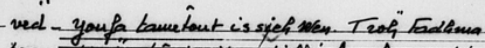

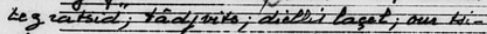

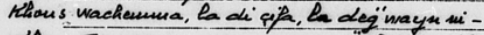

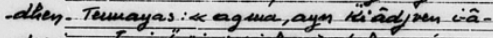

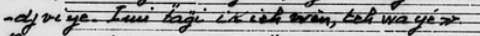

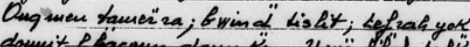

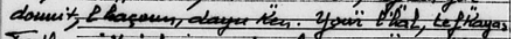

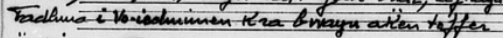

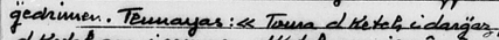
dHetef ara isengen, dHatef asa youm an roniek,

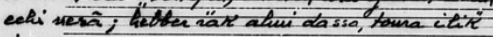

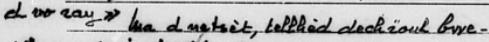

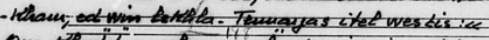

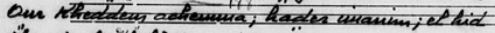

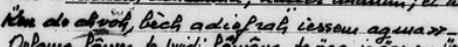

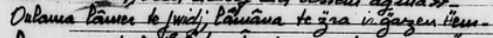

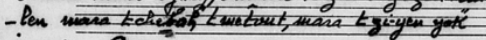

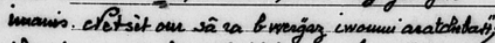

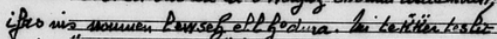

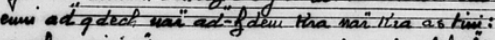

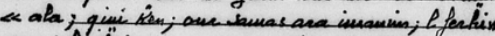

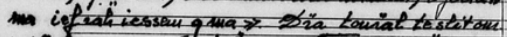

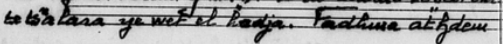

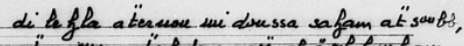
ada goum, at"ef dem yot" of iol bwe tam ha ol Vo-ieduniven, Me rsa choillis, de siada, to follatits, de soug. Iedf-hac outa duetsa delate.

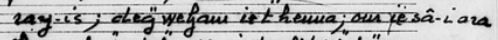
itamu, un roukthadja is teafitidid tgenenes-

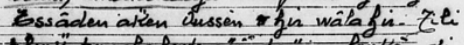

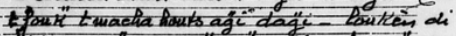
oulich di donimit sta-it" - Kra bwenda ara tili stout adieli char, adiel l heu, adietiva-um

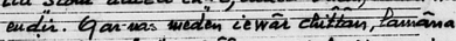
Eg \pm iel vit siant: Chit̂an ma ief zeit-ruadem adierwat filtis, wama stout... (Ienua, dac tow

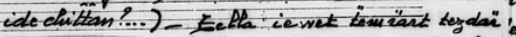

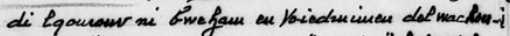

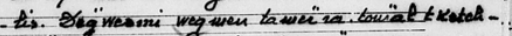

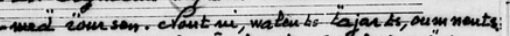
yerna mars teq ine pichoucha (Téstit) Wat des

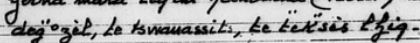

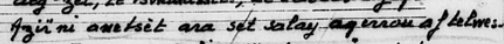

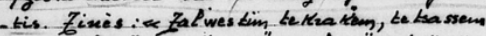

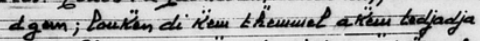

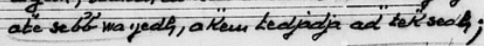


BIBLIOGRAPHIE SUR BÉLAÏD AÏT ALI

Les cabiers de Bélaïd ou la Kabylie d'antan, édition du Fichier de Documentation Berbère 1964.

Histoire de ma vie de Fadhma at Mansour Amrouche, François Maspéro 1982 (préface de Vincent Monteil).

Etudes et Documents berbères n² 1987 dirigé par Ouahmi Ould-Braham.

Redjala, Mbarek. Article sur « la Kabylie », Encyclopédia Universalis vol. 10.

Titouche, R. Les cabiers de Bélaid. Du conte à la nouvelle. Mémoire de Magistère.

KaCI OuALI, Kahina. Le renouvellement littéraire en langue kabyle : le cas de Bélaid at Ali.

Iвrahim, Mohand. Vie de Bélaid at Ali, auteur des cabiers de Bélaid ou la Kabylie d'antan? Analyse et notation du manuscrit, mémoire de maitrise Etudes berbères, Centre de recherche berbère, Inalco, Paris, octubre 1997.

AmÉziane, Amar. Tradition et renouvellement dans la littérature kabyle, thèse de doctorat, Inalco, Paris 2008.

Dallet, J., L. Degezelles (édition). Les cahiers de Bélaid at Ali ou la Kbylie d'Antan, Boudouaou, Dar Khettab, 2009.

Ittaft,taren $n$ Beleid yura af leqbayel $n$ zzman $n$ zik. Réscriture des manuscrits des cahiers de Bélaid avec la notation moderne avec des textes inédits par Ibrahim Mohand, éditions Dar Khattab, 2015.

Ommes et Femmes de Kabylie, sous la direction de Salem Chaker, Ina-yas / Edisud, 2001.

Les cahiers de Bélaid at Ali. Regards sur une oeuvre pionnière, ouvrage dirigé par Dr Amar méziane, Tira éditions, octubre 2013.

Un article ("Bélaid at Ali ; un précurseur ») a été consacré à Bélaid at Ali par Boussad Berrichi dans le journal La nouvelle République n 392 des 20/05/1999 et no 394 du 23/05/1999. 



\title{
THE HISTORICAL ROOTS OF AMAZIGH AND ITS ARABIZATION FACTORS IN ALGERIA
}

\author{
Ahfir Abdellah
}

\section{Resumen}

La cuestión amazigh se está actualmente erigiendo en el norte de África como problemática espinosa y altamente ideologizada vinculada a sensibles conflictos de identidad. Consecuentemente, en este trabajo planteamos un acercamiento histórico y científico integral que permita el reconocimiento cultural que la región merece.

Palabras claves: Amazigh, arabización, lenguas en extinción, transformación étnica, UNESCO.

\begin{abstract}
The question of the North African Amazighs is slowly emerging as a highly difficult and ideological issue because it is related to the sensitive problem of identity. All historical and scientific aspects need to be studied so that the region gains the recognition it deserves.
\end{abstract}

Keywords: Amazigh, Arabization, Algeria, languages in danger, ethnical alteration, UNESCO.

\section{INTRODUCTION}

Ancient Egyptian writings revealed the true history of the Amazighs, which dates back to about three thousand years BC. In ancient European languages, the Amazigh people were referred to with different names including the Moors (Mauri). The Greeks called them the Mazyes, while the Greek historian Herodotus used the Amazigh word Maxis. The ancient Egyptians called their Amazigh neighbours "the muddled". The Romans called them Numidians, or Libo. The Arabs often called them the Berbers. Berber in Arabic comes from the Graeco-Latin word Barbar, a Latin word used to describe all people who did not speak Latin or Greek believing Greek and Roman civilization superior to all others. The Berber or barbarian denomination was used by the Romans not only against the Amazighs but also against Germanic and English rebellious tribes. Some believe that the word is of Arab origin, on the basis that Berbers are of 
Arab descent. According to this theory, Berbers were Arabs who were deported from Yemen to North Africa by land and called Berber Arab land nomads. This theory has been refuted by researchers and scientists. DNA analysis performed on a large number of North Africans, ${ }^{1}$ showed that the E-M8I is I00\% of Amazigh origin. Genetic studies have shown that the percentage of Amazigh ancestry among Arabs is insufficient and that the Amazigh are local to North Africa.

The Amazighs have faced historical upheavals, conquests and invasions as well as attempts to obliterate their identity over thousands of years. These people live in a region representing a quarter of the African continent, from the Nile river to the Atlantic Ocean extending deep into the Niger and Mali deserts. Today, Arabic and not Amazigh is the region's official language and the language used in society. Nevertheless, the vast southern Sahara region, stretching from Senegal to Sudan's borders, as well as further communities, have maintained their Amazigh language.

\section{HOW DID ARABIZATION BEGIN IN NORTH AFRICA?}

First, it is necessary to distinguish between the spread of Islam and the imposition of Arabism. In fact, the former unfurled at a faster pace than the latter. Amazigh countries became Muslim over less than two centuries (during the $7^{\text {th }}$ and $8^{\text {th }}$ centuries), while their Arabization was never fully achieved to this day. The spread of Islam represented North Africa's first Arabization process, but the question remains as to why other people in different regions have not been Arabized; for example the Persians, Ottomans, and other areas of the Muslim world, such as Indonesia and others.

\section{MAJOR ARABIZATION EPISODES IN AMAZIGH HISTORY}

The ethnic transformation of the original Amazigh race to an Arab race can be explained by the Amazighs' initial religious wish to use the language of the Prophet, and the subsequent desire to adopt his Arab

1 «La découverte qui bouleverse l'histoire d' «Homo sapiens ». Article selected from the newspaper Le Monde (lemonde.fr, on 07/06/2017). See also: http://journals.plos.org/plosone/article/ figure?id=10.1371/journal.pone.0138453.g004. And also:

ـ تحليل الحمض النووي يثبت أنّ العرب ليسواعرباً، 15 يناير 2017 ( منذ عام واحد ) - الخبر أونلاين / و كالات 
affiliation. Thus, the idea that North Africa was formed by its inhabitants, indigenous Amazighs and migrant Arabs took root. Nonetheless, the whole population is actually formed by Amazighs, because Arabic speakers and inhabitants of Arab descent were all born to this North African Amazigh land, they were not migrants.

These Amazighs, who altered their etnicity to the Arab race, "played their part in Arabizing" the rest of the Amazighs, persuading them to "abandon their language and their ancestral customs" according to Mouliéras. ${ }^{2}$ Many Amazigh converts also adopted this attitude; they were ethnically transformed, they were proud of the fact and despised the non-converts and asserted that they were not Amazighs. The real Arabs in the Gulf countries respect the Amazighs, their language and their culture. This confirms that the Amazigh people are not real Arabs, but only ethnically motivated, which explains their hatred of their original race. Thus, every new ethnically Amazigh convert to the Arab race becomes a tool to convert more Amazighs from their Amazigh race to the Arab race.

In addition to this proliferation and continued Arabization -i.e. the conversion of the Amazigh race into the Arab race- everyone contributed to the destruction of Amazigh identity in North Africa, including the French. Amazigh people are today dispersed and under the sovereignty of various countries with different political systems. This explains the Amazigh movements within their borders as well as the policies of countries where Amazigh tensions exist. These political barriers hinder efforts to protect, promote and unify the Amazighs.

\section{THE ROLE OF FRANCE IN ARABIZATION}

I affirm that Arabism consisted in a process of controlling North Africa; in modern times, to Arabize the barbaric rebel regions against French colonialism as a reprisal policy. For me, Arabism is a modern French idea. Napoleon III spoke about an "Arab nation" in his ambition to create the so-called "Kingdom of the Arabs", ${ }^{3}$ extending from Morocco to the East in 1863. This idea, however, was rejected by the French Council.

2 Auguste Mouliéras, Le Maroc inconnu, Paris, J. André, 1895. p. 306.

3 Extracts from the letter of Emperor Napoleon III to the Duke of Malakoff, Governor General of Algeria, February 6, 1863. 
The colonial administration was the first to establish Arab offices in the provinces after the suppression of the Mokrani revolution in I87I. Subsequently, the names of many villages and cities in Amazigh areas were Arabized, and people were given Arab names in those same areas in I89I, the battle against the Amazigh.

They wanted everything to be according to the Arab tradition, Arabizing names, geographical regions and persons. To name a few, for instance Tariq ibn Ziyad was an "Arab leader" of twelve thousand North-African fighters that occupied al-Andalus. As for animals, what we hear today is the Arab horse, the Arab chicken, the Arab egg...

\section{AFTER INDEPENDENCE}

The regime pursued its targeting policy within its national Arab project, which contributed to the growing rejection of the Tamazight language by Kabylia people. A number of intellectuals and researchers attempted to define Amazigh language and culture. They also launched an academy based in Paris to collect and disseminate Amazigh heritage. But the issue ceased to be an elitist one and took on a public dimension when the researcher Mouloud Mammeri was forbidden from teaching courses at the university. Students were encouraged to take to the streets on ro March i980 to express their rejection of the exclusion policy adopted by the regime, concerning everything, which was related to the Tamazight. These student movements received significant response from residents in tribal areas: an unprecedented grand march was organised in Algeria, with demands that touched on Amazigh identity as well as democracy and human rights. Oppression followed, the requests were not addressed, leading to a range of subsequent conflicts.

After the Amazigh spring events, the struggle began to take on new dimensions, such as the democratic opening experienced in Algeria in the early i99os. It was followed by the establishment of the Amazigh Council by order of the president. The state's official media began to take Amazigh culture into account and broadcast in several Amazigh dialects.

Before 1996, Amazigh was recognized in the Constitution as a component of national identity alongside Arabism and Islam. In 1995, the 
Amazigh language was introduced into the curriculum in some parts of the country where Amazigh was the mother tongue.

In 2002, the state recognized Amazigh as a second official national language. The Amazighs celebrate Amazigh New Year's Day on I2 January, which has become a national holiday in Algeria. How is the Amazigh calendar followed in Algeria? - The Amazigh calendar is based on the solar system, and the agricultural New Year is the Amazigh New Year. The Amazigh calendar is not linked to any religious event, but rather to the history of the Amazigh defeat of the ancient Egyptians and the ascension of King Shoshenq I to the Pharaonic throne during the Ramesses in period. According to legend, this battle took place in Tlemcen, the Algerian city.

In 2009, a state television channel was launched to broadcast programs in Amazigh on all its channels. Worthy of note, there are several Amazigh dialects in Algeria, including the Kabylia, the Shawi and the Muzabi. Amazhig is an official language in Morocco alongside Arabic since 20II, and became an official language in Algeria in 2016.

\section{CULTURE AND EDUCATION}

Amazighs embrace Islam, most follow the Maliki doctrine, and others the Ibadi doctrine. In 1996, the Amazigh World Congress adopted an international cultural banner symbolizing Amazigh identity and cultural specificity across the world. This flag consists of blue, green and yellow colours, illustrating the Amazigh's natural environment. Blue symbolizes the colour of the sky and sea; green is the colour of the mountains and forests, while yellow represents the desert. In the middle, the Amazigh " $Z$ " is written in red, as this letter is part both of the word Amazigh and Izuran, which means roots.

Education programs are very influential in spreading the concept of Arabism and the idea of belonging to the Middle East. There is a clear tendency to marginalize North Africa's history in general and Algeria's in particular, and to adhere to a historical perspective centred on the East (an Arab-Islamic trend and focus on the Middle East). An example is that of a textbook: while a famous statue of the Emir Abdelkader may be on the cover of the book, the content of the book is unrelated to the Emir; 
forty illustrations of historical figures are linked to Egypt and Syria, while only four concern the Maghreb (Omar Mokhtar, Mohammed v, and of course Ibn Badis and Al-Bashir Ibrahimi). This must be understood as self-contempt and preference for all that is foreign.

More than $80 \%$ of textbook contents on this segment of Algerian history are dedicated to the Middle East. A generation has been created that knows everything about the Middle East and nothing about its homeland Algeria. Most books prefer to teach Middle Eastern literature and poets (Naguib Mahfouz, Abu Madi, Mutanabbi, etc.) rather than great local writers and poets. History books, especially those written in the 8o's, hardly refer at all to the history of Algeria or North Africa. Most of the teaching was limited to the modern Algerian state. References to the Amazigh civilization in history books were still linked to the Byzantine and Roman civilization in Algeria.

New Year's Day is the Amazigh's first and main celebration in Algeria and the entire Maghreb region. The Amazigh festival is celebrated every year on I2 or I3 January at the beginning of the Amazigh year - currently 2968 - and in the Amazigh language, January is pronounced Yennayer.

According to historical accounts, the celebration was the occasion of the victory of the Amazigh king Shashnaq over the Pharaohs in 950 BC, who ruled Egypt. For the Amazigh, this is a day of sacrifice, struggle and defence of the land. Other works interpret its meaning as the beginning of the agricultural year, the Vistbzron season of many yields; to celebrate, dishes based on wheat and vegetables produced by the land are prepared. It is an occasion to speak Amazigh Thimchrat, and that of social solidarity, caring for the poor and needy.

Almost all Amazigh regions in Algeria celebrate major religious events such as the month of Ramadan, Ashura and the Prophet's birth, as well as the Amazigh New Year. Villagers collect money, supervise operations, buy cows, slaughter and distribute their meat to poor families depending on the number of members. Celebrations relating to spring and the beginning of the harvest spread to the regions of Bordj Bou Arreridj and east of Algiers.

On March 2I each year, families take their young children out to enjoy nature. The day lasts until the evening, when they eat traditional dishes 
prepared with vegetables, as well as homemade bread based on wheat, barley, olive oil, oil or margarine and date dough.

\section{ENDANGERED LANGUAGES IN ALGERIA}

According to unEsco's Atlas report, which regularly lists endangered languages in the world, eleven languages are on the decline in Algeria. Degrees of vulnerability are differentiated by region. ${ }^{4}$

1- The Tamazight of Arzew (Arzew): Critically endangered according to UNESCO, barely 2000 people continue to speak the local variant of Berber in the Arzew region. If nothing is done, the language will inevitably become extinct.

2- Tayurayt (Cherchell): The Tayurayt language is one of the most vulnerable, spoken by 15,000 people in the Gouraya region and surrounding area.

3- Tasnucit (Tlemcen): The Berber language of Beni Snous is severely endangered, according to unEsco's classification. In this region of Tlemcen, considered a Berber island in western Algeria, local speech is sometimes related to the Rifain, and more particularly to Beni Iznassen. Today, only elderly people still speak Tasnucit. According to UnEsco estimates, there are around tooo speakers left.

4- Zenatiya (Tissemsilt): In the Ouarsenis and Tissemsilt regions, around 50,000 people still speak Zenatya, one of the variants of Zénète.

5- Tamzabit (Ghardaï): Vulnerable language, according to unesco's classification. It is spoken by 150,00o people, mainly in Ghardaï, in the Mzab Valley, El Ateuf and Berriane and Guerrara. The Mozabite language, however, seems to be well "spoken from birth to death", though restricted to family environments.

6- Taznatit (Timimoun): Zénète, or Taznant, is spoken by almost 80,000 inhabitants in the region of Touat out of a population of nearly 400,000 inhabitants. The Gourari, a local Arabic vernacular, has gradually overtaken the ancestral language.

7- Tidikelt (In Salah): Spoken in Ain Salah and in some surrounding

4 Publications of the United Nations Educational, Scientific and Cultural Organization (UNEsco) A detailed report on Amazigh languages and dialects that are subject to extinction. (UNEsco Atlas of the World's Languages in Danger): <http://www.unesco.org/languages-atlas/> 
oases, the Tidikelt language, with some 30,000 speakers, is declining according to UNESCO.

8- Tamacheq (Tamanrasset): It is vulnerable according to UnEsco experts. Around $\mathrm{I} 2 \mathrm{O}, 000$ people still speak this language, mainly in Tamanrasset (Kel Ahaggar) and Djanet (Kel Ajjer). Nevertheless, the Tuareg variants are the only Berber variants to have preserved the written form of the Libyan-Berber alphabet, called Tifinagh (or rather "Neo-Tifinagh" to be more precise), adopted by Algeria and Morocco in their attempt to make Tamazight official, thus removing the threat of total disappearance. The desert bluesmen may perhaps have to be relied upon to save the language.

9- Touggourt (Touggourt): The Touggout language from which the region took its name is spoken by a little over 8,000 people, according to UNESCO.

10- Taggergrent (Ouargla): This language dates back to more than 6,00o years and is concentrated in the age-old Ksar region after which it is named.

11-Tachenouit (Tipasa): Classified as vulnerable by unesco, the name "Tachenwit" comes from Mount Chenoua, which sits on the Mitidja. The Chenouis distinguish themselves by a number of original features, particularly language and traditions.

\section{CONCLUSION}

Current scientific research is interested in the Amazigh ethnicity. This nation is struggling to preserve its cherished culture and survive, refusing to be swallowed by other dominant cultures. The Amazigh do not, however, reject national taxations, nor scientific progress and logic. We must not forget that migrants formed the majority of the local population and that identity is given by the land, not by migrants: we are all Amazighs for territorial reasons, just as Mexicans speak Spanish but do not consider themselves Spaniards despite their Euro-Spanish heritage. 


\title{
الأداءات الإحتفالية للأمازيغ الجزائريين \\ LAS FESTIVIDADES DE LOS AMAZIGH EN ARGELIA
}

\author{
Azeddine Terbeche \\ Universidad de Djelfa
}

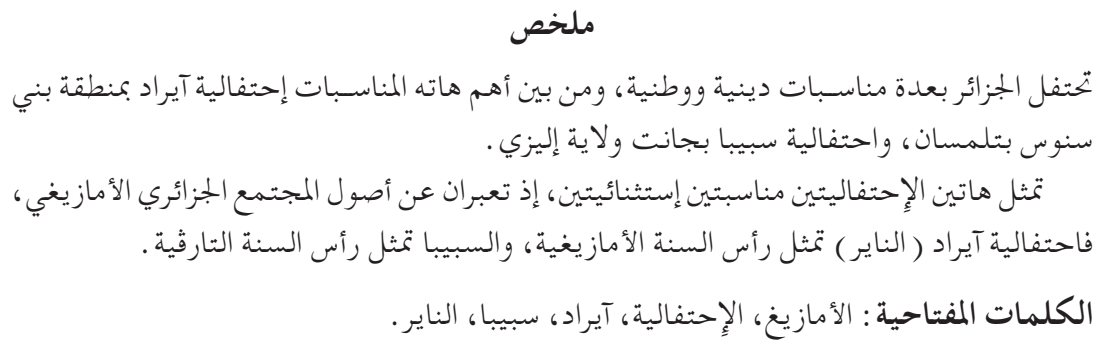

\section{Resumen}

Argelia celebra una serie de fiestas religiosas y nacionales. Entre las más importantes se encuentran las celebraciones en la región de Beni Snous de Tremecén y la celebración de Sabiba en Djanet, en la Wilaya de Illizi.

Estos dos acontecimientos representan festividades excepcionales, que reflejan los orígenes de la sociedad amazigh argelina.

Palabras clave: Amazigh, Festividad, Ayrad, Sabiba, Nayer. 


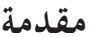

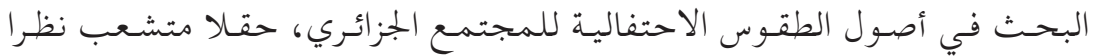

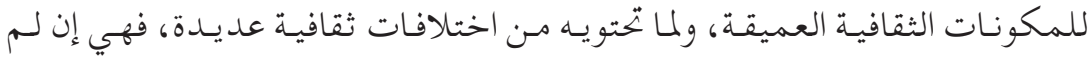

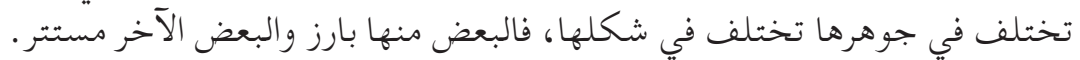

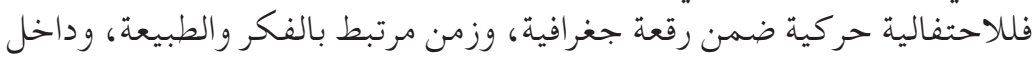

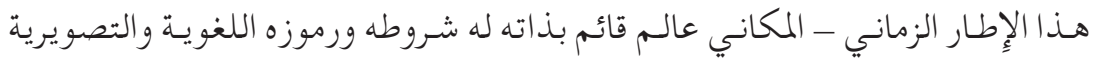
والتاريخية.

ومما لاشك فيه أن الإِنسان الجزائري الأمازيغي قديم جدا في أرضه، ووجوده ليس ليس

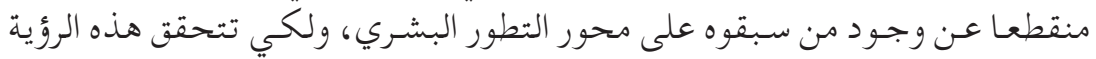

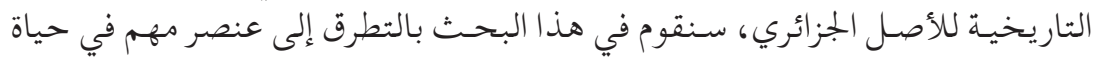

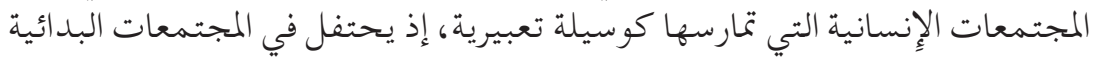

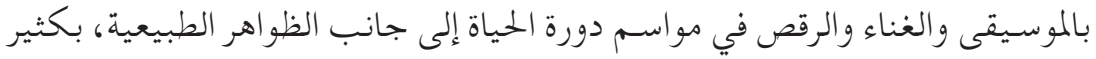
من التعابير ذات الصلة بالحياة العامة .

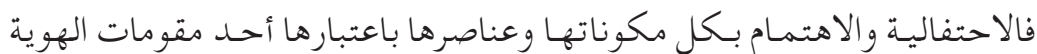

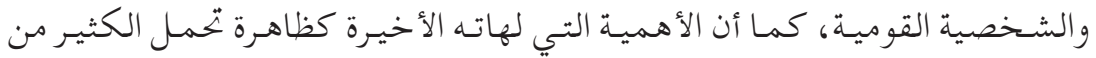

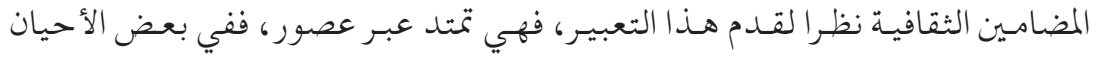

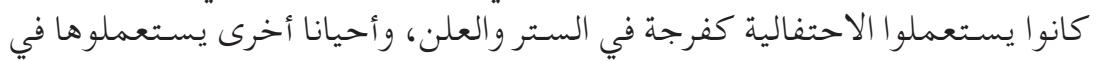

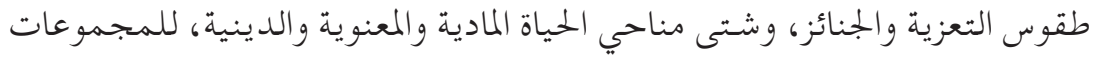

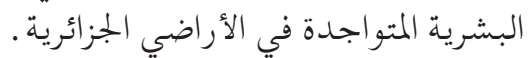

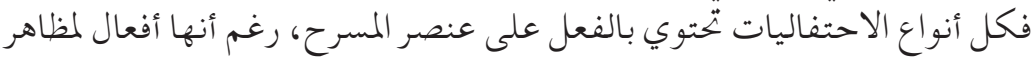

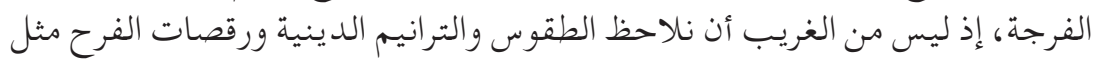

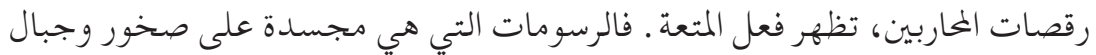

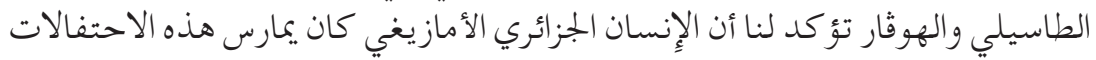

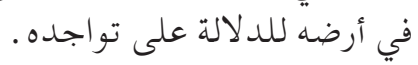

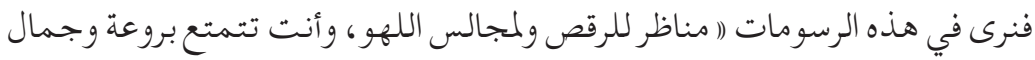

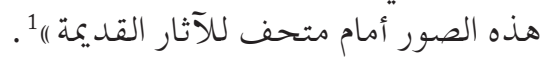

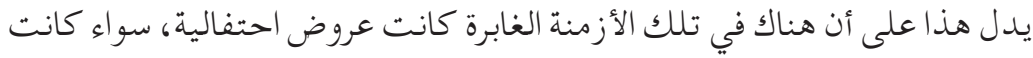
1 محمد طمار : الروابط الثقافية بين الجزائر والخارج، الشـركة الوطنية للنشــ والتوزيع، الجزائر، 
طقو سا أو احتفالات، فالإِنسان بطبعه ميال للمحاكاة والتشخيص والمتعة والانبهار ، إنها

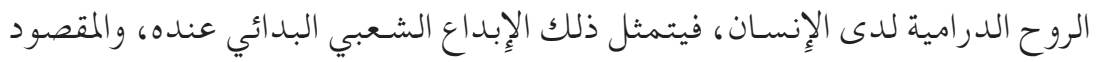

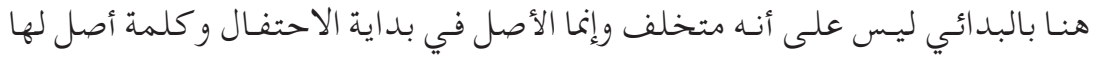

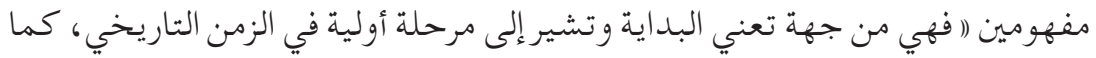

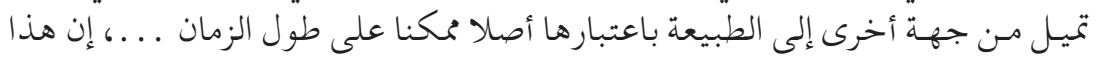

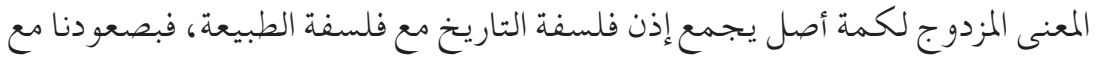

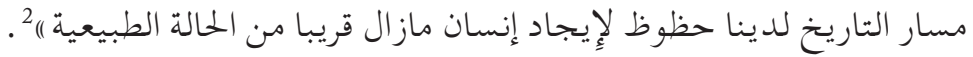

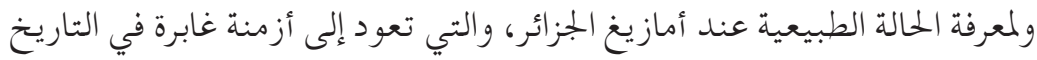

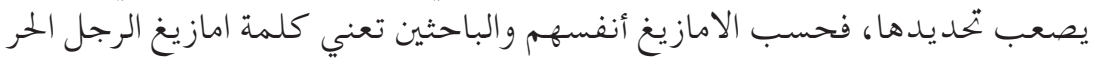

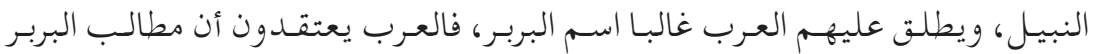

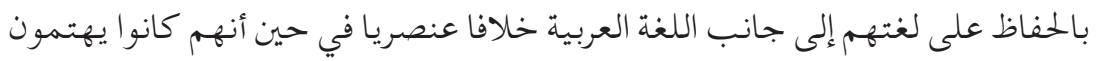

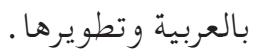

فكلمة (ا بربر تعني إما اللغط و الرطانة والضوضاء أو الهمجية والقسوة ، ولم تكن

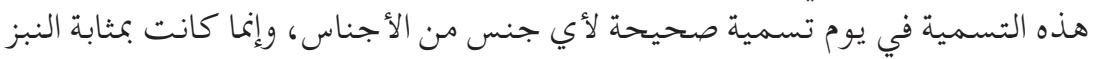

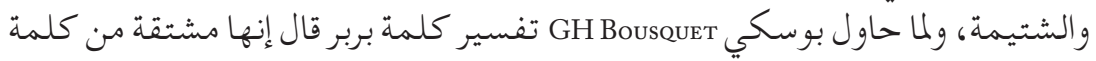

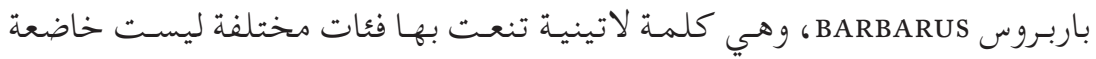

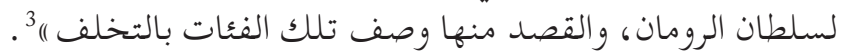

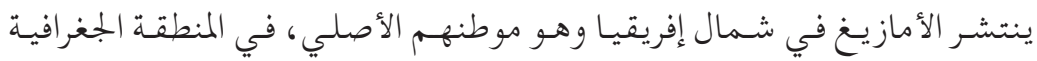

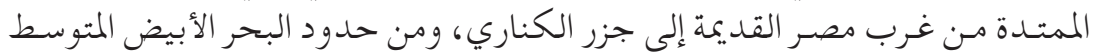

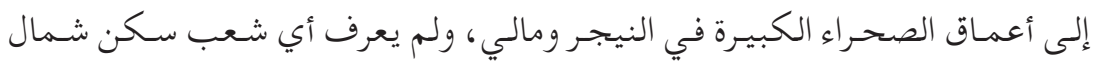

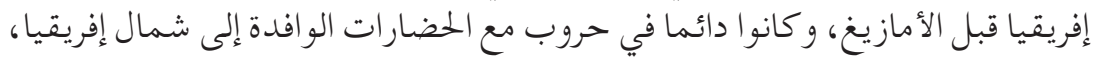

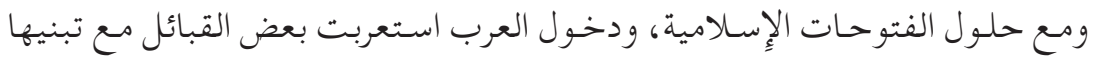

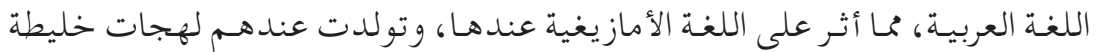

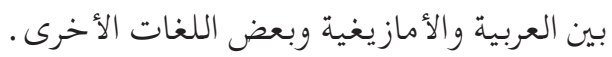

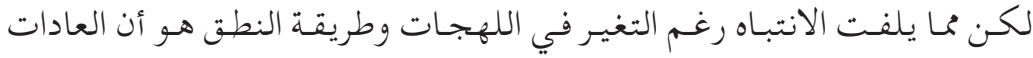

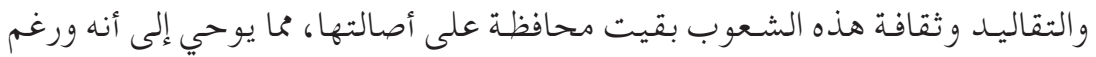

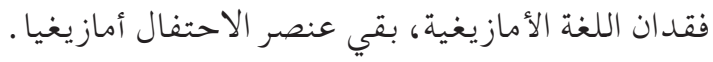

2 Henri Gouhier, Antonin Artaud et l'essence du théâtre, Librairie Philosophique J.Vrin, 1973, p. 108 .

3 Jean Servier, Les Berbères, Collection : «Que suis-je ? ", Paris, 2017, p. 8. 


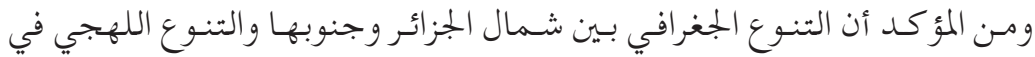

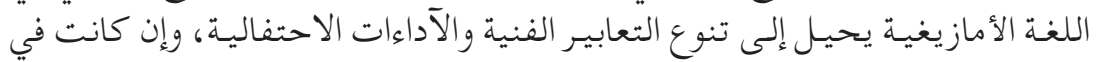

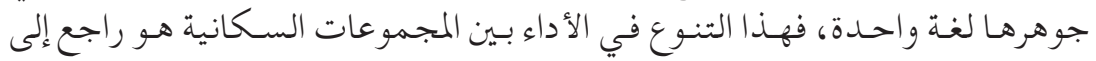

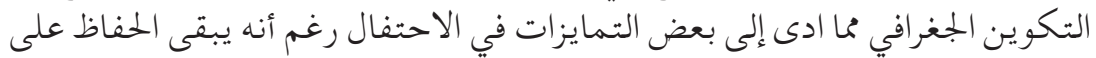

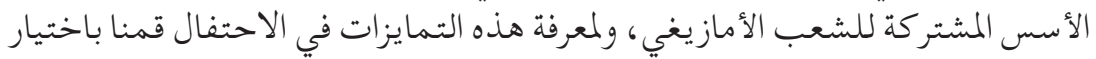

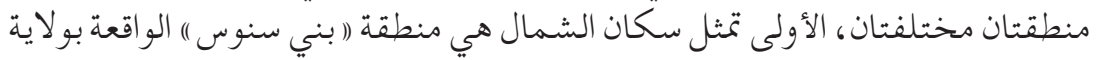

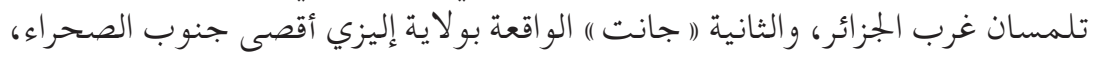

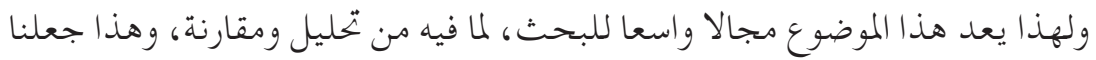

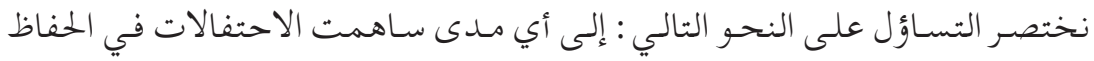

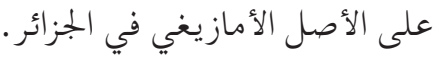

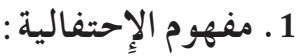

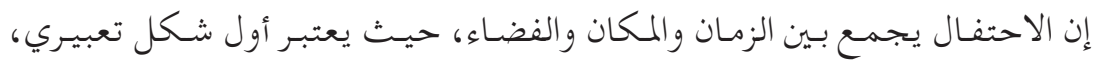

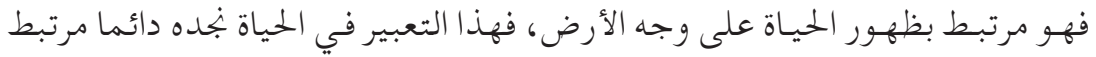

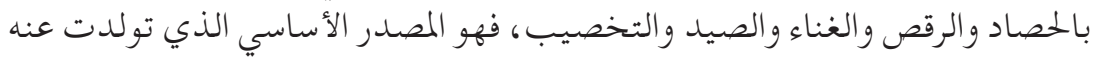

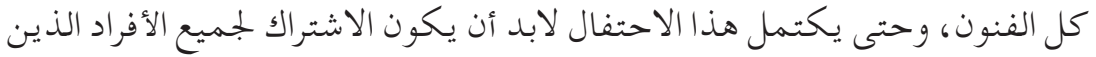

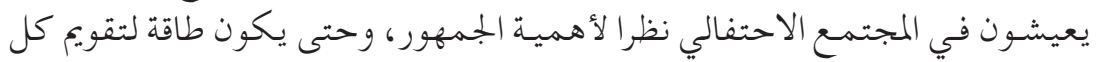

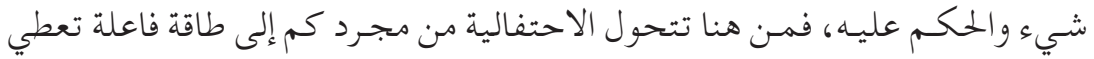
القيمة والشرعية للأشياء.

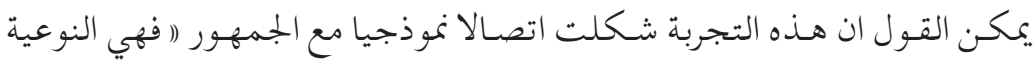

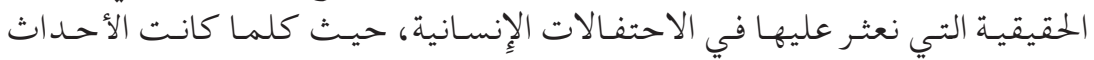

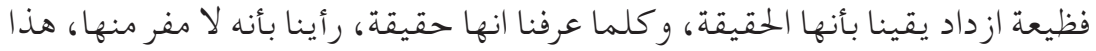

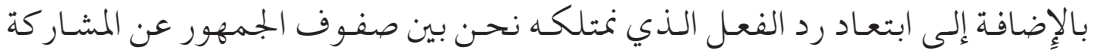

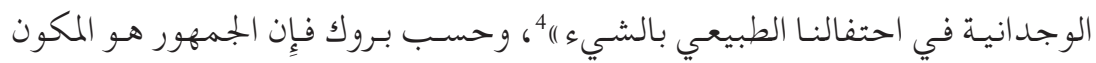

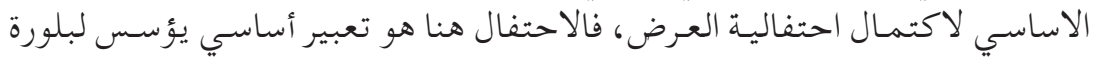

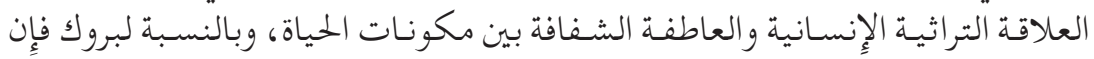

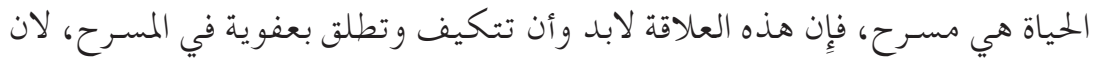
4 بيتر بروك : خيوط الزمن ـ سيرة شخصية ـ ترجمة وتقديم فاروق عبدالقادر، دار العلوم للنشر 
الاحتفال (ا في جوهره هو التعبير الحر والتلقائي عن الحياة وهي في حالة الفعل والحركة

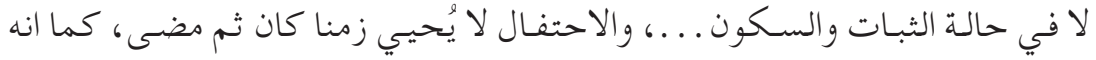

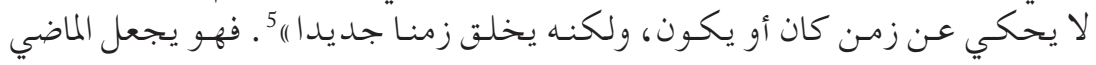

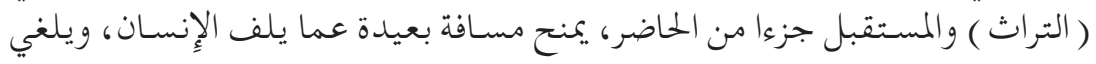

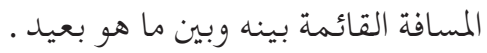

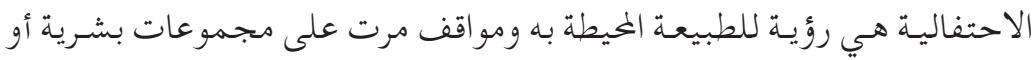

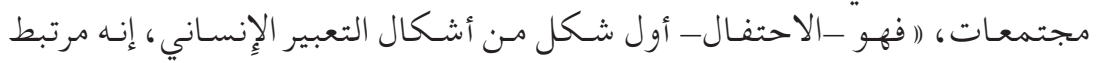

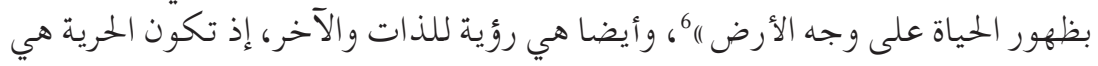

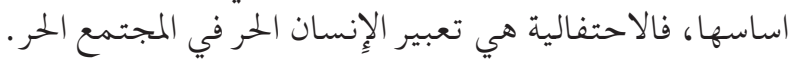

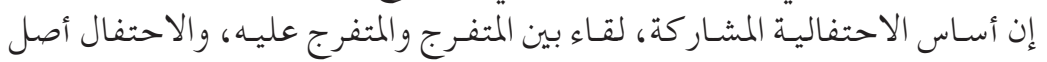

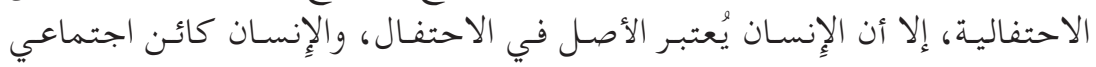

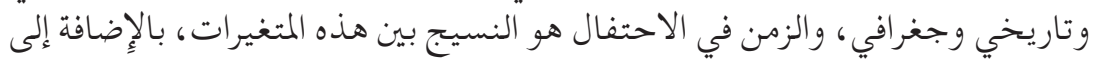

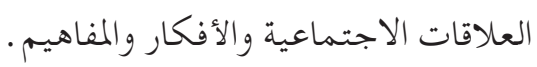
2 . 2 - إحتفالية آيراد :

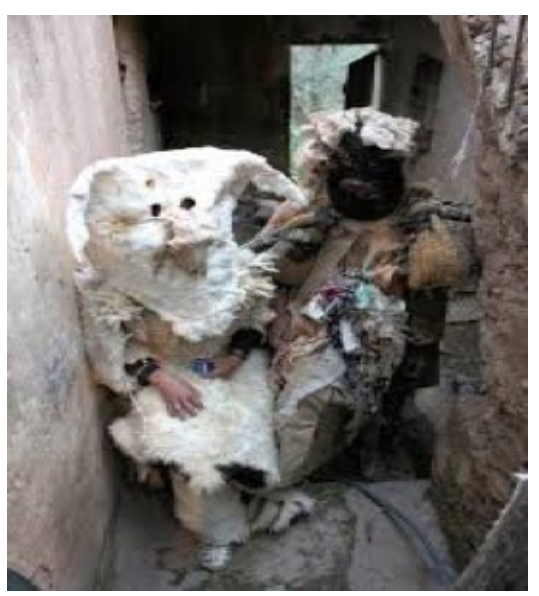

الأقنعة المستخدمة في احتفالية آيراد

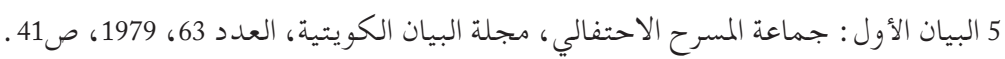

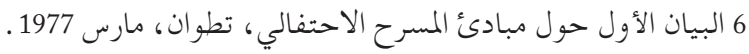




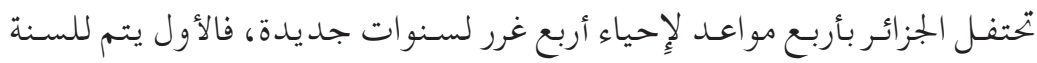

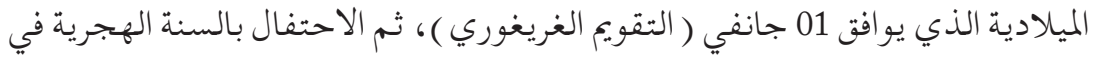

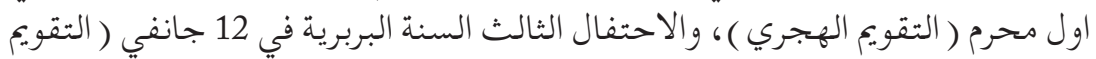

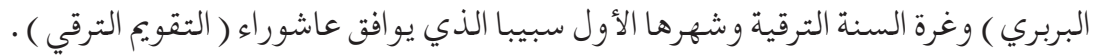

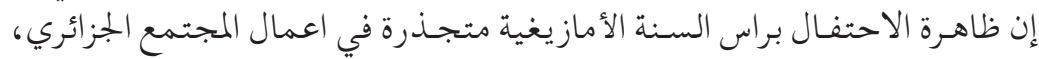

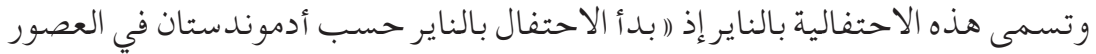

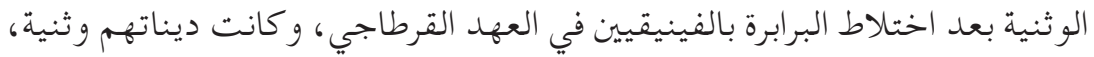

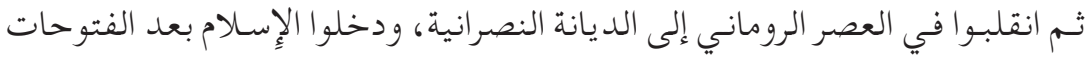

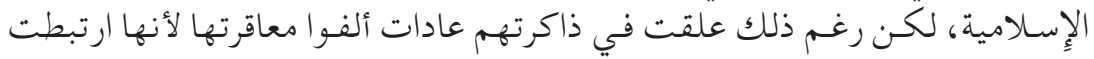

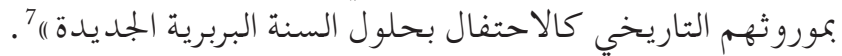

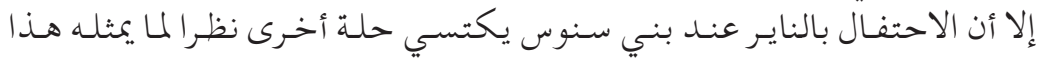

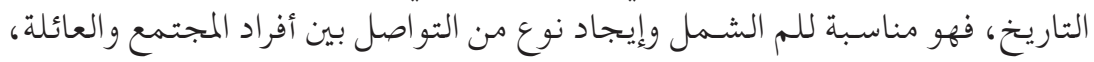

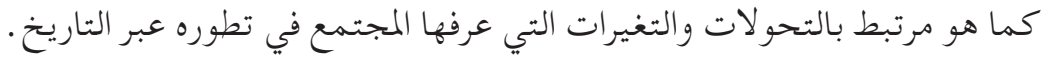

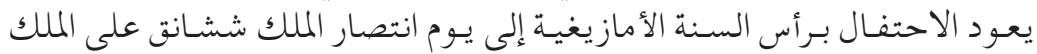

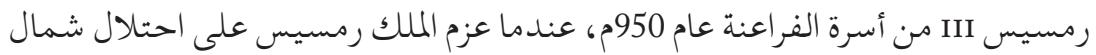

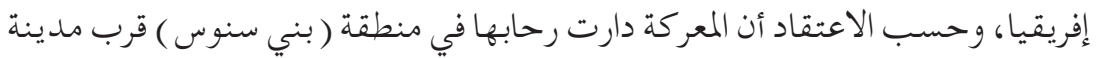

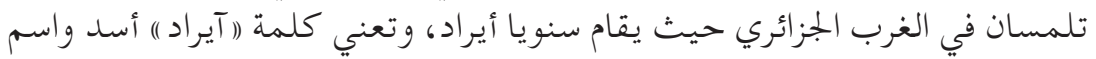

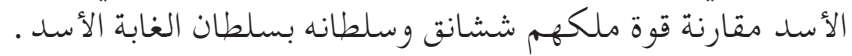

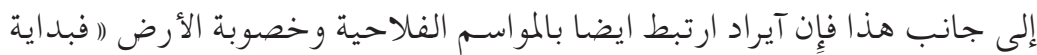

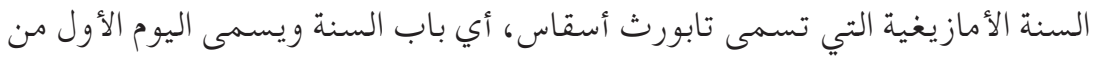

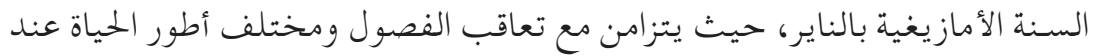

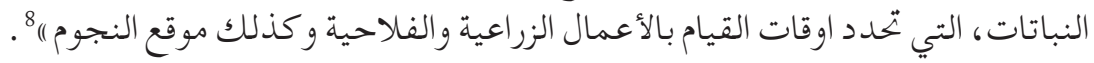

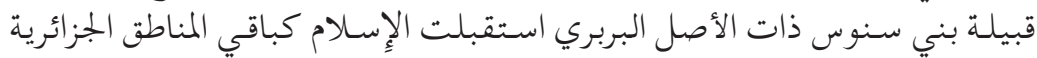

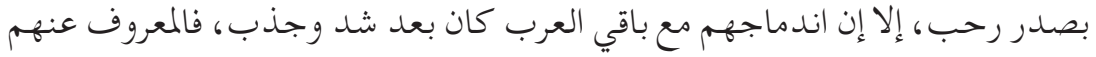

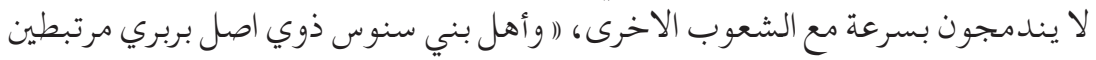

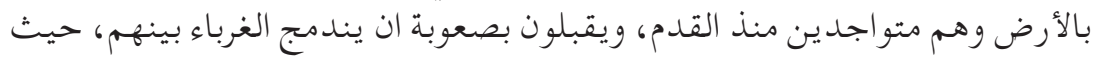

7 Edmond Destaing : «L'Ennayer chez les Beni Snous », Revue Africaine, t. $491^{\text {er }}$ trimestre, 1905, p. 70.

8 مروان فاتح قاديري : اللهجة الأمازيغية في بلاد السنوسيين، منشورات المحافظة السامية للأمازيغ، 
انتسبوا إلى قبيلة زناتة بصعوبة، و كان العرب يشيرون إليهم بالقبائل KABAYL لتميزهم

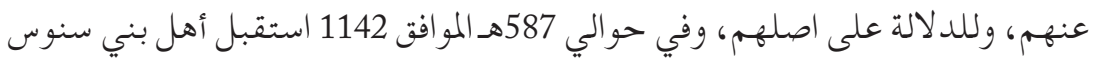

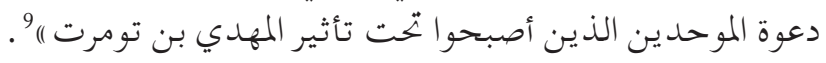

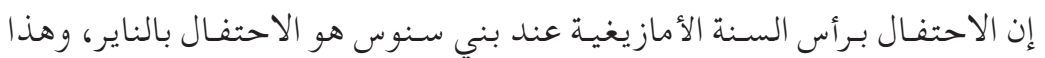

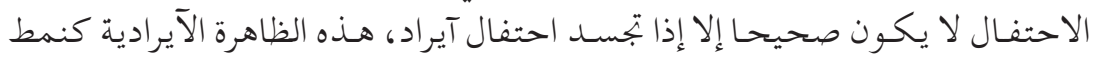

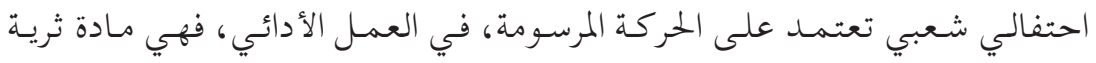

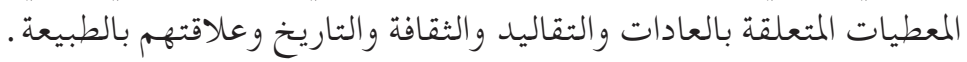

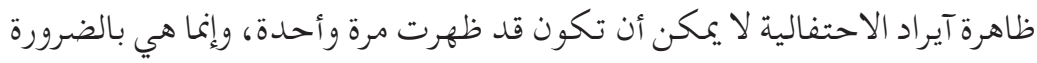

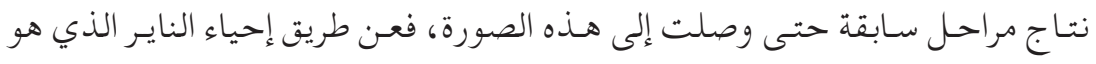

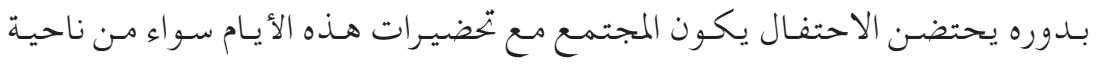

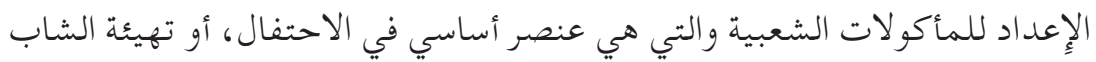

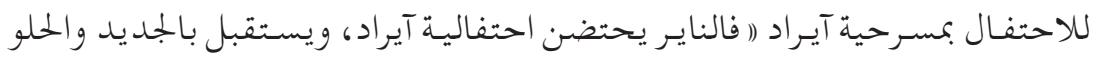

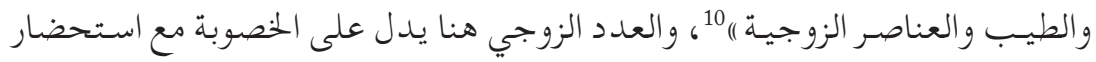
أو حضور كل العناصر الغائبة.

في حقيقـة الأمـر يتعامل الأداء الاحتفالي مع الواقع معتمدا في ذلك على المعلى المفهوم

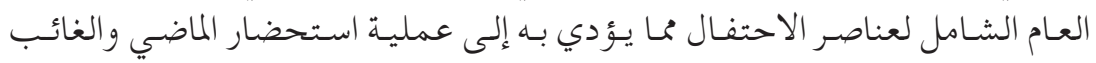

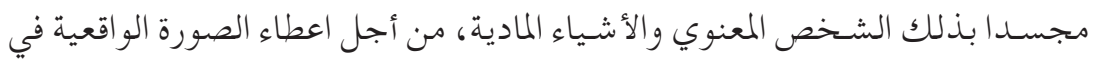

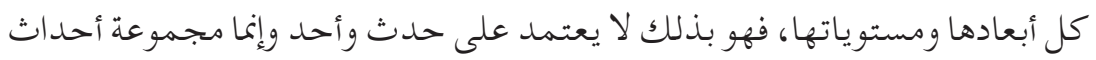
عايشتها المجموعة السكانية .

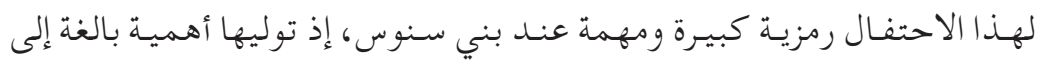

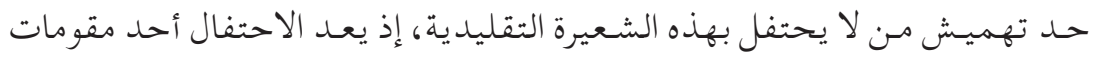

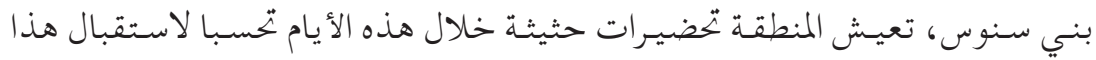

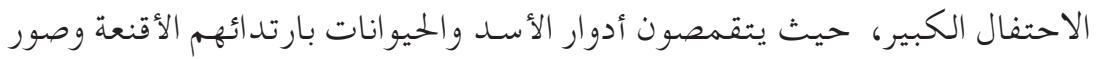

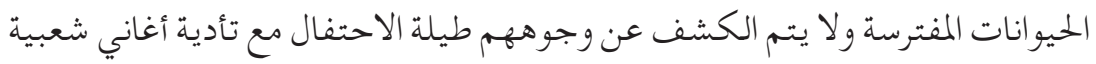

$$
\text { وشعارات موروثة عن الأجداد. }
$$

9 Jean Canal : «Monographie de l'arrondissement de Tlemcen », $2^{\text {eme }}$ partie, Bulletin de la Société de géographie de la province d'Oran, XII,1891, pp. 389-390.

10 Benhadj Serradj, Mohamed, "Les fêtes d'Ennayer au Béni Snous ", Revue de l'institut des belles-lettres arabes, 13, Institut des belles-lettres arabes (IBLA), Tunis, 1951, p. 35. 
يدوم آيراد لمدة اثناعشرة يوما و كل يوم يخصص لعمل إذ توزع على النحو التالي : - الأيام الثلاثة الأولى من 01 إلى 03 يناير و تعرف بالأيام التحفيزية. - يوم 04 يناير : يوم العرضة ( الدعوة ) . - يوم 05، 06 يناير: يتم فيها ترتيب اللقاء الكبير. - يوم 07 يناير : يدعى يوم التبخيرة .

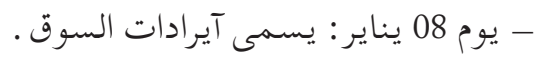
- يوم 09 يناير : يتمثل في طقوس الخصب بائس بلحناء.

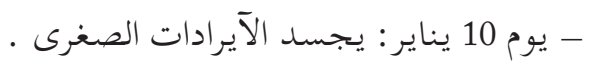
- يوم 11 يناير : يعرف بعينوز آيراد : ئجساد

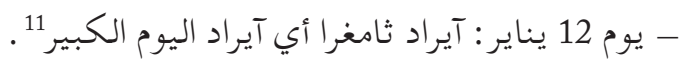
من المميز في احتفال آيراد أن كل يوم وله خصائصه وما يججب أن يحدث فيه هذا

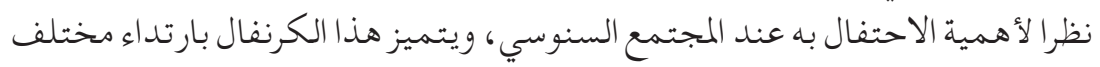

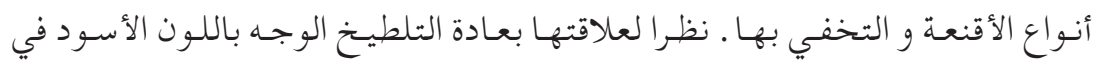

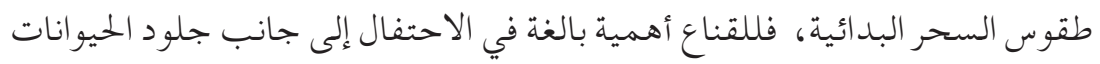

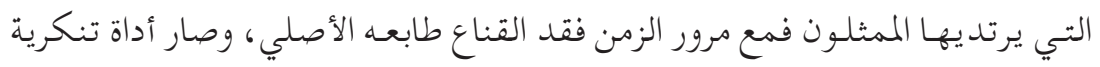

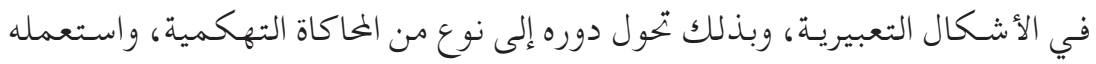

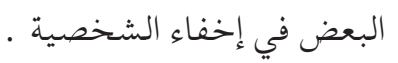
القنـاع وملابسس الحيو انـات إلى جانب الرقص واء الموسيقيى، هكذا تتمثثل احتفالية

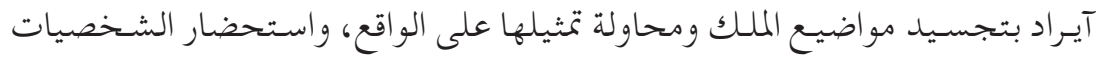

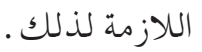

إن الإِبـداع الفنـي الآيـرادي تتجســـ فيـه عناصـر التمثيـل، فهـو يعيـش بنيـة الحيـاة

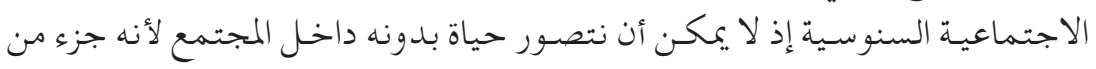
مكوناتها الثقافية، انعكاس لعاداتها و تقاليدها. 11 عبد الكريم بي عيسى : مسـرح آيراد الاحتفالية آليات الحركة المرسـومة، رسـالة لنيل شـهادة

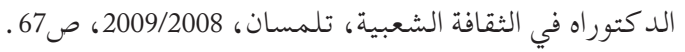


83 Las festividades de los Amazigh en Argelia

\section{3. إحتفالية السيبيا :}
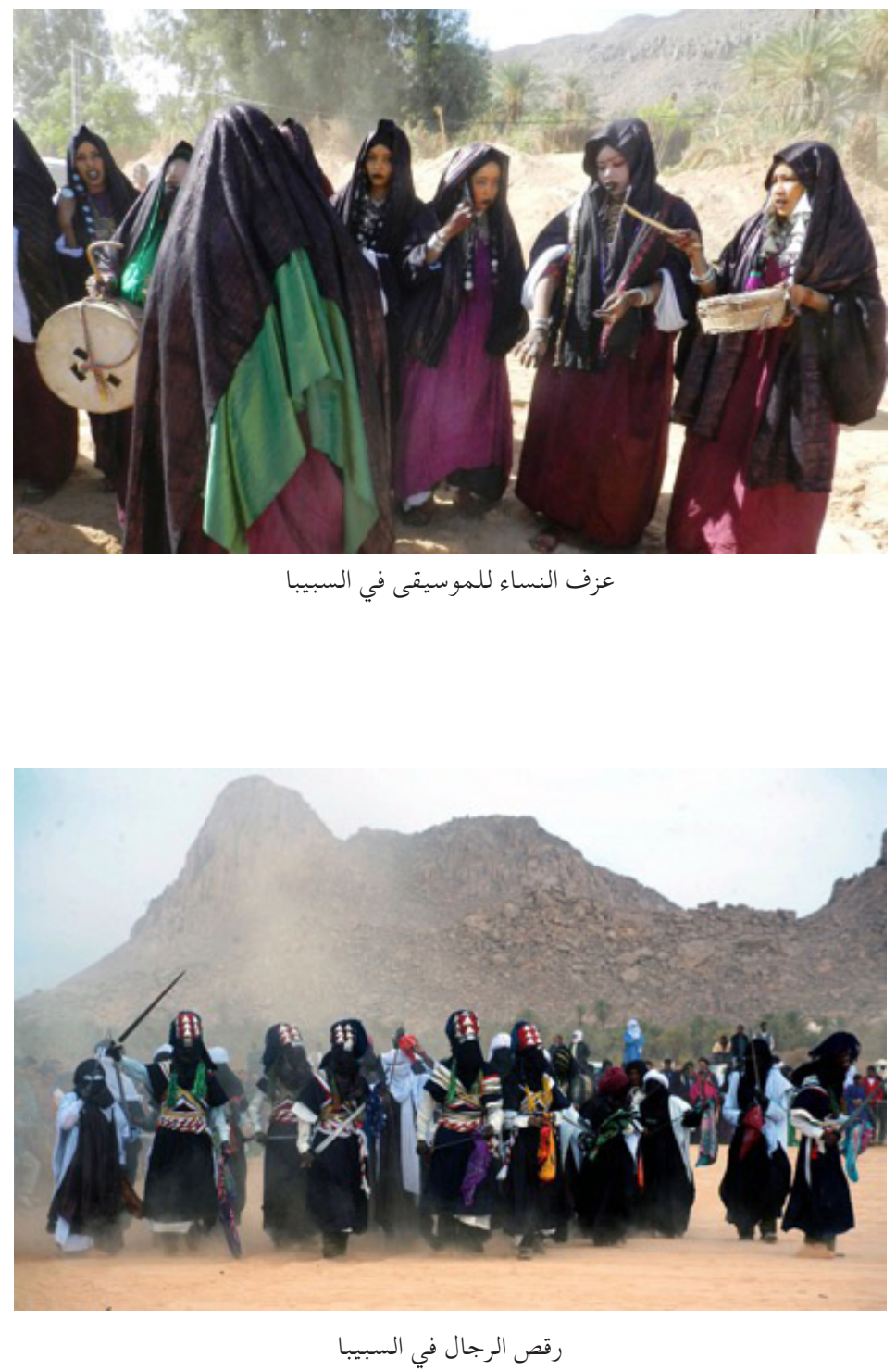
التاسيلي هذه المنطقة التي تزخر بالحيوية وحب الحياة، هذا ما يشير إلى أن الإنسان إنسان

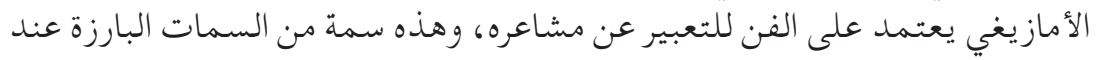

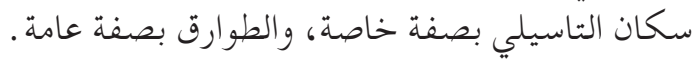

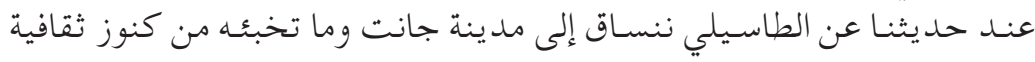

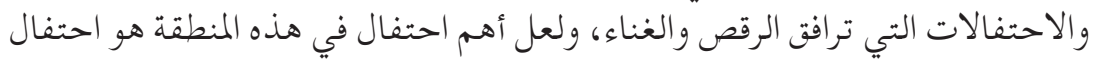

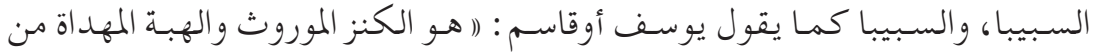

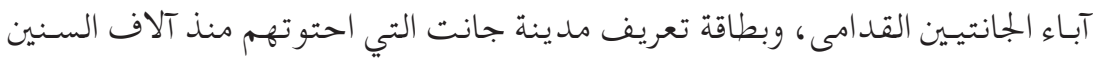

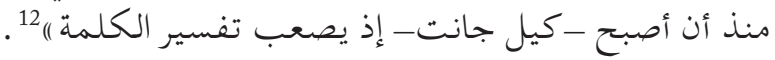

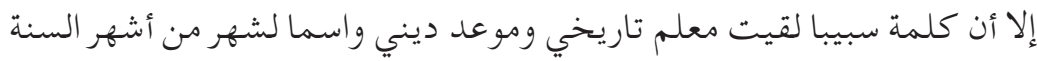

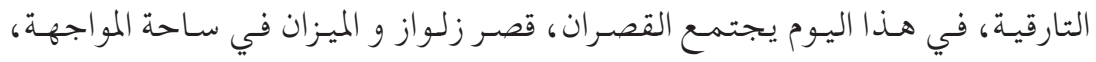

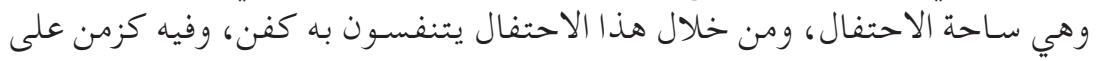

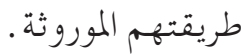

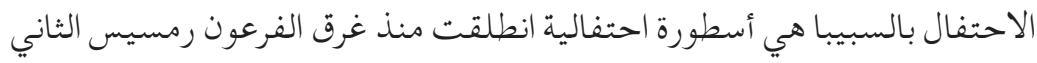

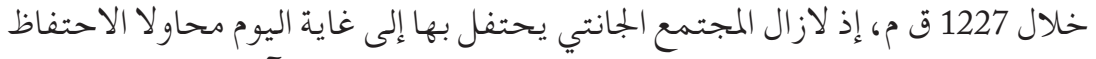

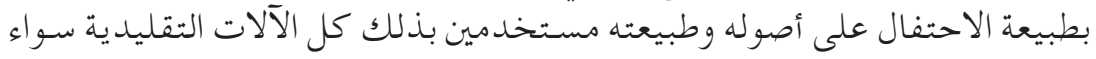

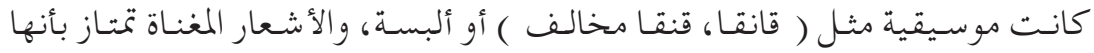

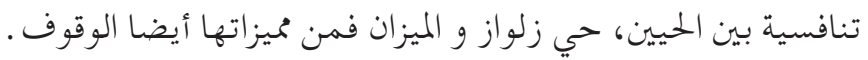

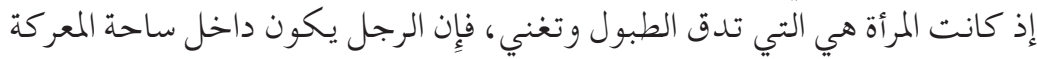

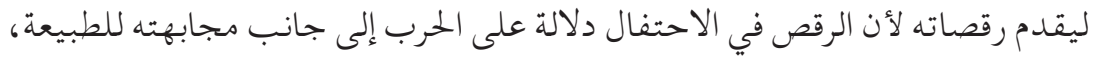

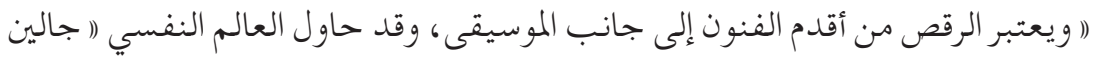

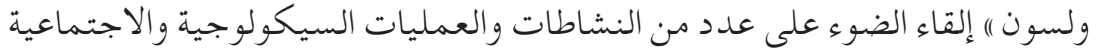

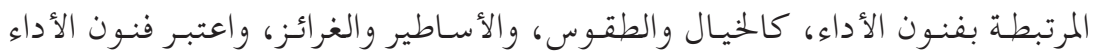

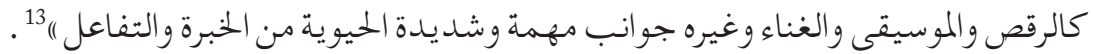

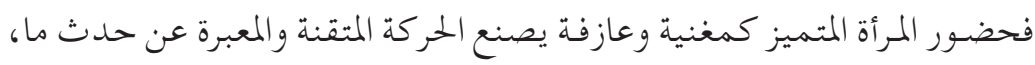

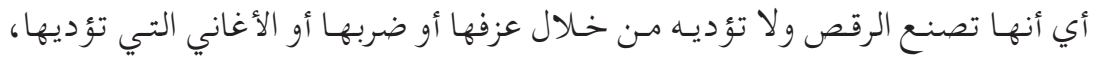

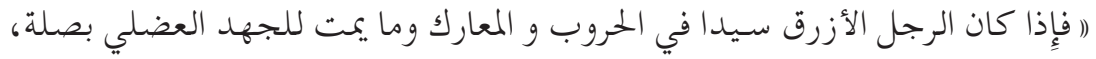

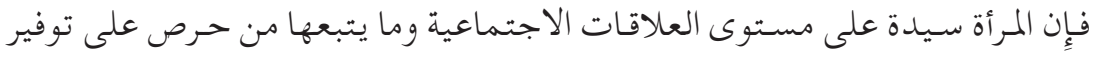

12 يوسف أوقاسم: باحث ورئيس جمعية السبيبا سابقا.

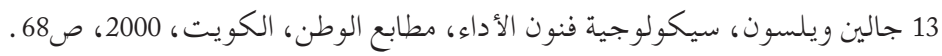




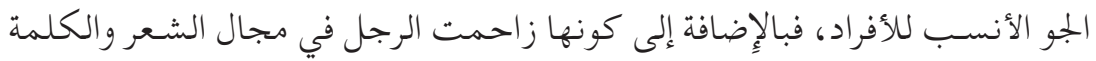

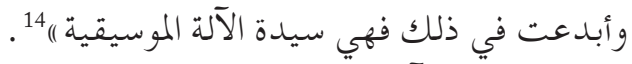

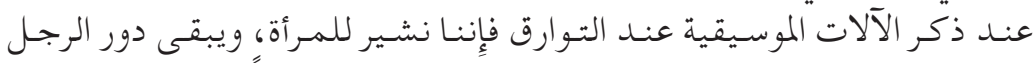

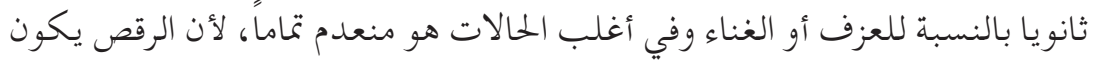

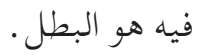
وعن احتفاليـة السـبيبا كمـا ذكرنـا سـالفاً فهي احتفال بمسوت فرعون ونجاة سيدنا

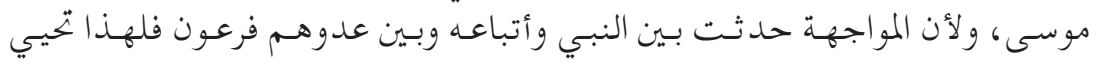

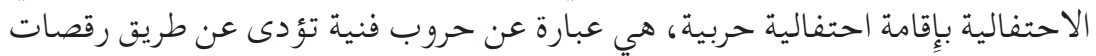

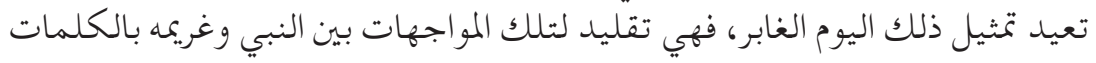
و القصائد و الرقص و الغناء.

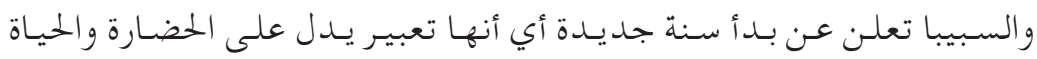

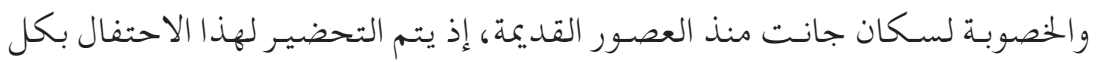

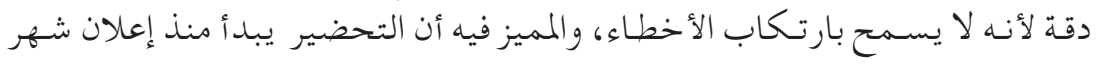

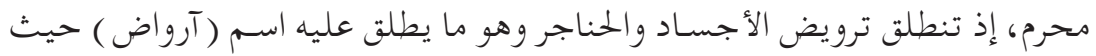

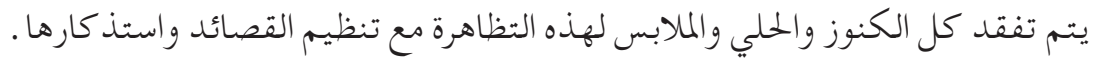

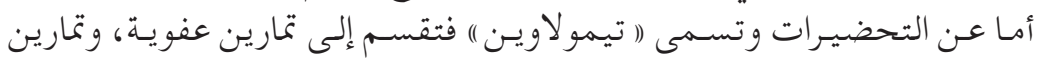

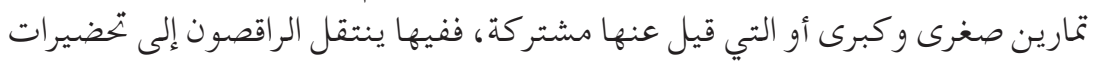

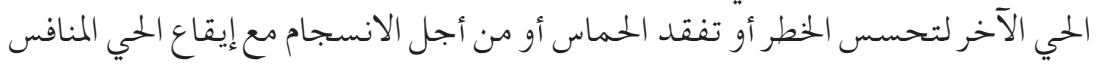

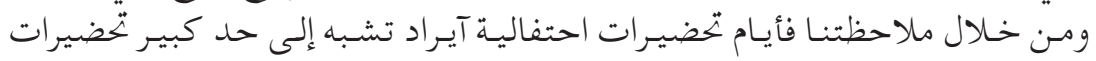

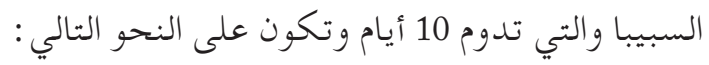

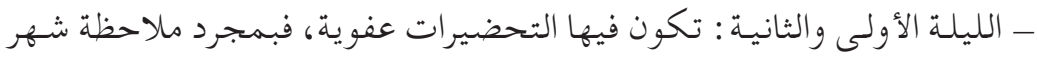

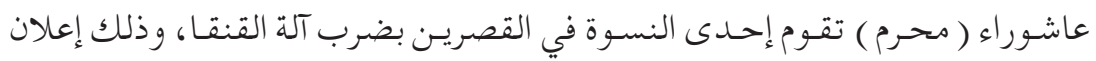

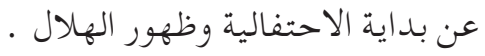

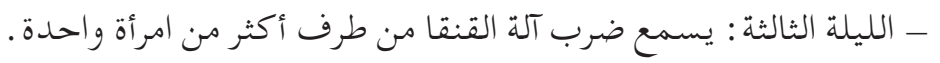

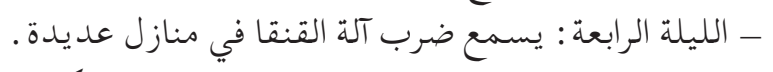

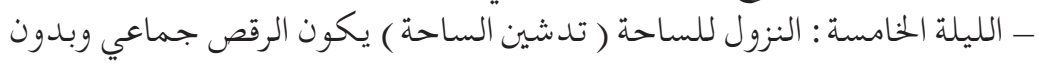

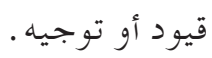

14 رمضـان حينوني : الكلمة والنغم والحرية وسـيادة المرأة الترقية، مجلـة جوليا التراث، جامعة مستغانم، العدد 11، 11، 2011، صغ ص 102. 
- الليلة السادسة : تدخل الراقصين والمغنيات كإعلان لبوان ادر التنظيم.

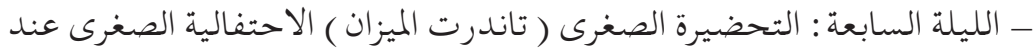

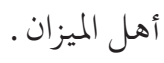

- الليلة الثامنة : تاندرت زالواز الاحتفالية الصغرى عند أهل زلواز .

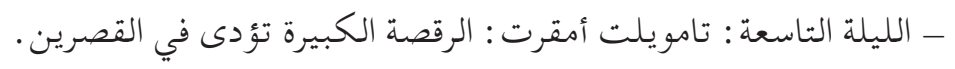

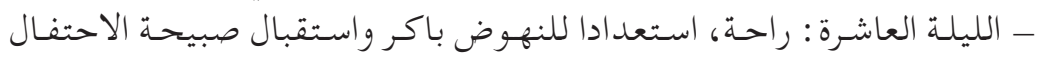

$$
\text { الأكبر ( السبيبا ). }
$$

الملاحظ في الليلتين السابعة والثامنة أي أن عند احتفال أهل الميزان بالتحضيرات

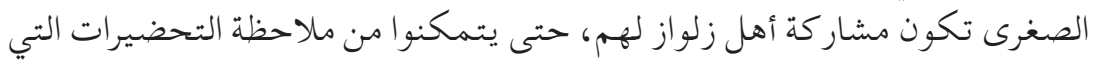

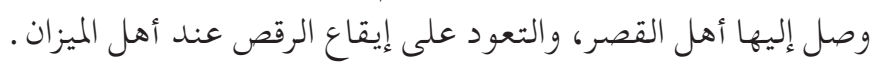

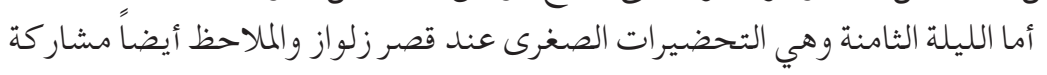

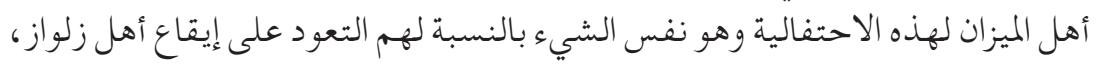

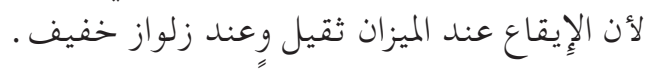

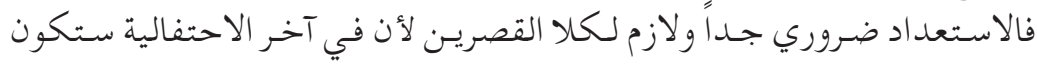

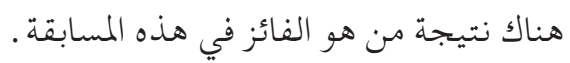

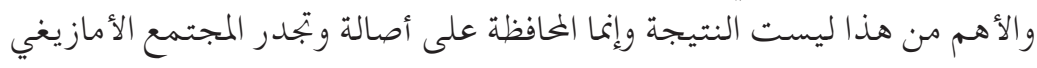
في التاريخ عن طريق هذه الاحتفاليات.

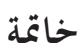

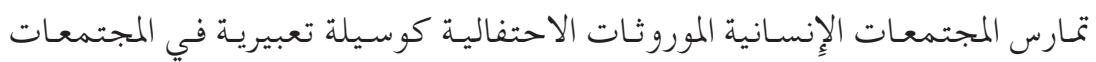

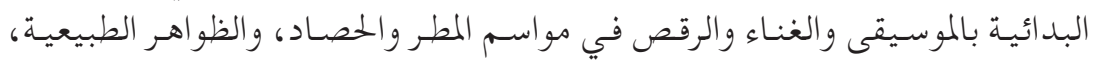

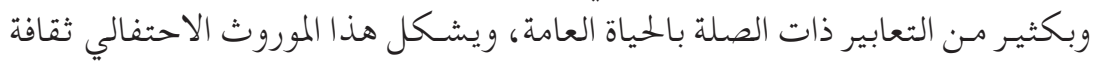
اجتماعية لا بد من الاستفادة منها.

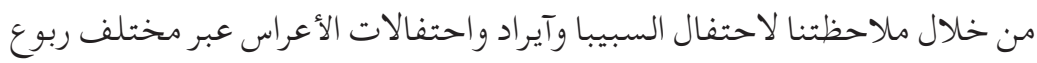

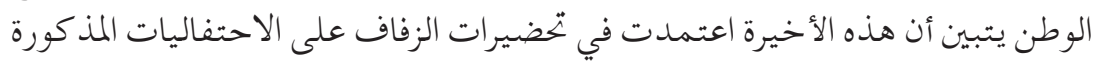

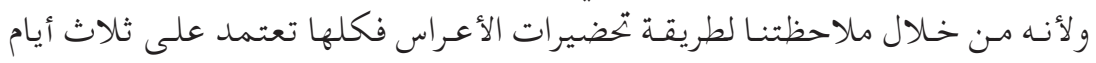
15 يوسف أوقاسم: باحث في التراث ورئيس جمعية السبيبا سابقا. 


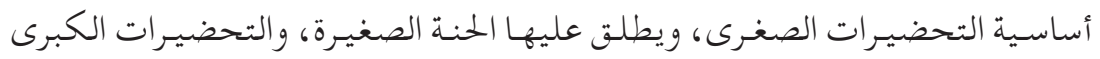

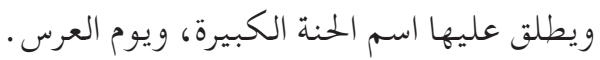

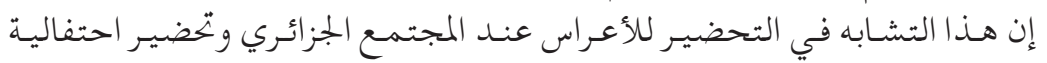

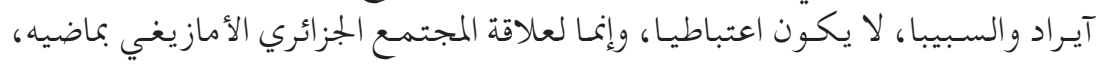

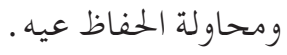
فالأيرادية الصغرى التي تقام صباح يوم العاشر، والتي يتم فيها رفع علم آيراد ثم

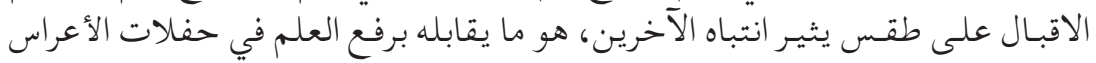

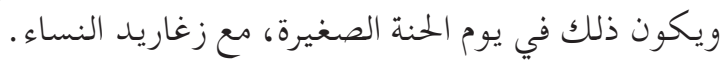

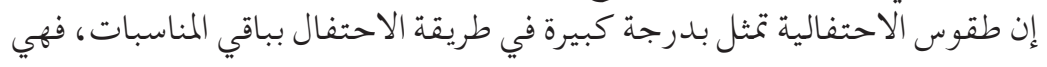

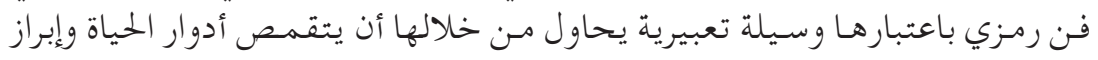
الأفكار و النصائح

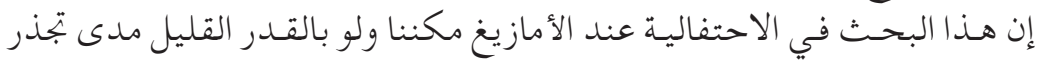

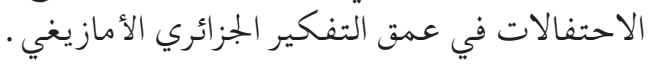





\title{
مظاهر الإحتفال بعيد يناير عند الأمازيغ تبعز

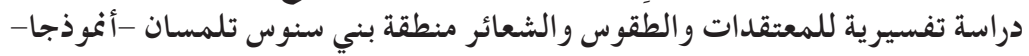 \\ LAS MANIFESTACIONES DE LA CELEBRACIÓN DE LA FIESTA DE ENERO DE LOS AMAZIGH \\ Un estudio interpretativo de creencias, rituales y leyendas \\ en la zona de Beni Snous, Tremecén, como modelo
}

\author{
نصيرة بكوش ونعيمة رحماني \\ Necera Bekkouche y Naima Rahmani \\ Universidad de Tremecén
}

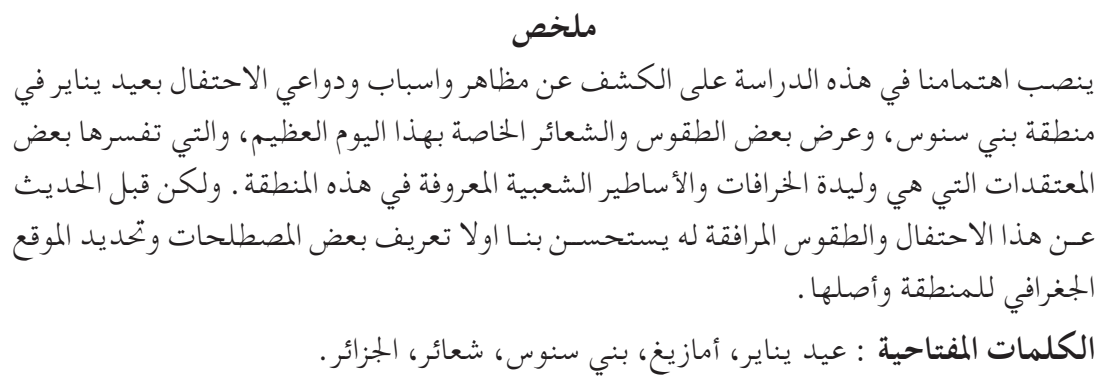

\section{Resumen}

En este estudio intentamos dar a conocer las razones de la celebración de la fiesta de enero por los amazigh en la ciudad de Banī Snūs (Tremecén). Expondremos algunos aspectos de los rituales de este gran día, que se explican por algunas de las creencias que son el resultado de las conocidas leyendas populares en esta zona de Argelia.

Palabras claves: Fiesta de enero, amazigh, Banī Snūs, leyendas, Argelia. 


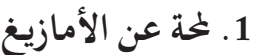

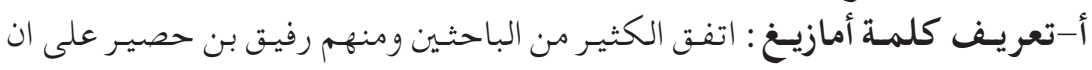

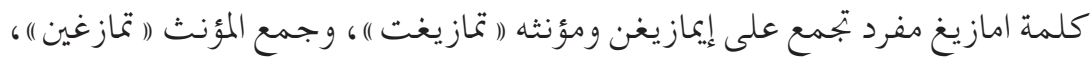

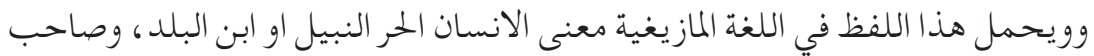

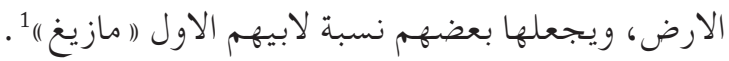

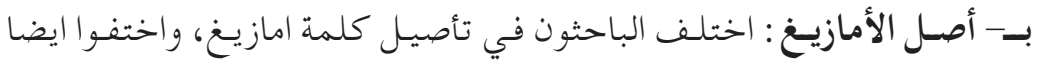

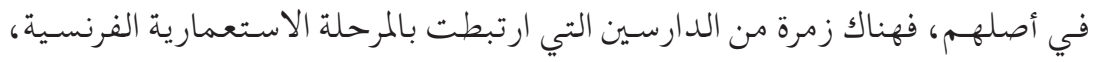

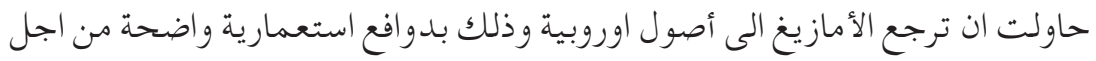

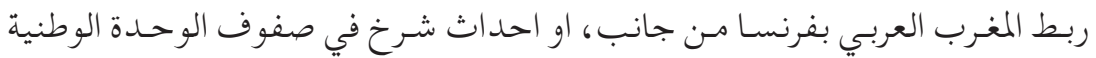

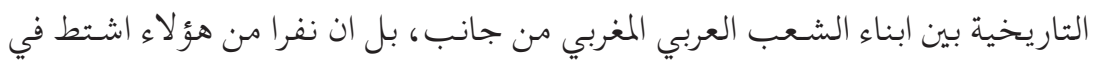

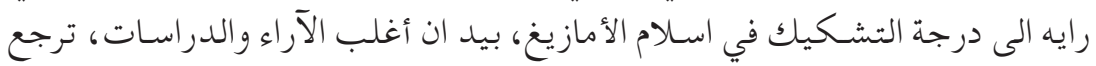

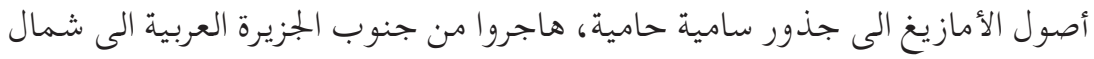

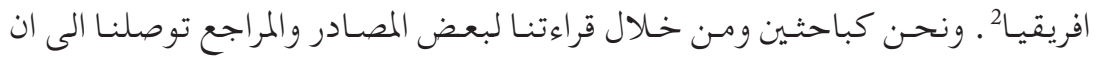

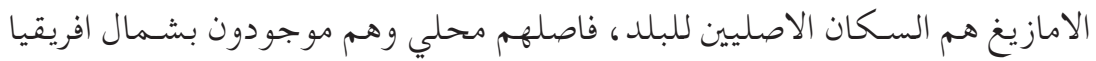

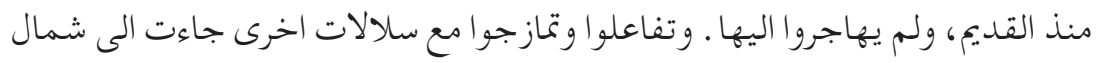

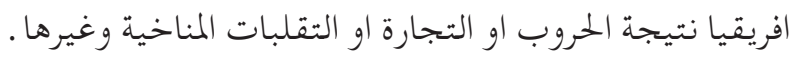

2. تحديد موقع بني سنوس وأصلهم و معنى تسميتهم

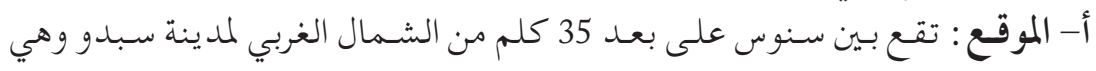

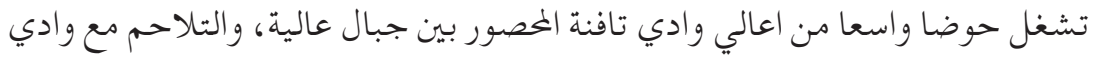

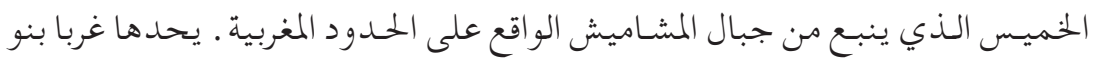

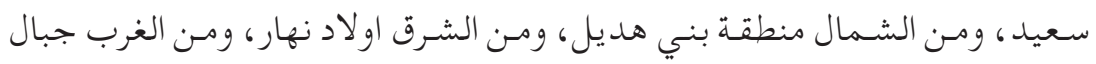

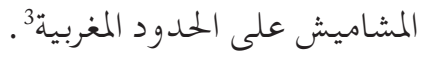

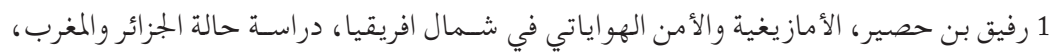

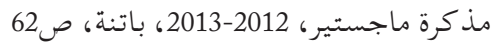

$$
2 \text { رفيق بن حصير، المرجع السابق، ص صن } 70
$$

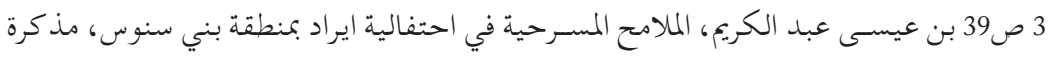

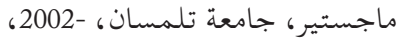


بـ- التسـمية و معنـاهـا : أصل كلمة (ا بني ) هي (( بن ) ) وفي اللغـة العربية (ا ابن )) وفي مقابل اللغة الامازيغية (( ايت )) و واسم بني سنوس مشتق من كلمة بربرية (( سنوس ))

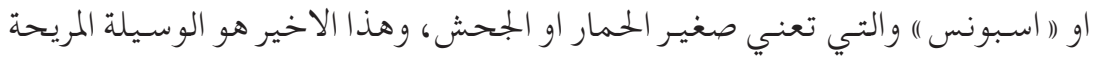
للتنقل في المنطقة، و كان حيو انا اليفا و مستغلال بكثرة في شمال افريقيا، ولهذه الاهمية

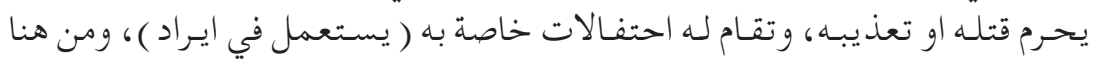
جاءت التسمية البربرية Ayt-asnus، وقد كانت تلدعى فيما مضى (( سنوسا ))، وبعلهـا الجبل الاخد

جـ- أصل بيني سنوس : يرجع نسبهـم الى قبيلة زناتة، وزناتة كما عرفها الباحثون

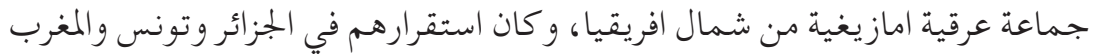

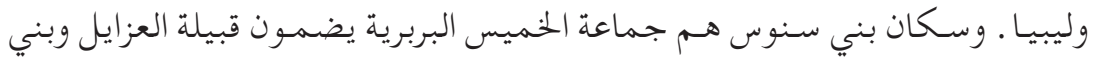

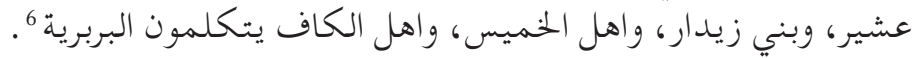

\section{3. الإحتفال بعيل يناير في منطقة بني سنوس}

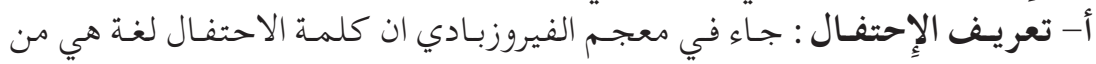

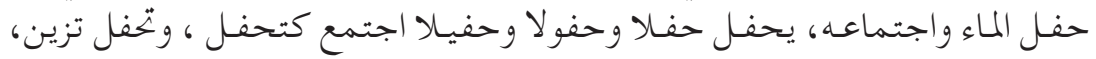

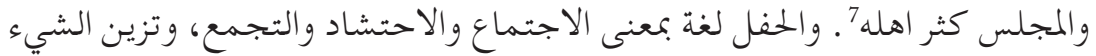
ووضوحـه، وهـو لا يبتعد كثيـراعن المفهوم الاصطلاحي للحفل، والاحتفال باجتماع

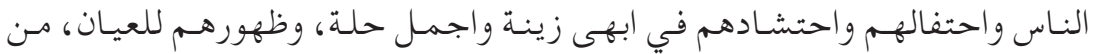

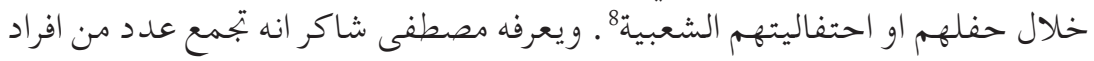
المجتمع، بهدف التعبير عن وجهات نظر مشتر كة بفعاليات منظمة رمزية، تؤدى في مئي مناسبات معلو مة 9.

4 بجاة العجال، الطقوس الاحتفالية في المجتمع الجزائري خلال العهد العثماني 1518-1830، دراسة

في الاحتفالات الشعبية الدينية، مذكرة ماستر ، حامعة الوادي، كادئ،

5 Mohamed Sanidji, "Venveine fiannée » coutume et traditions du pays des Bensous, édition : Där El Gharb, tome 1, 2001, pp. 32-34

6 ادموند ديسـتان، بن حاجي سـراج، بني سـنوس في النصف الاول من القرن العشرين، تقديم

وتعريب محمد حمداوي، موفم للنشر، 2011م، ص صناجي 75

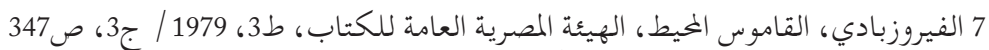

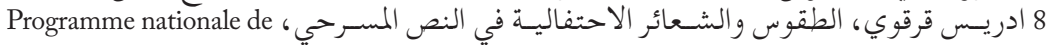

recherche culture et civilisation, PNR, 25, édition DGRSDT CRASC 9 مصطفى شاكر سليم، قاموس الانثروبولوجيا، جامعة الكويت، ط1، 1981، ص161. 
يتزامن الاحتفال بعيد يناير في منطقة بني سـنوس في اليوم الثاني عشـر والثالث

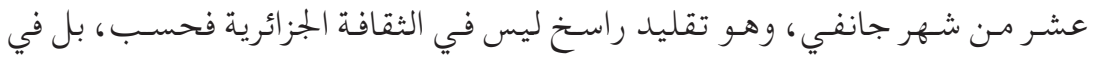

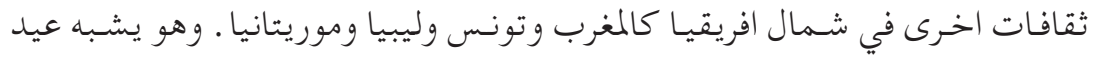

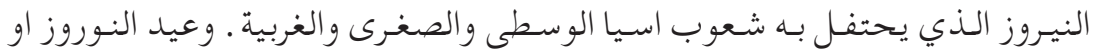

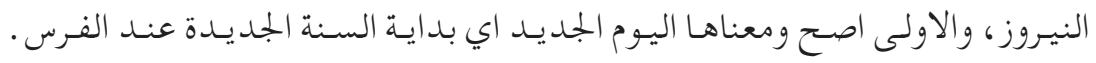

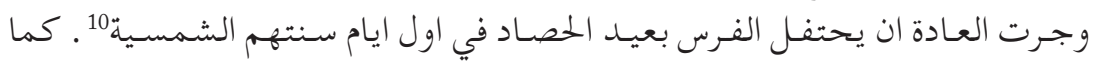

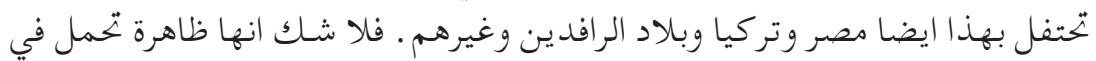

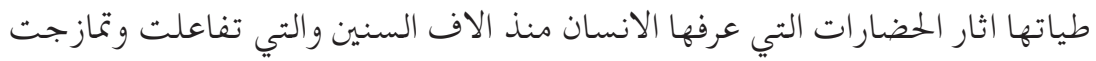

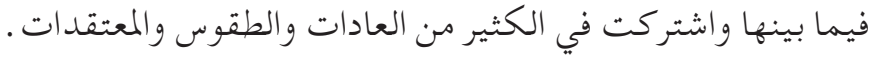

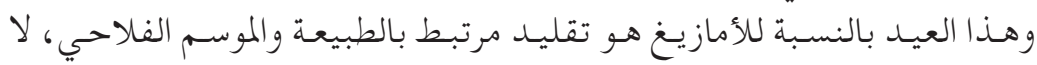

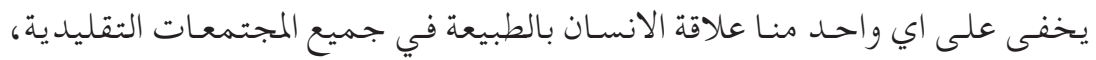

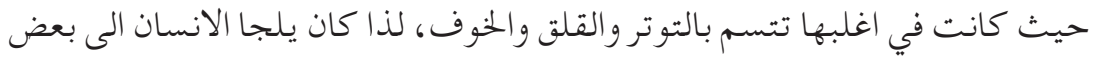

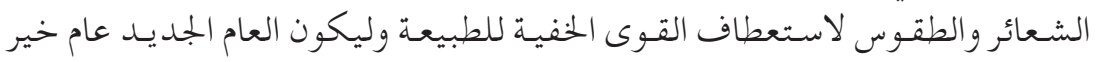
وبركة ورزق وفير.

وهـذه الشعائر والطقوس التي يقـوم بهـا الانسـان ليتقرب مـن الطبيعة والسـيطرة

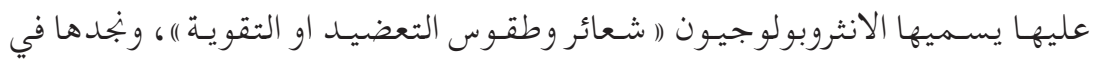

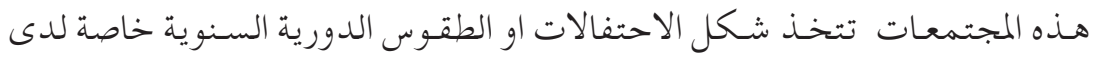

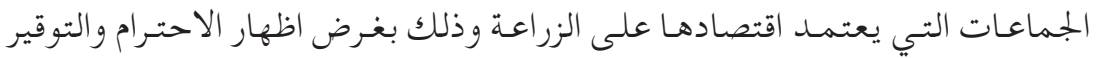

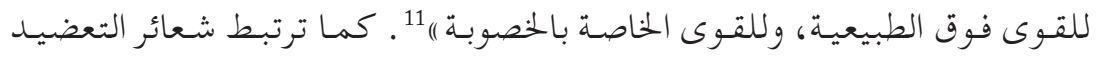

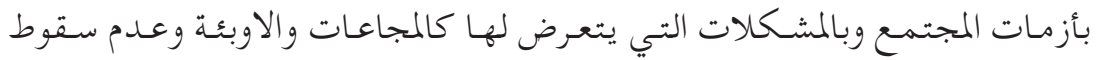

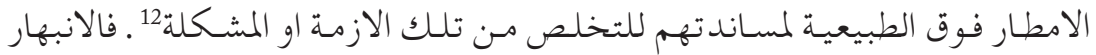

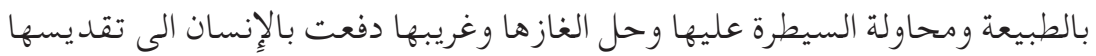

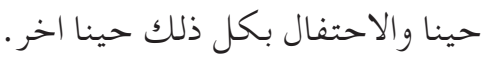

10 احمد مختار العيادي، في التاريخ العباسي والاندلسي، دار النهضة للطباعة والنشر، بيروت، 1971، ص190.

11 مرفـت العشـماوي، دورة الحياة، دراسـة للعـادات والتقاليد الشـعبية، دار المعرفـة الجامعية، 


$$
\text { ويحمل الاحتفال بعيد يناير حسب الباحثين معنيين: }
$$

المعنى الأول : تعود حكاية راس السنة الامازيغية الى يوم انتصار الملك الامازيغي

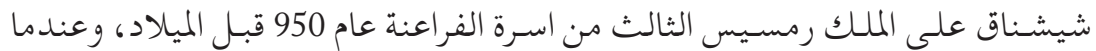
عزم الملك رمسيس على احتلال شمال افريقيا وحسب اعتقاد الامازيغ ان المعركة درات رحاها في منطقة بني سنوس، باحد المرتفعات الجبلية بين قريتي بني زدار وبني عشير،

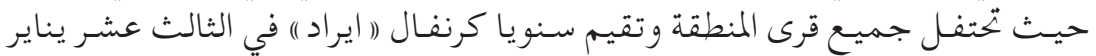
من كل سنة . وتعني كلمة (ا ايراد ) الاسد ربما مقارنة لقوة ملكهم شيشناق وسلطانه بسلطان الغابة الاسد 13.

المعنى الثاني : تفسره اسطورة شائعة عند البربر القدماء تسمىى (( اسطورة العجوز ))

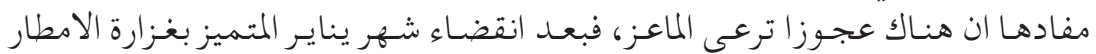

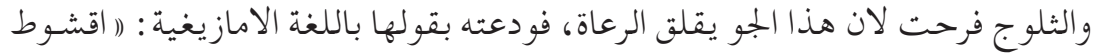
اثيطيك اعمي يناير )، و وهذه العبارة تفيد التشفي من رحيل شهر يناير، فغضب فئب يناير من موقف العجوز ، فقصف شهر فبراير طالبا منه ان يعيره يوما واحدا حتى ينتقـم من العجوز قائلا له :

$$
\text { اتخيلك اعمي فورار ارضهي ليلة ونهار }
$$

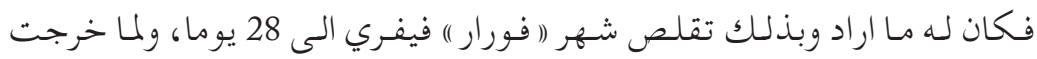

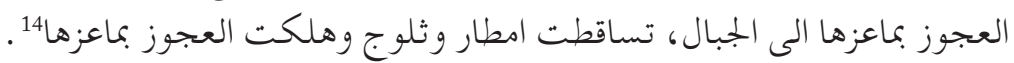

\section{4 ـ شعائر وطقوس الإحتفال بعيد يناير}

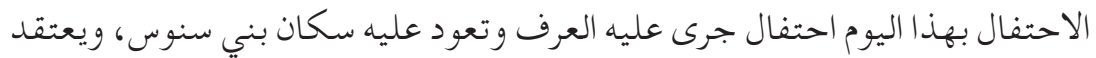

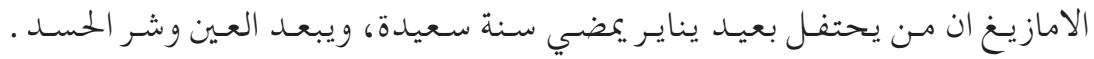

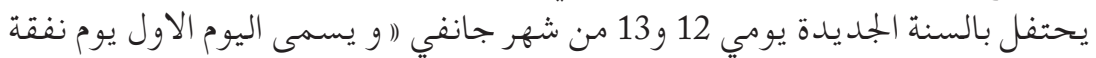

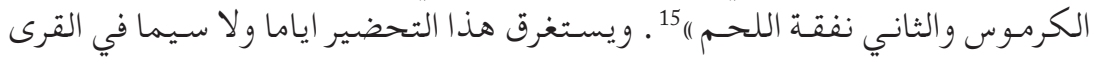
الجبلية . واول هذه التحضيرات ان تجمع النساء الحطب من الغابة وانو اعا من النباتات

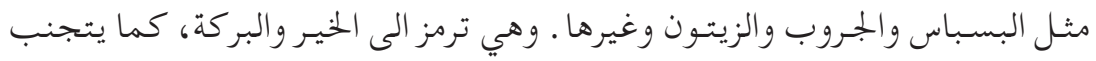

$$
\begin{aligned}
& 13 \text { عبد الكريم بن عيسى، مرجع سابق، ص46 } \\
& 14 \text { نجاة العجال، مرجع سابق، ص39 } 159 \\
& 15 \text { المرجع نفسه، صناه المنال }
\end{aligned}
$$




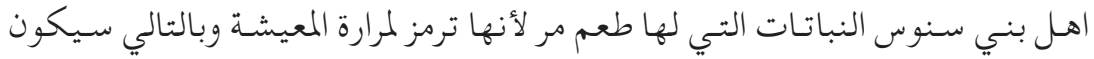

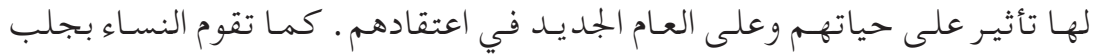

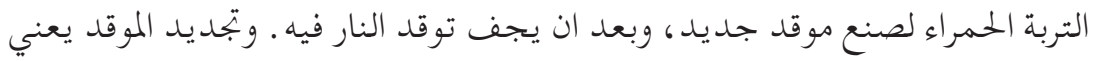

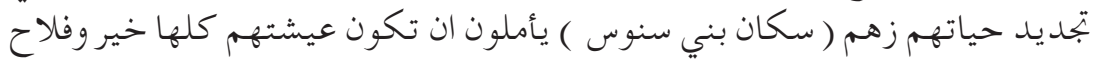

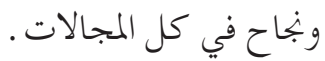

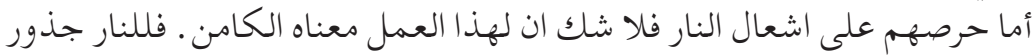

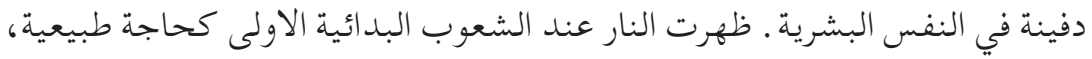

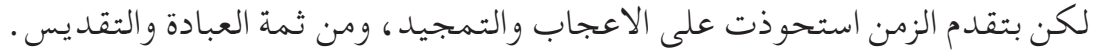

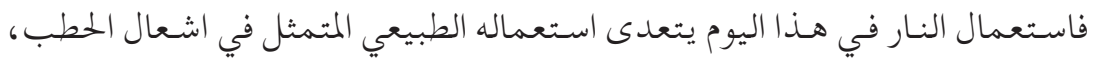

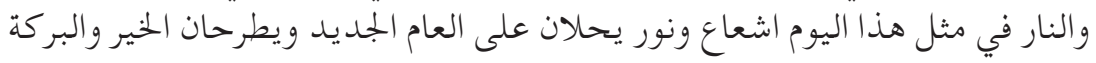

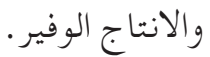

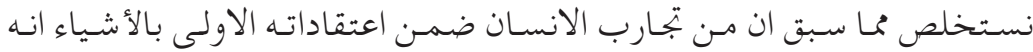

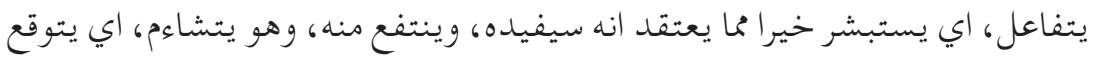

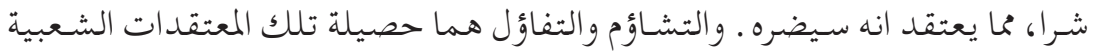

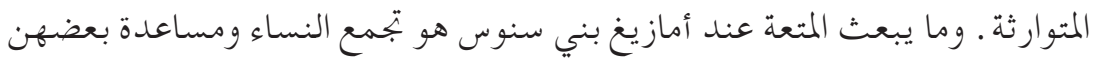

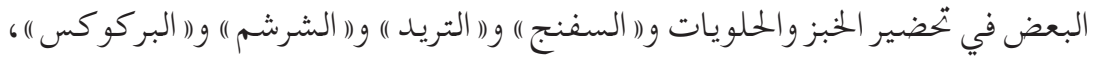

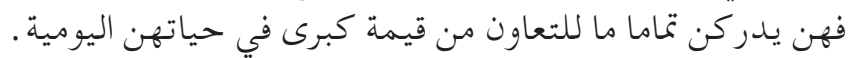

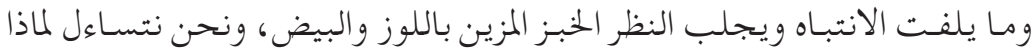

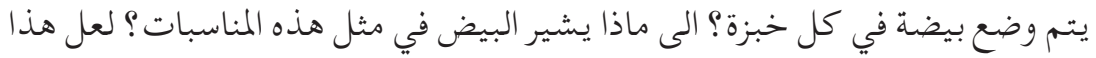

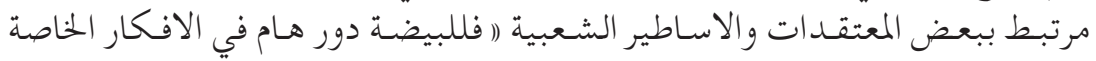

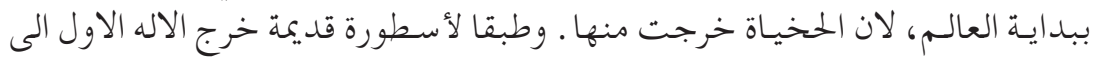

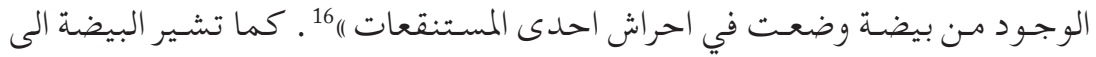

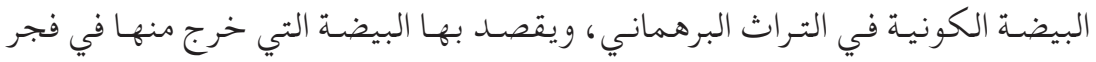

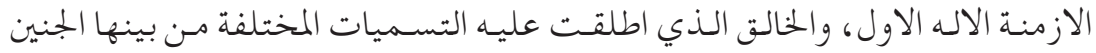

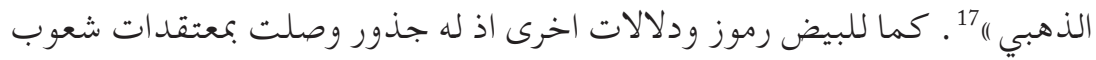

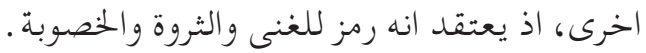

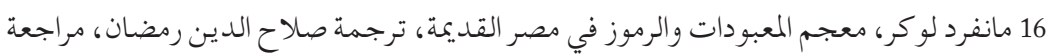

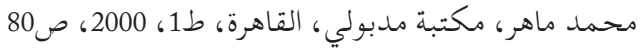

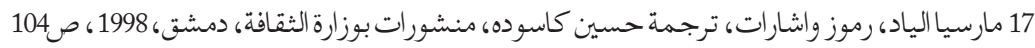




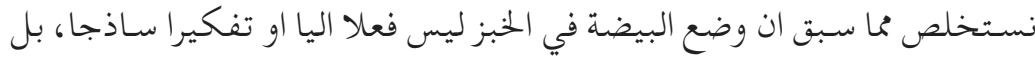

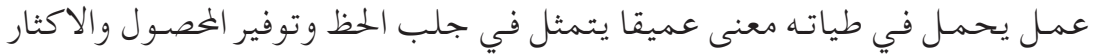

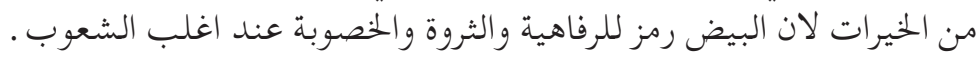

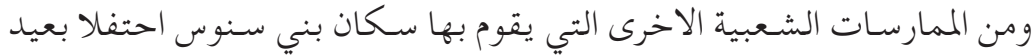

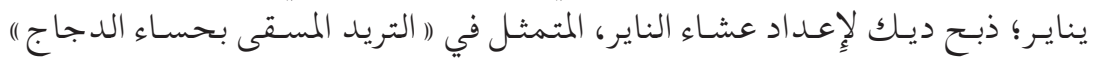

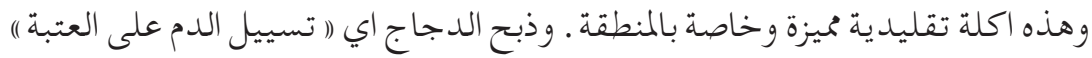

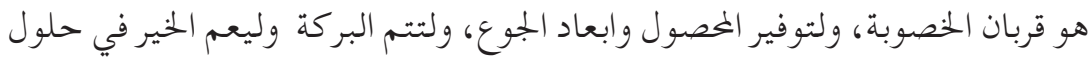

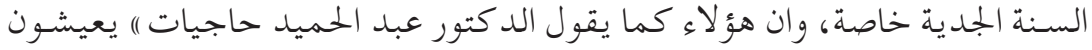

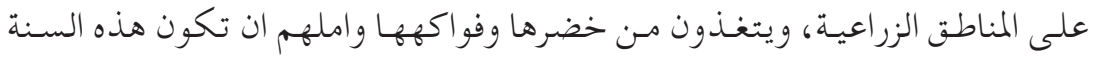

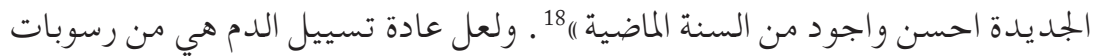

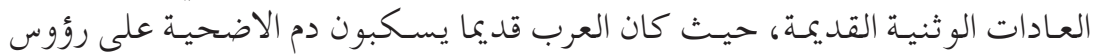

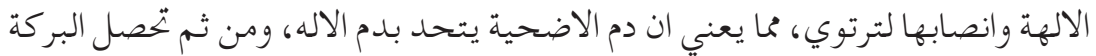

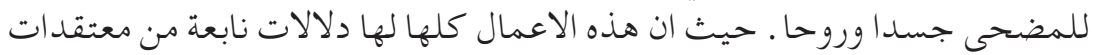

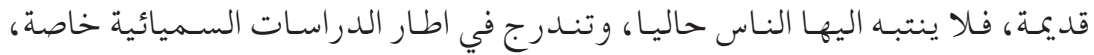

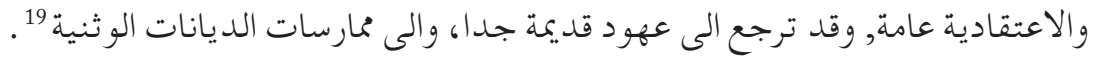

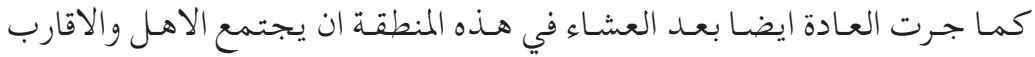

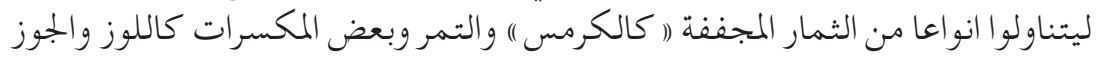

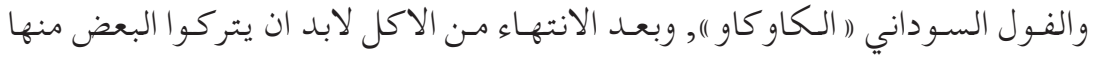

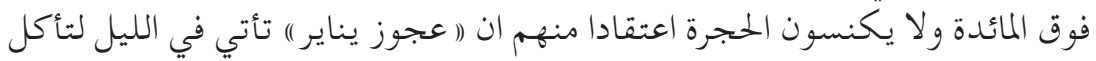

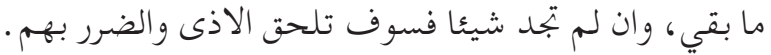

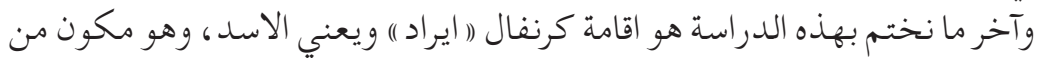

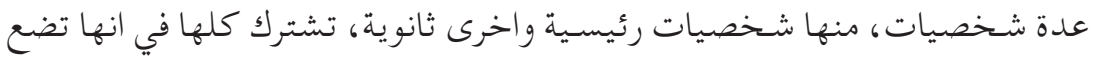

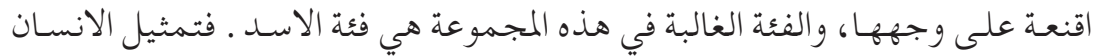

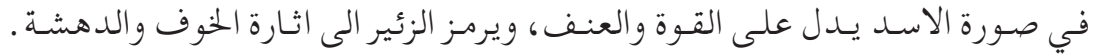

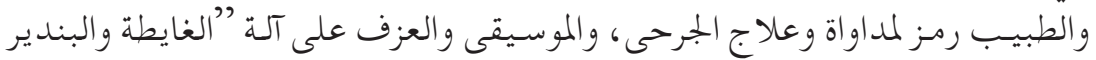

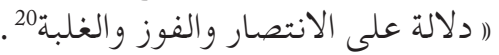

18 عبد الحميد حاجيات، محاضرة عيد يناير، جامعة تلمسان، 2002م 19 المرجع نفسه 20 للتوسع اكثر انظر محاضرة الدكتور عبد الحميد حاجيات، مرجع سابق. 
هـذه الطقوس والشعائر و التي تكـون لفظيـة وحركيـة، هـي في الاصل فعل يقوم

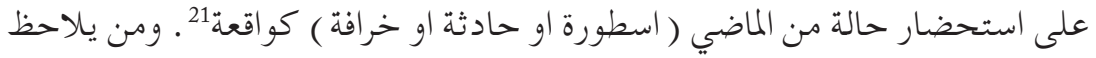

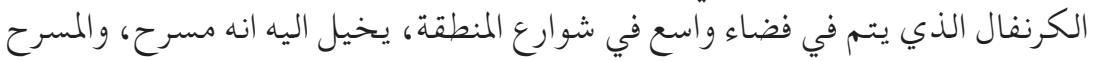

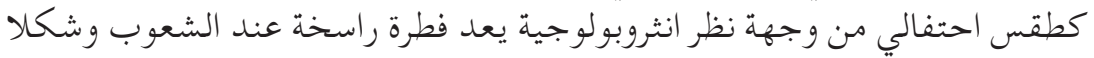

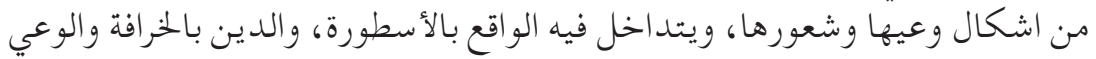

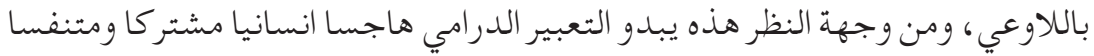

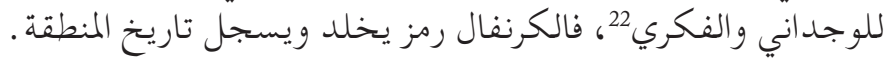

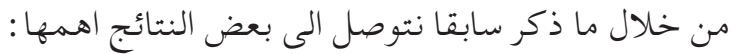

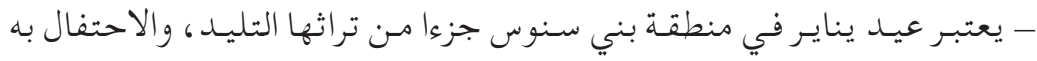

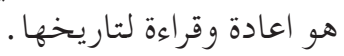

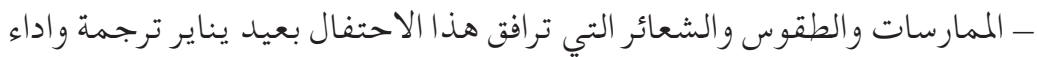

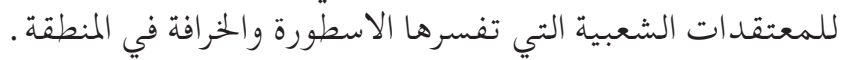

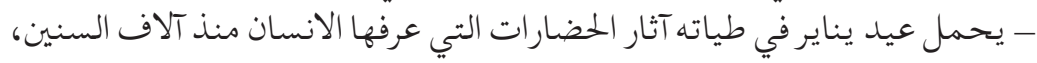

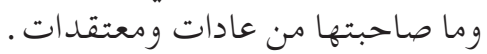

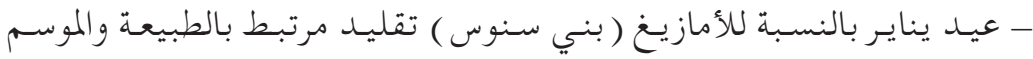

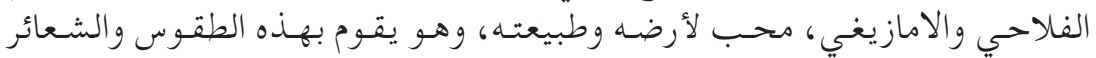

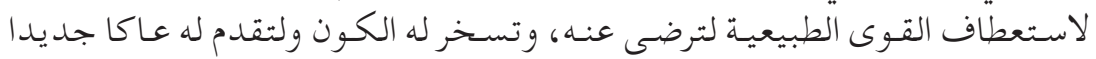

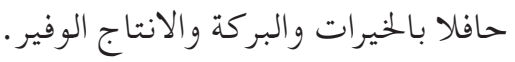


97 Las manifestaciones de la celebración de la fiesta de enero de los Amazigh

\section{قائمة المر اجع والمصادر :}

ـ احمد مختار العيادي، في التاريخ العباسي والاندلسي، دار النهضة للطباعة والنشر، بيروت، 1971

- ادريس قرقوي، الطقوس والشعائر الاحتفاليـة في النص المسـرحي، Programme Nationale de Recherche Culture et Civilisation, PNR, 25, édition : DGRSDT CRASC - ادموند ديستان، بن حاجي سراج، بني سنوس في النصف الاول من القرن العشرين،

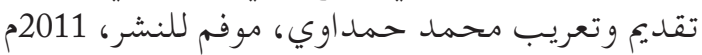

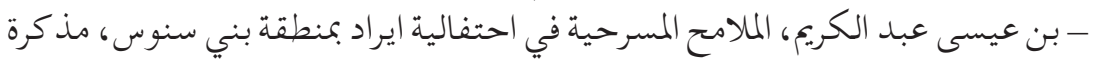

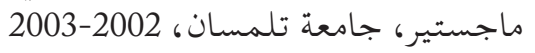

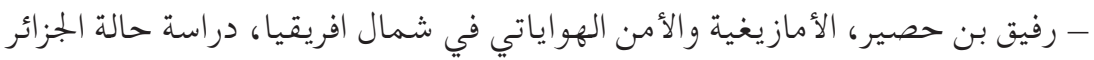

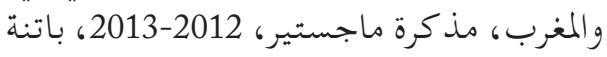

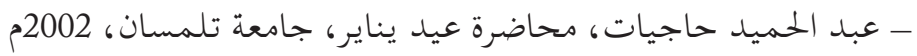

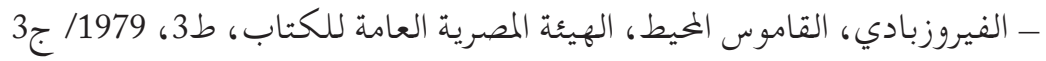

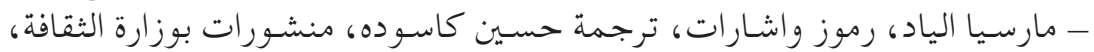
دمشق، مارس 1998

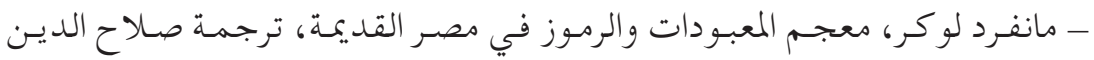

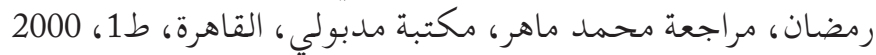

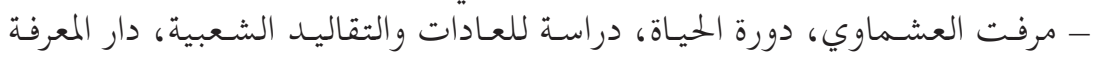

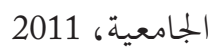

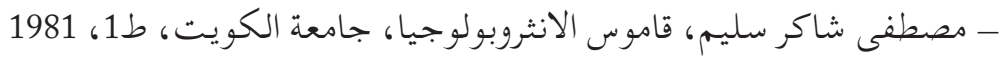

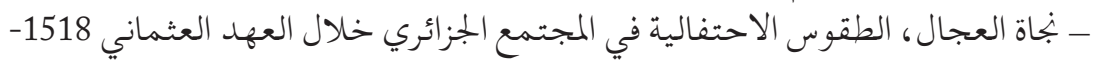

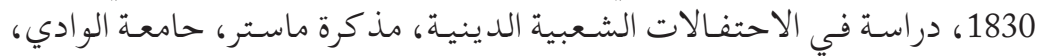
2014/2013

- Mohamed Sanidji, Venveine fiannée : coutume et traditions du pays des Bensous, édition : Dar El Gharb, tome 1, 2001. 



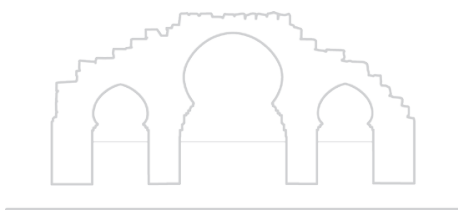

Reseñas y comentarios bibliográficos 

Mohand Akli Haddadou, Introduction à la littérature berbère suivi d'une Introduction à la littérature kabyle, Tizi-Ouzou, Haut Commissariat à l'Amazighité, 2009, 308 pp.

[ISBN: 978-9961-789-93-3]

Ciertamente la presente es una obra ya bastante antigua, de difícil localización y tal vez no de las más ajustadas para hacerse una idea historiográfica y geográficamente completa del fenómeno literario amazigh. Creemos sin embargo que, ante la falta de familiarización con las publicaciones especializadas, $y$ las pocas referencias que tenemos en lengua española, el volumen de Mohand Akli Haddadou puede ser excusa suficiente para adentrase y dar una serie de hitos en la bibliografía más o menos disponible.

El interés español por los estudios amazighs, berberología o las culturas preislámicas del norte de África tienen sin duda una gran tradición, comenzando por el hito de Julio Caro Baroja, Estudios Saharianos (1955). El vínculo histórico es evidente, desde la conquista islámica por Tariq ibn Ziyad y su ejército de bereberes, hasta los imperios de almorávides y almohades o el protectorado español del Rif. El vínculo étnico hoy en día parece menos claro, pero fue entusiastamente reivindicado desde Portugal por Oliveira Martins en su Historia da civilizaçao ibérica:

É nas instituções que nós vamos encontrar singulares traços de afinidade entre os Cabilas, entre o que a histórica nos diz da Espanha, e o que por debaixo das formas sociais, impostas pela civilização romana e germânica, encontramos ainda hoje no carácter e nos costumes peninsulares. A djemâa, ou aldeia das tribus do Atlas, assemelha-se de um modo tão notável ao pueblo español que é lícito supor na Espanha pré-romana djemâas constituídas pelos conquistadores em municípios e que sob esta forma vieram até nós ${ }^{1}$.

Para Martins los íberos eran población camítica europeizada, aunque los conflictos tribales aparecían a lo largo de la historia peninsular. Resulta reseñable en esta línea la búsqueda de los orígenes del euskera en

1 Oliveira Martins en su História da civilização ibérica, Mem Martins, Europa-América, [s.a.], p. 34. 
una posible afinidad con las lenguas ancestrales del norte de África. Así fueron surgiendo a comienzos del siglo $\mathrm{xx}$ interesantes y cuando menos entretenidos trabajos de lingüística comparada: Antonio Martínez $\mathrm{Pa}$ jares, El vascuence y el beréber. Estudio crítico de algunas de sus afinidades, Madrid, Imprenta Helénica, I9I9.

Tetuán se convirtió en el siglo xx en centro de la imprenta española africana y africanista, con edición de numerosas revistas, periódicos y monografías. Entre ellas muchas dedicadas a la cultura rifeña y su lengua, para uso de militares o no, entre otras: Ginés Peregrín, Rudimentos de bereber rifeño, Tetuán, Imprenta el Mahdia, I944. De forma más sólida, aunque esporádica, en la segunda mitad del siglo xx aparecieron apreciables esfuerzos con criterios cada vez más académicos: Ángel Muñoz Bosque, Manual de conversación bereber rifeña. Estudio práctico de la lengua bereber amaciga, Xéljha o zamáçijz del Rif, Madrid, Imprenta Isaac Martínez, [s.a.]; Esteban Ibáñez, ofm, Diccionario español-senhayi (dialecto bereber de senhaya de Serair), prólogo de José Díaz de Villegas, Madrid, Csic, I959; Omar Ouakrim, Fonética y fonología del bereber, Barcelona, Universitat Autònoma de Barcelona, 1995, y la reciente edición de Pedro Hilarión Sarrionandia, Gramática de la lengua rifeña, Barcelona, Bellaterra. Barcelona, 2007; y Diccionarios Español-Rifeño y Rifeño-Español, Barcelona, Bellaterra, 2007. En la actualidad las plazas de Ceuta y Melilla albergan numerosa población, autóctona o no, cuya lengua materna es el rifeño, de modo que es natural que comiencen a aparecer manuales básicos para la enseñanza y aprendizaje de la lengua, por ejemplo Jahfar Hassan Yahia, Tigri n tutlayt tamazig̀t tarayt tamezwarut. Curso de lengua tamazight nivel elemental, Melilla, Geepp Ediciones, 2014. ${ }^{2}$ Cabe citar, por último, los brillantes y recientes esfuerzos de Mohamed Meouk por desarrollar a pasos agigantados el interés en España por estos estudios, aunque algunas de sus publicaciones no se escriban en español, como la excepcional La langue berbère au Maghreb médiérval: Textes, contextes, analyses, Leiden, Brill, 2015.

La laguna de la bibliografía española es mayor si cabe en cuanto a la literatura propiamente dicha, pues son escasísimos los textos, divulgati-

2 Al que se puede acceder electrónicamente: <http://www.melillatamazight.es/wp-content/ uploads/2015/02/LIBRO_CURSO_DE_LENGUA_TAMAZIGHT_NIVEL_ELEMENTAL.pdf> 
vos o especializados, que permiten adentrarse en la literatura de lengua amazigh. Alguna excepción puede citarse, como por ejemplo Uwe Topper, Cuentos populares de los bereberes, Madrid, Miraguano, 2003.

En fin, seguro que se nos escapaban muchas referencias, e ignoramos libros que se podrían haber citado. Pero parece bastante innegable que el estado actual no difiere demasiado de la historiografía española en torno a la cultura bereber, que no ha sido nunca muy voluminosa a pesar de la cercanía geográfica y el interés que tiene para la propia historia de la Península. Contrasta más si se compara con la producción en lengua francesa, en la cual se escribe la monumental Encyclopédie berbère desde I984, proyecto reconocido por la UnEsco.

Lo cierto es que en la propia Argelia, hasta no muy recientemente, eran unos estudios poco atendidos, reconocidos y apreciados, por lo demás ahogados en una diglosia lingüística y una búsqueda de identidad que dificultaban la claridad de ideas, y tal vez todavía lo sigan haciendo. En efecto, al leer el libro de Mohand Akli Haddadou lo primero que llama la atención es su consideración como autores bereberes a los latinos Terencio y Apuleyo, a los cristianos San Agustín y Arnobio, a los árabes Makkī ibn Abū Ṭālib e Ibn Rašīq, y a los francófonos Mouloud Feraoun y Kateb Yacine. Y haciendo un repaso a las vidas y obras (en latín, árabe y francés) de estos autores se pasan las veinticinco páginas de la Introduction à la littérature berbère. Se considera por lo tanto que la literatura bereber es aquélla escrita en cualquier lengua, siempre que su autor sea norteafricano y haga, de algún modo, reivindicación de su condición de magrebí. No parece un criterio literario demasiado adecuado si de lo que se trata es de reconstruir un mundo cultural precisamente oscurecido y silenciado por los autores que han colmado y colonizado el canon norteafricano. Creemos que haría falta un criterio paleográfico, sin duda de arqueología literaria, que comenzara tal vez por la antropología y la oralidad. Por lo menos a este incipiente cometido, bastante más razonable, se dedica la mayor parte del volumen, en su segunda parte denominada Introduction à la littérature kabyle.

En este caso las obras sí están transmitidas o escritas en la variante cabileña de la lengua amazigh, haciendo al mismo tiempo un trabajo de campo recopilatorio y una antología de las tradiciones orales exis- 
tentes, organizadas en cuatro géneros: el proverbio (anzi), la adivinanza (timserreqt), el cuento (tamacahut), y el relato breve (taqsit). El final del volumen es una antología de más de cien páginas con un Corpus inédits de textes Kabyles (Région des At Waylis, vallée de la Soummam). Se reproducen textos pertenecientes a los cuatro géneros estudiados de forma ordenada, incluyendo texto en grafía latina y lengua cabileña, y traducción francesa.

El volumen por lo tanto ofrece una incipiente transformación del criterio para recuperar un mundo literario necesario en el futuro cultural del norte de África, conditio sine qua non para la normalización histórica e identitaria de naciones que han surgido en la lucha frente al otro, sin indagar quizá lo suficiente en la diversidad y riqueza de su patrimonio humano. Así lo van señalando libros recientes como el de Fazia Aïtel, We are Imazighen: The Development of Algerian Berber Identity in Twentieth-century Literature and Culture, Gainesville, Universidad de Florida, 20I4. El texto de Mohand Akli Haddadou, aunque antiguo y quizá todavía demasiado preliminar, nos esta mostrando que en el siglo XxI la recuperación cultural del mundo beréber es condición necesaria para suturar las heridas del pasado y dignificar un patrimonio excepcional y único de los pueblos del Mediterráneo occidental.

IsAAC Donoso

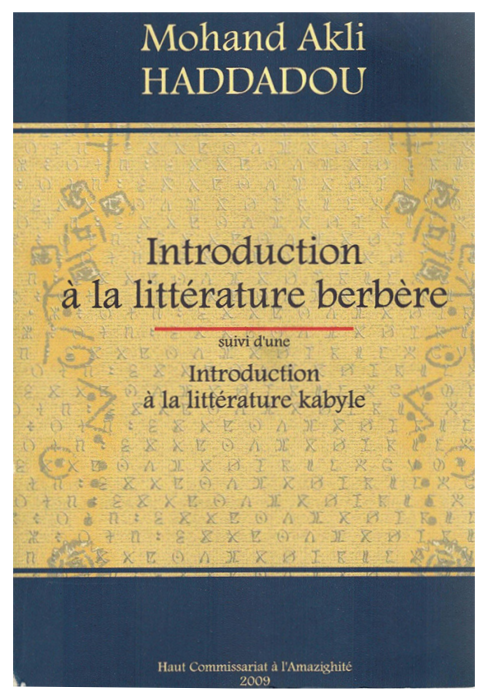




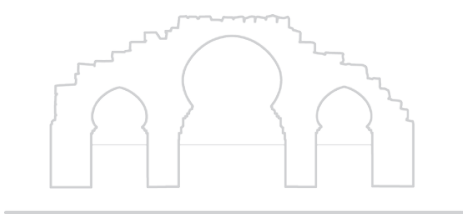

Biblioteca 



\title{
Algeria
}

\section{The Dwellers in the Garden of Allah}

\author{
By A. MacCallum Scott, M.A., M.P. \\ Author of "Barbary : The Romance of the Nearest East"
}

\begin{abstract}
A
LGIERS, say the Arabs, is like a diamond set in emeralds. The terraces of its white walls and flat roofs rise in a pyramid up the steep hillside, that looks eastward over the far-stretching bay to the distant violet and snowpatched peaks of the Diurdiura Mountains. It is embosomed in the vivid greenery of palms and orange and lemon groves, from the midst of which, like outlying
\end{abstract} pearls, peep the domes and Moorish arches of palaces and villas.

This is the sight that meets one approaching from the sea. A few fishing boats, dotted over the surface of the bay, with iong, raking, lateen sails, recall vividly the swift hawk-like pirate craft which used to swoop out from this lair, and earned for Algiers the name of the Scourge of Christendom. But it is in Europe that one lands. The harbour itself, with its trim goods sheds and custom house, is of Europe.

The promenade, which runs like a high terrace above the harbour, with its long, regular $f$ açade of tall houses, is of the type that you may see in every capital in Europe. And from it the visitor drives over a well-paved street, along which electric cars are running, through a boulevard which might be Paris.

All around are ladies in Paris costumes and dapper business men. In the arcades on either side luxurious shops display a wealth of beautiful ware. In front of the cafés chairs and little marble tables

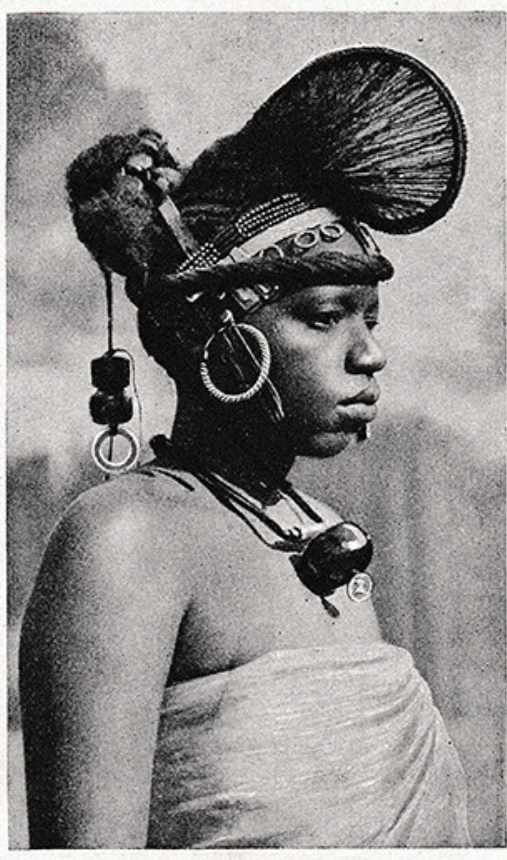

PREPARED FOR THE SLAVE TRADE Many a rich Moslem of Algeria dodges the law forbidding traffic in slaves by buying this kind of black girl, first for his harem, and then, as she grows old, for household work

Photo, Crtte invade the pavement, and comfortable citizens sit sipping their coffee. Surely France has conquered. This is not Africa, but New France.

But turn up one of the narrow passages that lead off this Parisian boulevard. Immediately we are in another world. It is as if we had been transported by enchantment to the Bagdad of Haroun alRaschid of the "Arabian Nights." We are lost in the labyrinthine galleries of a human hive. The mystery, the glamour of the East surrounds us. Fantastic figures stream past, unheedingly jostling us, living their own lives,pursuing 
ALGERIA \& THE ALGERIANS

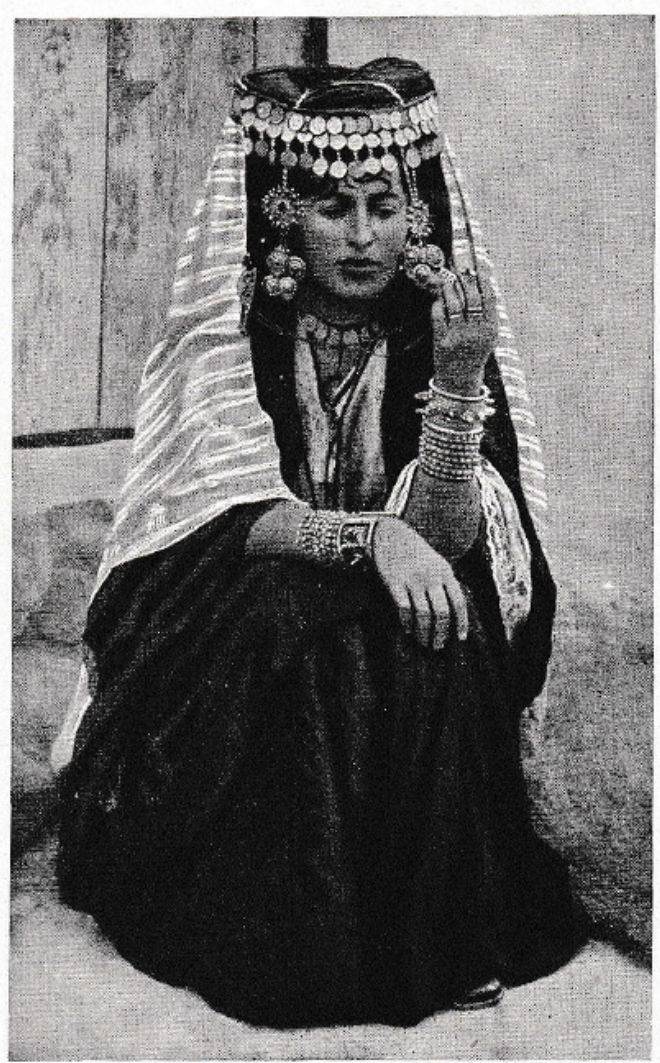

FAIR TYPE OF DESERT ENCHANTRESS

Being bred from negress captives by nomad Shawia mountaineers, the Ouled Nail tribe often produces fine Berber-like offspring, such as this highly-prized beauty, decorated in Berber silverwork, golden coins, and many rich bracelets

$$
\text { Photo, Crite }
$$

their inscrutable occupations, oblivious of the call of Western civilization a hundred yards away.

Closely-veiled women, shrouded in spotless white, flit past like shadows. Others, less scrupulously veiled, loll about in doorways invitingly open. Arabs in turbans and robes of purple and fine linen stalk past with the stately stride their ancestors acquired in the Desert. Moors, with gorgeously embroidered waistcoats and voluminous trousers gathered in at the ankle, long-haired Jews, Kabyle workmen, Mozabite traders, Biskra water-carriers and scavengers, and broadly-smiling negroes of all shades complete the throng.

The houses in the native quarter of Algiers are built on a steep hillside, and seem to rise on each other's shoulders, not in regular terraces, but huddled in accordance with all the irregularities of the site. The tiny passages between them mount the hillside like flights of stairs. They are quite impervious to horse or even mule traffic, but strings of little donkeys, laden with panniers, clamber nimbly up them. The houses overhang perilously on either side, the upper storeys being supported by long buttressing beams springing out at a sharp angle from the wall.

The shops of the native quarter have little in common with the magnificent emporiums in the French quarter. They are mere booths. Under the Turks it was dangerous for any trader to show signs of prosperity, and the air of secrecy and mystery which broods over the town is due to the instinct to conceal wealth and worldly possessions.

A vast business may be conducted from a dark little cave, which seems a mere hole in the wall. The shopkeepers are a race of troglodytes. At the tailor's there is no room for trying on a garment in the shop. The customer stands out in the middle of the street, and the vendor, with many 


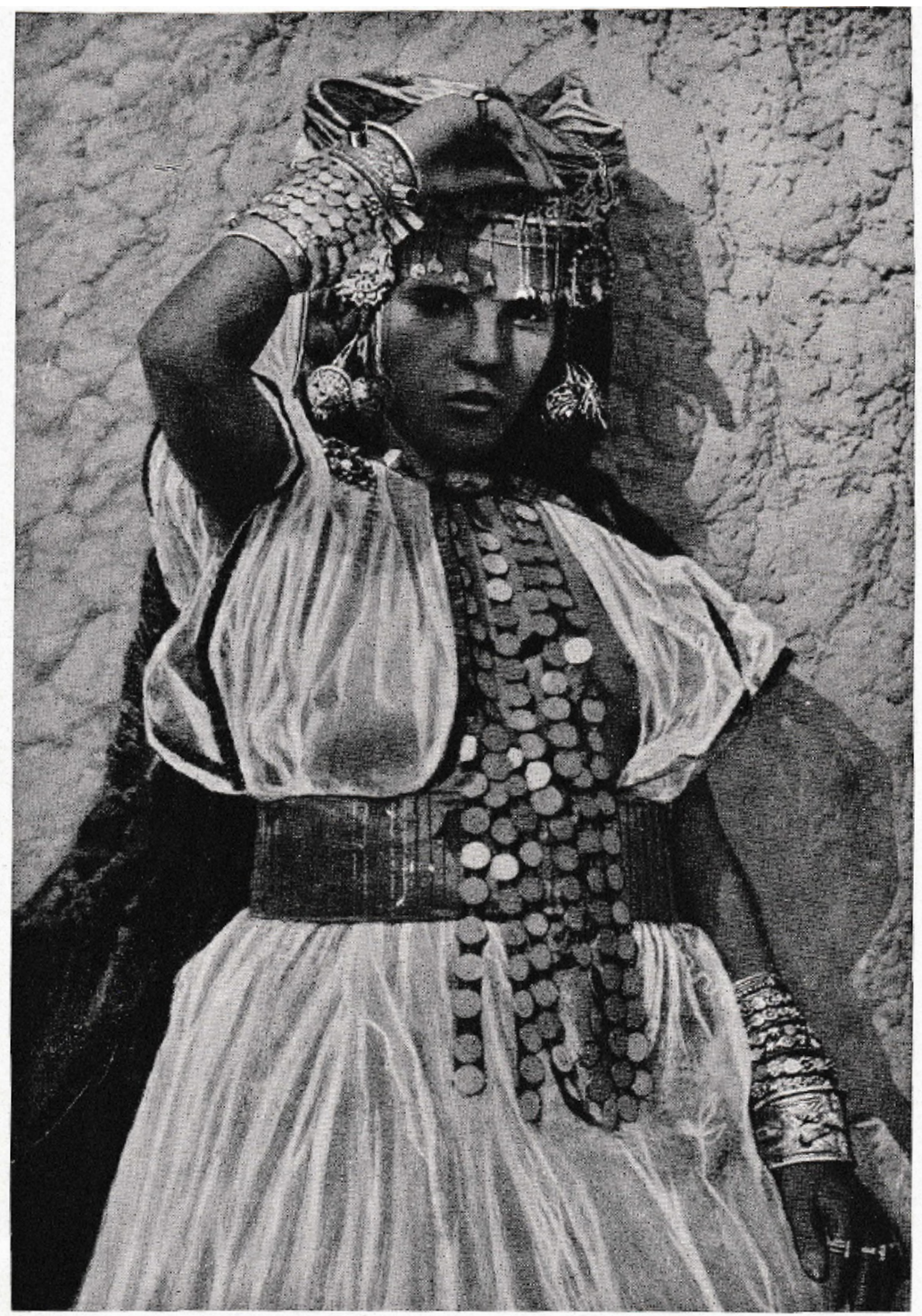

\section{A DANGEROUS BEAUTY IN SULLEN MOOD}

She has stood, until weary of attracting attention, by a wall in Biskra, this geisha of the Sahara, with her hard-won dowry of gold and silver adorning her person. She can sing Arab love-songs, play flute, hautboy, and zither, and dance more seductively than girls of any other tribe. Her zkill in making cigarettes and coffee is tamous, and all her charms and acoomplishments are for hire Photo, crets 


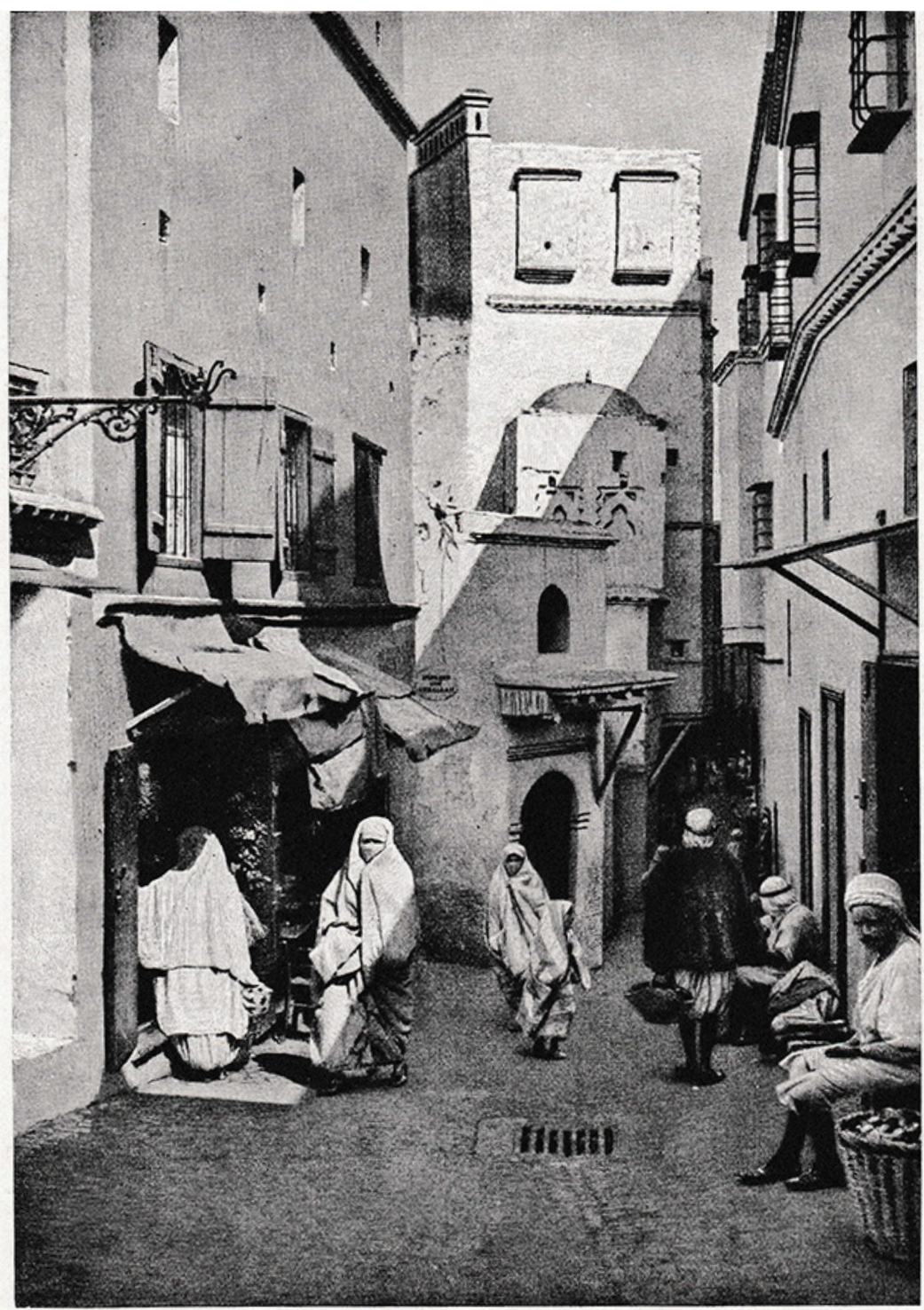

PICTURESQUE NOOK IN THE STREET OF THE ROYAL KASBAH

Above the white cascade of houses, mosques, and palaces, which is cliff-built Algiers, rises the Kasbah, the Moorish castle of the piratic old Deys. It is now a French barracks, but native life still centres, in a fine play of colour framed and dappled with white, by the old seat of power which serves as a grim reminder of the days when warfare and strife reigned supreme Photo, Critt 


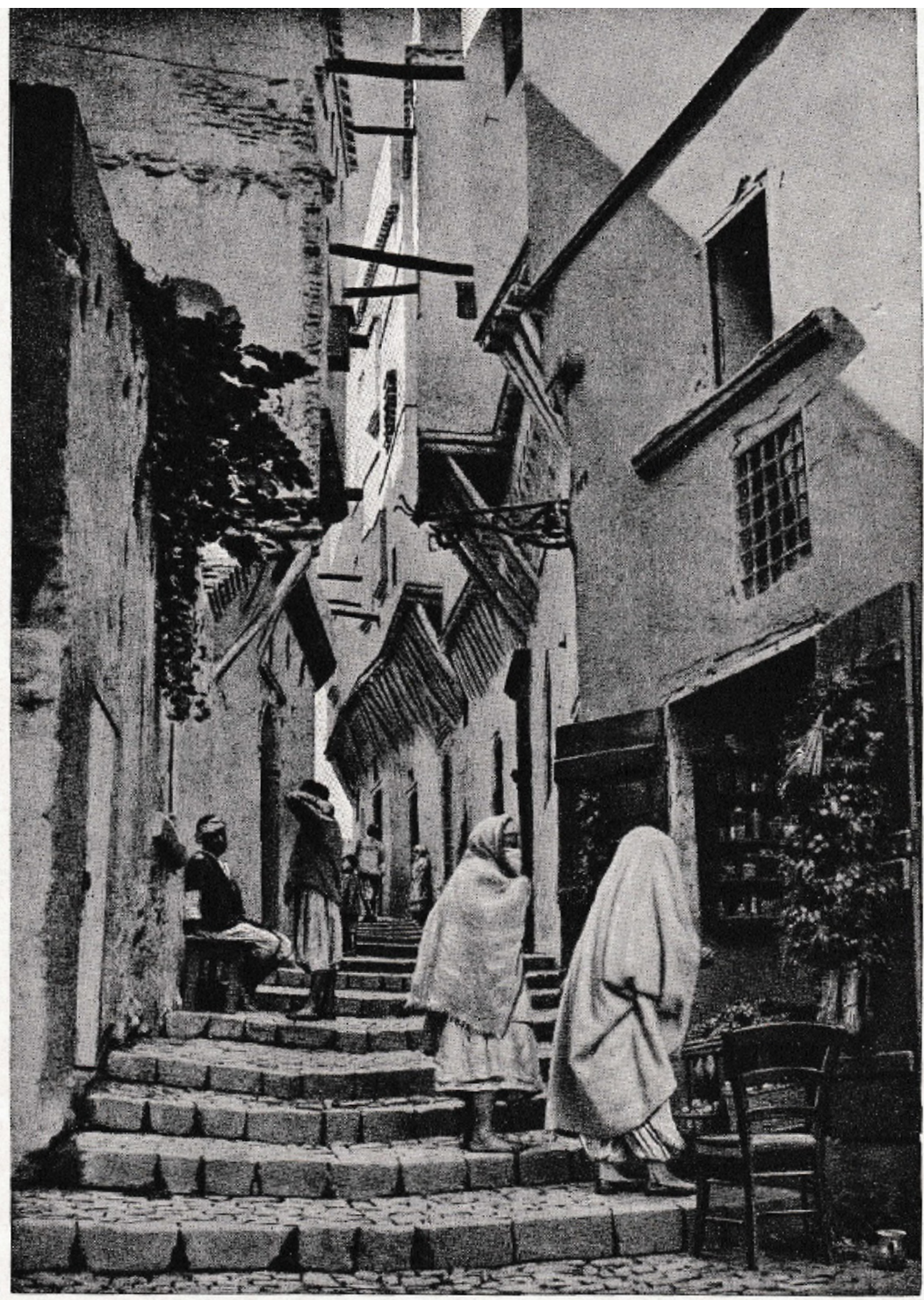

WOMEN OF THE HAREM SHOPPING IN CLIMBING ALGIERS

Many Moslem Ladies are famous tor the perfection of theit figures. Centuries of sucocsstu prracy enabled the leading Algerians to capture or purchase tens of thousands of European and Georgian girls of beauty, but in their outdoor dress, designed to conceal all their charms, the belles of Algiers resemble white toads standing on their hind teet

Phow Geotr 


\section{BibliotecA}

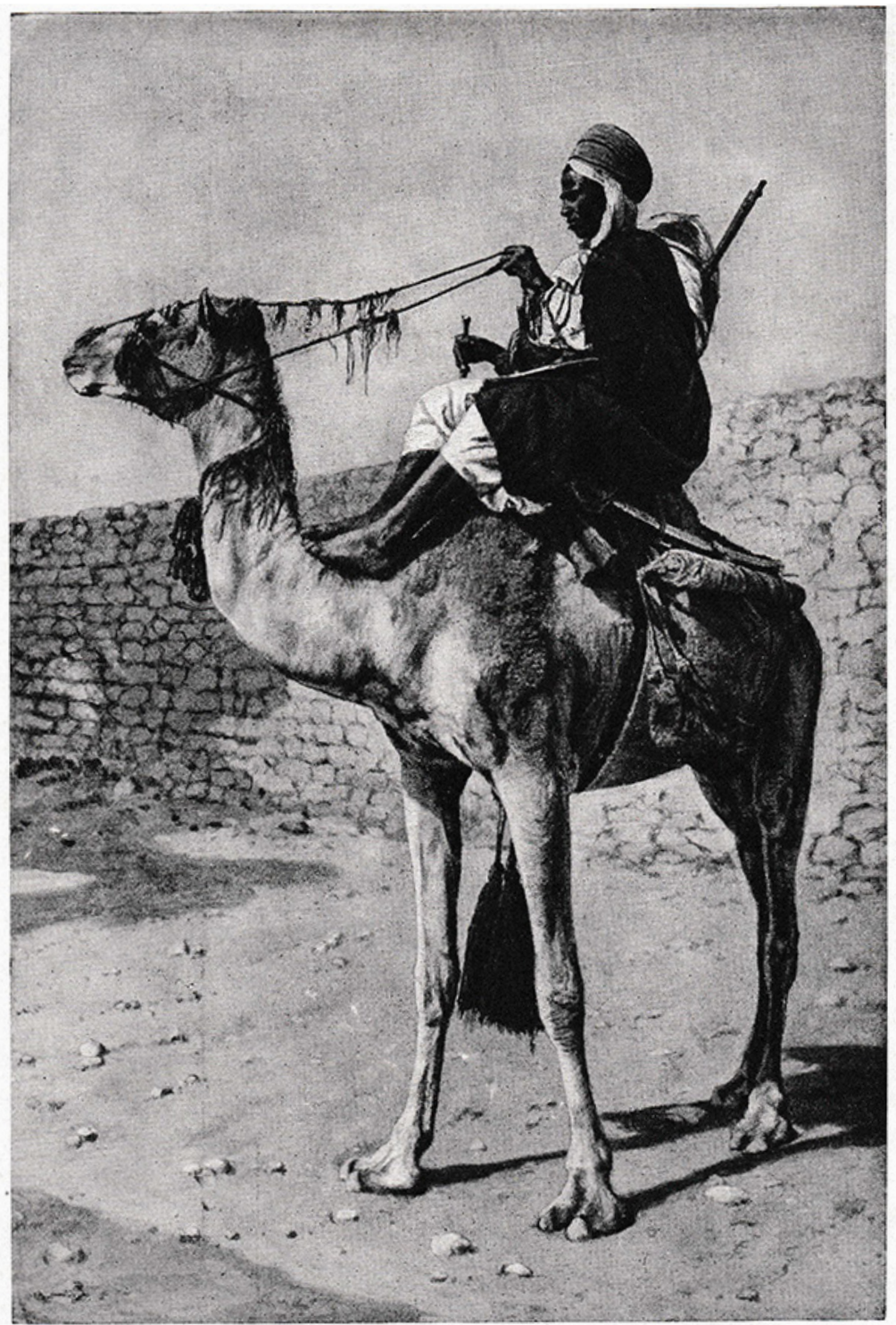

HALF-BREED SPAHI CAVALRYMAN OF THE SAHARA

As the coastland sharpshooters of Algeria could not stand the fighting life in the southern Desert a camel corps was formed of the Berber-negro stock of the Desert oases. Born and bred between the furnace sun and oven-hot sand, these men who were in the old days coloured serfs of the white slave-raiding Tuaregs have mastered their old masters 


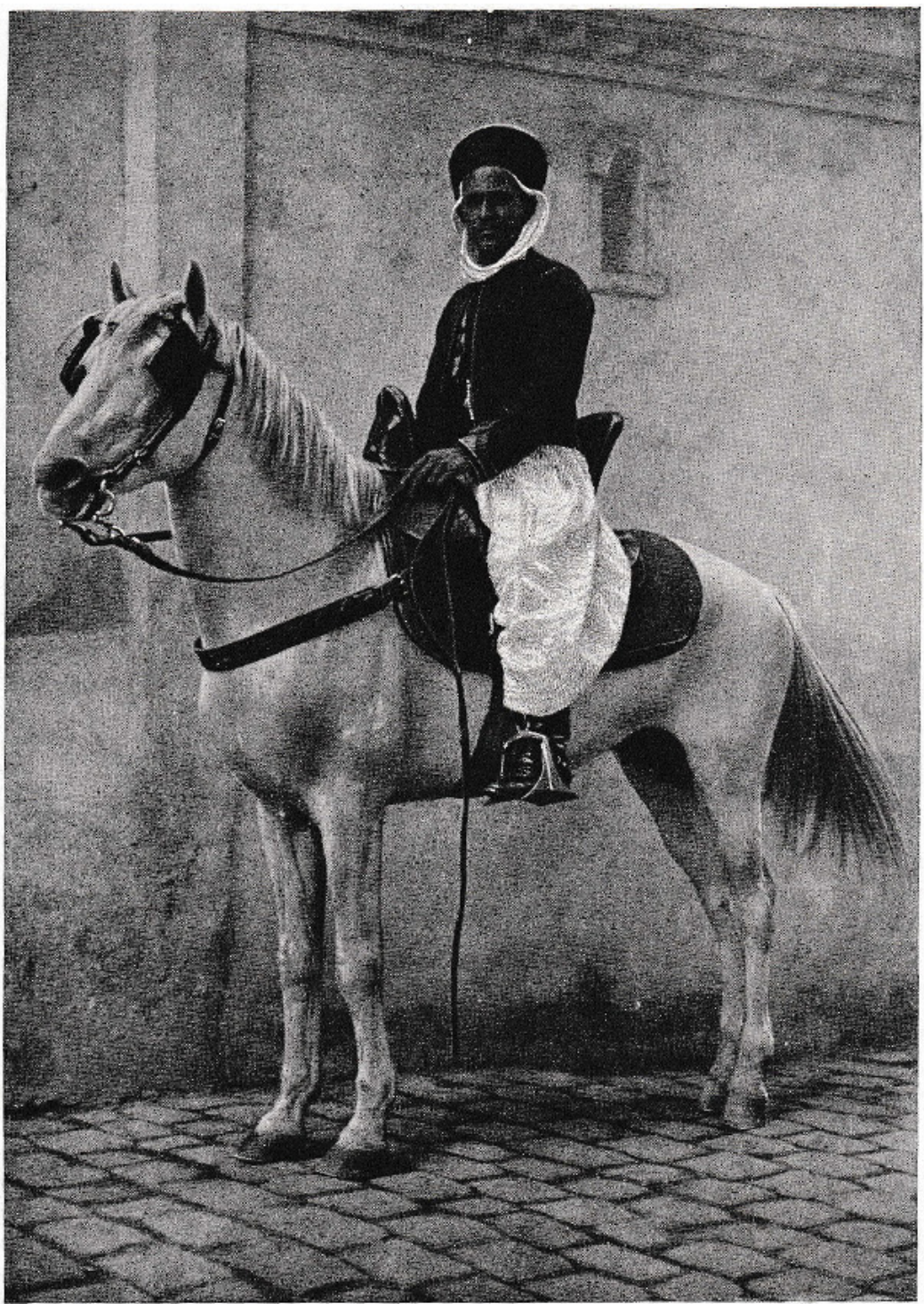

ONE OF THE BEST AND MOST FEARLESS HORSEMEN IN THE WORLD

When the white-skinned Berber of the Desert, with a face of the European kind, is turned into a loyal Spahi cavalryman it is hard to find a better soldier. Over bis own sands, on a mount of his choosing, he can outride or wear down even the Arab. With men of this sort, his famous Numidian cavalry, Hannibal broke the Roman legions in the Punic Wars Photo, Donald McLoish 
ALGERIA \& THE ALGERIANS

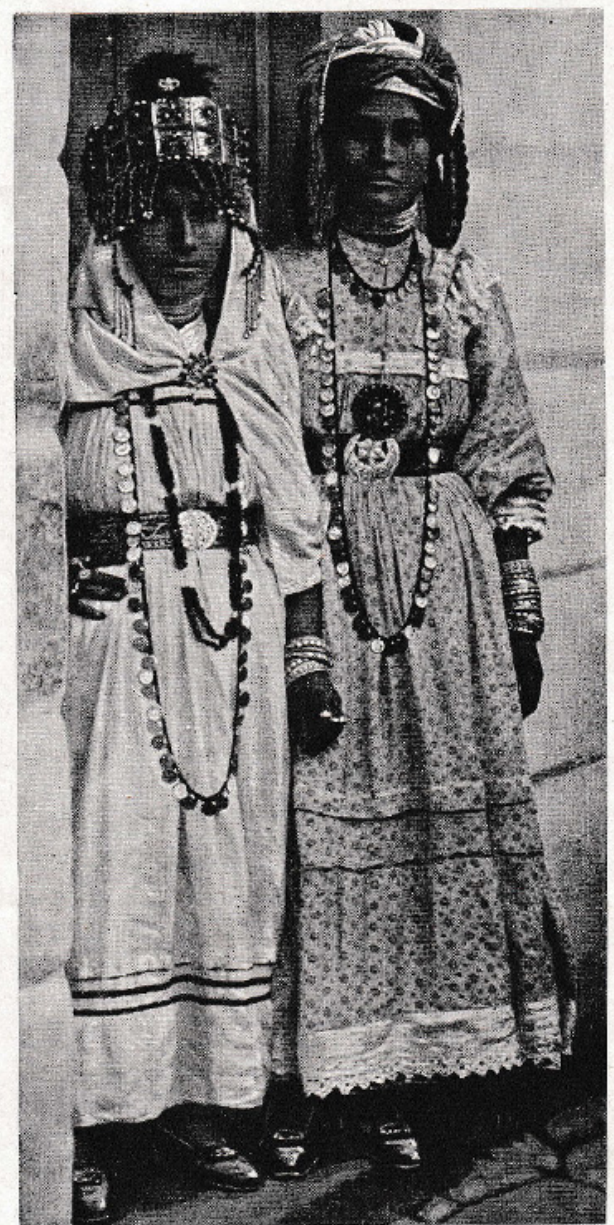

DANCING SIRENS OF THE OULED NAIIL

Born in the Ziban oases, south of Biskra, these girls wander from Tripoli to Tangier, and gaining, by dancing and love affairs, gold coins enough to make a breast-plate, they return and marry, in high honour, their own tribesmen

$$
\text { Photo. T. C. Hvam }
$$

exclamations of admuation, fits it on, giving it a pat here and a tug there. The neighbours join in with hints and suggestions, and the traffic is held up till the bargain is completed. Allàh did not make hurry!
The barber and the dentist and the protessional letter: writer pursue their avocations on the pavement. At the entrance of many of the caves sits the craftsman plying his hereditary craftstitching, cobbling, soldering tin, or mending musical instruments. The air is heavy with the indescribable odour of the East-a compound of spices, aromatics, cookery, and dust-heaps.

The native coffee-house café maure, is merely a bare room with a few benches about it, and a stove at the end. The frequenters squat on the benches or on the floor, or on straw mats out on the cobble stones in front of it. The coffee is thick and black and sweet as syrup, and they sip it from little cups, with long intervals for contemplation. Some are intent on garnes of cards, dominoes, or chess.

$\mathrm{U}_{\mathrm{p}}$ on the wider space, near the Kasbah, the citadel and palace of the former Deys of Algiers, there is a small market square, where fruit and cast-off clothing are displayed. Here may be seen one of the oldest and most familiar sights of the East. In a corner a large group are gathered round an aged, half-blind Arab storyteller or orator, who sits cross-legged and tells his tale with great unction and dramatic effect.

The prosperous merchant drops his newspaper and squats down in the circle. What is it that holds the audience in such rapt attention? Does he tell of the days of the Christian slaves? Is it doctrine or politics, or history, or mere idle and amusing tales ? Do the Thousand and One Nights thus live again? The 


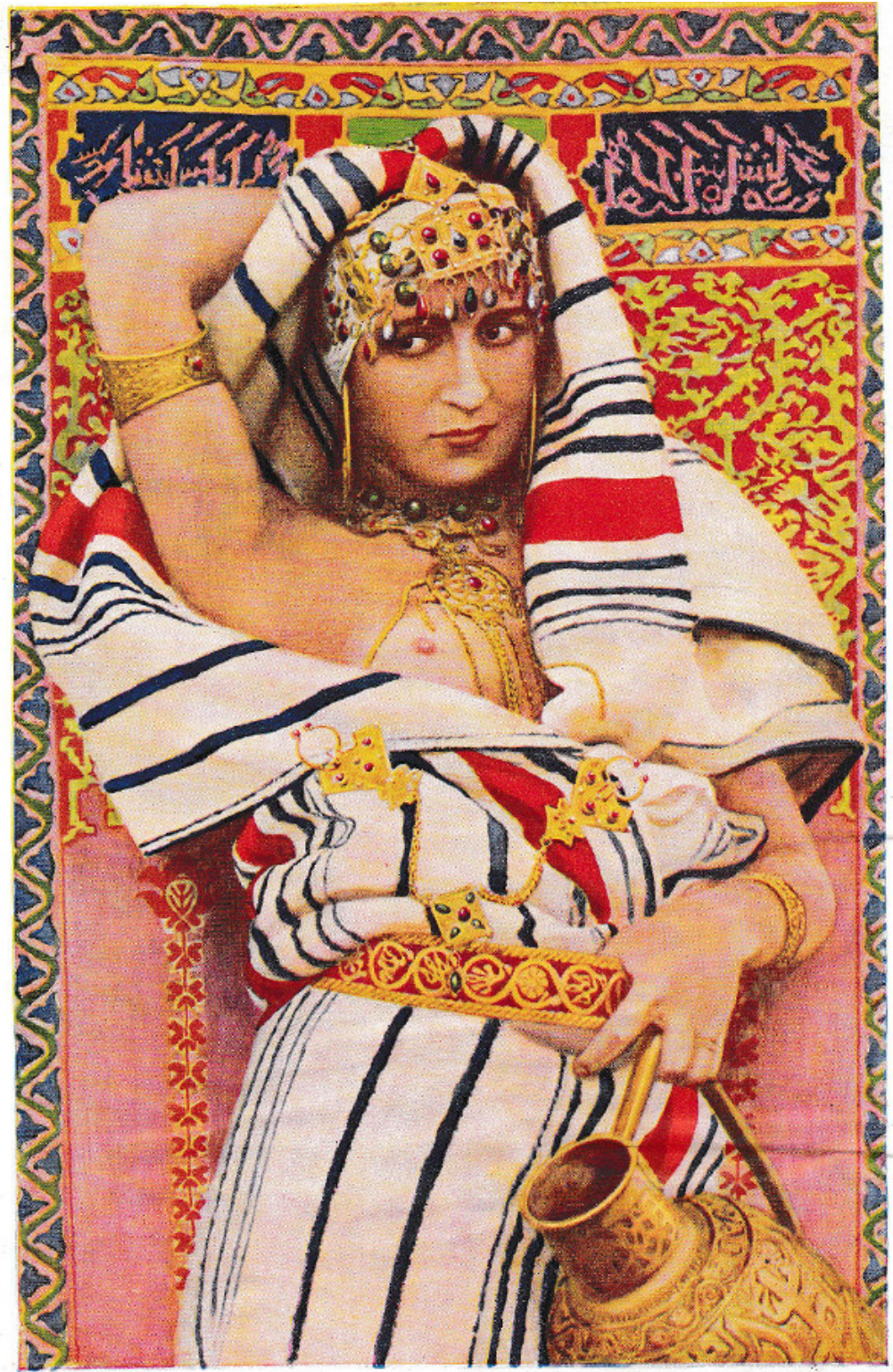

ALGERIA: A BEJEWELLED BEAUTY OF THE KABYLES 


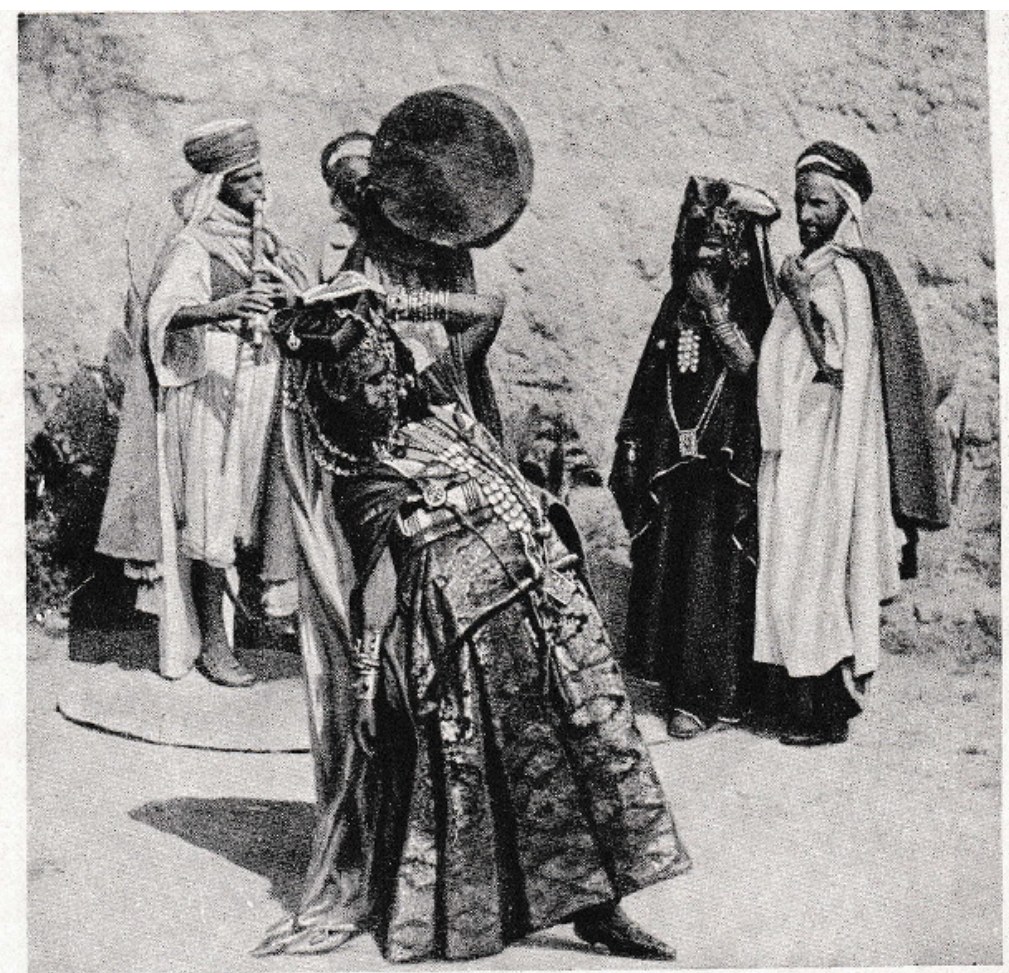

OULED NAIIL BEGINNING HER STRANGE DANCE OF PASSION

Shameless and attractive, and as learned in all the arts of love as Cleopatra, the dancing-girl from the Sahara will perform in the open street, in the pasha's harem, or in the native café. This dancer is beginning her career, and is only about thirteen years of age, for she wears few golden coins Photo, Crats

natives are largely illiterate, and this is their newspaper, their political pamphlet, ther novel. So the ancient memories and traditions of the race are kept alive.

The Moorish houses are singularly non-European. They offer nothing but blank, precipitous, and sometimes overhanging walls to the gaze of the passer-by. There is no external decoration. There are no windows. only a few narrow grated loopholes. The door is the door of a fortress or a prison. And, mdeed these houses of mystery are both prison and tortress, a prison to the veiled women. and a fortress against European influence. It is only the back of the house that we see from without: the decorative façade is all turned within Like a shell, it is rough without, but within are all the exquisite rainbow tints of mother-of-pearl.

In the centre of all is a square court paved with marble or tiles, with a fountain rippling continuously, and perhaps an orange tree, the dark green of the foliage lit up by golden globes. Right round the court runs an arcade of Moorish arches, supported by delicate pillars. From this the public rooms and offices open. An upper gallery sumilarly arcaded, and with a wooden balustrade of intricate 


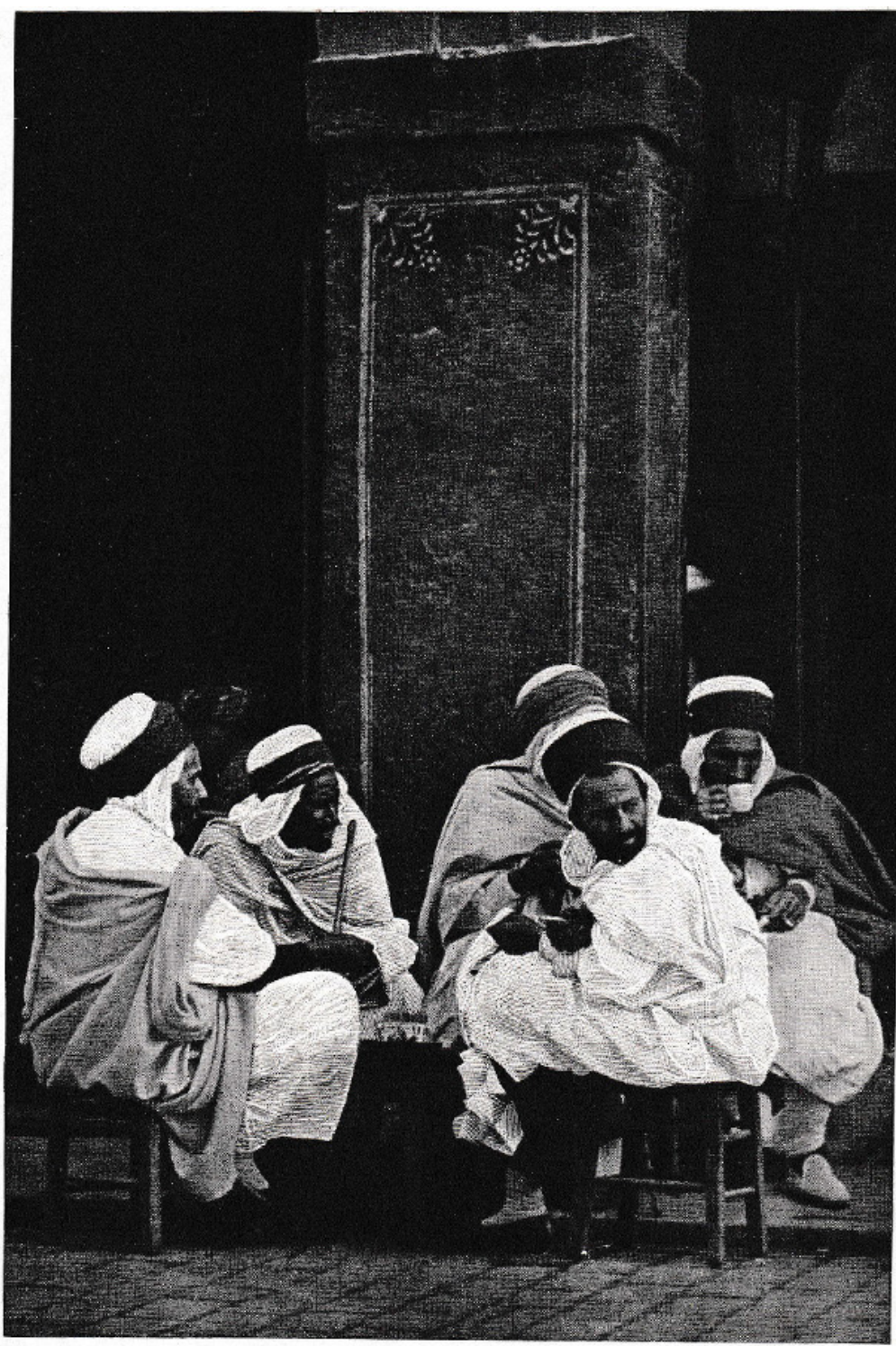

THE SUGARY LURE OF THE MOORISH COFFEE TAVERN

Founded in its present form by Moorish fugitives from Spain, the coffee tavern has spread from Algiers to the Sahara. It attracts and holds loafers of all classes, usually remarkable by their obesity. Over a charcoal fire the coffee decoction is thrice whipped of the boil and sugared into a thickish syrup Pho: Donaid McLeish 
ALGERIA \& THE ALGERIANS

arabesque pattern, also runs right round the square. From it open the private apartments. The walls, where visible, are generally encrusted with lustrous and brilliantly-coloured tiles.

As the houses rise in terraces up the steep hillside, each flat roof affords a view of the harbour and the bay, and the more distant prospect of the Mediterranean or the Djurdịura Mountains. There is no busy street scene to view, for the tortuous alleys burrow, like tunnels or galleries in an ants' nest, far below the overhanging roofs. Here is the woman's realm. Here is all the world they know. From here they listen to the distant hum of traffic and watch the great ships come and go in a world that is beyond their ken.

In Turkish times the roofs were strictly reserved for the women. They took the air here. they enjoyed the freshness of the evening breeze, they climbed over the parapets, and passing from roof to roof visited their female friends. The system lent itself to intrigue, for nothing was easier than for the bold lover to disguise himself in female attire and to thread his way through the maze of roofs, under the guidance of some old hag bribed by mistress and lover alike

Many a time he found the adven. ture as perilous as Leander found the crossing of the Hellespont. The traditional literature of the people is full of romantic stories of such adventures of the kind so well known to Western readers through the "Arabian Nights" tales. Moreover, this custom throws a

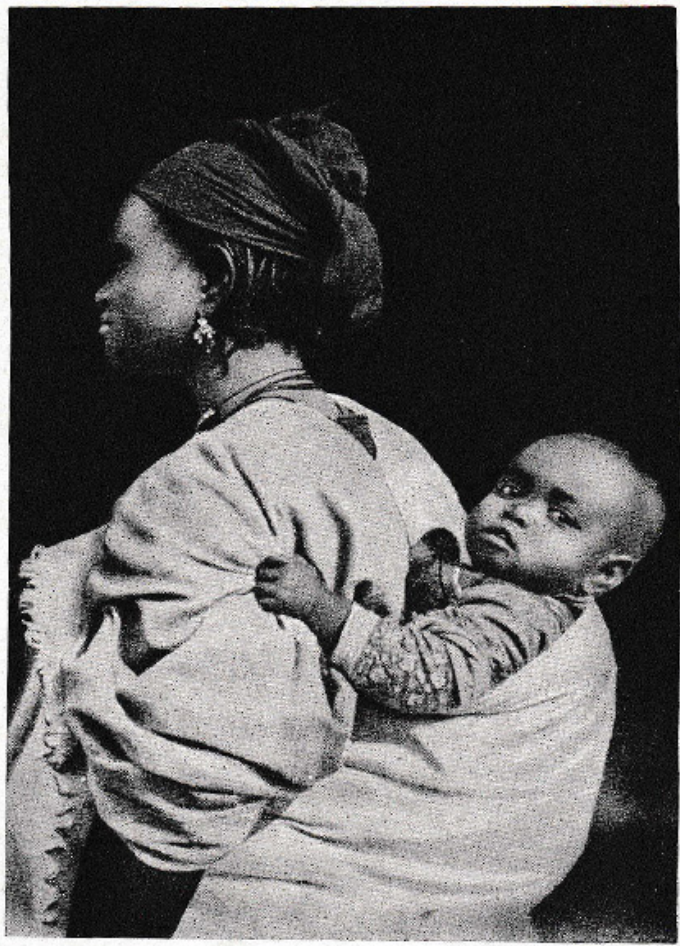

TAR-BRUSHES THAT BLACKEN OLD BARBARY This young negro mother and her piccaninny are weapons of destiny. Negress slaves in the harem have changed the former verning Arab stock into weak-minded blackamoors. The purePhoto, Crete

somewhat interesting light upon the Bible story of David and Bathsheba.

The veil and all that it implies with regard to the seclusion of women is one of the most powerful of social institutions, and it is one of the most formidable barriers between the two races in North Africa. It is not merely an incidental custom or freak of fashion, like a fez or a bowler hat.

It is the symbol of a whole system of social life and ethics, utterly alien to us. It is futile to measure it by our European standards and to dismiss it as a badge of sex inferiority and the degradation of family life; even 


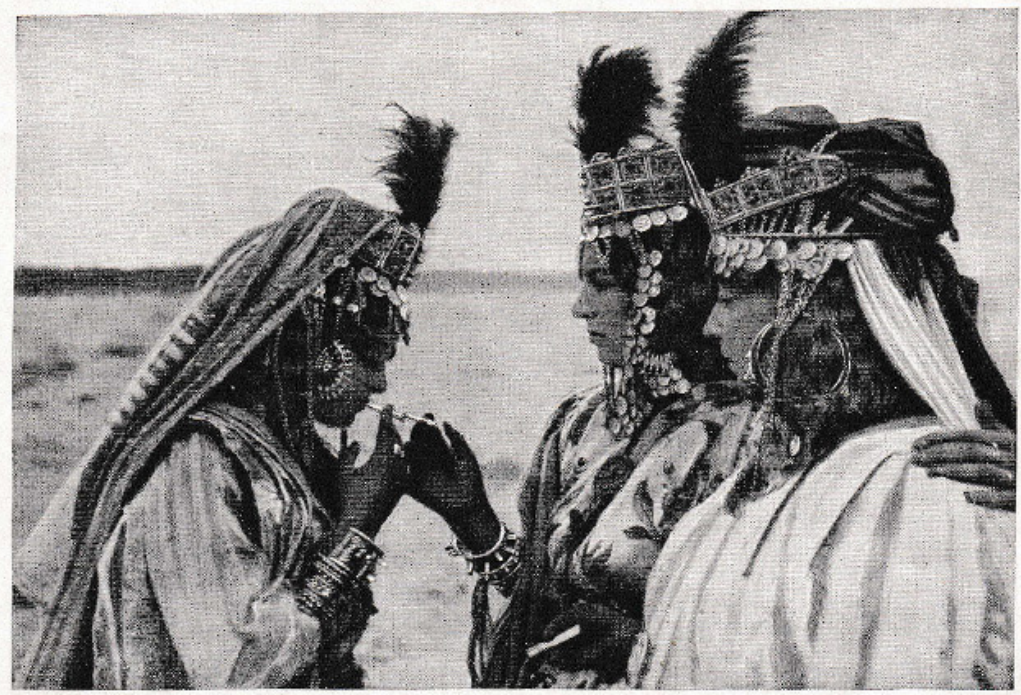

MISTRESSES IN ALL ARTS OF FASCINATING MEN

Mulatto girls of the Ouled Nalls are works of art. Their hair and eyebrows are dyed blue-black. Their carmine lips and red nails are, like their picturesque coifs and rich and varied jewelry, additions to the tar-brush tint of skin. The cigarette is but an item in their sophisticated charms

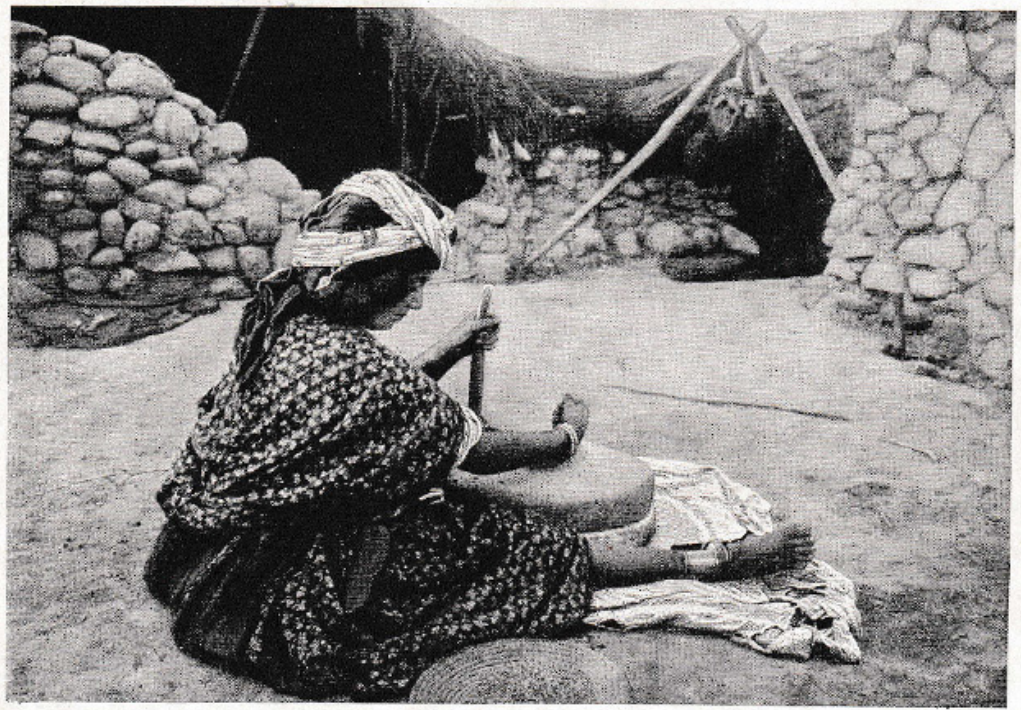

NOMAD MAID OF THE MILL PREPARING COUSCOUS

She pours the barley through a hole in the upper stone, which she turns by means of the stick. The grain is cooked with mutton, honey, and a variety of things to form the national dish, couscous Photos, A. Bowrault 


\section{ALGERIA \& THE ALGERIANS}

so, an Arab might talk about our social customs, if they were to be measured by his standards.

Just as Japan has its Yoshiwara, the resort of the geishas, so Algiers has its Kattaroudjie. An even more remarkable street of this character exists in the Desert town of Biskra, the street of the Ouled Nails. The Ouled Naïls are a tribe in the Aurès Mountains, whose women are the hereditary geisha of the Desert. They come down to the towns to earn their dowry and return to resume the veil, and settle down to married infe in their mountain homes.

In this quarter may be seen the Moorish dances, the more exotic danse du ventre, and the so-called Andalusian fandango. This latter orgy, as the name indicates, is more in accordance with European conceptions, a dance of mænads and corybantes, a display of violent motion and tossing limbs. The others are as alien as the camel, the cactus, and the palm tree. They are full of the subtle seduction of the East They ase like an opium eater's dream. The difference is that between drugs and wine.

Most alien to our ears of a!l the sounds of Algiers is the native music. Throughout Europe music is an international language. It makes its direct appeal to the emotions independently of all differences of language race, custom, and religion. But here in Africa even the music is in a different idiom. It is something more primitive than the immemorial civilizations of Asia which still hold North Africa in their gripsomething that springs out of the savage black heart of Africa itself, beyond the Desert.

The basis of this weird music would seem to be the tom-tom, or African drum. The range of stringed or flute music is limited to a few notes which are repeated over and over again. In our ears this music is almost the negation of music-

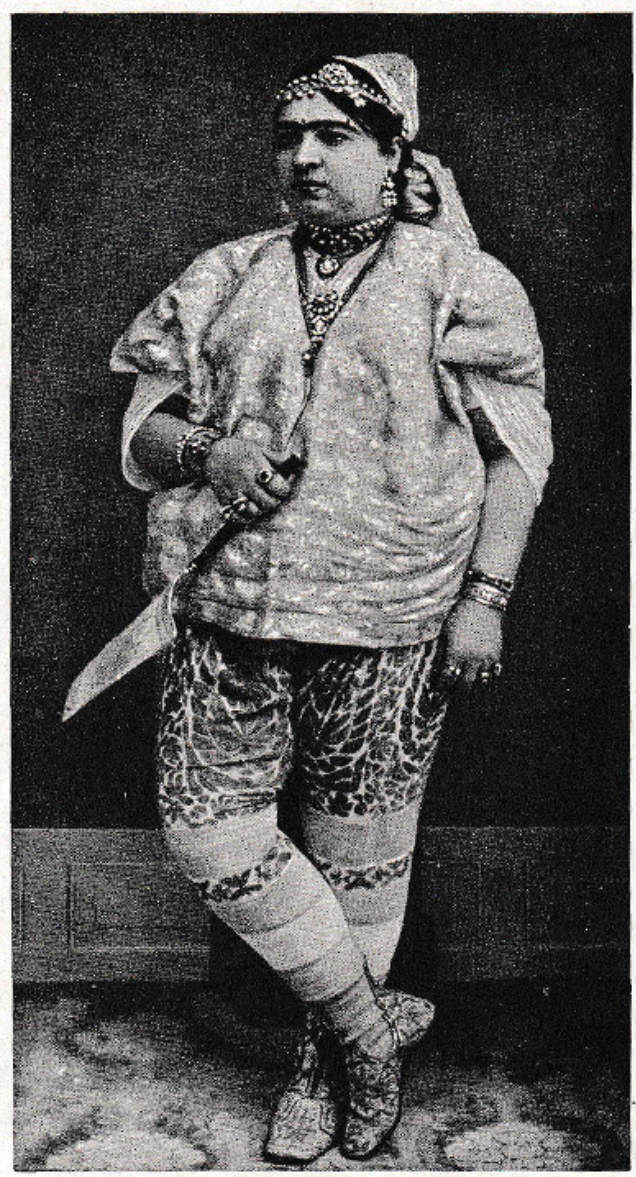

TROUSERED JEWESS OF ALGIERS

The women of the richest race in French Africa are tamous for their voluptuous figures. Made up in harem fashion, with gay Persian-like trousers, fly-flappers, quaint puttees, painted eyebrows and lips, they reek of beavy scents 


\section{ALGERIA \& THE ALGERIANS}

dull, uninteresting, crude, monotonous. In fact, it is not tonic, but rhythmic. But it exercises a powerful spell upon the natives. Packed audiences will sit and listen in ecstasy to this thrumming and drumming. The atmosphere vibrates with the reiteration of rhythmic beat, and the listeners are swayed by some hypnotic influence.

Throughout Algiers the mosques are freely open to Christian visitors, provided they remove their shoes or pull over them the large slippers which are supplied in the vestibule. Within these sanctuaries of Allah one can still feel the living force of the great Prophet of the Desert, who established a religion which has more followers than Christianity to-day. Mahomet was a religious reformer. A fierce monotheism was the essence of his creed. He suppressed polytheism and idolatry, and the superstitious abominations which enslaved his people. He made his Desert tribe the rulers of a world as great as that of Rome, the masters of a civilization that preserved science and learning when the lamp of Rome was flickering.

The Church he founded is the greatest and most successful missionary church in pagan Africa to-day. Millions of men throughout the world still regard his lightest word as law. And within the cloistered gloom of these Mahomedan temples even the northern Protestant, noting the austere simplicity of the mechanical

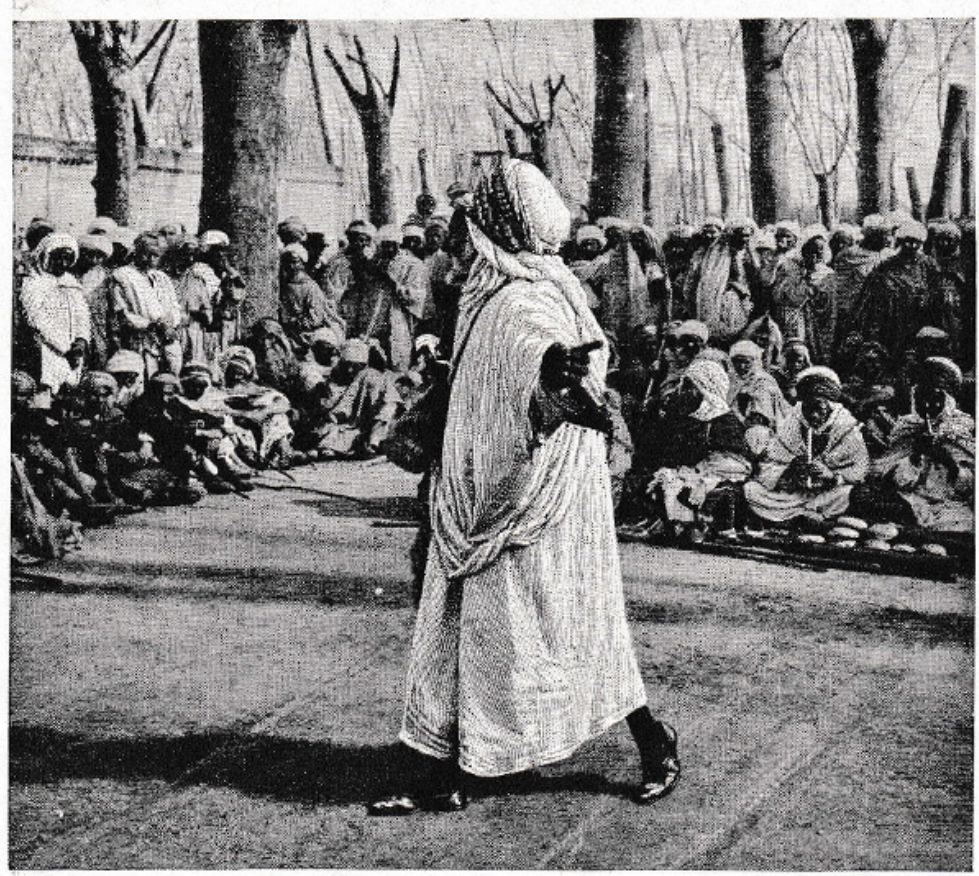

ALGERIAN ORATORY DRAWS A CROWD TO THE KASBAH SQUARE

The little market-place at the top of Algiers is the sounding-board of the native mind. Round it a crowd will rank itself to listen to such a dramatic speaker as this. News, old tales, or political speeches will usually hold an audience that is particularly eager because it is largely illiterate Photo. Mr. Hewry Porritt 


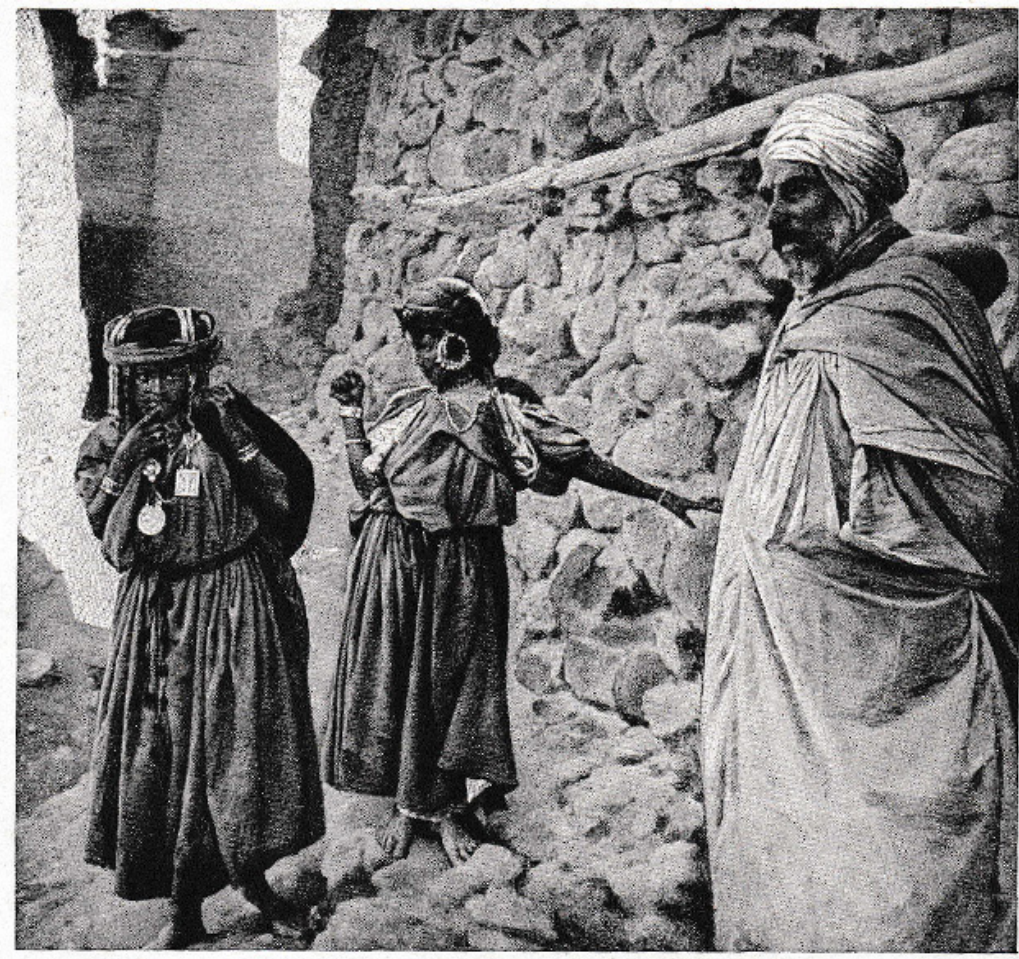

PRETTY SHAWIA WOMEN IN THE MOUNTAIN TOWN OF MENAA

Unveiled and jingling with jewelry as they walk, the fair-haired, blue-eyed Shawia women of the fighting Aurès villages darken their skin with pigment. They are proud, free, hardworking Berber beauties, who are saved by ancient pagan rights from the close restrictions of the ordinary Moslem harem. Here they are seen in working dress. Festive attire is a blaze of colour

aids to piety, cannot fail to be $1 \mathrm{~m}$ pressed by the air of intense adoration and worship which pervades the place.

Religion is the supreme expression of the difference between Europe and Africa. Mahomedanism has laid its spell over all the land. It completely obliterated the great African Church of Cyprian, Tertullian, and Augustine through which Christianity first became the religion of Europe. It inundated Spain, and its waves beat against the barrier of the Pyrenees, but it ebbed back to Africa again.

There it remains settled, supreme, unmoved in its empire over men's minds, though the sceptre of temporal power has slipped from its grasp. In the observance of religious rites the Mahomedan is surpassed by the professors of no other religious faith, and his religion colours his whole outlook upon life, his hopes and fears for the future, his social and domestic habits, his morality. The real distinction is this-that modern Christianity embodies the ethics of the temperate zone, while Mahomedanism embodies the ethics of the heat belt.

France has not been unduly tender with regard to Mahomedan susceptibilities. The civil rights of the natives are scrupulously safeguarded by legislation and administration. The people are free to worship in 


\section{ALGERIA \& THE ALGERIANS}

accordance with the tenets of their own faith, provided they do not interfere with the exercise of similar rights by others. But there must be no doubt as to who is master in civil affairs. The Republic which broke the power of the Church of Rome in France will not submit to any dictation or presumption on the part of the Church of Mahomet in Algeria. The fierce, conquering creed of Mahomet must learn to tolerate rivals and to restrain its aversion from the "dog of an unbeliever." The cathedral was formerly a mosque, and many other mosques have been

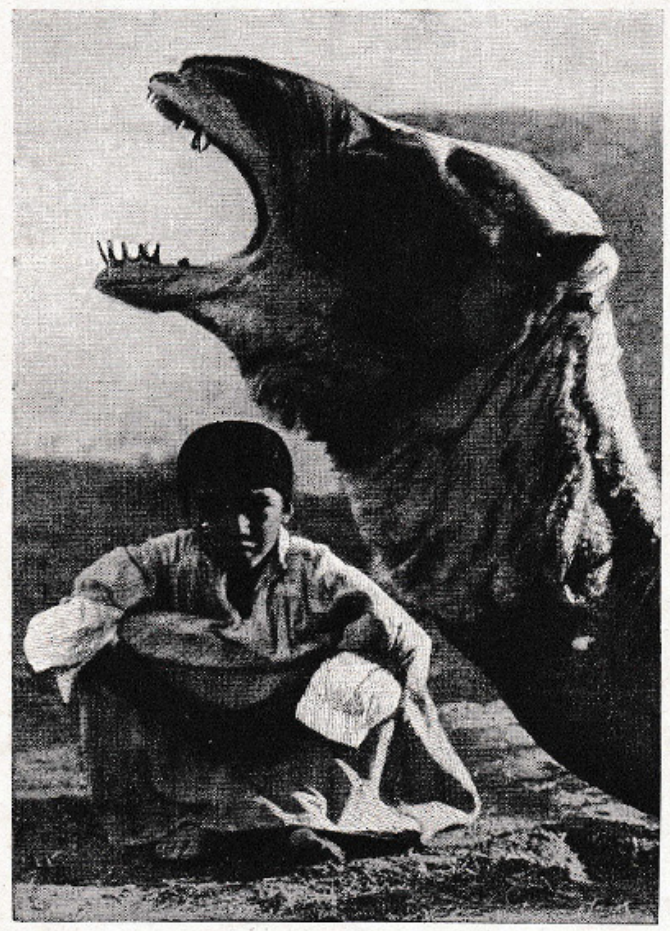

CAMEL BOY AND HIS HUMPY DARLING Lovingly does the Saharan speak of his "mehari," On this tall, fast-trotting dromedary the Tuareg boy will cover fifty miles. So shaped is he from childhood to his racing camel that he looks and feels awkward when dismounted Pkclo, Crite diverted to secular uses. At a prominent view-point outside Algiers a cross has been erected with the inscription: "In hoc signo vinces."

But, so far, the Cross does not prevail. The Government of the Republic is not a religious institution, much less a proselytising one. A strict impartiality is all that can be expected from it. Great efforts have been made in missionaty work, but they have produced little result. The greatest efforts were those made by Cardinal Lavigerie, the archbishop of Carthage, a man whose magnetic character and great energy entitle him to be ranked among the great figures in African history. Among his manifold labours he founded an order of priests, the White Fathers, consecrated to the work of the conversion of Africa. They received a special training and they went out into the Desert and penetrated remote parts of Central Africa dressed as Arabs and living the life of the natives.

Their labours did much to end the slave trade, and during a great famine they rescued many children. The White Fathers still work and pray and sacrifice their lives to the conversion of Africa. But the seed they have sown has not yet grown and fructified. The spiritual dominion of Mahomedanism is absolute and unshaken.

The Great Atlas range runs along the edge of the Desert about two or three hundred miles from the Mediterranean. Along the coast, almost parallel to it, but converging to meet in Tunisia, runs the Little Atlas range. 


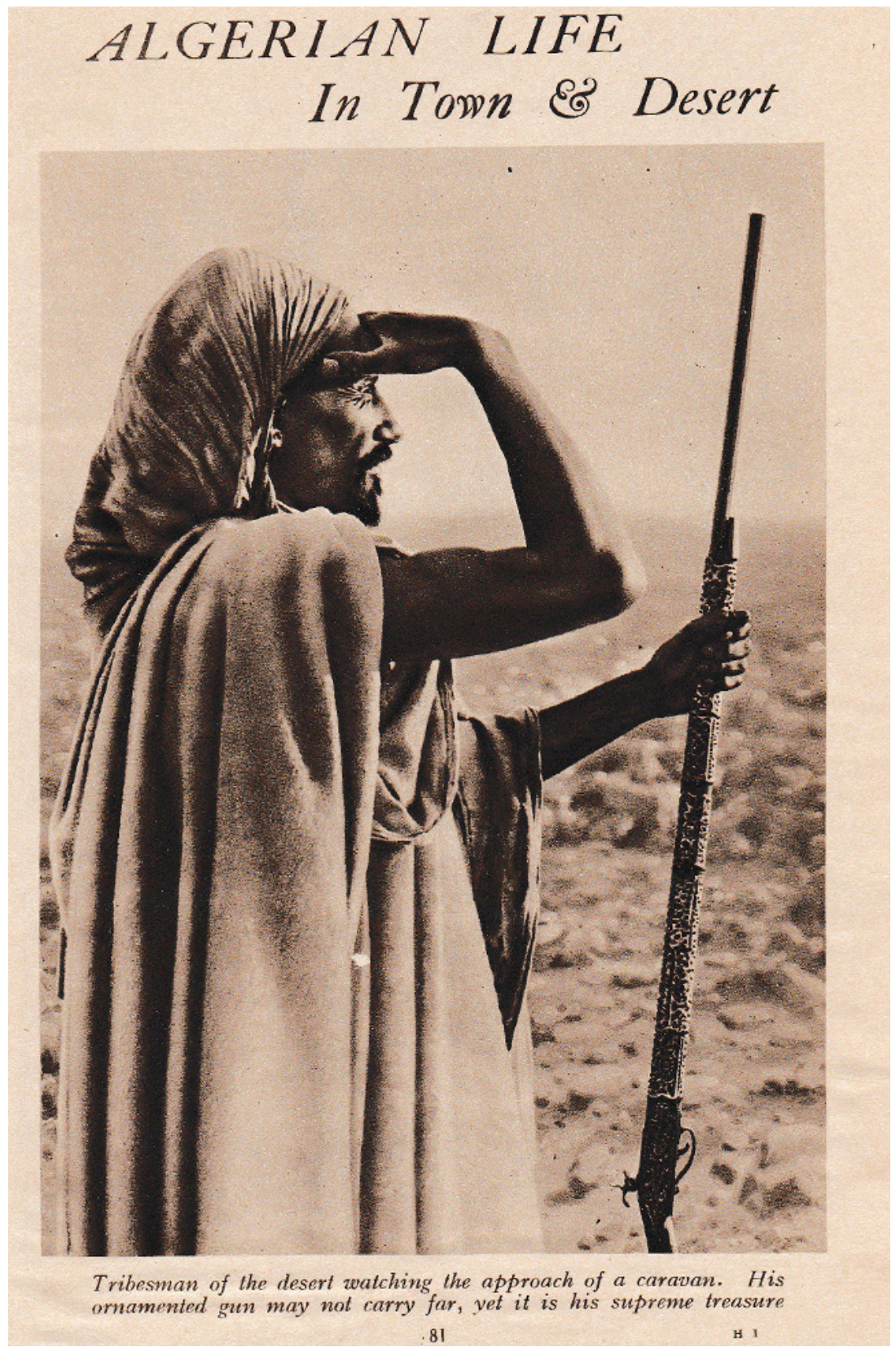




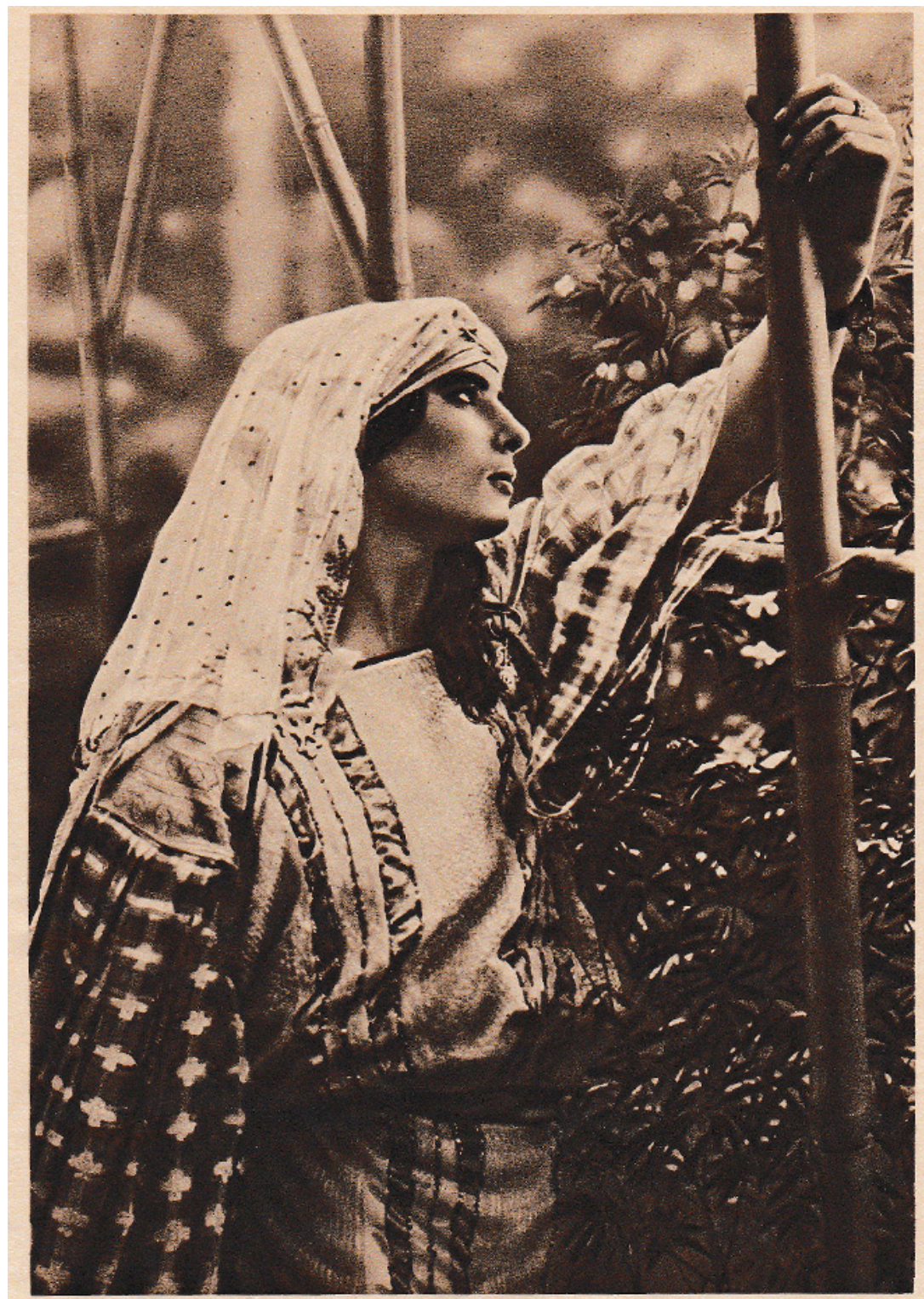

The Arab beauties of the old ruling class in Algiers are seldom seen unveiled, except by their husbands, parents, and the women of the harem 


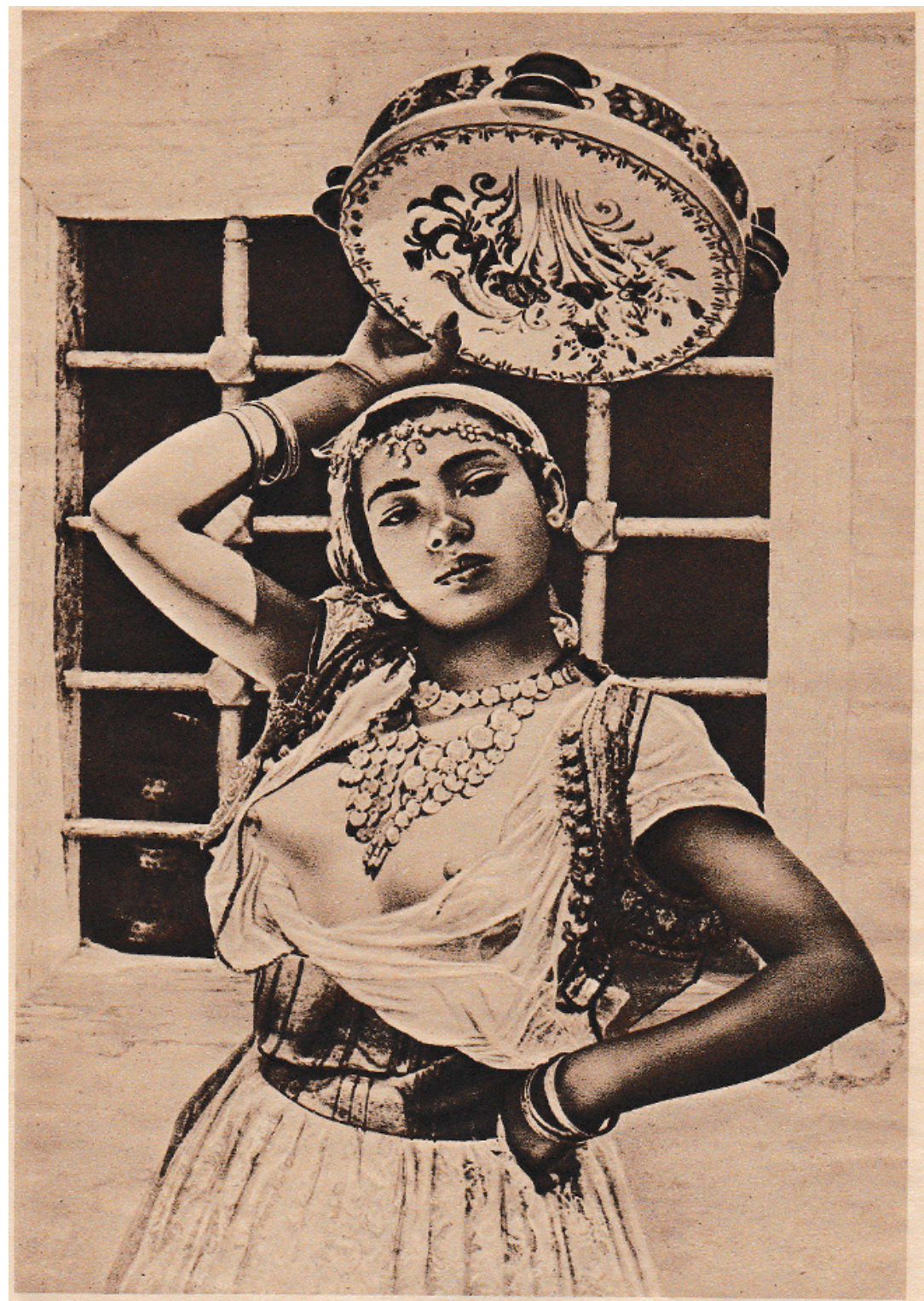

Her tambourine serves as collecting-box, as well as accompaniment to her dancing, in the Biskra cabaret, where she is the star attraction Photo, Crété 


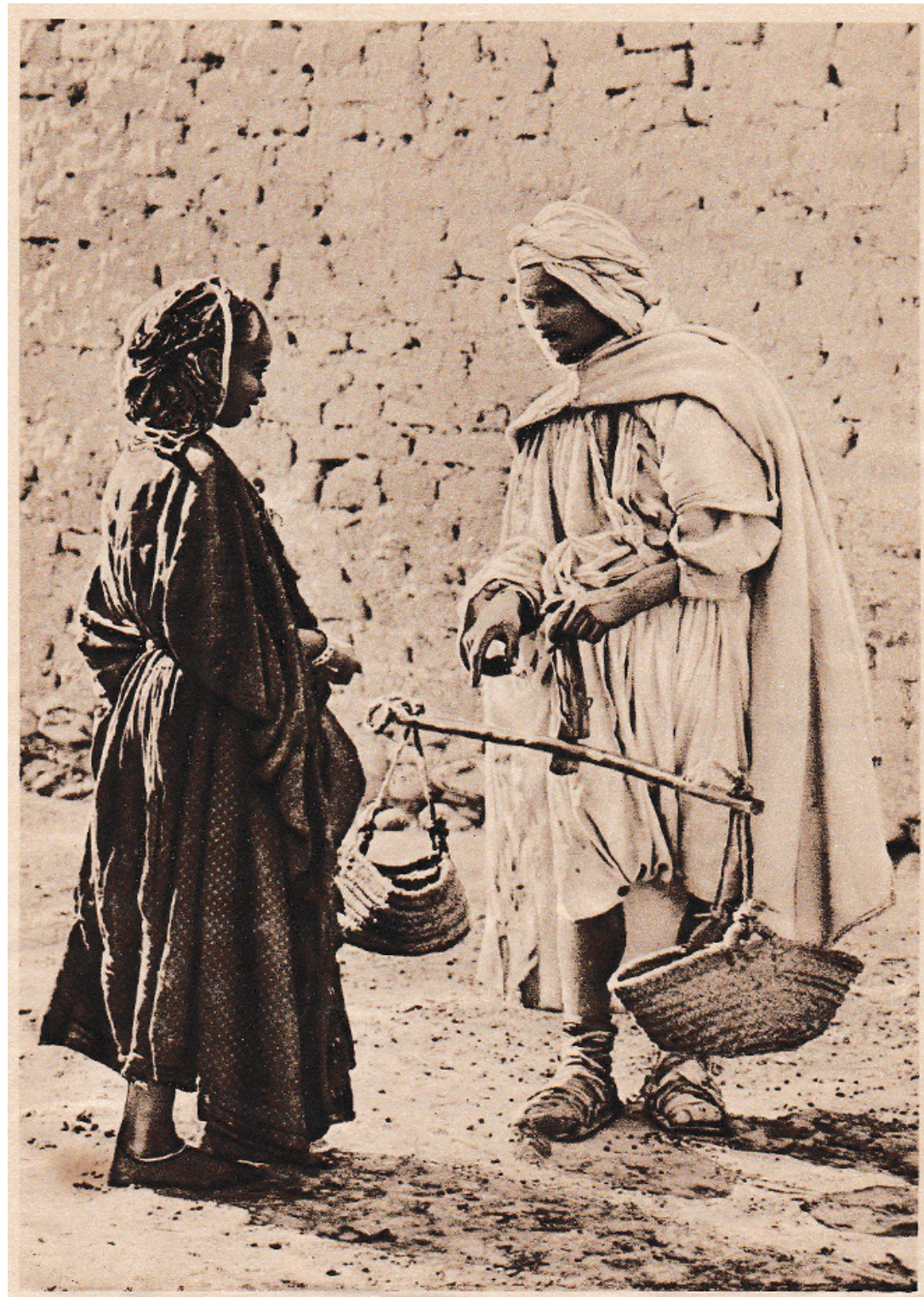

An Arab costermonger, looking as romantic as a robber sheikh, weighs out vegetables to a negress. His scales allow manipulation! 


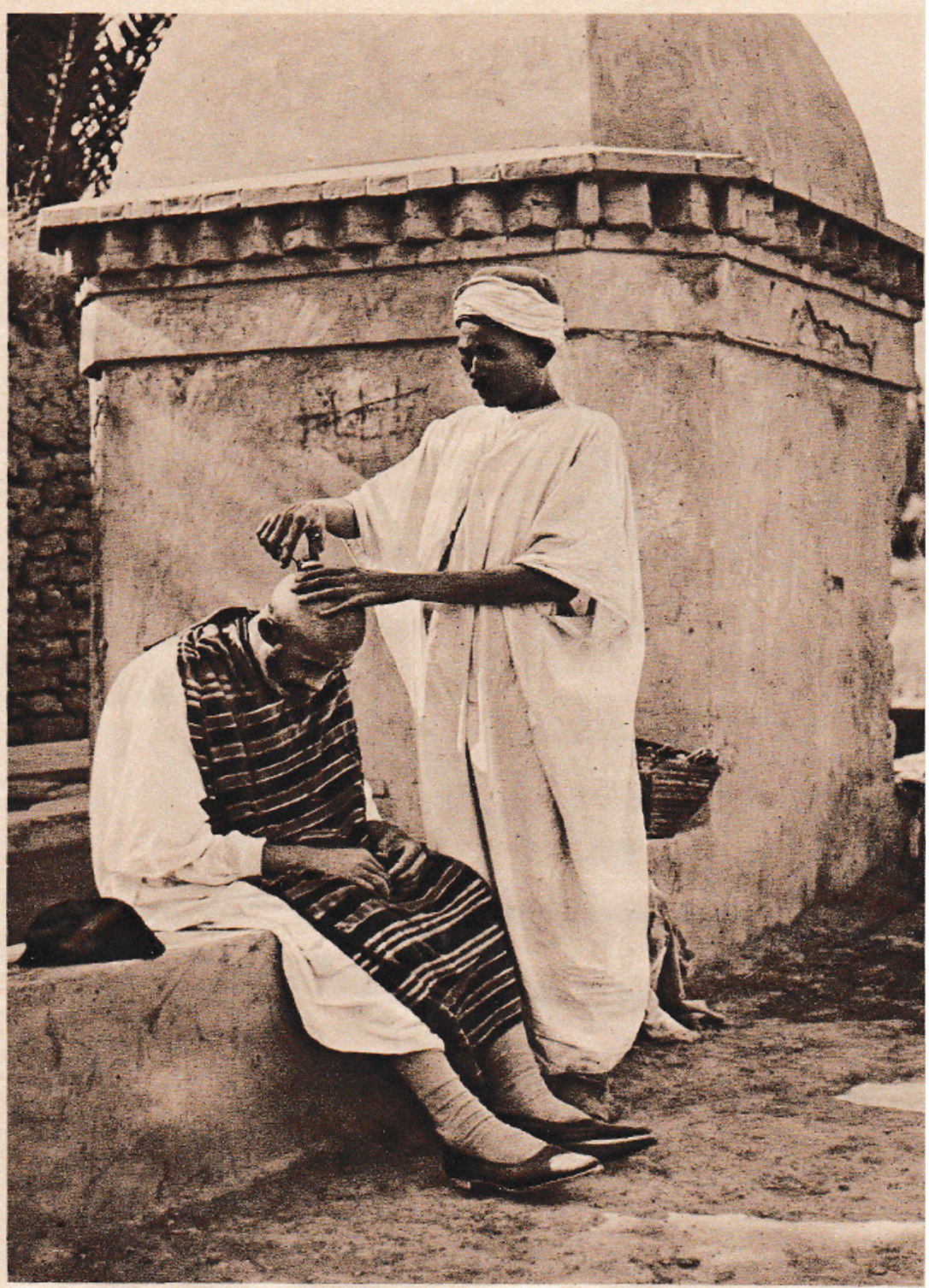

This is the public way Saharan barbers shave a customer's head. Usually one tuft is left by which angels can haul him into Paradise Photo, Donald McLeish 


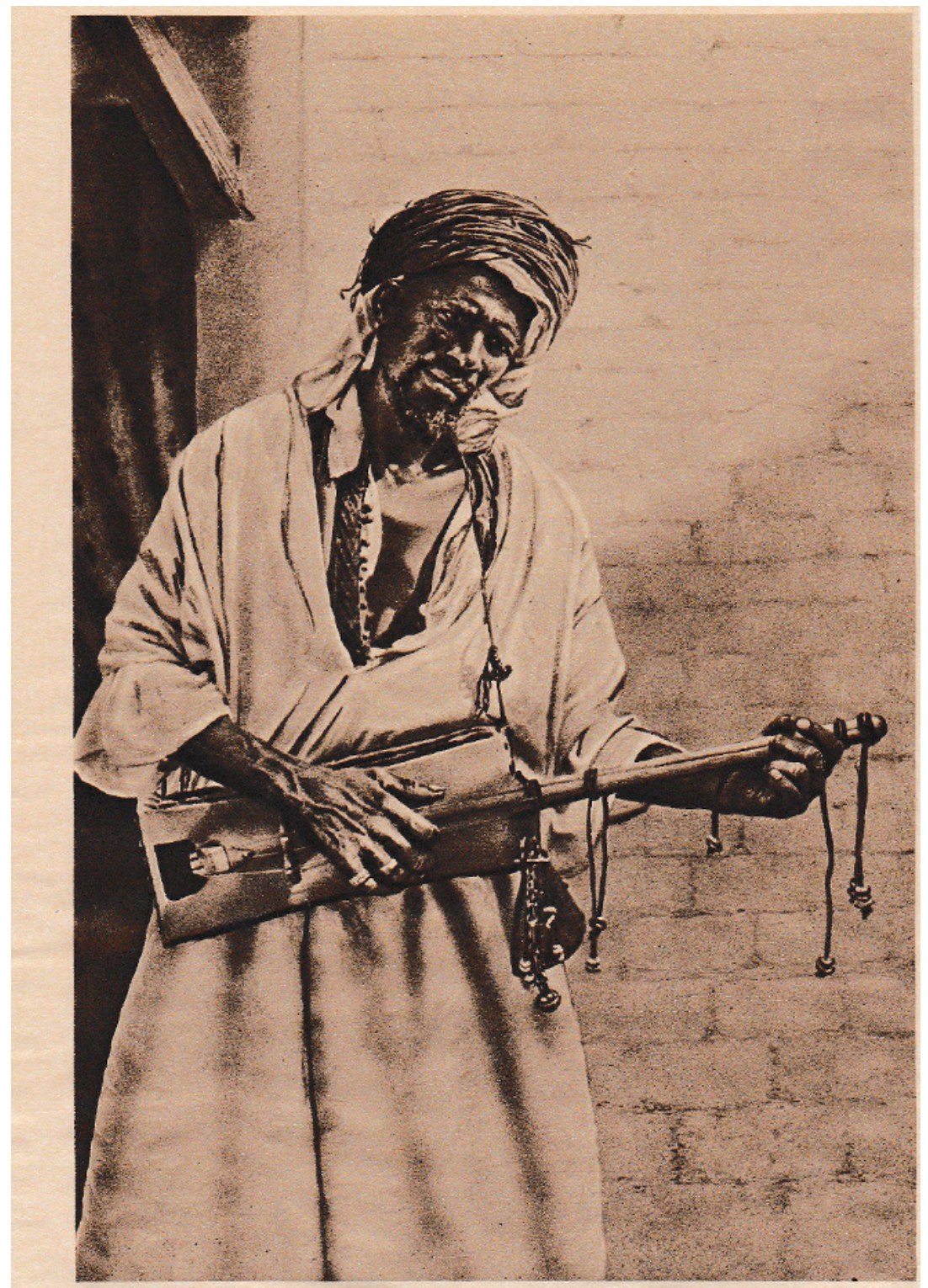

Negro minstrel of Algeria strumming monotonous airs on his quaint guitar, while his face is a study in the art of mendicant pathos Photo, Crété 


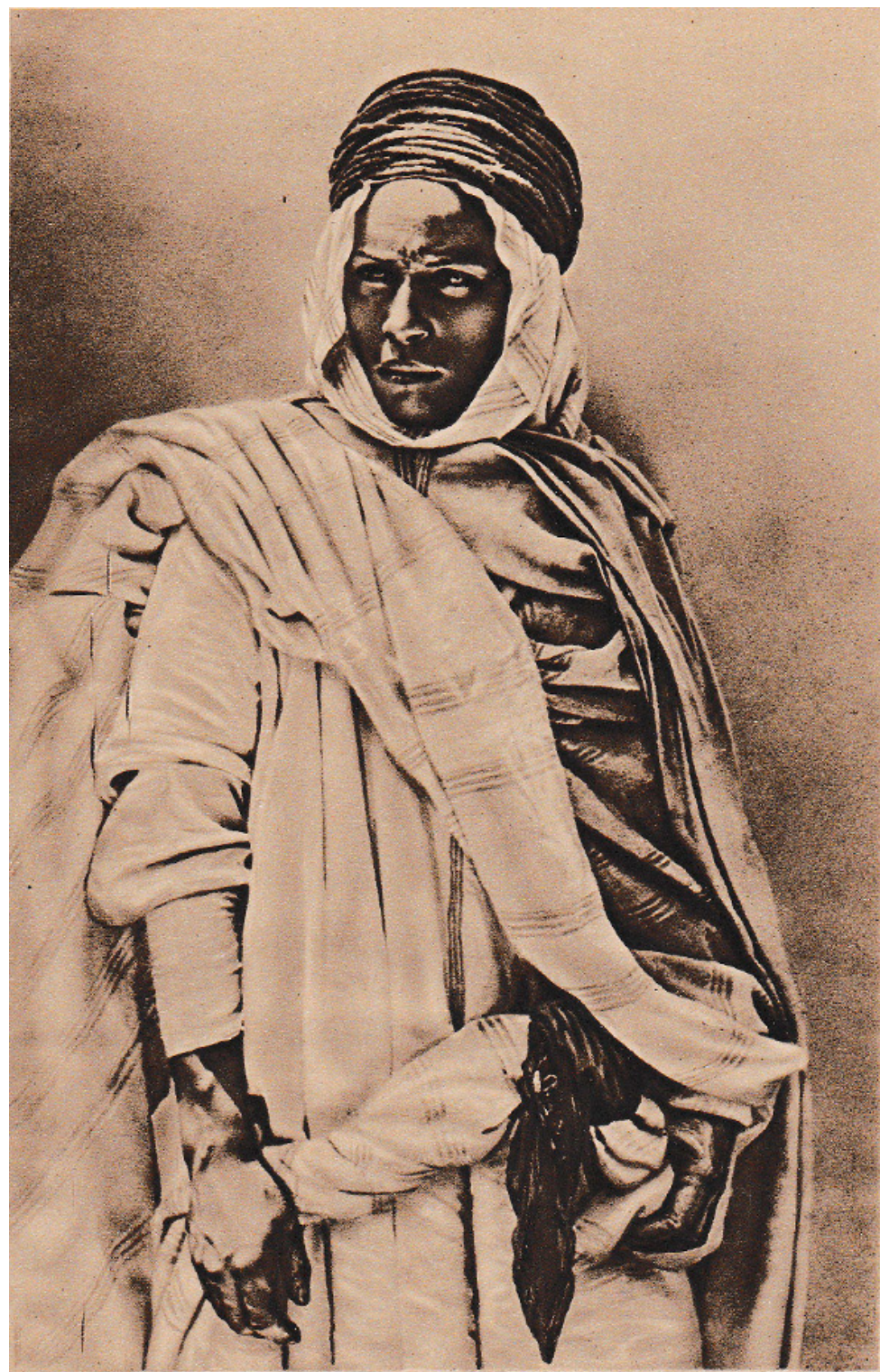

Berber mulatto of Northern Sahara. Since his tribe aided France against the white Berbers the mulatto has been pampered and proud Photo, Crété 


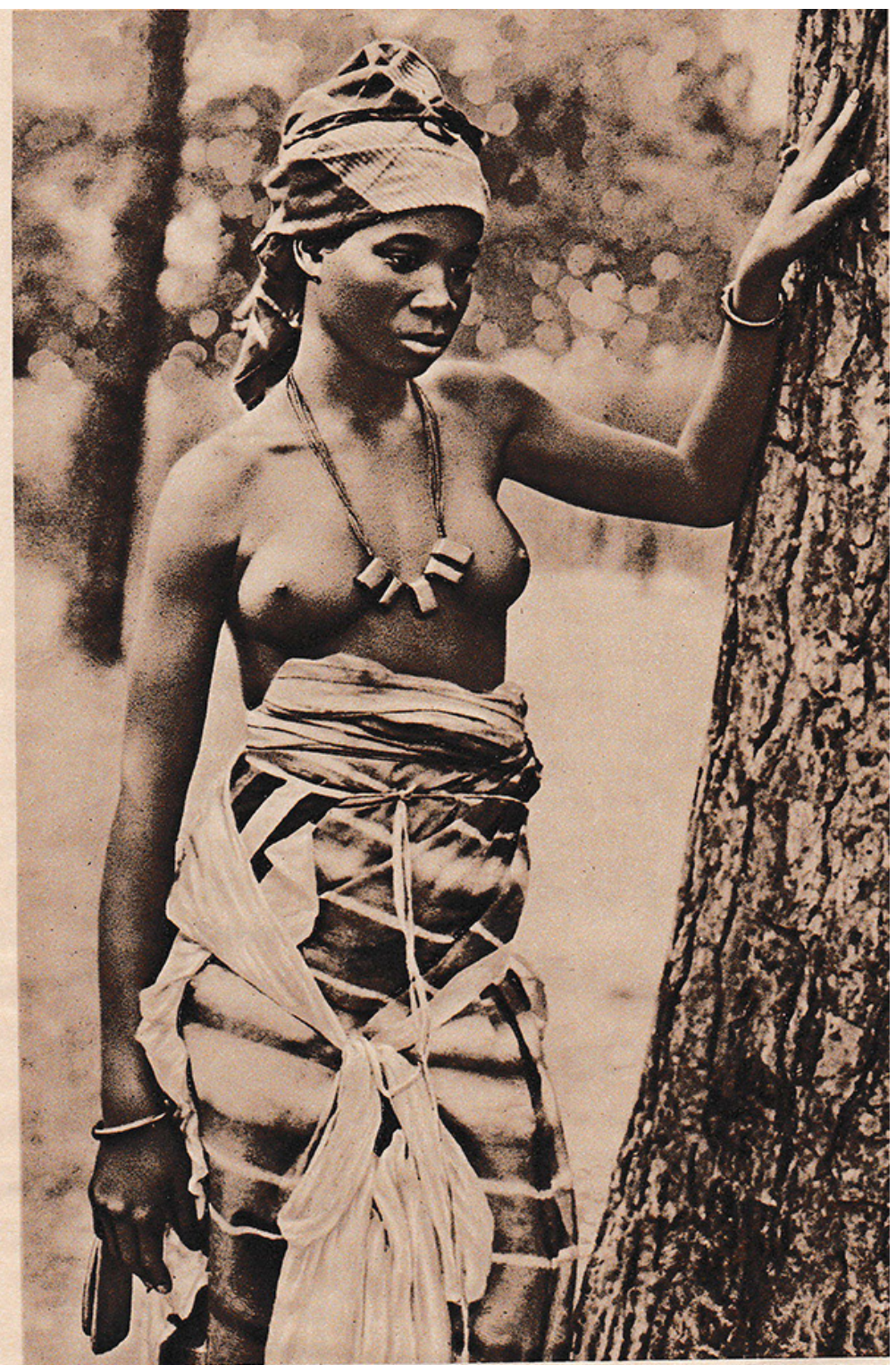

A young negress who cares little for modern conventions of dress in Algiers. Amulets on her bosom are meant to protect her charms Photo, Crété 


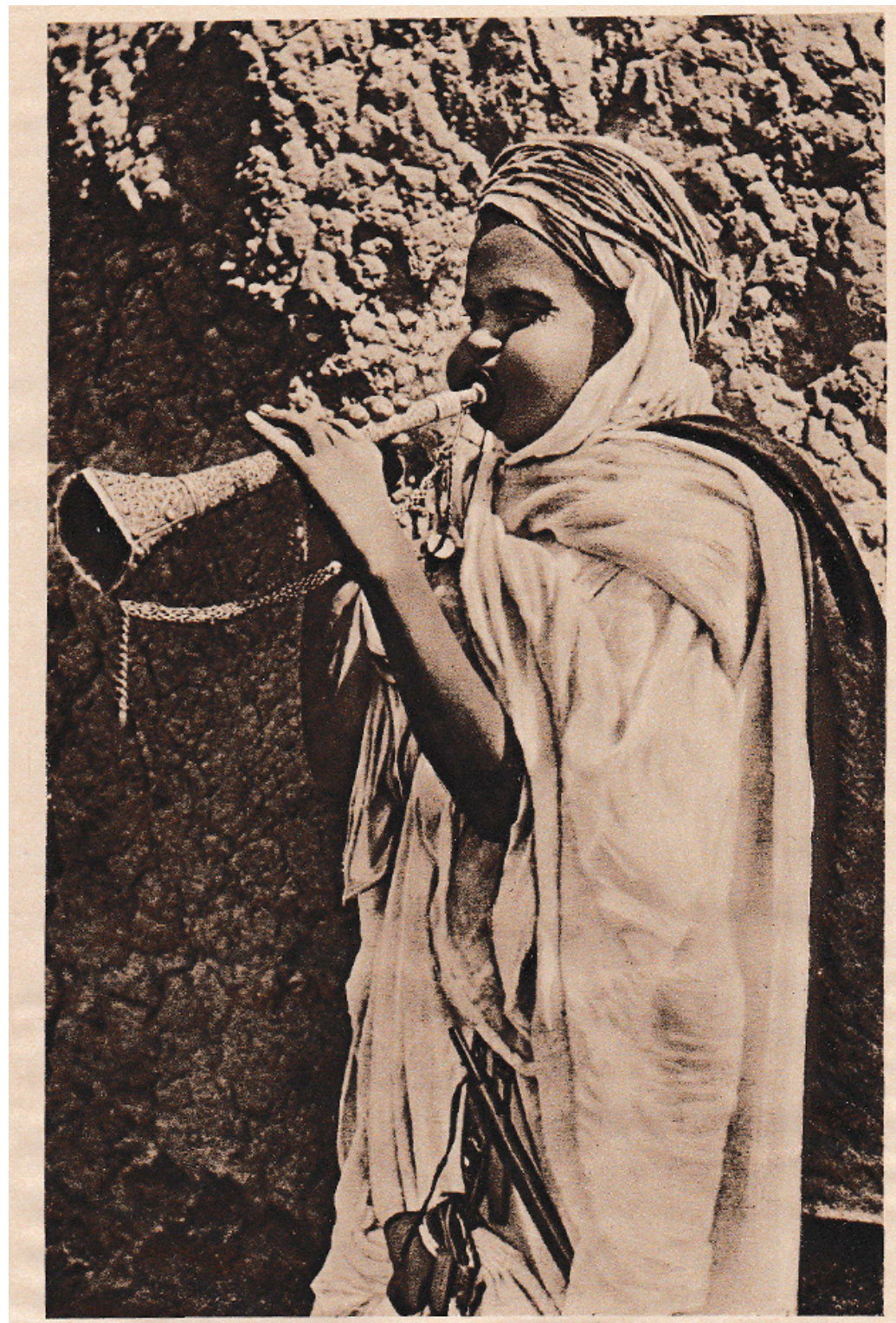

Fortissimo! The Saharan negro's zest for noise rather than music: even a delicate reed instrument he blowes like a trombone Photo, Crété 


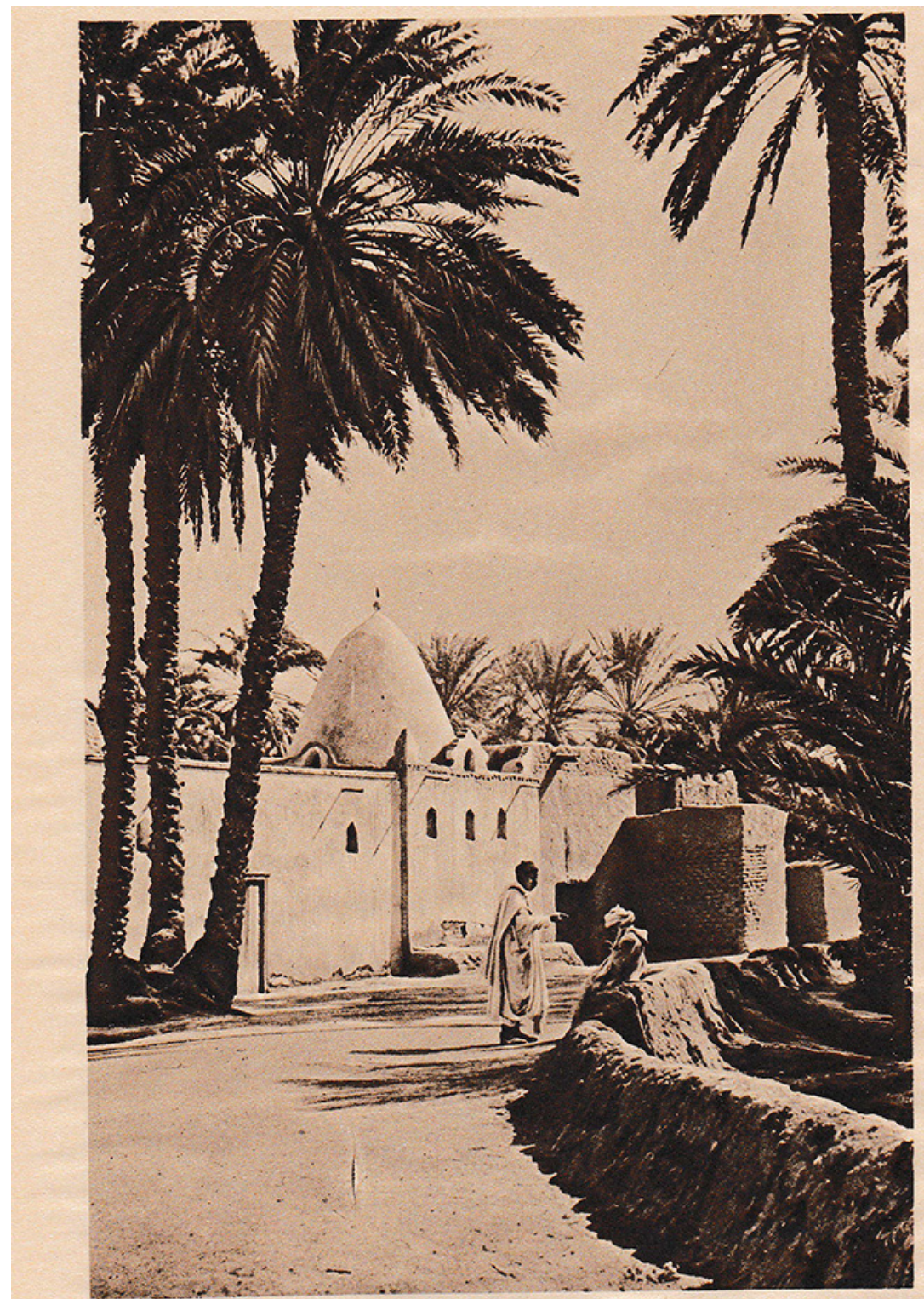

Old village mosque, standing amid myriads of feathery date palms, in the lovely oasis of Biskra, now famous as the "Garden of Allah" Photo, Donald McLeish 


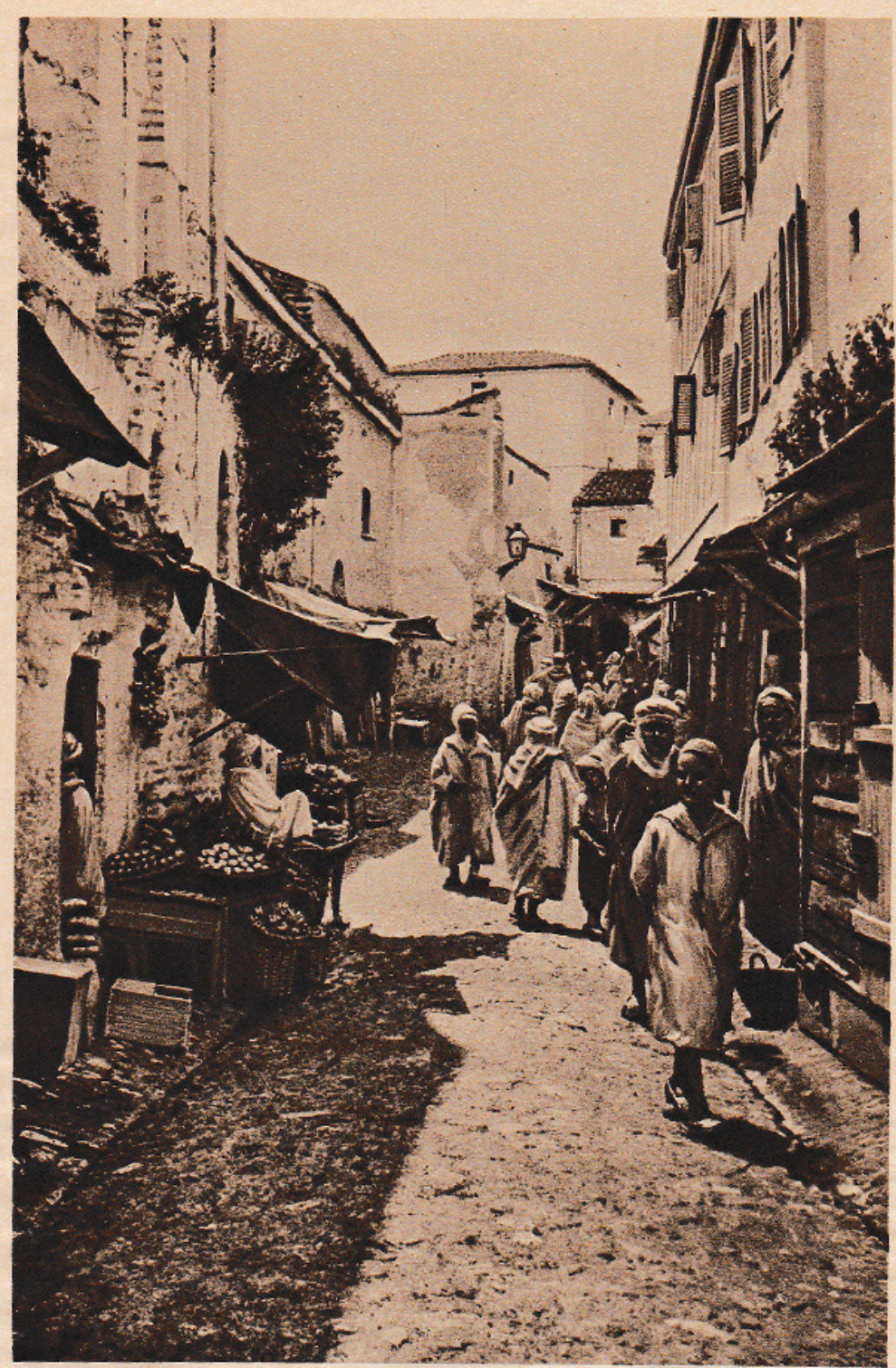

Quaint old Sidi Okba street in Algiers, with its stream of dark faces and white burnouses, retains the exotic wild charm of bygone days Photo, Henry Perrin 


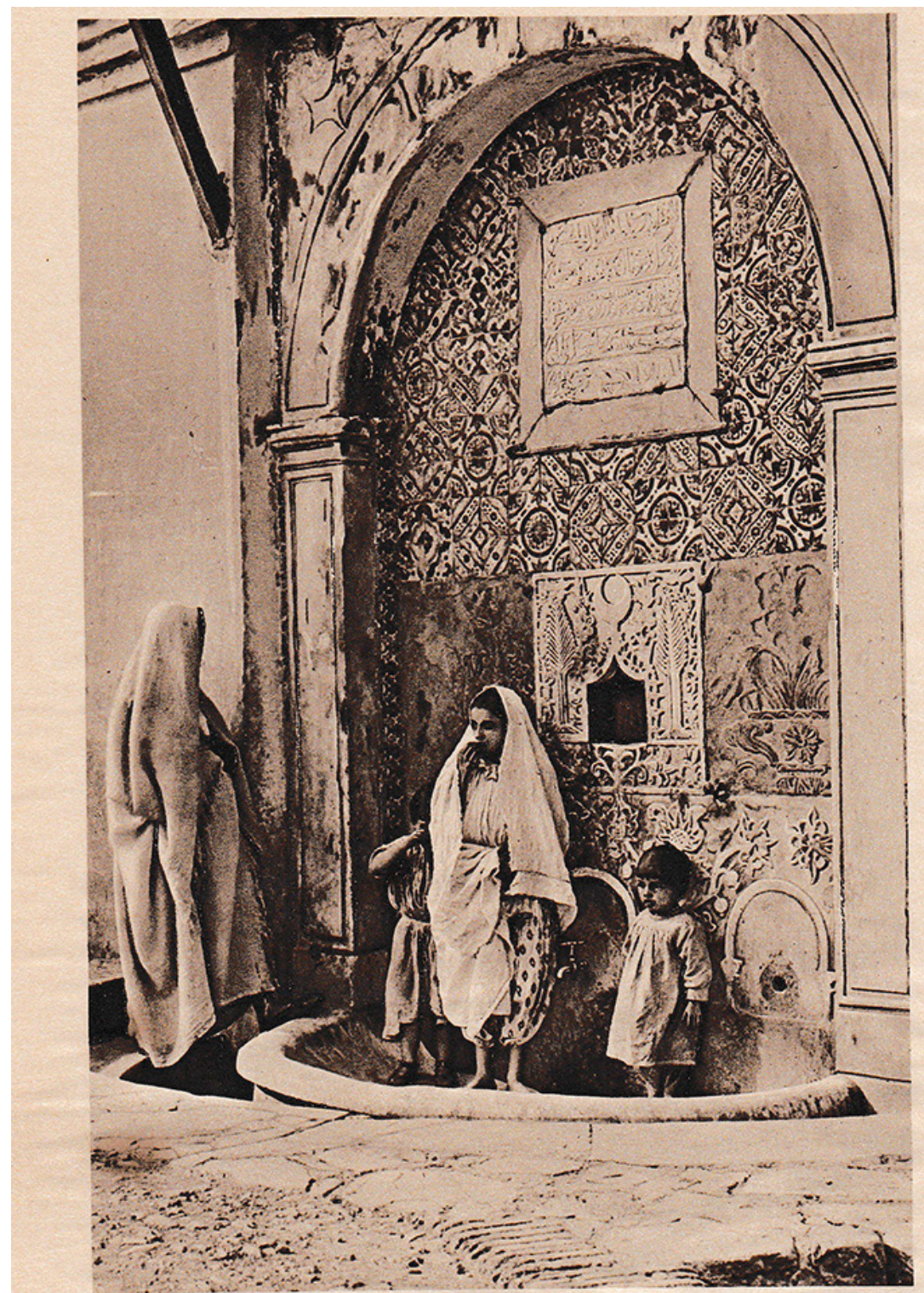

Graceful group of natives by a fine, ancient fountain in Algiers. The barefooted girl, with baggy trousers, is a pretty town type Photo, Donald McLeish 


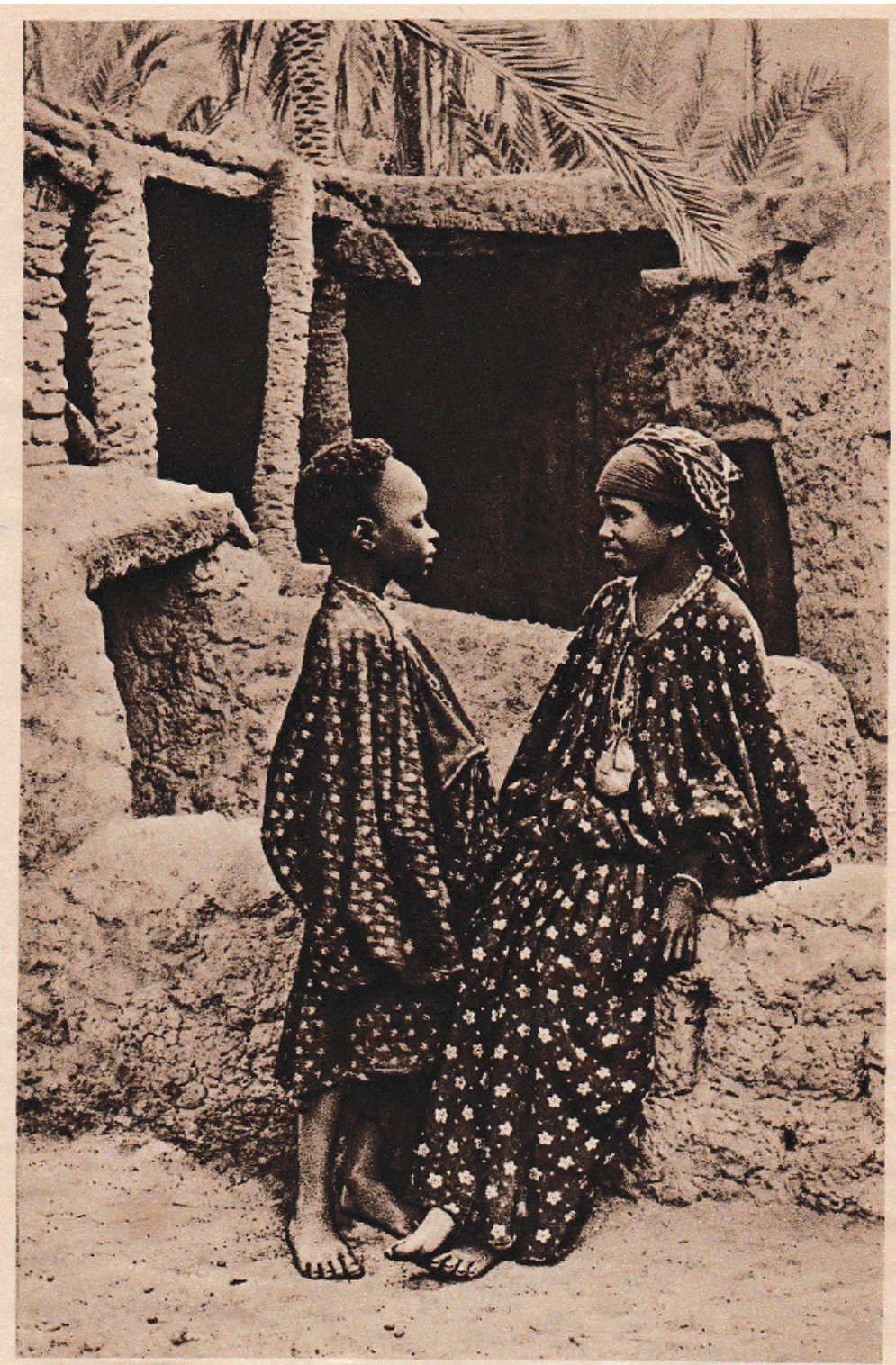

Girls of a northern oasis, showing the effect of seventy years' French culture; and, in the taller, the lingering faith in fetish charm bags 


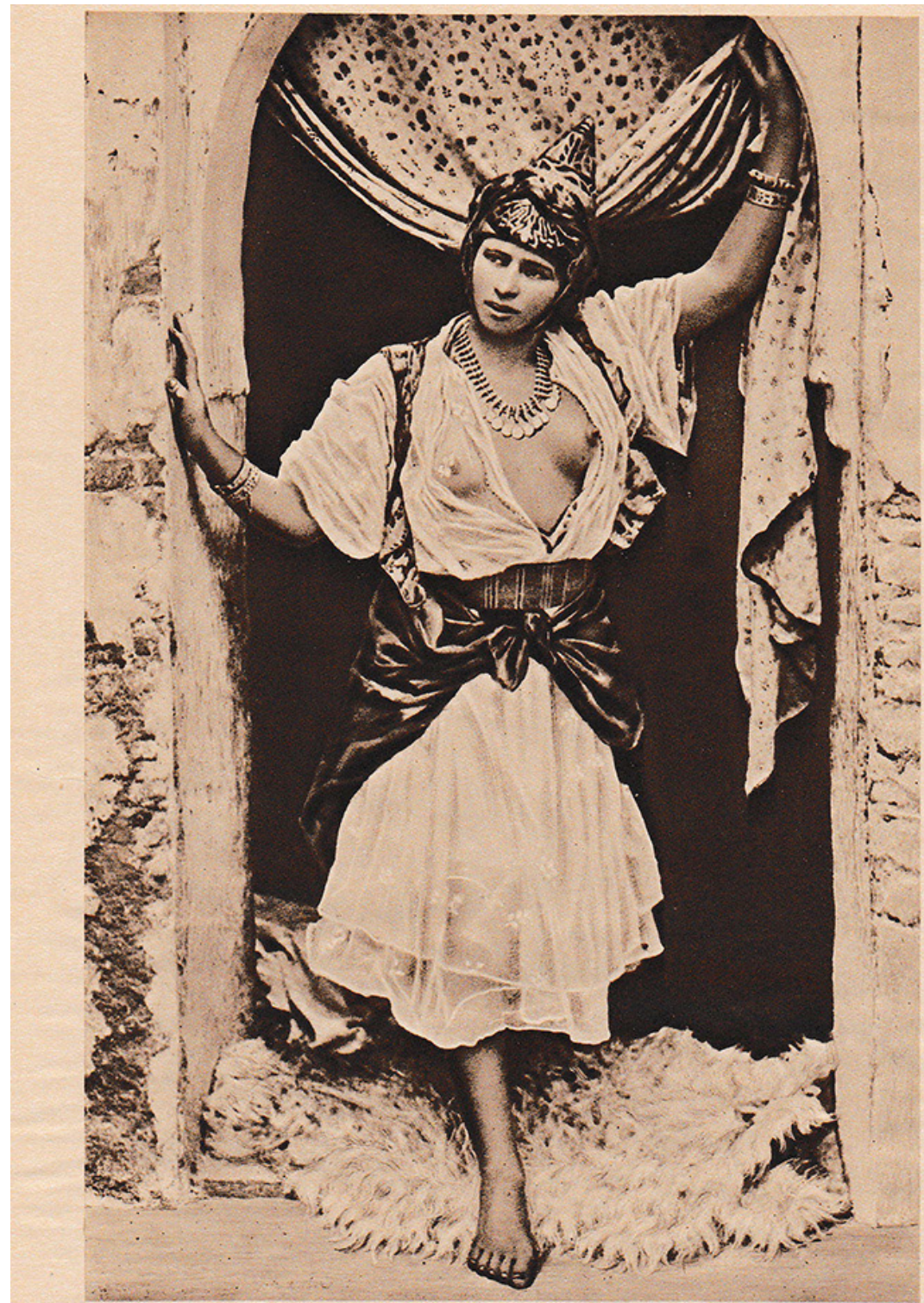

One of the Mauresque dancing women in whose veins runs the blood of European women captured by Algerians in the old piratic days Photo, Crété 


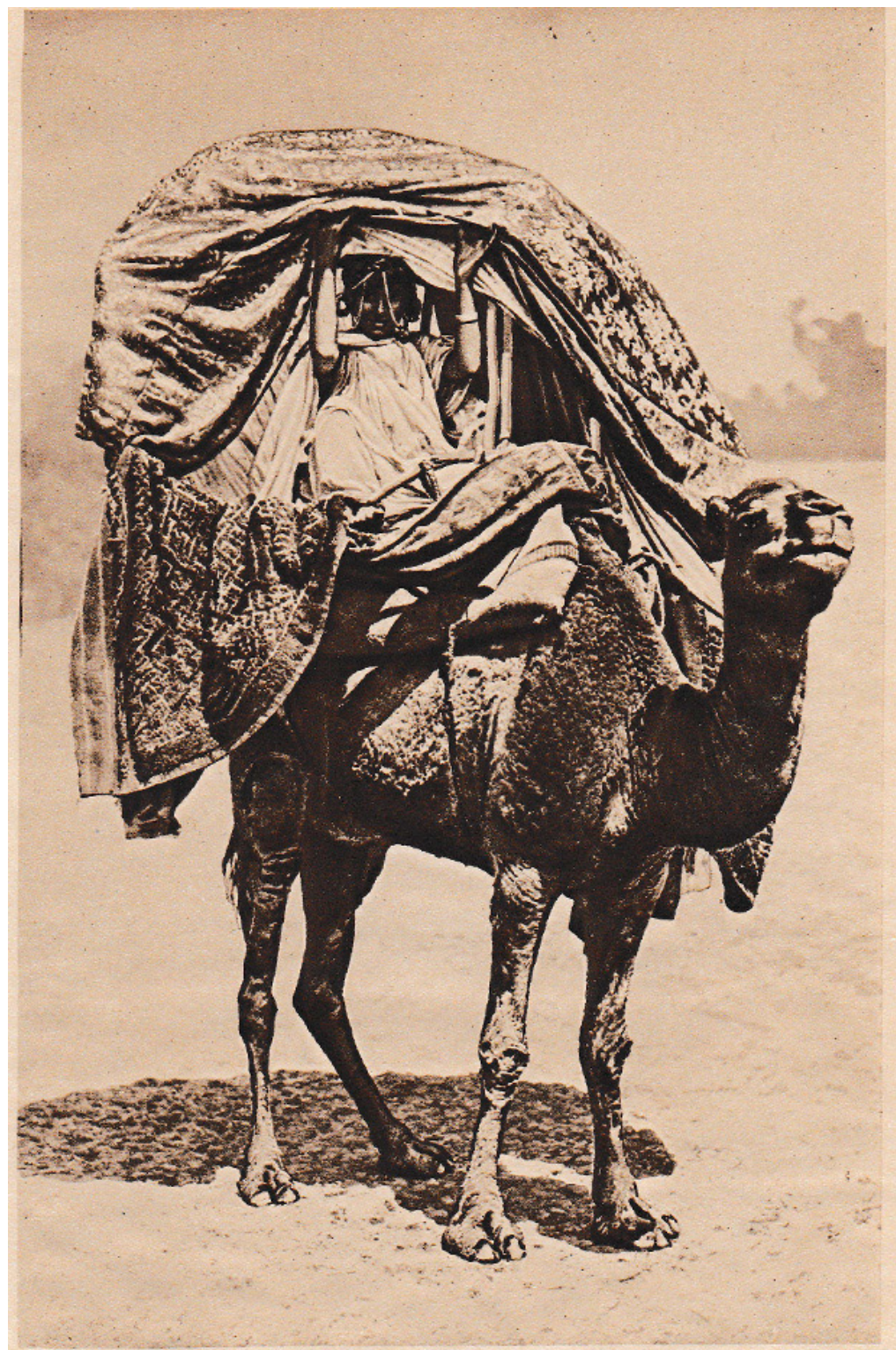

In her swaying camel litter, a desert beauty with barbaric ornaments keeps to the custom of the veil by carpet hangings easily lifted? Photo, Crété 


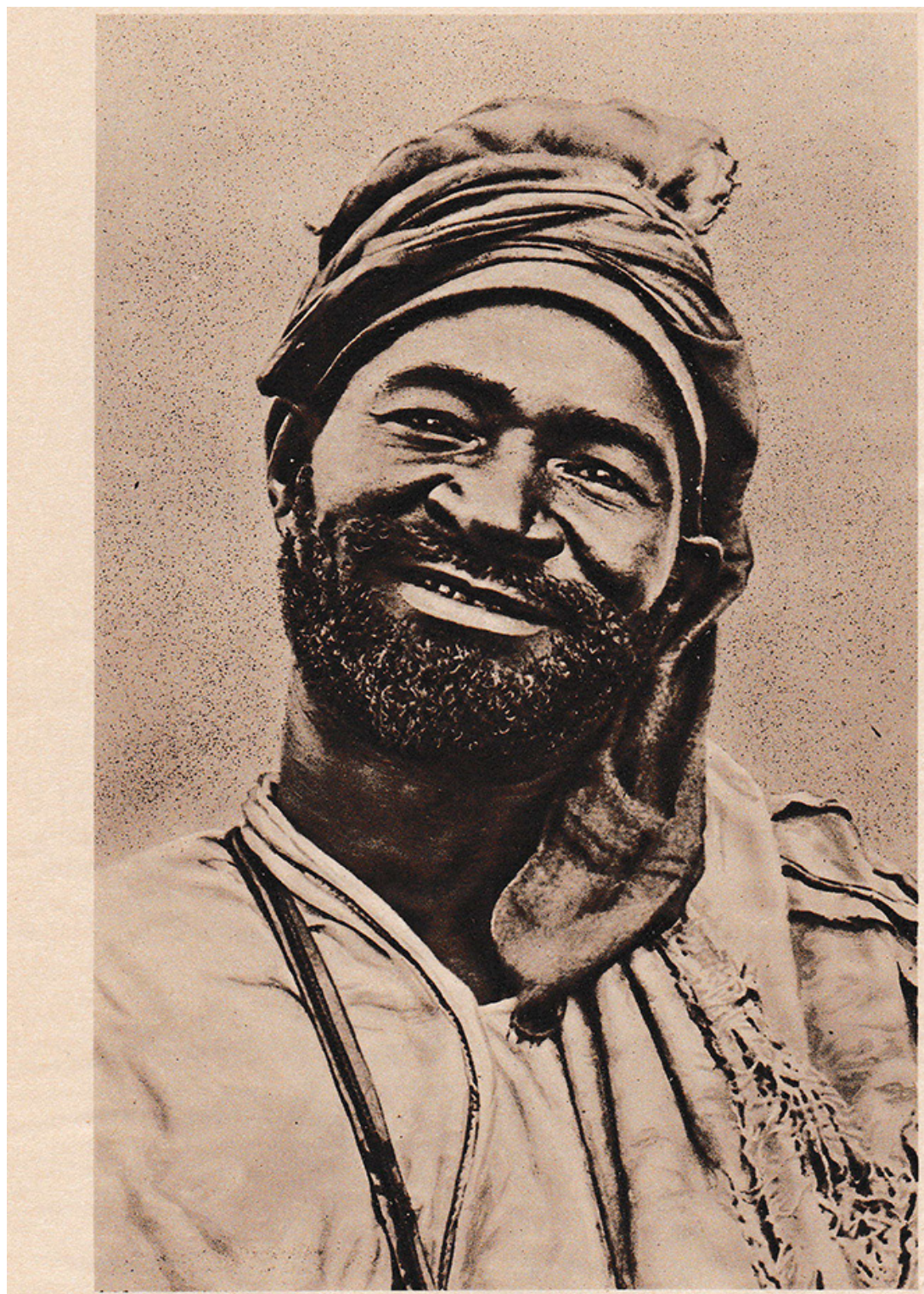

Like this jolly, swaggering negro, many of the blacks of Algeria are happy, self-satisfied fellows. There is no colour-line in Islam Photo, Crété 


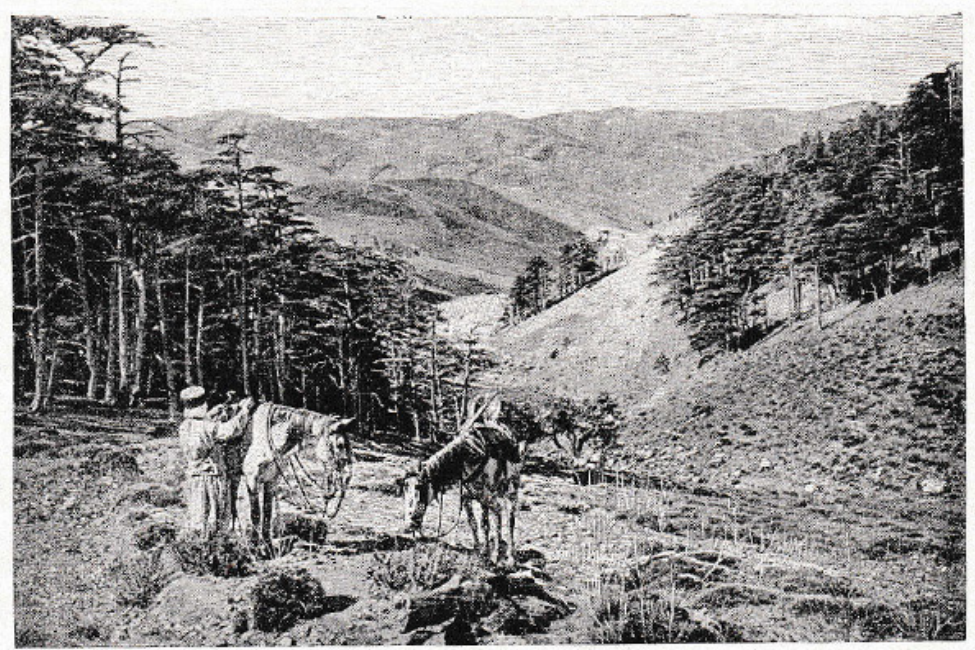

MOUNTAIN RAMPARTS BETWEEN CIVILIZATION AND SAVAGERY

From its cedar-dappled flanks the huge, broad masses of the Aurès can be seen rising some 7,650 teet to the crest of the Chelia. On the near side it stands above lakes and tilled fields to which raiders cannot penetrate. On the farther side it pours its streams into the Touggourt wastes

The space between the Great and Little Atlas is occupied by a tableland some 2,000 or 3,000 feet high.

The higher peaks of the Great Atlas are within the region of perpetual snow, and the drainage from them feeds many rivers, some of which are lost in the Desert sands to the south, and others cut their way north through numerous gorges and valleys to the Mediterranean. The high platean is swept by snowstorms in winter, and in summer bears large crops of alfa or esparto grass.

Besides Algiers there are a number of ports along the coast from which an extensive trade is done in the fruits of the Tell and the esparto grass from the high plateau. Oran, in the west, has a large Spanish element in the population. Bougie, Philippeville, and Bona are east of Algiers, on harbours which the Phœenicians first exploited.

Of all the inland towns the most remarkable is Constantine, which, under the name of Cirta, was the native capital of Numidia before the Romans came. It had its origin in a prehistoric rock fortress, and for moat it has the wild and romantic gorges, nearly $\mathrm{I}, 000$ feet deep, of the River Rummel, which circles round it. No city in the world has a more picturesque and remarkable situation.

The southern territories of Algeria, which are under a separate administration, stretch far into the burning sands of the Sahara, and the railway has now been pushed beyond Biskra to the distant oasis of Touggourt. Contrary to expectation, the Desert sustains a considerable population. It is interspersed with oases, many of which contain great forests of date palms.

The chain of oases in the Oued Rirh, on the way to Touggourt, contains 600,000 date palms, and supports a population of $\mathrm{r}, 7 \mathrm{OO}$. The wild Tuaregs have been tamed, and now bave a greater interest in the date harvest than in plunder. The oases are occupied by numerous tribes of Berber, Arab, Jewish, and Negro origin, some of whom, like the Mozabites, are famed as traders all over the country.

The French people, as a race, have a marvellous capacity for the logical development of an idea, and nowhere 


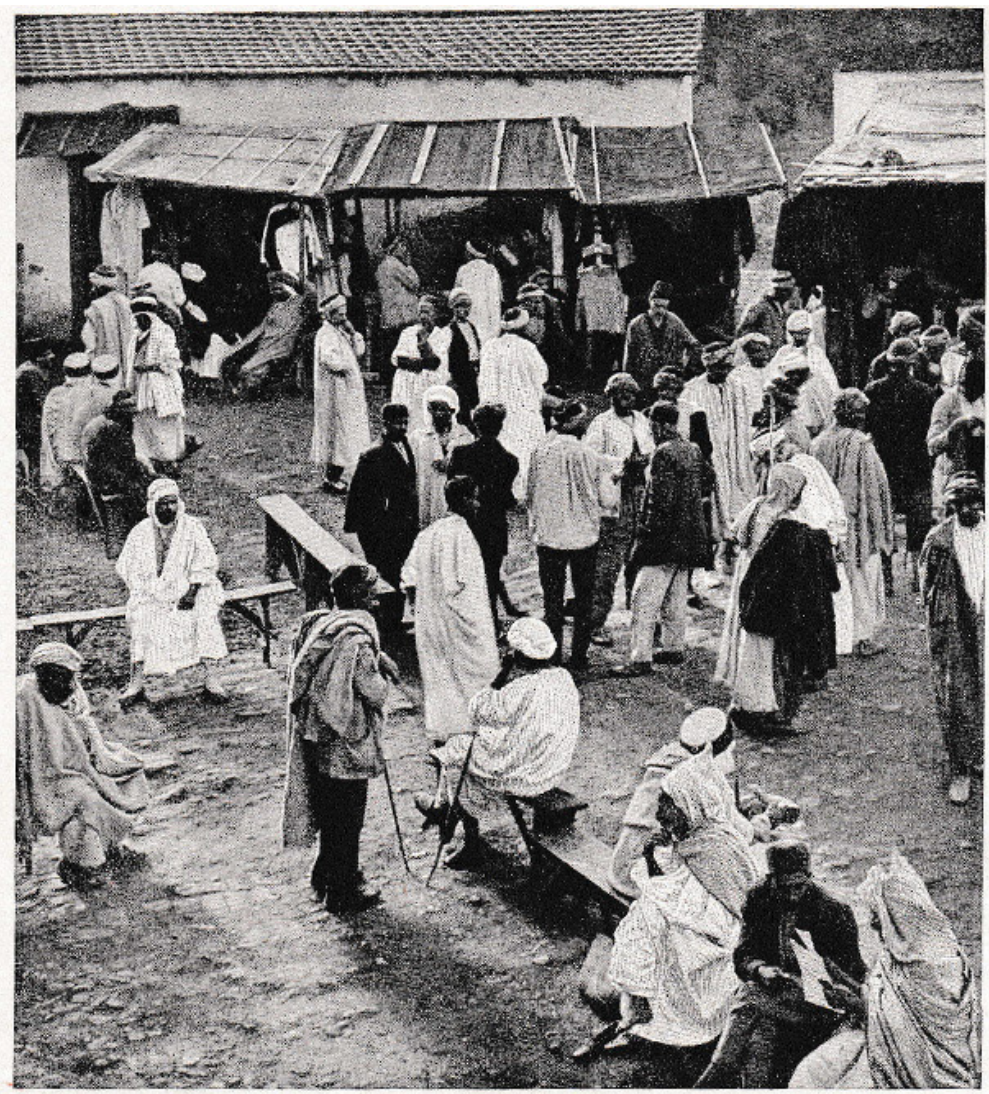

WHERE THE ALGERIAN MOOR IS BEST SUITED

In the clothiers' market in Algiers no man tries on a new garment in a shop. He walks out into the crowded centre of the market-place, and, after being fitted, takes the admiration and criticism of the public. Then follows a long dispute over the price, with the crowd as clamant chorus

Photo, Donald MoLeisth

is this trait more evident than in the manner in which they have dealt with Algeria. With conscious purpose they have set before themselves the Roman model. Their great military roads and railways which have opened up the country, their extensive irrigation works, their municupal development, their encouragement of agriculture by European colonisation their great permanent military camps, their dealings with the native population, and their lavish extension of the rights of French citizenship, are Roman in intention. The modern Frenchman finds Paris in Algiers, just as the Roman found the Forum, the Market Place, the Theatre, the Temples, the Baths of Rome at Timgad on the slope of the Aurès Mountains.

Many races have mingled their blood in North Africa since the days of the Romans, but the indigenous native stock remains in essential respects the same. The Berbers speak the same language to-day as they spoke in the 


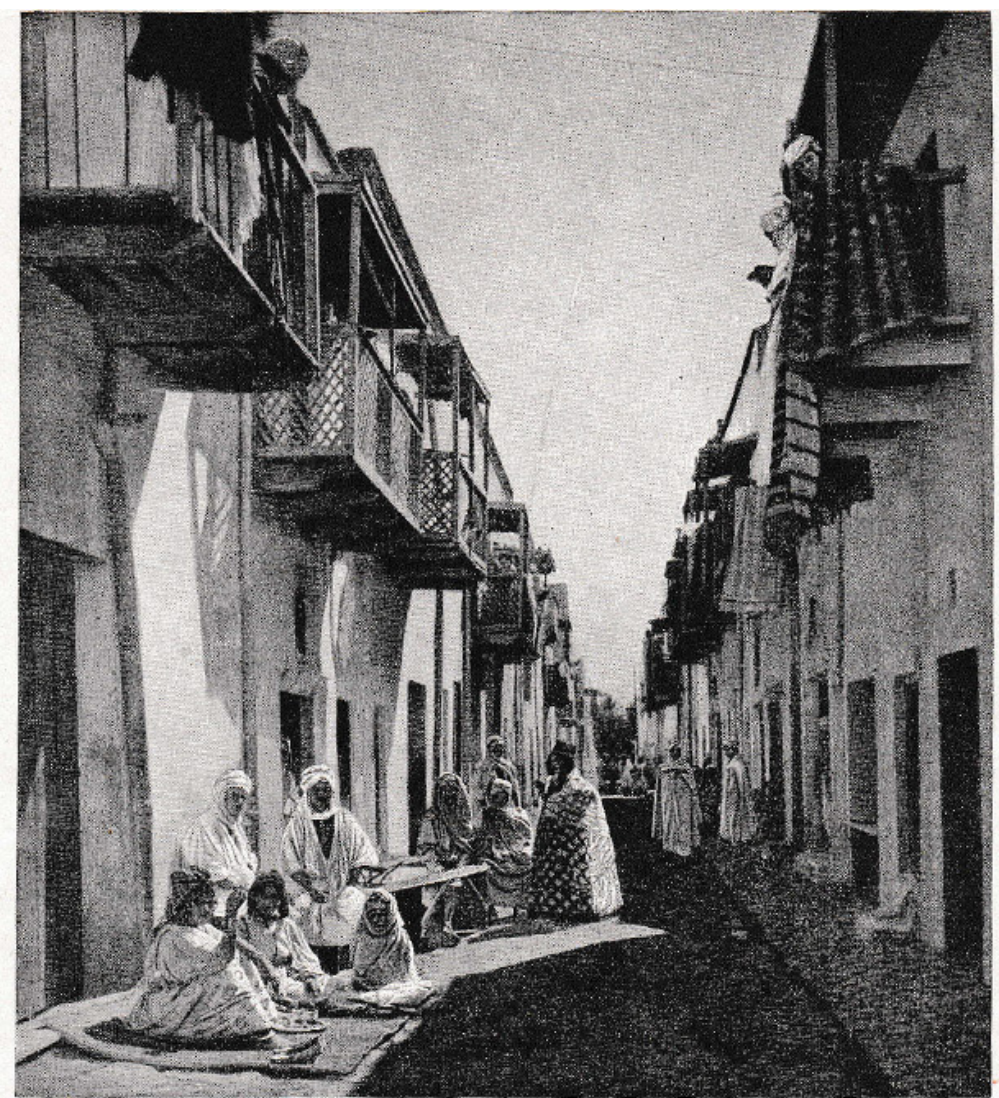

SIRENS OF THE SANDS IN BISKRA'S HOLY STREET

When thetr training is finished, the girls of the Ouled Nail often make their first appearance in a Biskra alley, oddly named "Holy Street." Squatting on their dancing-carpets in the open air, or lcaning from their balconies, they gaily await admirers of their arts and charms

Photo, A. Bosparth

days of the Phøenicians and the Romans. The chief branches of this widespread race are the Kabyles and the Shawias, the highland tribes of the two great mountain ranges of Djurdjura and Aurès respectively.

In the gorges and valleys of these mountains they have preserved the purity of theit race and language in a remarkable degree. Many of ie Desert tribes are of Berber ongin. As a race they have many European characteristics, and they are supposed to be a branch of that Iberian stock which once populated the northern shores of the Mediterranean, and even reached as far north as Britain. With the exception of those who have acquired the nomad habit from the Desert, they are an industrious agricultural and pastoral people.

The Phonicians, the Romans, the Vandals came and passed, leaving hardly a racial trace. There were great numbers of them, but they were absorbed. The Asiatic races, the Arabs, and the Jews have preserved their 


\section{ALGERIA \& THE ALGERIANS}

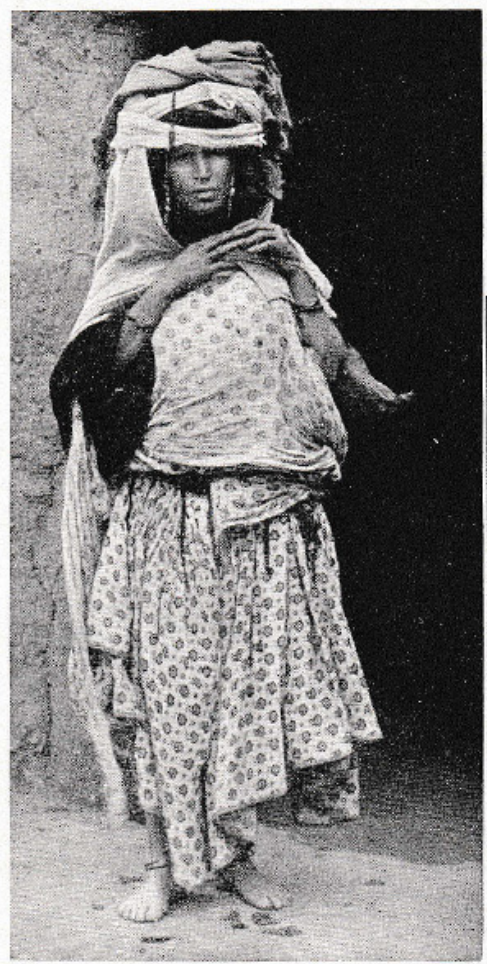

NEW CLOTHES, OLD FASHIONS

This Biskra woman thinks that dress is civilization, but she wears the old grease, wool, and hair frame for her saffron-dyed face

$$
\text { Photo, Donald MeLeish }
$$

type more persistently, but even the Arabs show signs of becoming merged in the indigenous stock. The so-called Moors, who inhabit the towns and the coast villages, and who carry on the trade and crafts of the country, are really a mixed race, showing the Arabs in process of absorption.

Religion has kept the Jews a separate and exclusive community, as it has done throughout Europe. A relic of slavery is the noticeable infusion of negro blood.

France has laboured to promote European colonisation by generous grants of land, and by scientific irrigation, railway development, and education. The soil is rich, the climate is sub-tropical. The elevation of the tableland gives it a European character, and in the Tell, the broad belt where the tableland breaks down to the coast, intersected by fertile valleys and plains, moisture is abundant, and vegetation luxuriant. Here

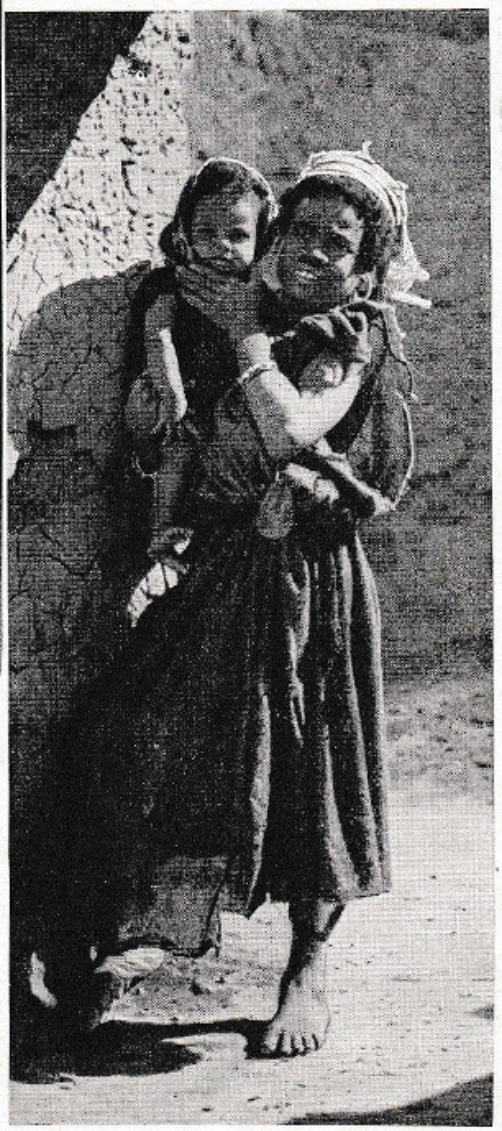

BABIES THEY LEAVE BEHIND THEM Biskra's wealth of mulattoes is largely due to the Senegalese negroes of the garrison of the oasis town, whose temporary alliances completed the work of the old slave-hunters

Photo, Donald acterish 


\section{Biblioteca}

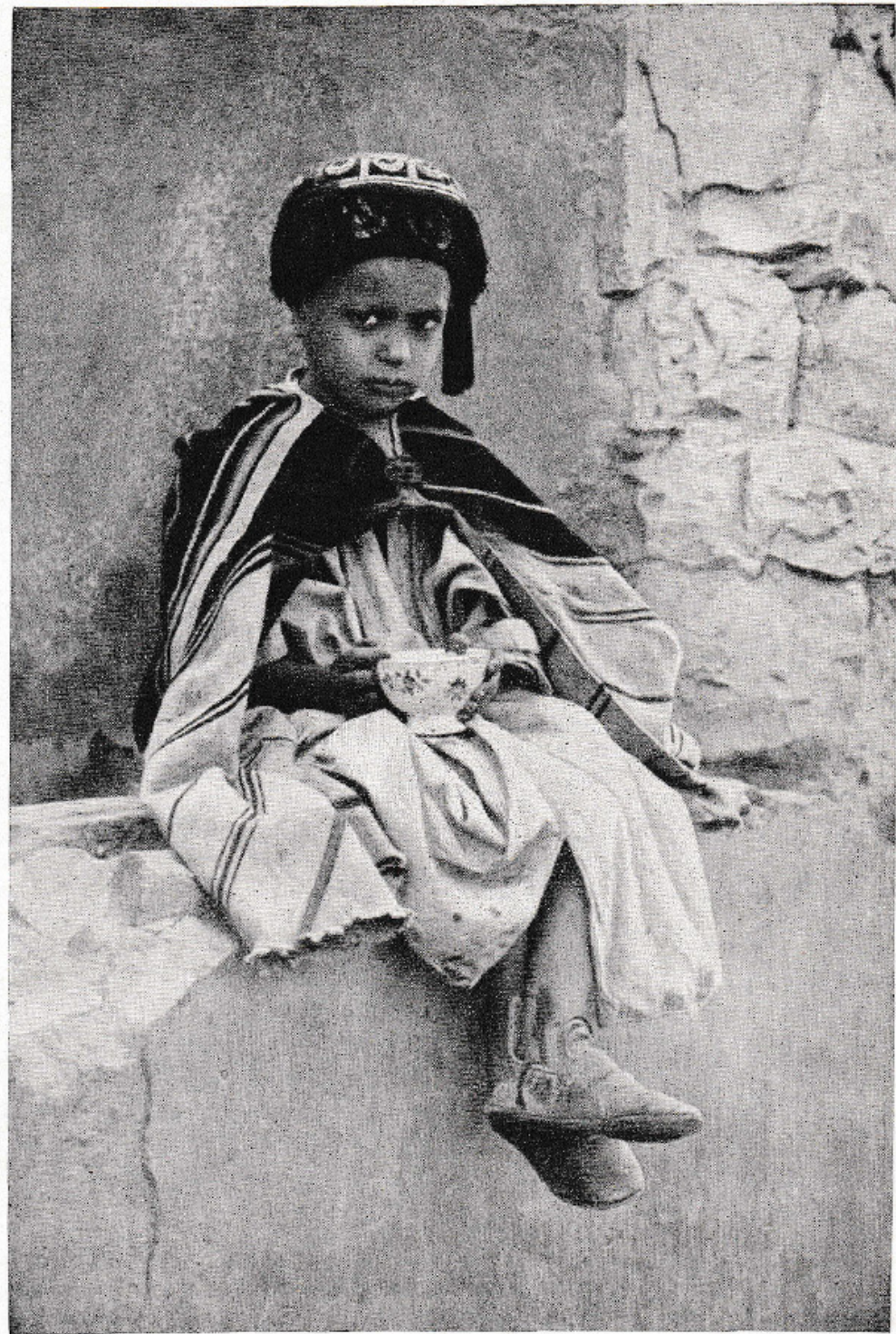

THE CHILD WHO IS FATHER TO A NATION IN THE MAKING

In the expanding oases-land south of Algeria this improving type of the young half-breed is being gently crammed with modern knowledge by French schoolmasters, while the fanatic marabouts try to keep him in Islam with Koran lore. He is the new mulatto; as he shapes so will a nation Photo, Donald McLoish 


\section{ALGERIA \& THE ALGERIANS}

flourish the vine, the olive, the fig. the orange, the lemon, the almond and the tobacco plant. Vineyards and groves extend on every side. On the wide alluvial plains of the Mitidja and the Chelif large crops of wheat, barley, and oats are raised.

Up on the tableland the soil lacks sufficient natural moisture, but responds readily to Irrigation by artesian wells. The nomad dwellers on these high plains pasture great herds of cattle, sheep, horses, mules, and goats. Enormous quantities of esparto grass (alfalfa) are collected and exported for paper making.
The date palm grows luxuriantly all over the country, but its fruit ripens only in the Desert; not north of the thirty-third parallel of latitude. It stands, as the Arab proverb says, "with its feet in the water and its head in the fires of heaven." In the channels of the intermittent streams which flow down from the Atlas and lose themselves in the Desert, and in the oases which have been extended by irrigation, the palm spreads a perpetual canopy of grateful shade. Each tree produces from one to two hundred pounds of fruit in the season.

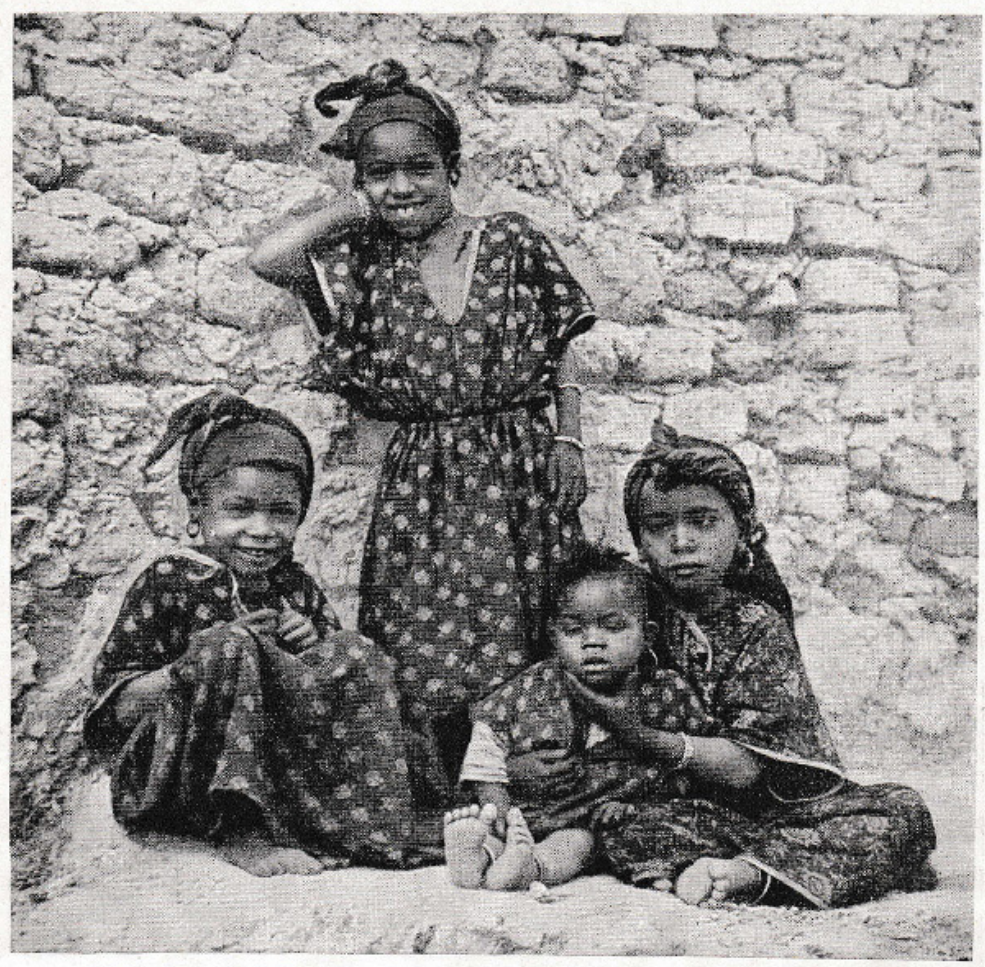

BITS OF LIVING JOY IN AN ARID WASTE OF DEAD SORROWS

These happy negro children of the oasis of Biskra are the best evidence of the humanising influence of France in Algeria. They are descendants of the miserable, diseased oasis slaves of the Tuareg tribesmen, who were marched like cattle from Timbuktu and then almost worked to death. The old place of doom is now gay with life in winter Photo, Donald McLeishi 


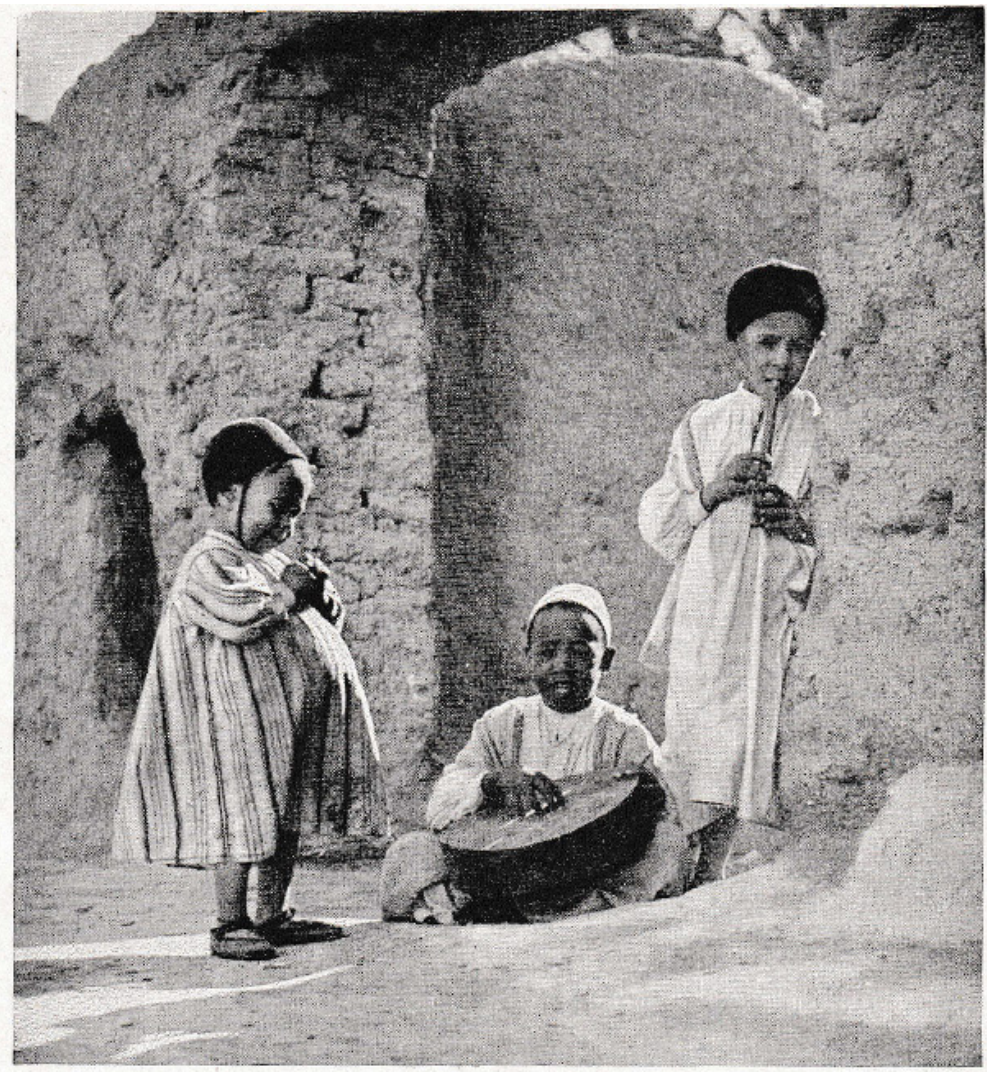

LITTLE MUSICIANS OF A GREAT OASIS

The fife of the Arab lad is made from a reed from an Atias svatercourse, and the tunc soc: wandering as it likes. The tambourine of the young negro is a sheepskin stretched over two wooden hoops; from it is beaten out a rhythm that doesn't agree with the fifing. The duet is symbotical of racial characteristics at Biskra

\section{Photo. Donald MALersh}

Without the palm, the Sahara would be uninhabitable. Its delicious, sweet, and nutritious fruit is a source of wealth to the Arabs, and the basis of a prosperous export trade.

In many respects this land is smlar to Palestine, the land flowing with milk and honey. It has the same climate, the same fertile belt along the coast, the same mountainous interior, and the same Desert beyond.

Such is the Promised Land which France has laboured for nigh on a century to Europeanise. Her success, in all material respects, has been great, surpassing even that of Rome in her first century. The Pax Gallica has been established. The rich lands which had relapsed into wilderness have been reclaimed. Colonists have been settled. The natives have been given the rights of French citizenship.

And yet, as Gaston Boissier confesses in his inspiring book on "Roman Africa," spiritually Algeria remains obstinately alien to Europe. The 


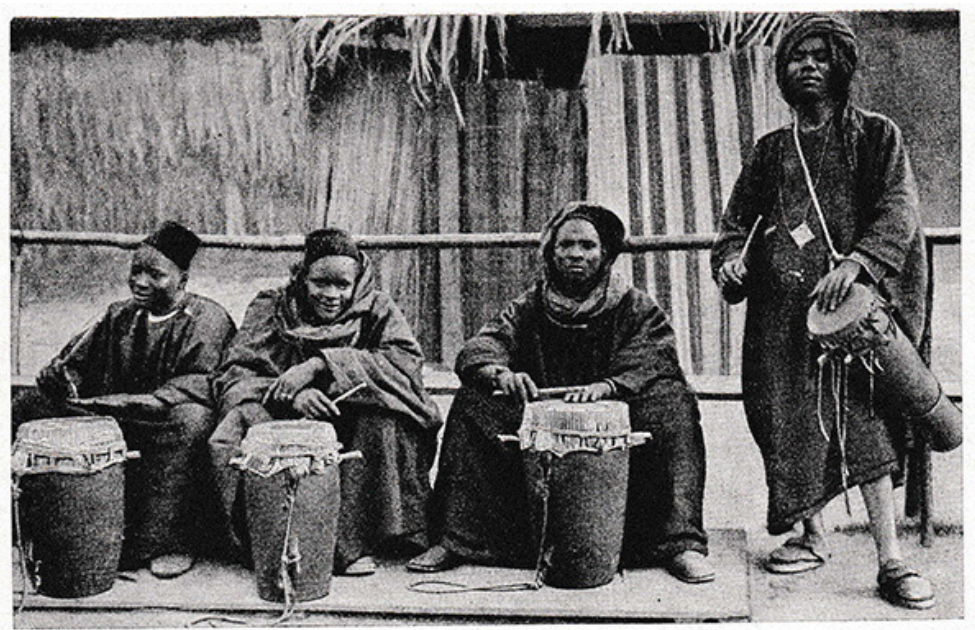

NEGRO MINSTRELSY IN ALL ITS PRIMITIVE CLEVERNESS

Out of the black heart of Africa comes the fierce element of strength in the weird music of old Barbary. With nothing but their four tom-toms, these negro drummers make a music of pure, pulsating rhythm charged with emotional effects that throb upon the nerves and sway the soul Photo. Crele

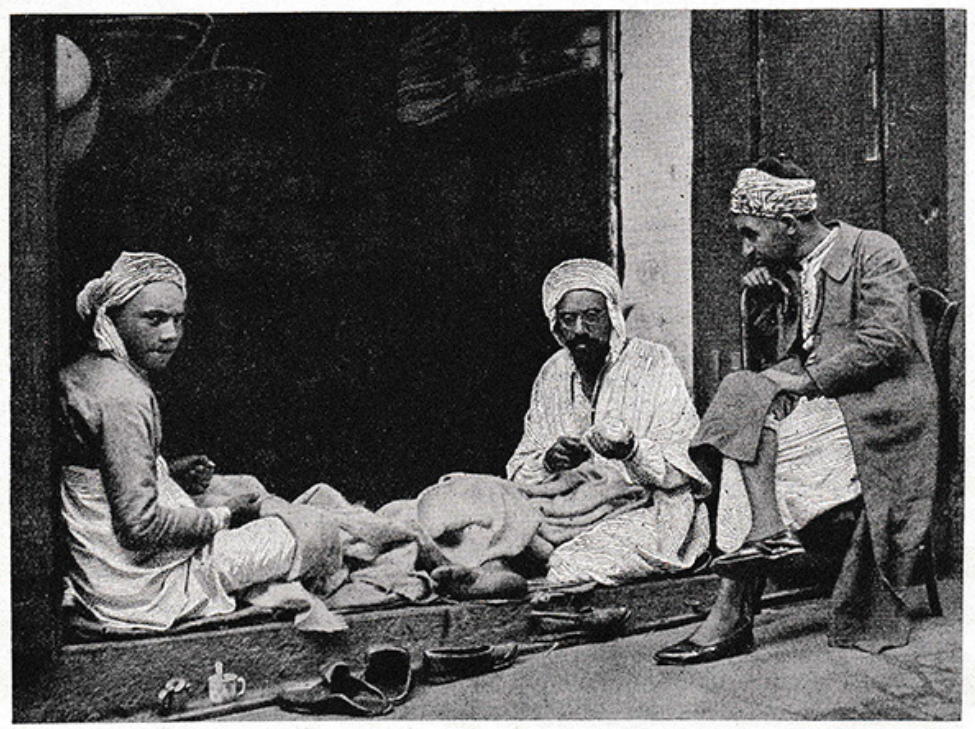

THE SHOP CAVE IN THE WALL AND ITS REASON

By the timiest of booths, these Algerian tailors are finishing a burnous, or long, white woonen cloak. Under the Turks, prosperity in shopkeepers was a crime; their descendants still squat at work by an open cave, however good their business, for this was the old way of avoiding confiscation Photo, Donald MeLeish 


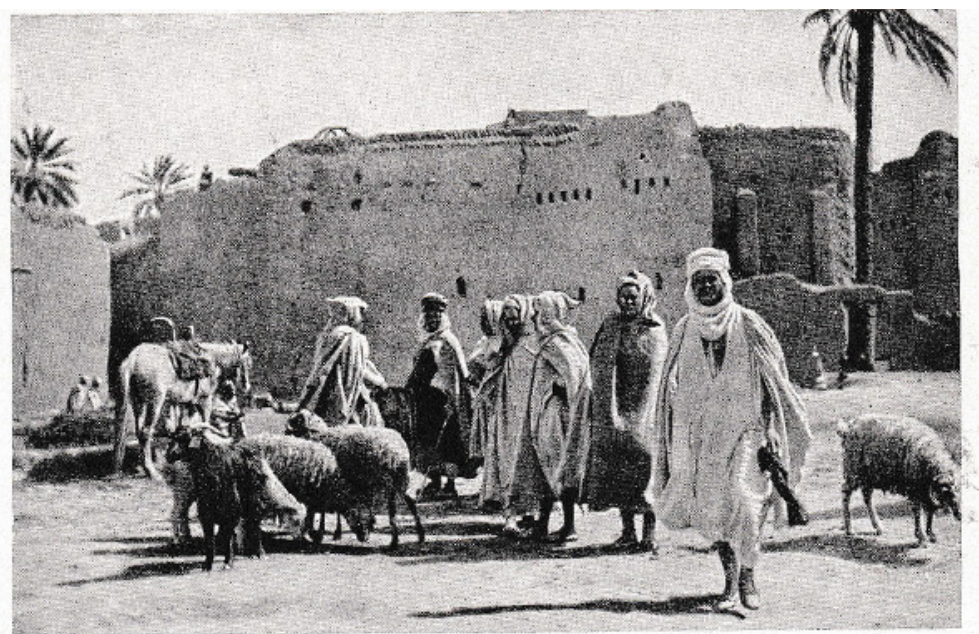

BY THE GOLDEN GATEWAY OF THE OLD SAHARAN PLUNDERERS

At Biskra, where these shepherds now peacefully tend their sheep, there is a break in the great rock wall of the Atlas. Through it Desert raiders used to pour, and through it from Roman days marched avenging forces. A source of gold it was also, when columns of slaves toiled wearily through it Photo, Miss C. Y. Huter

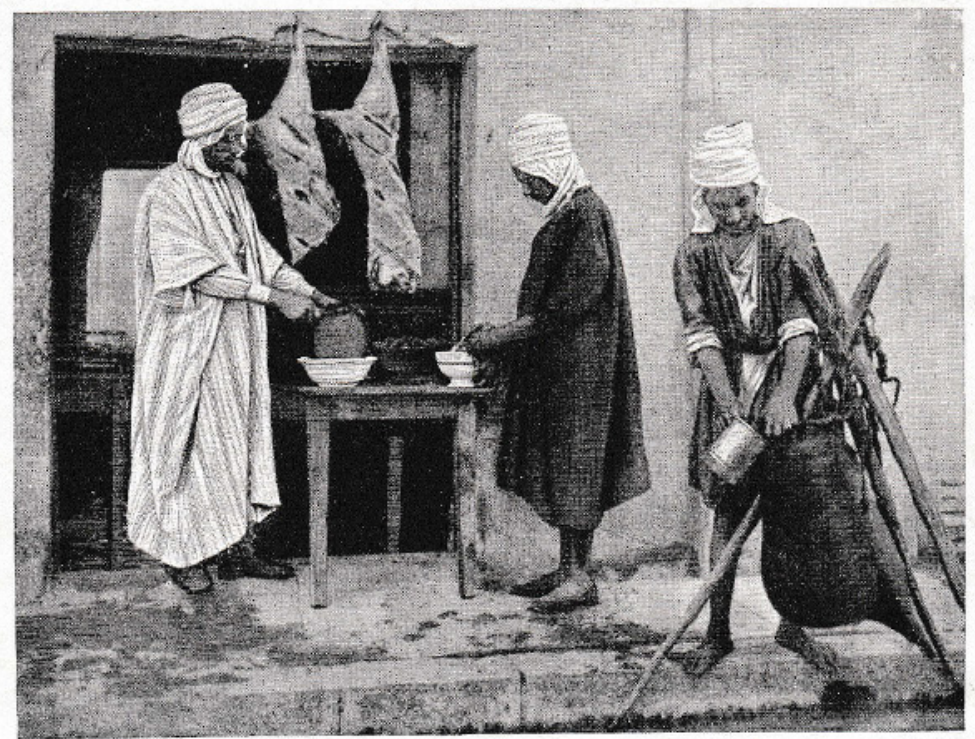

THE LAST REFUGE OF ROMAN ARTS OF COOKERY

It is an adventure to eat a meal in the spicy, smelly, native quarter. The Moorish cook is a It is an adventare the men who served Lucullus. His meat flavourings are sometimes fearful to remote descendant of the men who served Tuculus. Photo, Crete 


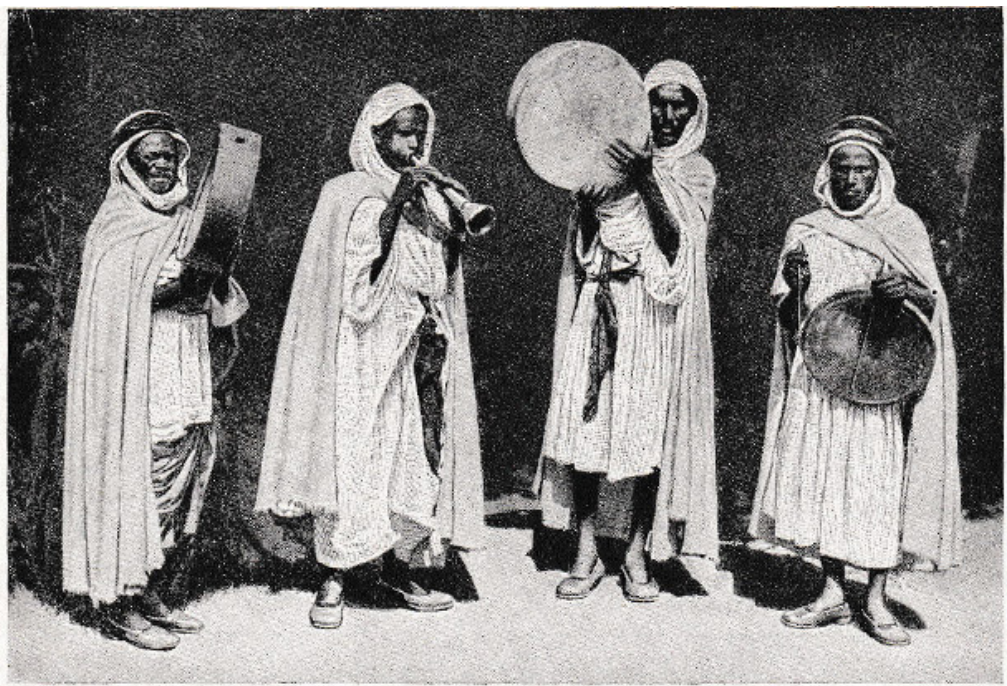

ONE BLACK FLUTE TO TWO BLACK TAMBOURINES AND A DRUM

The curious airs this flute-player can finger out of a few notes are not remarkable, but in the rhythms and cross-rhythms which the tambourine strummers and drummer weave as an accompaniment are

strange, wild effects of which syncopated Negro-American melodies are but faint, poor echoes

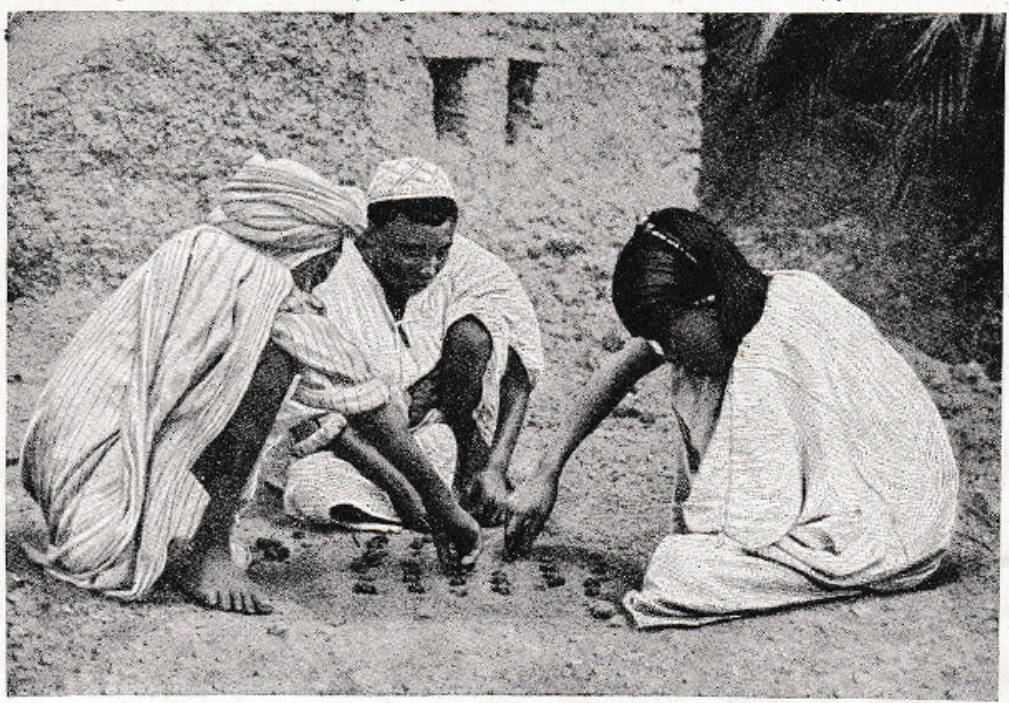

THE WAY THEY PLAY DRAUGHTS IN THE SAHARA

Arab boys of the Desert love checkerboard games with all the zest of their Saracen foretathers, but boards of morocco leather and pieces of ivory are only for sheikhs Even wood is so scarce in the Sahara that camel dung is used for fuel. So the young players draw their lines in the sand, and make their draughtsmen out of the fuel material

photos, Crett 


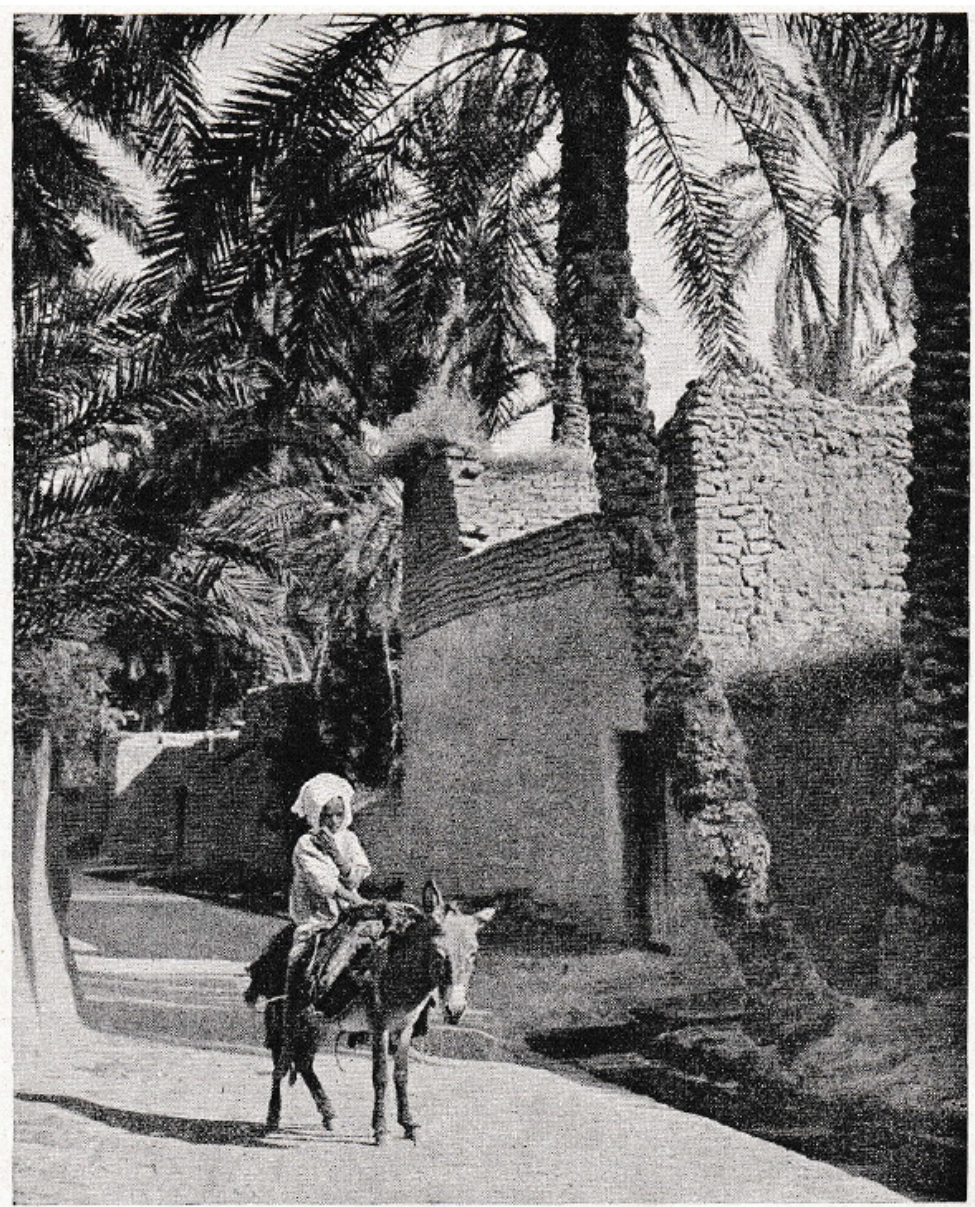

TRANSFORMING A ROCKY WASTE INTO A PALM-SHADED TOWN

When the French Army conquered Biskra it was a poor, mud-built hamlet set on the dry, stony fringe of the sands. Underground streams were found by digging, and now Biskra, with a quarter of a million date palms, lordly pleasure gardens, rich ficlds, railway, trams, cabs, and hotels like palaces, attracts the Sahara tripper from all parts of Europe

$$
\text { Pkoto, Donali MoLeisis }
$$

inhabitants have not been won over. There has been no fusion, no real union. The natives cherish their separatebeliefs, customs, instincts, antipathies. At heart they are the mortal enemies of Europe. Indeed, so far as any movement is discernible, it is in the contrary direction. The European element in
Algeria is becoming gradually Africanised. The African sun will not be denied. The streams of European colonisation are gradually absorbed into an African stock which is different from that of Europe in spirit, just as the snow-fed rivers from the Atlas sink into and are absorbed by the Desert sands. 


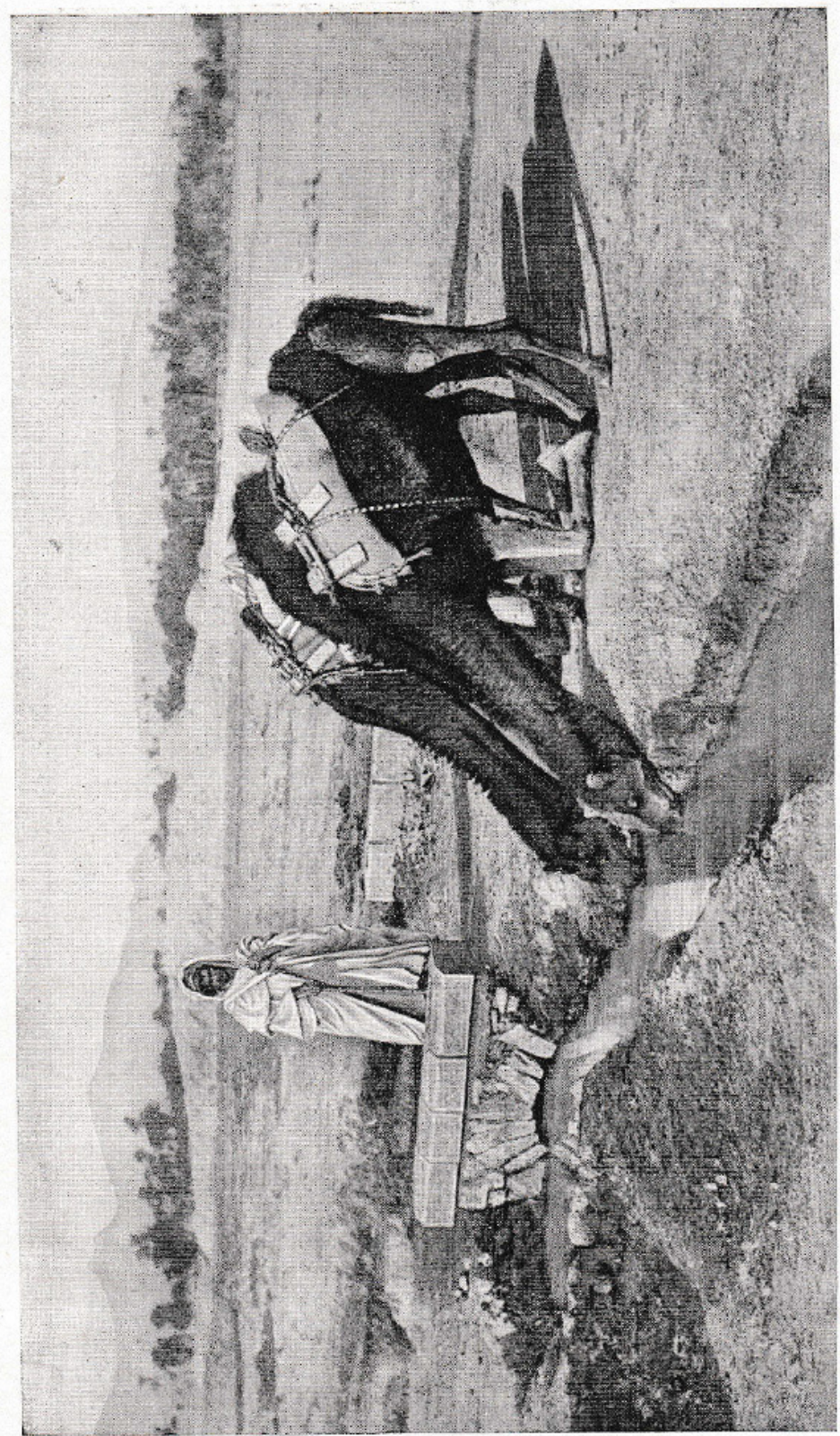

월

Z

동영

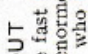

우용

占可器

3.

$\rightarrow \stackrel{f}{>}$

品骂总

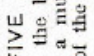

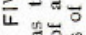

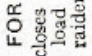

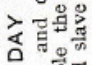

《卷亭蒙

o 5

这的跑

$\succ$ 해를

造的

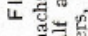

ㅇํㅇ हुำ

ํㅗㄹ

의웜

w

$\vdash$ 도융

过

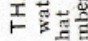

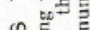

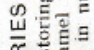

in

合

$\sum_{0} \Phi$

吅高

$\overrightarrow{0}$ б

送

콜롤 



\title{
Algeria \\ II. The Story of Old Barbary and New France
}

\author{
By Rachel Humphreys, F.R.G.S.
}

Author ot "Algiers, Sahara and the Nile"

$\mathrm{A}^{\mathrm{r}}$ GERIA, the ancient Barbary, now the chief of the French Colonies, extends about 600 miles along the African coast of the Mediterranean, and southward to the Sahara, its entire area being one-sixth larger than France. The fertility of the land has always made it a target for the invader, and it now consists of at least seven distinct racesArabs, Moors, Turks, Jews, Kabyles, Negroes, and Koolooglis. Probably the aborigines were the Kabyles.

Three thousand or so years ago, says Sallust, the army of sundry Oriental nations which Hercules conducted into Spain being dispersed, many Persians, Armenians, and Medes passed over to Africa, and mixing with the natives they became one nation called Numidia. This territory was again divided into North and South Numidia, the kingdoms of Massinissa and his rival, Syphax.

Syphax ingratiated himself with the Romans against the Carthaginians at the beginning of the Second Punic War, but later went over to the side of Carthage. Then it was that the Romans came on the scene; the Numidian territory was divided into severa! parts and enjoyed the bounty of the Roman Senate in tranquillity till Jugurtha, King of Numidia, gave their rulers the first trouble, causing a war of five years. At the end of it he was betrayed into the hands of Marius and Svlla. After hus death there was much guerrilla warfare which only ceased when Julius Caesar decreed Numidia a Roman province, with Sallust, the historian, as governor.

\section{The Vandals Over-run the Land}

The Vandals, now not content with their kingdom in Spain, which was founded in $4 \mathrm{II}$, invaded these Roman territories of Barbary, under Genseric, and conquered them in A.D. 429. Till the beginning of the eighth century, these peoples over-ran the land, despoiling everything, so that many of the former fine cities were destroyed, and the strides towards civilization the country had made under the Romans were altogether retarded ; trom being a flourishing colony with its capital, Algiers, a metropolis of great note, it became the centre of fighting and turmoil.

Such were the conditions when Arab tribes from Arabia Deserta came upon the North Africans, according to an old historian, "with many warlike tribes consisting of no less than 50,000 men fit for battle, all cavalry, with multitudes of women, children, and other useless people." These dispersed and settled all over the country, mostly in the mountainous districts, looking with contempt on the dwellers in towns.

The country being in this manner divided among peoples without any supreme head, the chief of each tribe disclaining to acknowledge a superior, it is not surprising that anarchy and confusion continued for centuries, and the whole province was given over to piracy, giving substantial cause for the term "barbarism" standing for all that was lawless and violent.

\section{Triumphs of the Pirate Barbarossa}

After a lapse of many years, Ferdinand $V$. of Spain. surnamed the Catholic, after driving the Moors from his own country, sent an expedition to Africa under his Minister, Cardinal Ximenes, and Don Pedro Navarro, which took possession of the chiet town of the northern territory which we now call Algiers.

This did not satisfy the natives for long, so they invoked the aid of Barbarossa, the famous Turkish pirate, whose ambition was stımulated by this offer, and he used his great wealth, accumulated by daring piracies, to lay the foundation of the Turkish dominion in Algeria, proclaiming himself king of Algiers. At his death his brother, Heyradin, succeeded him, becoming commander of the Turkish naval forces under Suliman I., emperor of the Turks.

Algeria was now a province of Turkey and governed by a pasha appointed by the sultan at first, but later the army obtained the right of choosing their own governor. Any man might aspire to supreme rank, short reigns were therefore in vogue, and few of the rulers died a natural death. Piratical outrages against Spain continued, and the Emperor Charles V. of Germany and Spain therefore turned his attention to Algeria, collecting a fleet and army from all parts of his realm in Europe, and in $\mathrm{I} 535$ an army consisting of Spanish, German, Italian, Maltese, and Portuguese troops set sail in five hundred 


\section{Biblioteca}

\section{ALGERIA \& ITS STORY}

vessels from Cagliar1 and took Godetta by assault. Heyradin was defeated and ten thousand Christian slaves liberated

The city of Algiers, nevertheless, remained a hot-bed of piracy, and the pasha who succeeded Heyradin continued to make incursions against Spain, which enraged Charles V. so greatly that an expedition was sent by him from Spain to Algiers. It consisted of twenty-six thousand regular troops and a fine fleet.

\section{Algiers Defeats the Might of Spain}

A landing was effected in spite of great opposition, but, owing to the unseasonable time of year with tempestuous weather, the Spaniards, having no tents, could not endure the violence of the storms they encountered, so they had to re-embark, losing about eight thousand men and one hundred and forty ships. At the retreat Charles is said to have thrown his diadem into the sea, saying, "Go, bauble, let some more fortunate prince redeem and wear thee."

From that time Algeria thought itself invincible, and extended its piracies all over the Mediterranean, and even as far as the Atlantic, seizing vessels of all nations till in 1655 Robert Blake, the English admiral, terrified the people into pacific measures for a period, and during Cromwell's attacks on Spain the Dey of Algiers was forced to promise the repression of piracy.

In 1682 Iouis IV. of France caused Algiers to be bombarded by Admiral Duquesne, which effected a peace between the two countries, and also the drawing up of articles of peace and commerce between "the Most Serene and Mighty Prince Charles II. of England, etc., and the most illustrious Lords the Basha, Dey, and Aga, governors of the famous city and kingdom of Algiers in Barbary."

During the next hundred years the Spaniards again landed at Algiers1775-but had to re-embark in haste with great losses, and the Dutch, angered by repeated attacks, obtained respect temporarily for their flag after various combats. Danes and Swedes also were in conflict with the piratical AlgerinesAustrians and Russians managed to receive protection for their vessels by special intervention of the Porte in consequence of treaties with the latter but Italians suffered badly, their ships and cargoes were invariably seized and their sailors captured as slaves.

\section{Overthrow of the Pirates}

This continuous piracy could not be carried on without serious interference, and in $18 I_{5}$ the United States gave a check by capturing a frigate and brig and compelled the Dey to conclude a treaty with the Americans, and to pay sixty thousand dollars as compensation for the ships they had plundered. This was followed by a bombardment by English and Dutch under Lord Exmouth in 1816 ; he compelled the Dey to release a large number of Christian slaves, and a better state of affairs lasted for a few years.

An insult by the Dey to the French Consul in 1827 induced the French Government to send an expedition on a very large scale to Algeria. An army

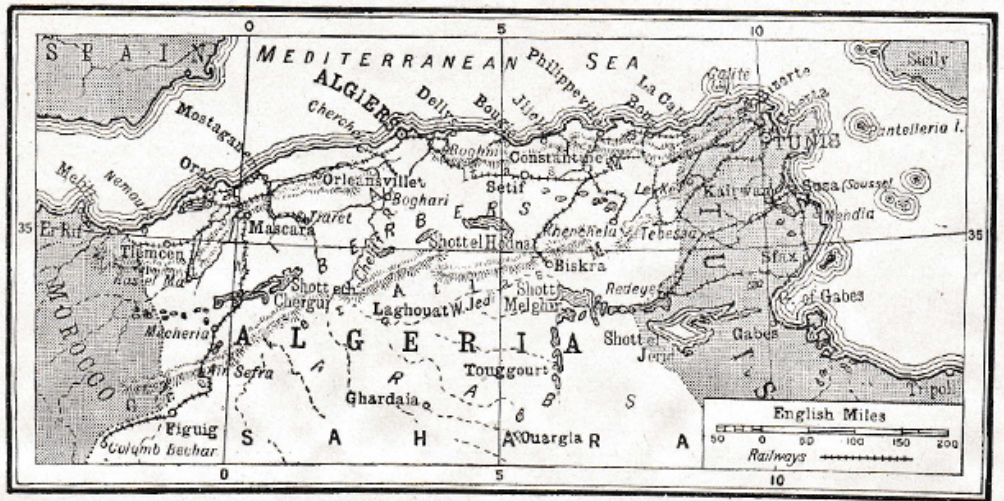

ALGERIA AND ITS PEOPLES

This map shows the northern division of Algeria and the southern division except a portion of the sparsely populated rezions of the Saharan Oases territory. The French spherc of influence stretches far into the Desert with necessarily indefinite boundaries 


\section{ALGERIA \& ITS STORY}

of 40,000 men under General Bourmont and Admiral Duperté took possession of the capital, the fleet, and the treasury, which latter brought in about two millions sterling in precious metals and stones. The Dey was deposed, the barbarian government wholly overthrown. and the French now in power.

The settlement of the French in Algeria, though at first undertaken for political and military purposes, was the greatest inroad on the headquarters of Mahomedanism since the time of the Crusades, and has been a great asset to all the Christian nations of Europe

France thus became possessed of Algiers and the forts and harbours depending on it in 1830 , but no mention was made of the provinces and native tribes. Arabs and Kabyles of the mounta.1nous districts, becoming aware of the fact, joined forces against the new rulers; even the Turkish Beys of the provinces took their side and much guerrilla warfare was the consequence.

The most notable antagonist was the Arab chiet, Abd-el-Kader, the Ameer of Mascara, who defended his country with great military skill year after year against the best troops of Lous Philippe. For fifteen years he inflicted great losses on them, having trained his Arabs to tace artillery, and did not yield till I847. when he was taken prisoner.

At the outbreak of the Franco-German War the French forces in Algeria were recalled for home service. This was an opportunity not to be missed by the lawless Algerines, and a general insurrection took place in $187 \mathrm{I}$, which spread rapidly and assumed such proportions that at the end of the war the French found themselves obliged to reconquer the whole country.

To subdue it was impossible, and in I 876 another revolt occurred under El-Hamri, and a second in 1879 , headed by Mahomet-hin-Abdullah in the Aurès Mountains, whence the insurgents were eventually driven south into the Sahara, where most of them met their death. Continuing their subduing policy the French in 1882 occupied the territory of Laghouat, which had long been the centre of insurrectionists, and annexed it to Algeria.

Since that period advance posts have been established in the Sahara, and under the guidance of the French Government there are now signs of tranquility and prosperity in all parts of Algeria except on the south-west part of the Morocco frontier.

During the Great War Algeria contributed loyally and largely to the French forces, and considerable numbers of native tirailleurs and Arab cavalry took their part along with regular troops. Now, in spite of untold money and lives which Algeria has cost France, this fine colony with its fertile lands and rivers is an enormous and increasingly valuable asset.

\section{ALGERIA : FACTS AND FIGURES}

\section{The Country}

Algeria (L'Algérie) a coiony of France in North Africa between Morocco, Tunis, and French Equatorias Atrica. Organized in northern and southern divisions, sub-divided into arrondissements and communes. Total area 222 , I 80 square miles. Northern division consists of départements of Alger, Oran, and Constantine (pcpulation $5,069,522)$ southern division made up of four territories of Ain Sefra, Ghardaia, Touggourt, and Saharan Oases (population 494,306). Population (I911 census): Europeans, 795,522 (492,660 Frenchi, native, $4.768,306$. Total, $5,563,828$.

\section{Government}

Governor-General at Algters acts throughout Algerian territory in name of the French Republic. Governor-General is assisted by Superior Council (elected members and high officials) and Financial Delegations (representing French colonists, French taxpayers and Mahomedan native;, by elected delegates.) Territories of southern division are each inder military command.

National Assembly in Paris controls ali legisıa. tion, other matters being regulated by presidentiai decree Each département elects one senator and two deputies to the National Assembly.

French citizenship is granted by law ot rgrg to monogamous natives over twent $y$-five who served in the Great War, are farmers or proprietors, can read of write or who hold a French decoration.

\section{Army}

French coronists are subject to conscription as in France; natives serve threo years with the colours and can be called up as reservists. Troops in Aigeria consist of three divisions, including Zouaves, Chasseurs d'Afrique, Algerian Tirailleurs, and Spahis. Headquarters of the ramous Foreign Legion (two regiments) is also in Algiers.

\section{Commerce and Industries}

Greater part of Algena is little suited to agriculture. Intensive cultivation in plains and villages near the coast produced about 524,000 vilages near the coast produced about 524,000
tons ot cereals in 1920 . Wine (about 160 million gallons in 1920), fruits, olive oil, and fisheries are important industries. Forests cover six and a half million acres, but the greater proportion are of little value.

Imports, I920, 1 ICI, 406,000 (60 per cent. trom France): exports, $157,662,000$ ( 88 per cent. to France)

\section{Communications}

Many fine Government-built roads (about 3,300 miles), but most of the mountain districts are extremely difficult of access. About 2,200 miles of railway connecting coast towns and running south of Biskra. Considerable shipping (mercantile marine of Algeria, I020, amounted to 364 vessels). Telegraph lines, $25,28 \mathrm{c}$ miles : 364 vessels).
telephone lines, r 9,580 miles.

\section{Chiel Towns}

Algiers $(172,397)$. Oran (I23,086), Constantine $(65,173)$, Tlemcen $(39,784)$, Philippeville $(27,1,37)$. 



\section{Criterios de edición:}

Revista Argelina. Revista semestral de Estudios Argelinos es una publicación electrónica e impresa evaluada por pares con tres criterios de selección: I) aceptación; 2) aceptación con cambios; 3) devolución. Se aceptan contribuciones en castellano, valenciano, árabe, francés e inglés.

Los originales se presentarán registrándose como usuario y subiendo el documento a la plataforma ojs de gestión del proceso editorial en el sitio web: https://argelina.ua.es

El aparato crítico deberá ajustarse a las siguientes normas de edición:

-Texto en formato estándar a un espacio de interlineado.

-Fuente en Romanas (Times New Roman) a I2 puntos.

-Título del trabajo en mayúsculas a I6 puntos seguido en línea inferior por el nombre del autor en versalitas.

-Notas a pie de página a ro puntos.

-Cita: Libro (Nombre, Título, Ciudad, Editorial, Año); Artículo (Nombre, “Título”, en Revista, Año, vol. x, núm.x, pp. xx).

-Sistema internacional para las citas y transcripciones del árabe. 


\section{معايير النشر :}

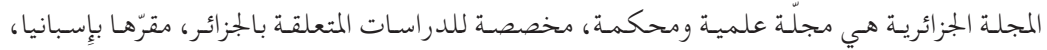

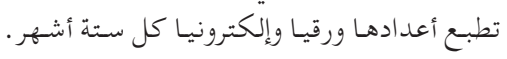

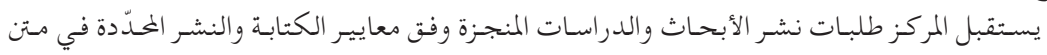
هـذه الوثيقـة.

- تخضع المواد المرسلة كلّها للتّقييم والقراءة الأكاديميّة . - في حال الموافقة، يُجري الكاتب التعديلات كليات المقترحة قبل تسليم المادّة للتحرير النّهائي.

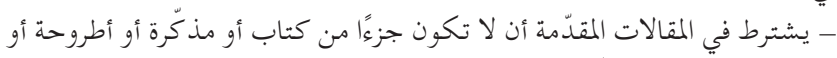

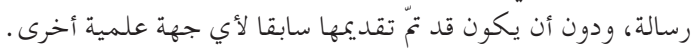

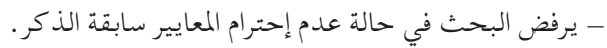

يمكن المساهمة باللغات التالية : العربيّة، الإِسبانية، الفرنسية، الفلنسيانية والإِنجليزيّة.

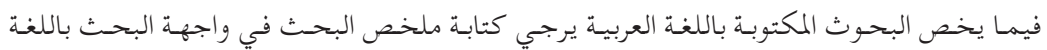

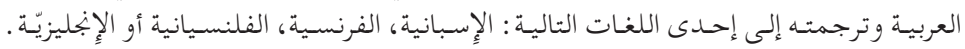

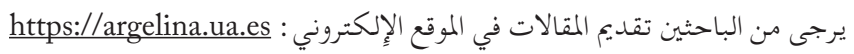

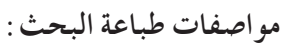

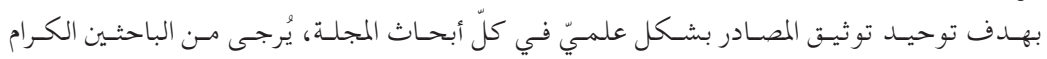

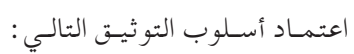

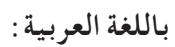

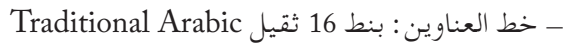

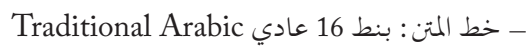

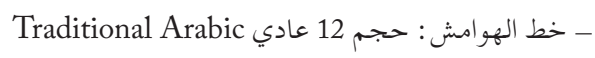
باللغات اللاتينية: - تنسيق النص القياسي في مسافة سطر . بالغات

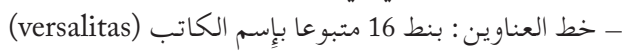
- خط المتن: بنط 12 عادي (Times New Roman)

- الإشارة إلى الهو امش أسفل الصفحة بالطريقة الالكترونية، بنط 10 (Times New Roman)

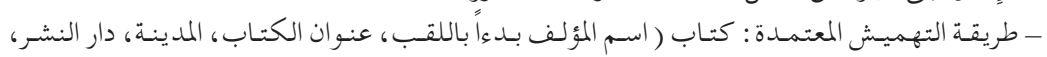

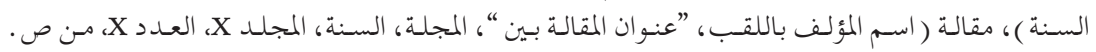

- يرجى استعمال النظام الدولي للتعيينات والنصوص العربية . - يلي كل مقالة قائمة المراجع والمصادر المعتمدة عليها في البحثث. 



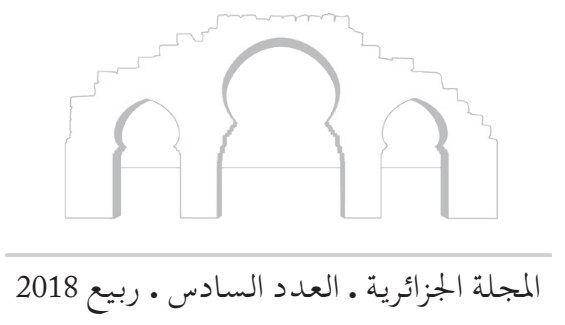

فهر ست

مقالات

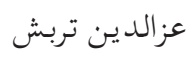

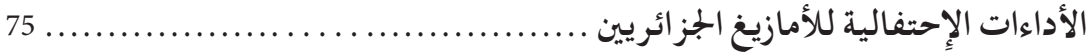

$$
\text { نصيرة بكوش ونعيمة رحماني }
$$

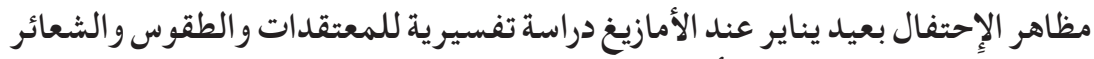

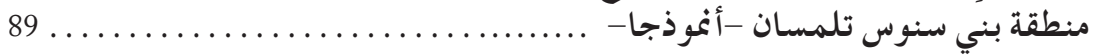



العدد السادس • ربيع 2018

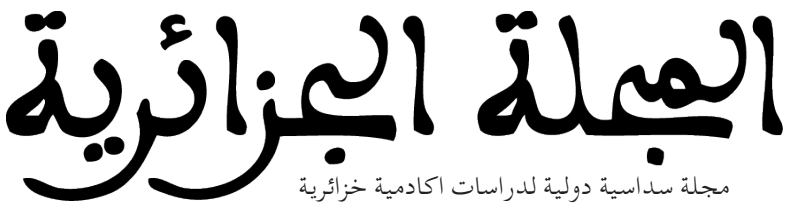




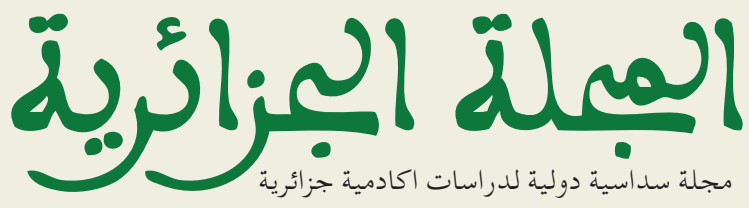

ÍNDICE

Editorial

Ensayo

Karim Aкоuche

Le paradoxe de la liberté.

Artículos y notas

Meriem Skander

Les "Métamorphoses» d'Apulée.

Danielle Pister

La Kabina, la reine palimpseste

MoHand IвRAHim

Introduction à l'ceuvre de Bélaïd Aït Ali, comme première initiative d'écriture de Tamazight en caractère latin.. 53

Ahfir Abdellah

The historical roots of Amazigh and its Arabization factors in Algeria

Azeddine Terbeche

Las festividades de los amazigh en Argelia 75

Naima Rahmani y Necera Bekкouche

Las manifestaciones de la celebración de la fiesta de enero de los amazigh. Un estudio interpretativo de creencias, rituales y leyendas en la zona de Beni Snous (Tremecén) como modelo.....

\section{Reseñas y comentarios bibliográficos}

Mohand Akli Haddadou, Introduction à la littérature berbère suivi d'une Introduction à la littérature kabyle .... 101

\section{Biblioteca}

A. MacCallum Scott, "Algeria. I. The Dwellers in the Garden of Allab", y Rachel Humphreys, "Algeria. II. The Story of Old Barbary and New France", en J.A. Hammerton (ed.), Peoples of All Nations: Their Life Today and Story of Their Past, by Our Foremost Writers of Travel Anthropology E History, Londres, The Amalgamated Press Limited, 1920, vol. 1, pp. 65-111 107
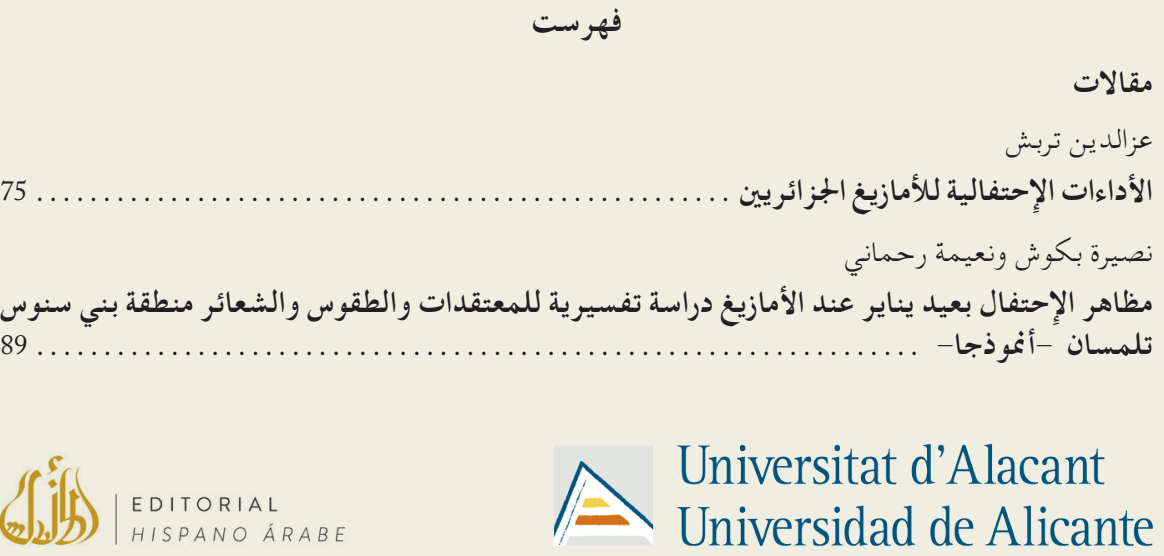